\title{
Investigations towards the design, synthesis and application of new sulfur-based transfer reagents
}

\author{
Dissertation \\ zur Erlangung des mathematisch-naturwissenschaftlichen Doktorgrades \\ „Doctor rerum naturalium“ \\ der Georg-August-Universität Göttingen \\ im Promotionsprogramm der \\ Georg-August University School of Science (GAUSS)
}

vorgelegt von

Bernd Waldecker

aus Emden

Göttingen, 2019 



\section{Betreuungsausschuss:}

Prof. Dr. M. Alcarazo (Institut für Organische und Biomolekulare Chemie, Tammannstr. 2, 37077 Göttingen)

Prof. Dr. L. Ackermann (Institut für Organische und Biomolekulare Chemie, Tammannstr. 2, 37077 Göttingen)

\section{Mitglieder der Prüfungskommission:}

Referent: Prof. Dr. M. Alcarazo (Institut für Organische und Biomolekulare Chemie, Tammannstr. 2, 37077 Göttingen)

Korreferent: Prof. Dr. L. Ackermann (Institut für Organische und Biomolekulare Chemie, Tammannstr. 2, 37077 Göttingen)

\section{Weitere Mitglieder der Prüfungskommission:}

Prof. Dr. D. Stalke (Institut für Anorganische Chemie, Tammannstr. 4, 37077 Göttingen)

Dr. S. Das (Institut für Organische und Biomolekulare Chemie, Tammannstr. 2, 37077 Göttingen)

Dr. F. Thomas (Institut für Organische und Biomolekulare Chemie, Tammannstr. 2, 37077 Göttingen)

Dr. M. Hansmann (Institut für Organische und Biomolekulare Chemie, Tammannstr. 2, 37077 Göttingen)

Tag der mündlichen Prüfung: 02.05.2019 

Die vorliegende Arbeit entstand unter Anleitung von Herrn. Prof. Dr. Manuel Alcarazo in der Zeit von Juli 2015 bis Dezember 2015 am Max-Planck-Institut für Kohlenforschung in Mülheim an der Ruhr und in der Zeit von Januar 2016 bis Dezember 2018 an der GeorgAugust-Universität zu Göttingen.

Teile dieser Arbeit wurden bereits veröffentlicht:

J. Peña, G. Talavera, B. Waldecker, M. Alcarazo, Chem. Eur. J. 2017, 23, 75-78.

B. Waldecker, F. Kraft, C. Golz, M. Alcarazo, Angew. Chem. Int. Ed. 2018, 57, 12538-12542.

Ein Patent $\mathrm{zu}$ den in der Arbeit synthetisierten Verbindungen und $\mathrm{zu}$ deren synthetischer Anwendbarkeit wurde von der Universität Göttingen eingereicht (DE102018211606.7). 

Hiermit versichere ich, dass ich die eingereichte Dissertation selbständig verfasst und keine anderen als die angegebenen Quellen und Hilfsmittel benutzt, sowie Zitate kenntlich gemacht habe.

Bernd Waldecker 



\section{Abbreviation}

$\AA ̊ \quad$ Ångstrom $\left(10^{-10} \mathrm{~m}\right)$

ACM Alkyne cross metathesis

ADIMET Acyclic diyne metathesis polymerization

A

Bn

Boc

BuLi

$\mathrm{Bz} \quad$ Benzoyl

cald. calculated

cat. catalytic

$\mathrm{Cbz} \quad$ Carboxybenzyl

$\mathrm{CF}_{3} \quad$ Trifluoromethyl group

CoA Coenzyme A

CPPA Cycloparaphenyleneacetylene

CuAAC Copper-catalyzed azide-alkyne cycloaddition

DBCO dibenzylcyclooctyne

DBU 1,8-Diazabicyclo(5.4.0)undec-7-ene

DCE 1,2-Dichloroethane

DCM Dichloromethane

DDQ 2,3-Dichlor-5,6-dicyano-1,4benzochinon

DIPEA N,N-Diisopropylethylamine

DMAP 4-Dimethylaminopyridine

DMF N,N-dimethylformamide

DMP Dess-Martin periodinane

DNA Deoxyribonucleic acid

EBX EthynylBenziodoXolone

ECHC 4-epoxycyclohexenylmethyl-3,4epoxycyclo-hexenyl carboxylate

EI Electron Ionisation

equiv. equivalents
ESI-MS Electrospray Ionisation Mass

Spectrometry

et al. et alia

EtOAc Ethyl acetate

EtOH Ethanol

${ }^{18} \mathrm{~F} \quad$ Fluorine-18

g gram

GC-MS Gas Chromotography Mass

Spectrometry

HRMS High Resolution Mass

Spectrometry

ho Light irradiation

IR Infrared spectroscopy

$i \operatorname{Pr} \quad$ iso-propyl

J Joule

$J \quad$ Coupling constant

K Kelvin

KAPA Potassium 3-aminopropylamide

KB cell Subline of tumor cell line HeLa

L Ligand

LDA Lithium diisopropylamide

m meta

M Metal

M Molar $\left(\right.$ Mold $\left.\mathrm{m}^{-3}\right)$

mCPBA meta-Chloroperoxybenzoic acid

$\mathrm{MeCN} \quad$ Acetonitrile

MOF Metal-organic framework

MS Molecular sieves

$\mathrm{NEt}_{3} \quad$ Triethylamine

NMR Nuclear Magnetic Resonance

$\mathrm{Nu} \quad$ Nucleophile

o ortho 


\begin{tabular}{|c|c|c|c|}
\hline$p$ & para & $X$ & Generic heteroatom \\
\hline P388 & Leukaemia cell line & $\mathrm{X}$-ray & $\mathrm{X}$-ray crystallography \\
\hline \multicolumn{4}{|l|}{ cells } \\
\hline PBS & Phosphate-buffered saline & $\mathrm{Y}$ & Generic substituent \\
\hline \multicolumn{4}{|l|}{ buffer } \\
\hline PET & Positron emission tomography & $\mathrm{Z}$ & Generic heteroatom \\
\hline $\mathrm{Ph}$ & Phenyl & $\delta$ & Chemical shift \\
\hline PMB & 4-Methoxybenzyl & $\lambda$ & wavelength \\
\hline ppm & parts per million & & \\
\hline PPTS & Pyridinium p-toluenesulfonate & & \\
\hline $\operatorname{Pr}$ & Propyl & & \\
\hline q & quartet (NMR) & & \\
\hline quant. & quantitative & & \\
\hline $\mathrm{R}$ & Generic substituent & & \\
\hline RCAM & Ring-Closing Alkene Metathesis & & \\
\hline RNA & Ribonucleic acid & & \\
\hline ROM & ring opening metathesis & & \\
\hline $\mathrm{rt}$ & Room temperature & & \\
\hline RuAAC & ruthenium-catalyzed azide-alkyne & & \\
\hline & cycloaddition & & \\
\hline $\mathrm{s}$ & singlet (NMR) & & \\
\hline SAM & S-(Adenosylmethionin) & & \\
\hline $\mathrm{T}$ & Temperature & & \\
\hline $\mathrm{t}$ & Time & & \\
\hline TAMRA & Tetramethylrhodamine & & \\
\hline TBAX & Tetra- $n$-butylammonium salt & & \\
\hline TES & Triethylsilyl & & \\
\hline$t \mathrm{Bu}$ & tert-butyl & & \\
\hline TBS & tert-Butyldimethylsilyl ether & & \\
\hline $\mathrm{Tf}$ & Trifluoromethanesulfonyl & & \\
\hline THF & Tetrahydrofurane & & \\
\hline TIPS & Triisopropyl & & \\
\hline TMS & Trimethylsily & & \\
\hline
\end{tabular}




\section{Table of Contents}

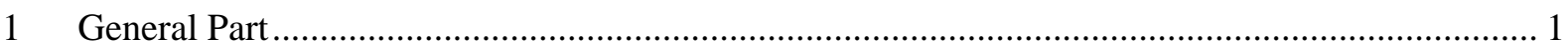

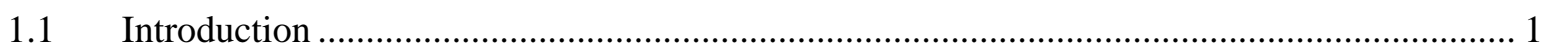

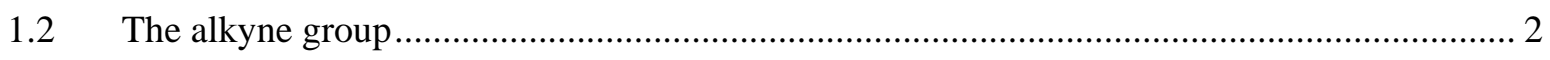

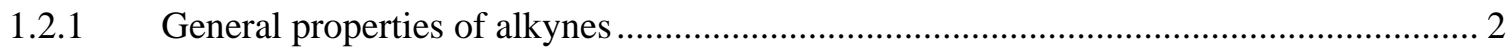

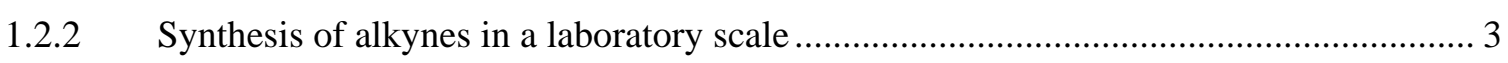

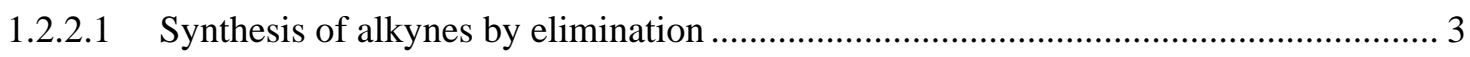

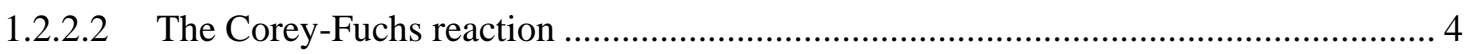

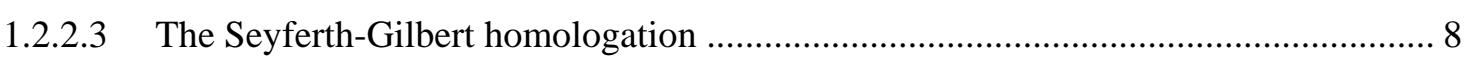

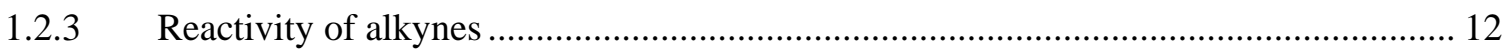

1.2.3.1 Azide-alkyne cycloaddition ("click chemistry")...................................................... 14

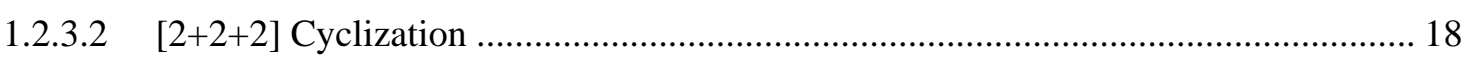

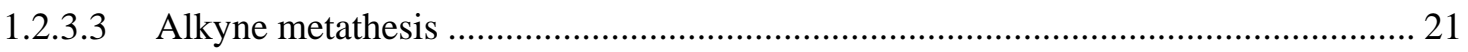

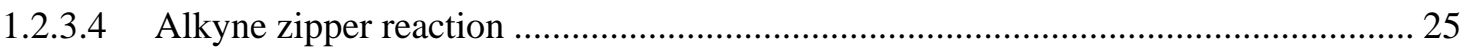

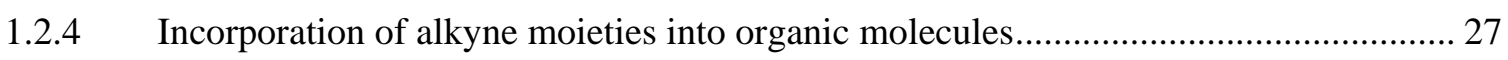

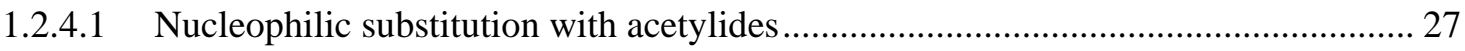

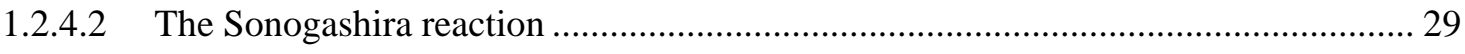

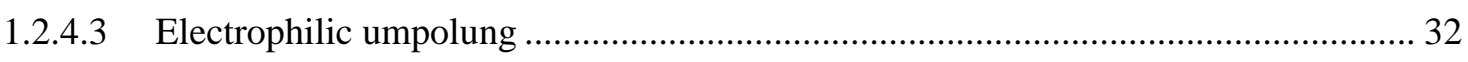

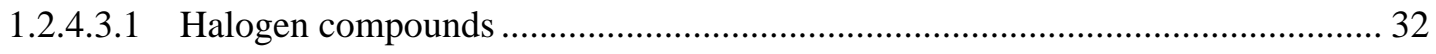

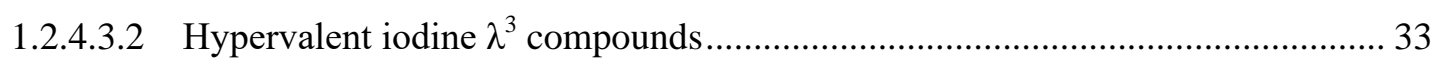

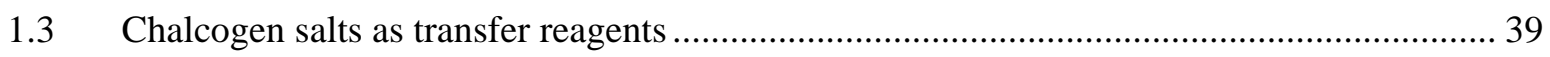

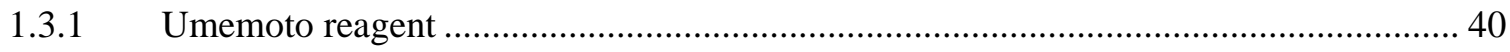

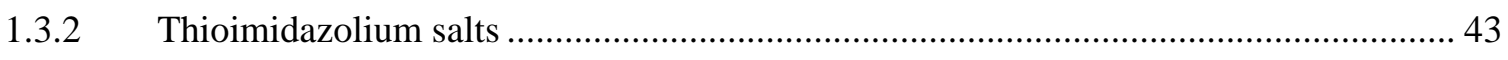

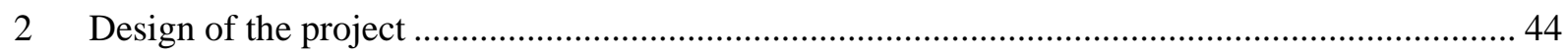

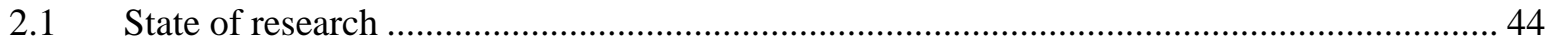

2.1.1 Alkyne-transferring reagents formerly developed in the Alcarazo group ..................... 44

2.1.2 Alkyne-based cationic polymerization initiators developed by Liska et al................... 46

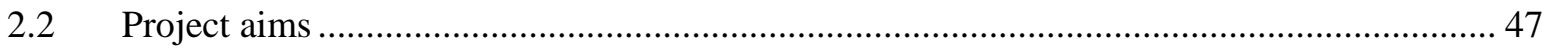

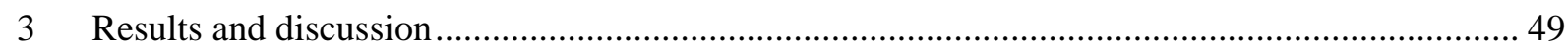


3.1 Further development of the newly discovered thioalkynylation reaction

3.1.1 Synthesis of new thioimidazolium-based alkynylation reagents .................................. 49

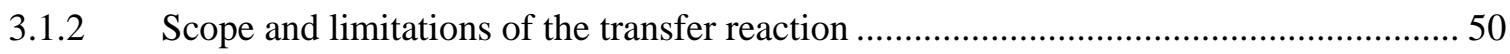

3.1.3 Further derivatization of the synthesized sulfides ...................................................... 52

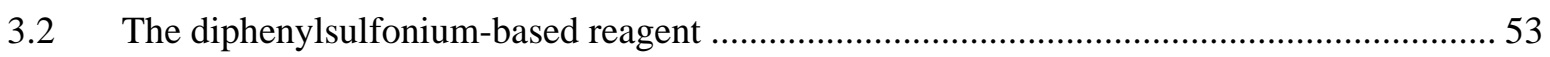

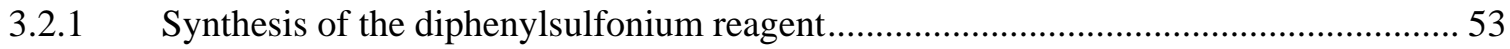

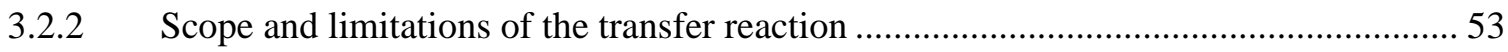

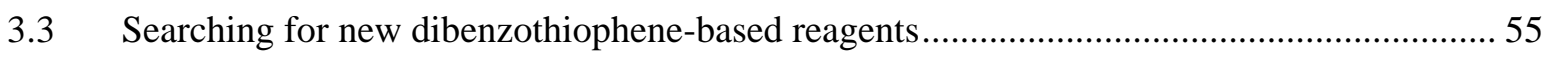

3.3.1 Synthesis of the dibenzothiophene-based reagents ....................................................... 55

3.3.2 Expanding the scope towards different dibenzothiophenium salts..............................56

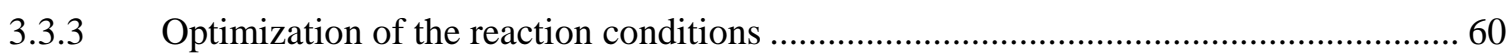

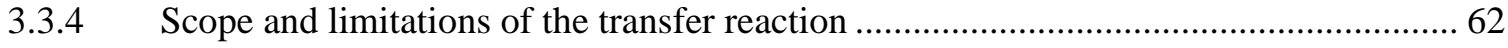

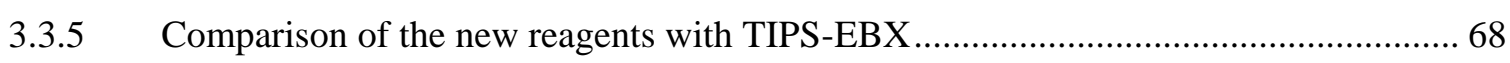

3.3.6 Investigations towards mechanistic rationalization of the transfer reaction................... 71

3.3.7 Investigation towards metal-catalyzed reactions ..................................................... 75

3.3.7.1 Investigations towards reactions with metal-based Lewis acids .............................. 75

3.3.7.2 Investigations towards directing group based $\mathrm{C}-\mathrm{H}$-alkynylation with metal catalysts 77

3.3.8 Synthesis attempts towards a system with internal base 80

3.4 Investigations towards potential trifluoromethylation reagents based on the thioimidazolium backbone.

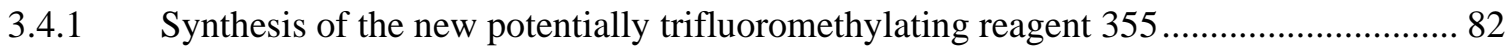

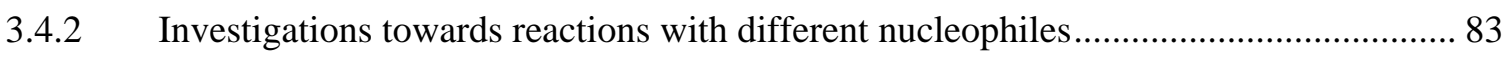

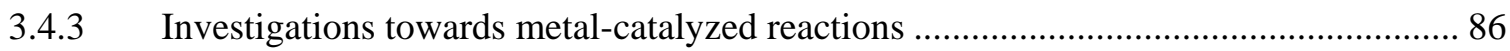

3.4.4 Application of thioimidazolium salts as phase transfer catalyst by Mizuta and

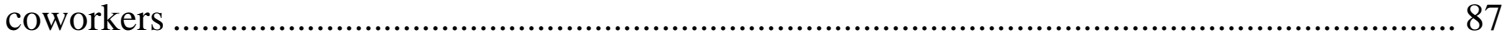

3.5 Investigations towards a new trifluoroethylenating reagent ............................................... 89

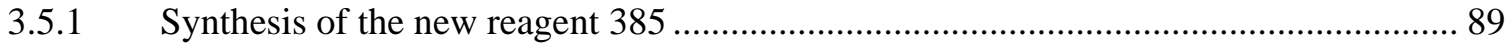

3.5.2 Investigations towards reactions with different nucleophiles..................................... 90

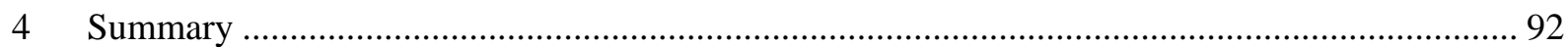




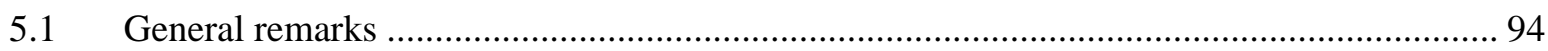

5.2 Reactions towards the newly discovered thioalkynylation reaction.................................... 96

5.2.1 Synthesis of new thioimidazolium-based alkynylation reagents................................... 96

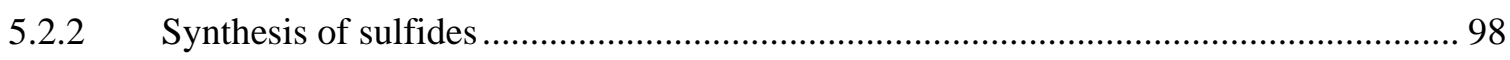

5.2.3 Synthesis of derivatization products of the synthesized sulfides.................................. 99

5.3 Synthesis of new diphenylsulfane and dibenzothiophene based reagents .......................... 102

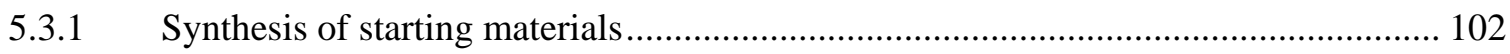

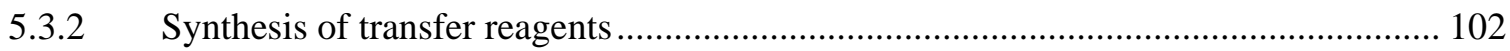

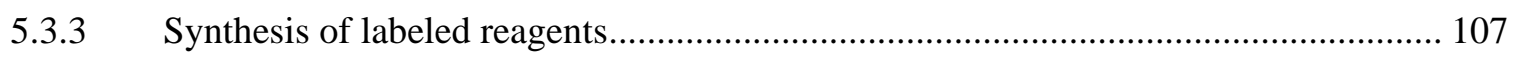

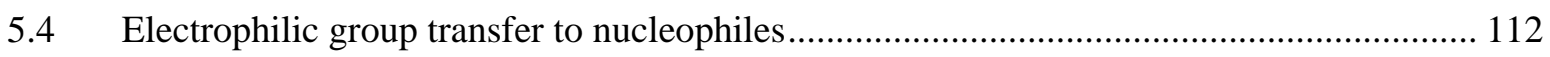

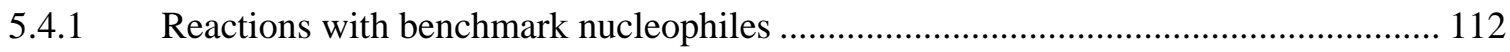

5.4.2 Attempts towards metal catalyzed reactions .......................................................... 131

5.5 Synthesis attemps towards a system with internal base .................................................. 135

5.6 Synthesis of potential fluorine containing transfer-reagents ............................................ 138

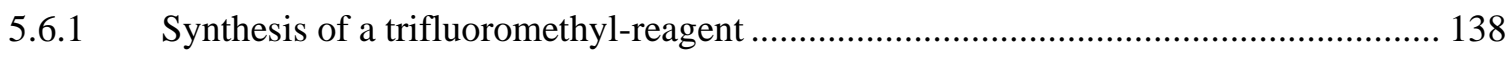

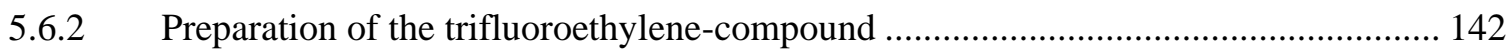

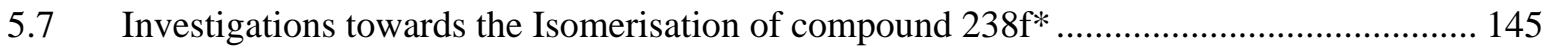

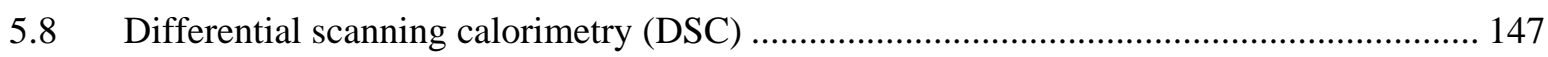




\section{General Part}

\subsection{Introduction}

Alkynylation is an important reaction class to incorporate a $\mathrm{C}_{2}$-unit into organic molecules. Similarly, the majority of the utilized building blocks in nature such as acetyl-CoA, shikimic acid or mevalonic acid are $\mathrm{C}_{2}$-units or a multiples of it. ${ }^{1}$ As a result, many natural and bioactive compounds are constructed by a repetitive introduction of these units. Furthermore, alkynes are very versatile groups for further functionalization (compare Chapter 1.2.3). Therefore, it is not surprising that in the years that in the years 1997-2009 methods for the introduction of carbon units to molecules, such as alkylation, acylation or C-C-bond formation, including alkynylation were some of the most frequently used reactions in innovative chemistry, such as library synthesis, lead optimization, process chemistry and bioactive compounds synthesis (Figure 1 ). ${ }^{2}$

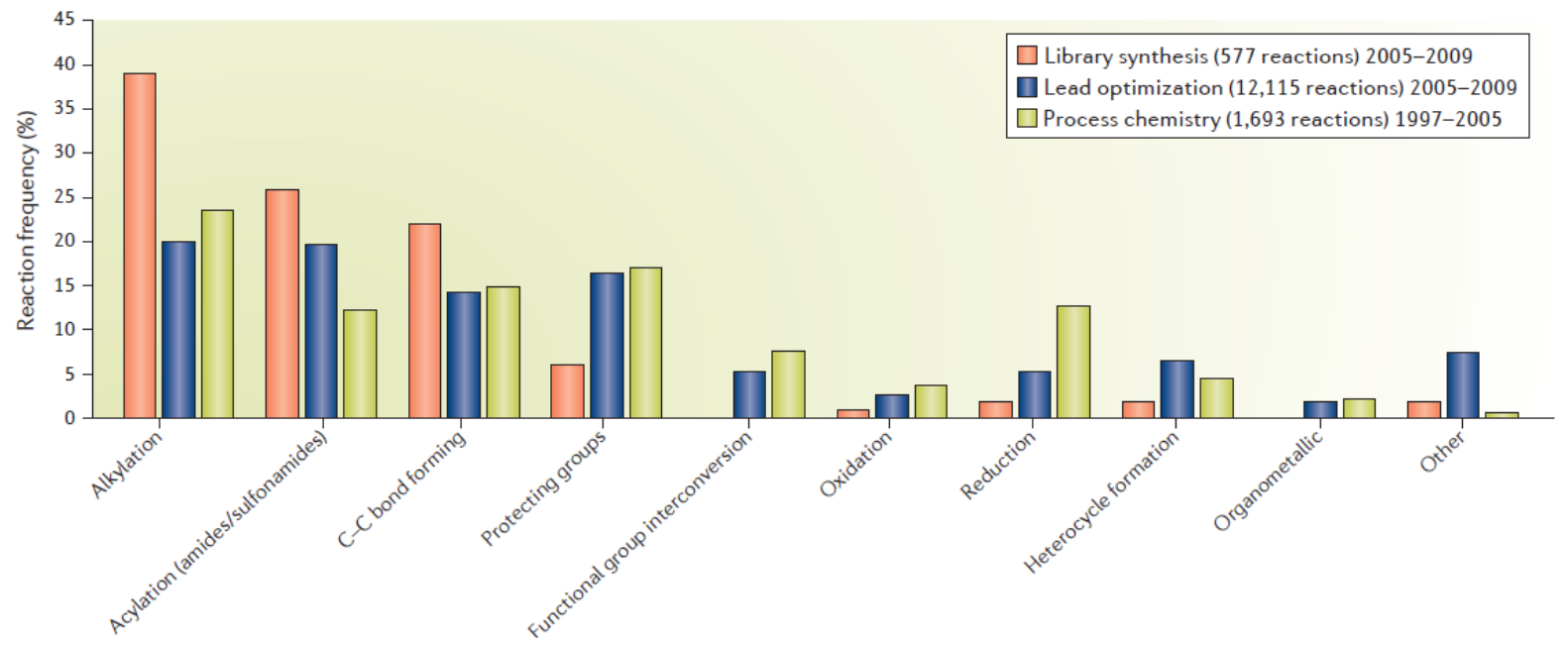

Figure 1 Reaction types used in library synthesis (GlaxoSmithKline (GSK): 2005-2009), lead optimization (AstraZeneca, GSK and Pfizer: 2005-2009) and process chemistry for the synthesis of candidate drugs (AstraZeneca, GSK and Pfizer: 1997-2005).2

However, the introduction of alkyne moieties into organic molecules is clearly limited by the structural features of this functional group, e.g. the strong tendency to react as a nucleophile due to easy deprotonation. Therefore, new methodologies, which open new reaction pathways, are required for these purposes. These processes could in turn facilitate the synthesis of new drug candidates and allow the preparation of new compounds and materials. The aim of this work is to consider alternative possibilities for the incorporation of this versatile building block, to avoid harsh reaction conditions and to enable the functionalization of complex highly functionalized molecules, thus, offering a new instrument for the chemist's toolbox of introducing alkynes. 


\subsection{The alkyne group}

\subsubsection{General properties of alkynes}

Alkynes are highly energetic, linear compounds. The characteristic structural element of this functional group is the triple bond. From a formal viewpoint, it consists of a $\sigma$-bond formed by the overlap of two axial sp-hybridized orbitals of two carbon atoms, and two orthogonal $\pi$-bonds, formed by unhybridized p-orbitals (Figure 2$)^{3}$

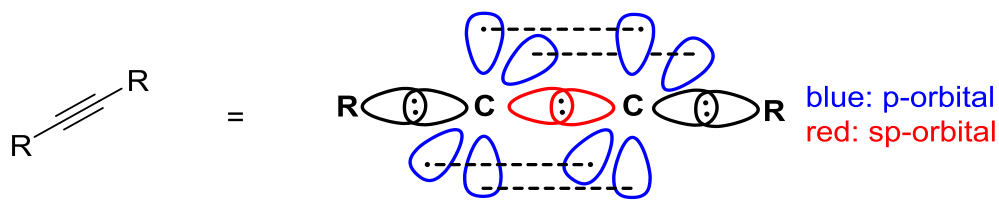

Figure 2 Schematic representation of the triple bond in alkynes.

A variety of different reactions can be applied towards the synthesis of alkynes on laboratory scale (compare Chapter 1.2.2). ${ }^{4 a}$ In contrast, on an industrial level alkynes are mainly synthesized by homologation of short terminal alkynes like acetylene or propyne. The latter can be accessed by common procedures like the calcium carbide process or cracking methods from oil, coal or gas. ${ }^{3,4 b, c}$ With a pKa of around 25, terminal alkynes are considerably easier to deprotonate, when compared with alkenes or alkanes. Consequently, the resulting acetylides react normally as nucleophiles and can be used for a variety of substitution or addition reactions (compare Chapter 1.2.3). Nowadays, many natural products are known to contain alkyne moieties. ${ }^{5}$ Often these compounds show interesting biological activities like the antibiotic (-)-marasin $(\mathbf{1})^{6}$ or the natural antifeedant tonghaosu (2) (Figure 3). ${ }^{7}$

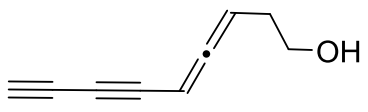

$1(-)$-marasin

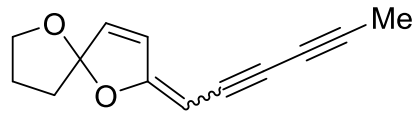

2 tonghaosu

Figure 3 Alkyne containing natural products (-)-marasin (1) and tonghaosu (2).

Furthermore, alkynes are applied in many different research fields, such as in the synthesis of organic electronics, ${ }^{8}$ in medicinal chemistry ${ }^{9}$ or in the functionalization of metal organic frameworks (MOFS). ${ }^{10}$ Additionally, alkynes are known to be biorthogonal and can be introduced to complex biological molecules and systems. ${ }^{11}$ 


\subsubsection{Synthesis of alkynes in a laboratory scale}

\subsubsection{Synthesis of alkynes by elimination}

Elimination is a classical, widely used method for the formation of an alkyne moiety in the laboratory. Commonly used methods are the dehydrohalogenation of haloalkenes, the twofold dehydrohalogenation of dihaloalkanes or the elimination reactions of alkenes with heteroatomcontaining substituents. ${ }^{12}$ An early example for the dehydrohalogenation of haloalkenes was given by the synthesis of phenylacetylene (4) from (2-bromovinyl)benzene (3) using a strong base like $n \mathrm{BuLi}$ (Scheme 1). ${ }^{13}$

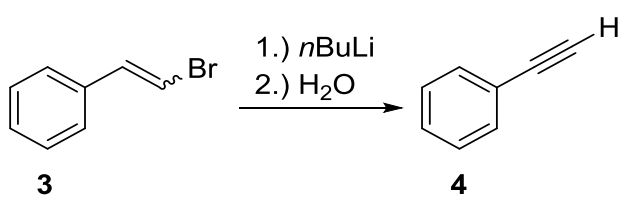

Scheme 1 Synthesis of alkynes by dehydrohalogenation of haloalkenes. ${ }^{13}$

Dihaloalkanes can easily be synthesized by the addition of bromine to alkenes. In a publication by Wong et al., the tetrabromide $\mathbf{6}$ was obtained by the reaction of cyclooctatetraene 5 with elemental bromine. Afterwards, the cyclic dialkyne 7 was synthesized by a four-fold dehydrobromination with the base potassium tert-butoxide (Scheme 2). ${ }^{14}$<smiles>CC(Br)(Br)CC1(C)C(Br)c2ccccc2C(Br)C(Br)c2ccccc2C1Br</smiles>

Scheme 2 Synthesis of alkynes by fourfold dehydrohalogenation. ${ }^{14}$

Another example for the synthesis of alkynes via elimination reactions was given by Tsuji and coworkers. Enoles of the type $\mathbf{1 0}$ were synthesized from ketones $\mathbf{8}$ and 2-chloro-3-ethylbenzoxazolium tetrafluoroborate (9) in the presence of $\mathrm{NEt}_{3}$ (Scheme 3). Subsequently, a set of different alkynes was obtained from the intermediate $\mathbf{1 0}$ by the elimination of 3-ethylbenzoxazol-2(3H)-one (12). ${ }^{15}$

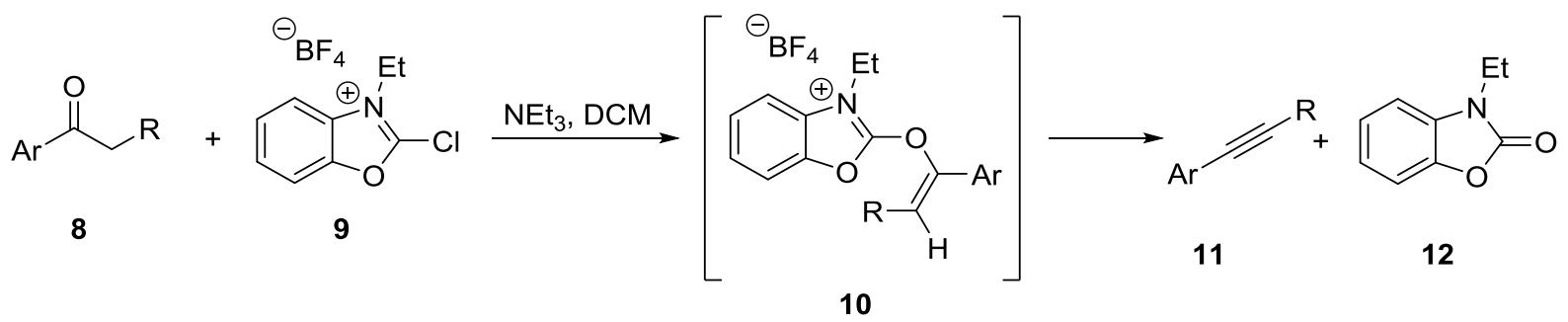

Scheme 3 Synthesis of alkynes employing 2-chloro-3-ethylbenzoxazolium salt (9). ${ }^{15}$ 


\subsubsection{The Corey-Fuchs reaction}

The Corey-Fuchs reaction is a two-step reaction sequence, which can be used to furnish alkynes. In their publication, Corey and Fuchs ${ }^{16}$ reported a method consisting initially preparing 1,1dibromoolefins from aldehydes as reported by Ramirez ${ }^{17}$ with a consequent Fritsch-ButtenbergWiechell (FBW) rearrangement ${ }^{18}$ to synthesize alkynes. For example, this methodology was utilized by Corey and Fuchs to afford phenylacetylene (4) from benzaldehyde (13) (Scheme 4). ${ }^{16}$ The latter was treated with a mixture of triphenylphosphine, tetrabromomethane and zinc to synthesize the dibromide 14. Afterwards, the dibromide 14 was transformed to phenylacetylene (4) upon reaction with $n \mathrm{BuLi}$.<smiles>O=Cc1ccccc1</smiles>

13

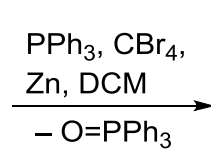

$-\mathrm{O}=\mathrm{PPh}_{3}$<smiles>BrC(Br)=Cc1ccccc1</smiles>

14
1.) $n \mathrm{BuLi}, \mathrm{THF},-78^{\circ} \mathrm{C}$

2.) $\mathrm{H}_{2} \mathrm{O}$

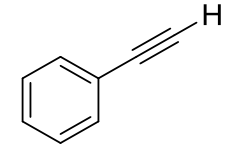

4

Scheme 4 Synthesis of phenylacetylene (4) by Corey and Fuchs. ${ }^{16}$

The dibromoolefination also proceeds in the absence of $\mathrm{Zn}$. For the mechanism of the latter reaction, an initial attack of triphenylphosphine to tetrabromomethane is proposed (Figure 4). ${ }^{19}$ This results in the formation of the carbanion $\mathbf{1 5}$ and the phosphonium salt 16, which are in equilibrium with the phosphonium salt 17. Subsequently, a second triphenylphophine molecule debrominates the phosphonium salt $\mathbf{1 7}$ to form the ylide 18. Therefore, a minimum of two equivalents of triphenylphosphine is necessary to conduct the reaction. ${ }^{19 \mathrm{c}}$ The ylide $\mathbf{1 8}$ undergoes a Wittig-type reaction and attacks the aldehyde $\mathbf{1 4}$ to offer the zwitterionic structure 19. The latter undergo a ring closure to form the oxaphosphetane $\mathbf{2 0}$ and in the next step the desired dibromide $\mathbf{2 1}$ is formed by cycloreversion, eliminating triphenylphosphine oxide. A strong base such as $n \mathrm{BuLi}$ or LDA is applied in the subsequent Fritsch-Buttenberg-Wiechel rearrangement, which furnishes alkyne $23 .{ }^{20}$ In the peculiar case of $\mathrm{R}=\mathrm{H}$, the resulting acetylene $\mathbf{2 3}$ is attacked by a second equivalent of the base affording the corresponding lithiated alkyne 23. Afterwards, phenylacetylene (4) is obtained after protonation. 
Formation of the dibromide 21:

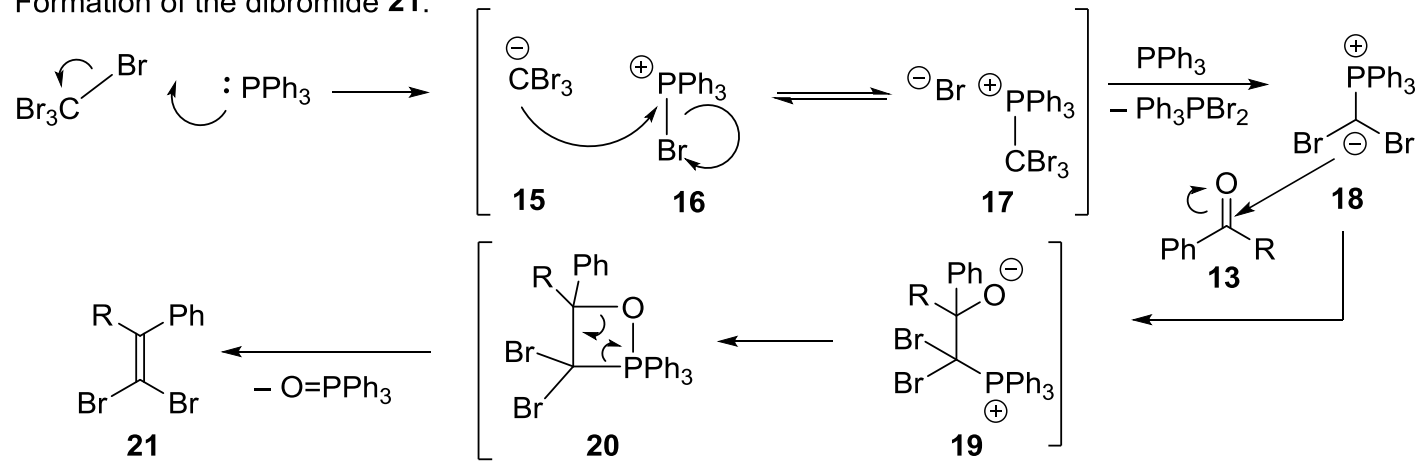

Fritsch-Buttenberg-Wiechel rearrangement:

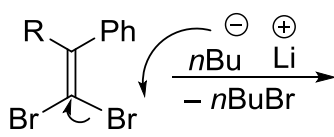

21

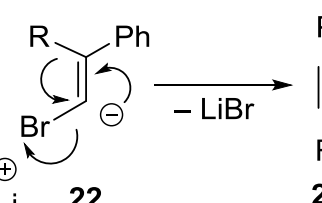

$\mathrm{Li} \quad 22$

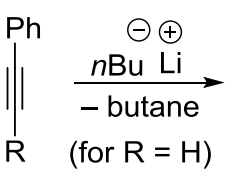

23

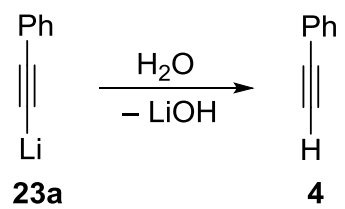

Figure 4 Proposed mechanism of the Corey-Fuchs reaction. ${ }^{19,20}$

This methodology was utilized by Clément et al. to afford ( \pm )-4-ethynyl[2.2]paracyclophane (26) in $86 \%$ overall yield (Scheme 5). ${ }^{21}$ Compound 26 is an interesting target in coordination chemistry. ${ }^{22}$ The aldehyde $\mathbf{2 4}$ was treated with a mixture of triphenylphosphine, tetrabromomethane and zinc to synthesize the dibromide 25. Afterwards, the dibromide $\mathbf{2 5}$ was converted to ( \pm )-4ethynyl[2.2]paracyclophane (26) with $n \mathrm{BuLi}$.

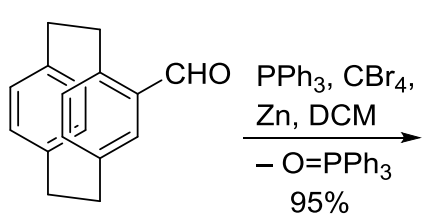

24

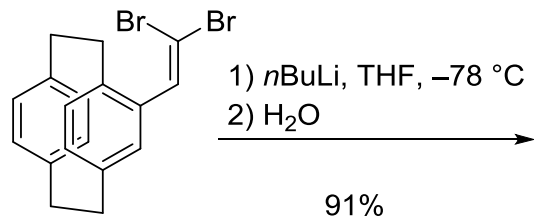

25

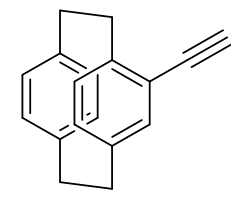

26

Scheme 5 Synthesis of ( \pm )-4-ethynyl[2.2]paracyclophane (26) by Clément et al. ${ }^{21}$ 
Another example of a Corey-Fuchs reaction, which illustrates the relevance of this transformation in the synthesis of intermediates for the preparation of complex molecules such as Amphidinolides, was presented by Roush and coworkers. ${ }^{23}$ Amphidinolides are a group of macrolides isolated from the dinoflagellate Amphidinium. Many representatives of this family demonstrate a potent antitumor activity and are therefore interesting targets for total synthesis. ${ }^{24}$ In their synthesis of the macrolide Amphidinolide E (30), the authors used a three-step sequence to build up the alkyne 29. Initially, the alcohol 27 was oxidized under Parikh-Doering conditions. The resulting aldehyde $\mathbf{2 8}$ was treated with the ylide 18, formed from a reaction of tetrabromomethane with triphenylphosphine. Finally, the desired alkyne 29 was obtained by workup with $n \mathrm{BuLi}$ in a total yield of $88 \%$ over three steps. After this, Amphidinolide E (30) was synthesized from the intermediate 29 (Scheme 6).
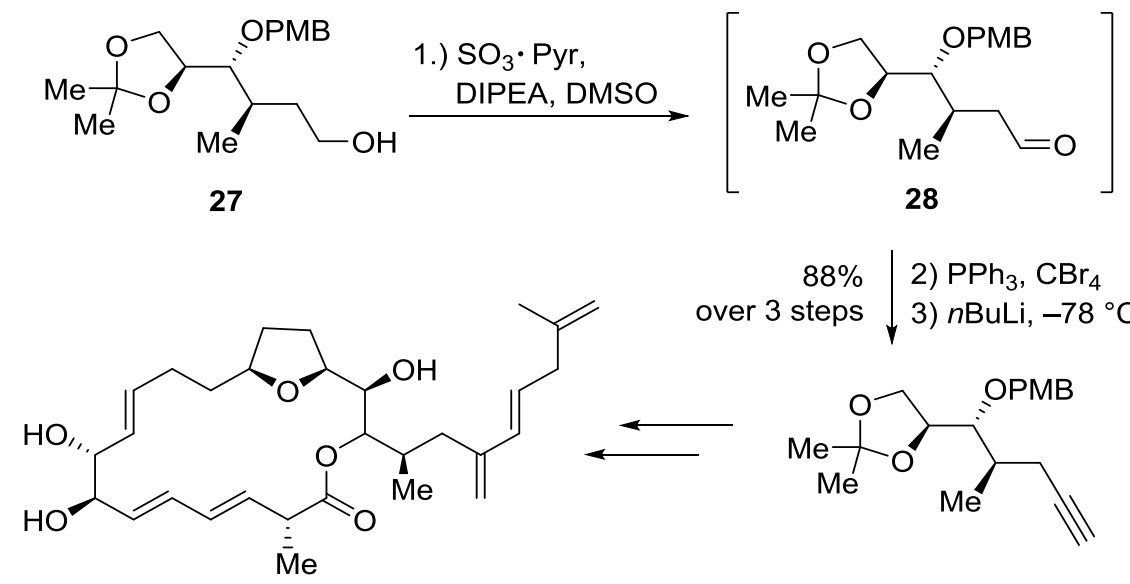

30 Amphidinolide $\mathrm{E}$

29

Scheme 6 Synthesis of Amphidinolide E by Roush and coworkers utilizing the Corey-Fuchs reaction. ${ }^{23}$ 
Wong and coworkers used a Fritsch-Buttenberg-Wiechell rearrangement in their synthesis of alkaloide Himbacine (34) (Scheme 7). ${ }^{25}$ The latter is a muscarinic receptor antagonist and, consequently, possesses a large potential to find application in the treatment of Alzheimer's disease or other neurodegenerative disorders. ${ }^{26}$ Accordingly, the Boc-protected piperidine $\mathbf{3 1}$ was treated with the ylide formed from deprotonation of the phosphonium salt $\mathbf{3 5}$ with potassium tert-butoxide, before addition of $n \mathrm{BuLi}$ to obtain the alkyne $\mathbf{3 2}$ in a high yield of $78 \%$ over two steps. The alkyne $\mathbf{3 2}$ with a piperidine moiety was then converted though a radical hydrostannylation to the corresponding stannane 33, which was incorporated via Stille coupling into the lactone core of the Himbacine framework.

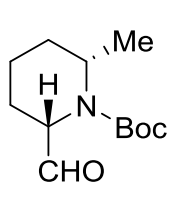

31

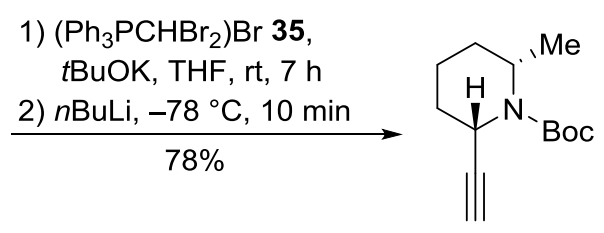

32

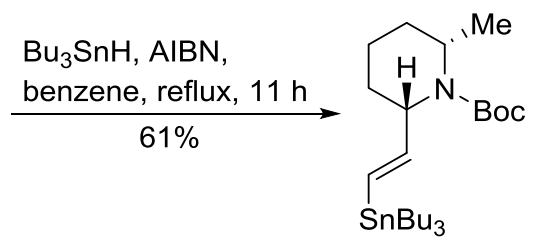

33<smiles></smiles>

34

Scheme 7 Synthesis of Himbacine (34) by Wong and coworkers. ${ }^{25}$ 


\subsubsection{The Seyferth-Gilbert homologation}

The Seyferth-Gilbert homologation ${ }^{27}$ and the corresponding Ohira-Bestmann modification ${ }^{28}$ are common methods to introduce alkynes into organic molecules. Similarly to the Corey-Fuchs reaction, aldehydes and ketones are used as starting materials. These are treated with dimethyl (diazomethyl)phosphonate (37) or dimethyl 1-diazo-2-oxopropylphosphonate (38) and a base to obtain terminal and internal alkynes (Scheme 8).

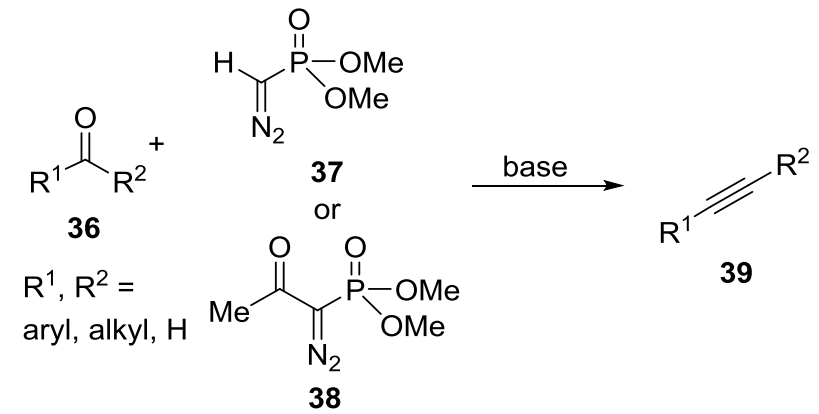

Scheme 8 General reaction scheme of the Seyferth-Gilbert homologation and the Ohira-Bestmann modification.

A mechanism was proposed by Gilbert et al. ${ }^{29}$. First, the deprotonated Seyferth-Gilbert reagent 39 is formed by deprotonation of dimethyl (diazomethyl)phosphonate (37) with a strong base in the unmodified Seyferth-Gilbert homologation or by retro-Claisen-type cleavage of the acetyl group in dimethyl 1-diazo-2-oxopropylphosphonate (38) (the Ohira-Bestmann variation). In the latter case a base is required although milder bases can be used than in the unmodified Seyferth-Gilbert homologation. As a consequence, a number of base-sensitive compounds can be applied in the OhiraBestmann-variation. Afterwards, the deprotonated Seyferth-Gilbert reagent 39 attacks the aldehyde or ketone 36 to form the alkoxide $\mathbf{4 0}$. Subsequently, the alkoxide $\mathbf{4 0}$ cyclizes to the oxaphosphetane $\mathbf{4 1}$. A dimethyl phosphate anion is then eliminated to form the diazoalkene $\mathbf{4 2}$, which is followed by elimination of nitrogen from the latter. As a result, the carbene $\mathbf{4 3}$ is formed. Finally, the desired alkyne 39 can be obtained by an 1,2-migration of one of the substituents in $\mathbf{4 3}$ (Scheme 9). 


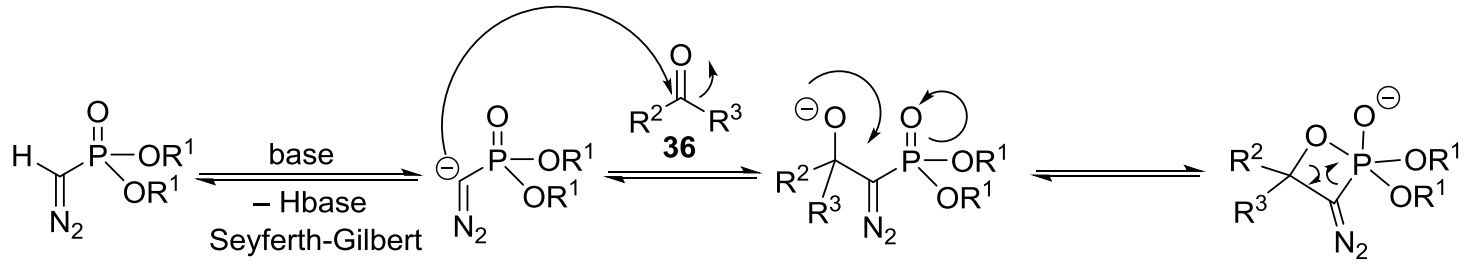

37

39

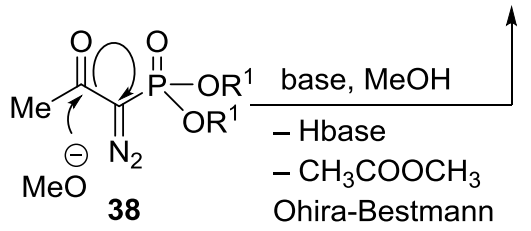

40

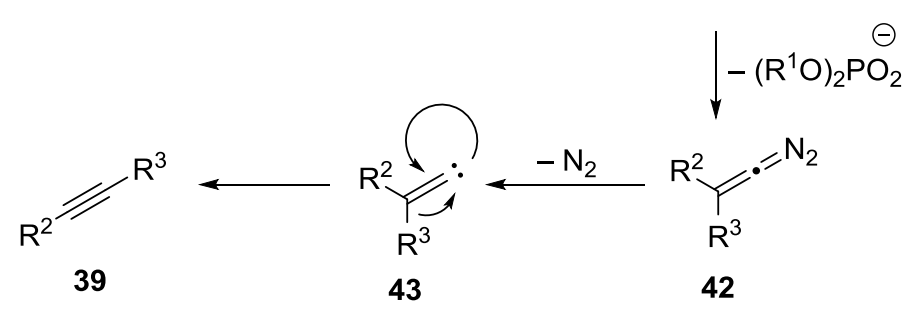

Scheme 9 Proposed mechanism of the Seyferth-Gilbert homologation and the Ohira-Bestmann modification. ${ }^{29}$ 
Recently, Neumaier and coworkers reported an application of an Ohira-Bestmann homologation in the synthesis of ${ }^{18} \mathrm{~F}$-labeled building blocks for positron emission tomography (PET). ${ }^{30}$ PET is a methodology to visualize processes on molecular level of ${ }^{18} \mathrm{~F}$-labeled compounds in clinical diagnostics, utilizing the positron emission of radioactive decay of ${ }^{18} \mathrm{~F}$. Because of the low half-time of ${ }^{18} \mathrm{~F}$ (110 min), it is necessary to use reliable and fast reactions. In their synthesis, the authors utilized the labeled benzaldehydes $\mathbf{4 4}$ and the Ohira-Bestmann-reagent 38 for the synthesis of the labeled alkynes 45 in high radiochemical yields of up to $60 \%$ in only 15 min. Finally, these labeled alkynes were transformed applying common synthetic methods to biologically interesting compounds. Thus, the triazol 47 was synthesized by a "click reaction" (see below in Chapter 1.2.3.1), the protected amino acid 49 was obtained using Sonogashira coupling, the $\beta$-lactam 51 - via the Kinugasa reaction and the phthalan $\mathbf{5 3}$ through a rhodium catalyzed $[2+2+2]$-cyclization (Scheme 10).

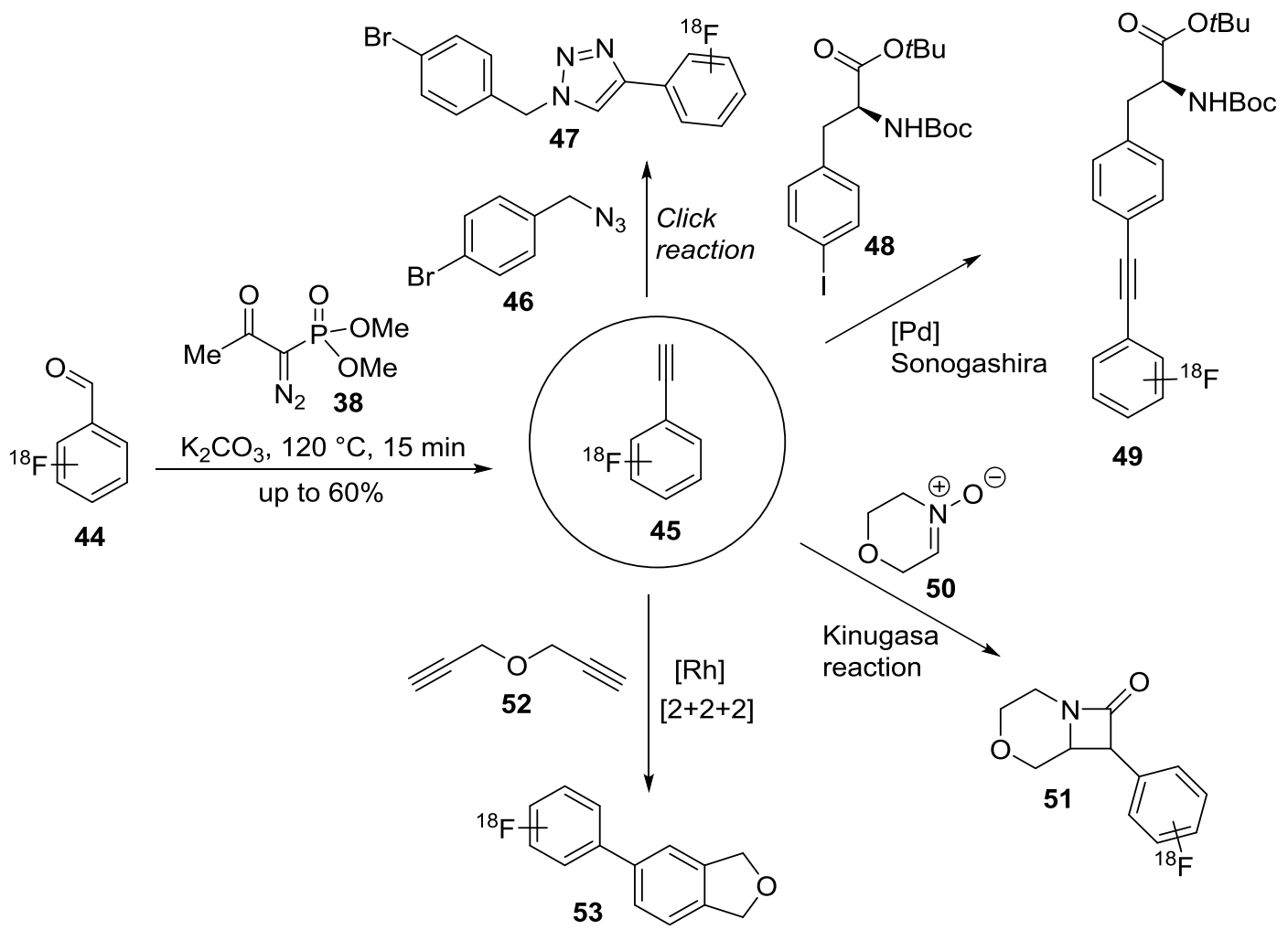

Scheme 10 Synthesis of ${ }^{18} \mathrm{~F}$-labeled alkynes $\mathbf{4 5}$ and their further derivatization to different biologically interesting compounds by Neumaier and coworkers. ${ }^{30}$ 
An interesting modification of the Seyferth-Gilbert homologation was presented by Harusawa and coworkers. ${ }^{31}$ First, the authors synthesized cyanohydrin- $O$-phosphates $\mathbf{5 5}$ from the reaction of aldehydes and ketones with diethyl phosphorocyanidate (54). Alkynes of the type 39 were then obtained under very mild conditions through reaction of $\mathbf{5 5}$ with $\mathrm{TMSN}_{3}$ or $\mathrm{NaN}_{3}$ in high yields of up to $88 \%$ (Scheme 11). No additional base was necessary. Thus, challenging functionalized compounds, which could not be accessed in high yields or in high selectivity by other variations, could be prepared. In line with their mechanistic studies, the authors suggest the initial formation of either tetrazolylphosphate $\mathbf{5 6}$ or azidotetrazole 57. Afterwards, fragmentation by the elimination of either diethyl phosphoric or hydrazoic acid derivatives leads to the tetraazafulvene 58. Subsequently, an elimination of two nitrogen molecules from $\mathbf{5 8}$ affords the carbene $\mathbf{4 3}$, which then undergoes a 1,2migration to form the desired product 39 .

A.

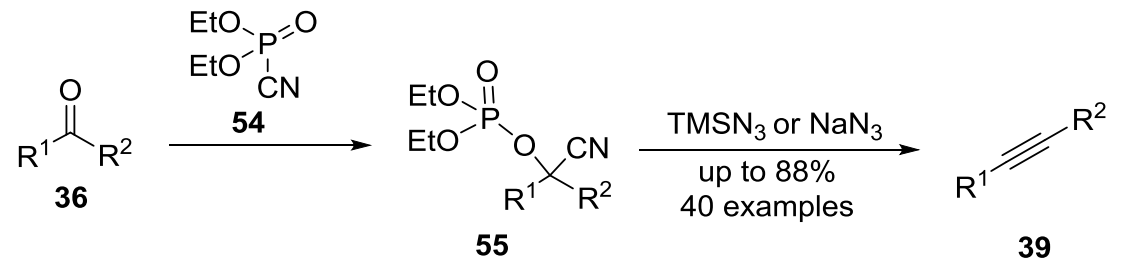

B.

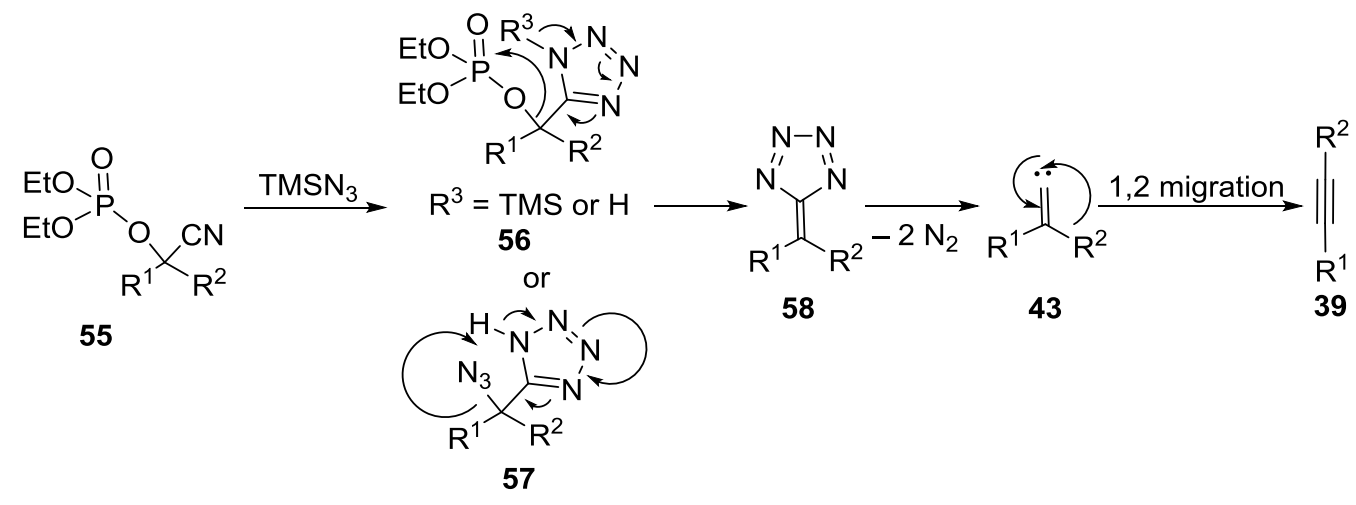

Scheme 11 Modification of Seyferth-Gilbert homologation as reported by Harusawa and coworkers. A. General reaction scheme. B. Proposed mechanism of the reaction. ${ }^{31}$ 


\subsubsection{Reactivity of alkynes}

The versatility of alkynes is based on the low oxidation state of the carbon atoms and the resulting possibility for further functionalization to a multiplicity of other functional groups. Hydrofunctionalisations are one of the most famous reactions (Figure 5). Typical examples are hydrogenations and the addition of halogens or hydrogen halides. ${ }^{32}$ Furthermore, reactions such as hydroborations ${ }^{33}$ hydrosilylations, ${ }^{34}$ hydrostannylations ${ }^{35 a}$ as well as additions of alcohols, thiols, amines, etc. ${ }^{35 \mathrm{~b}}$ are commonly used. In general, it possible to obtain the cis or trans products from addition reactions. Therefore, a catalyst is normally applied in an addition to obtain a defined stereoselectivity and to prevent overreaction. An illustrative example is the well-known Lindlar catalyst, which can be utilized for the hydrogenation of alkynes to alkenes. In case of this catalyst system, lead acetate is applied to poison the catalyst partially, preventing over reaction. ${ }^{36}$ Besides, with double addition reactions alkanes can be accessed from alkynes. ${ }^{3}$ The hydration of alkynes affords aldehydes or ketones ${ }^{37}$ and 1,2-diketones are accessible via the Wacker-Oxidation. ${ }^{38}$ In contrast, the oxidation with strong oxidants like potassium permanganate leads to the formation of acids. ${ }^{39}$ Another reaction commonly applied towards alkynes is the synthesis of aromatic systems by $[2+2+2]-$ cyclization. ${ }^{40}$ Furthermore, alkynes can be used in a variety of other cycloadditions such as the DielsAlder-reaction. ${ }^{41}$ Lastly, substituted 1,2,3-triazoles can be obtained from 1,3-dipolar cycloaddition of azides and alkynes ("click reaction", see Chapter1.2.3.1).

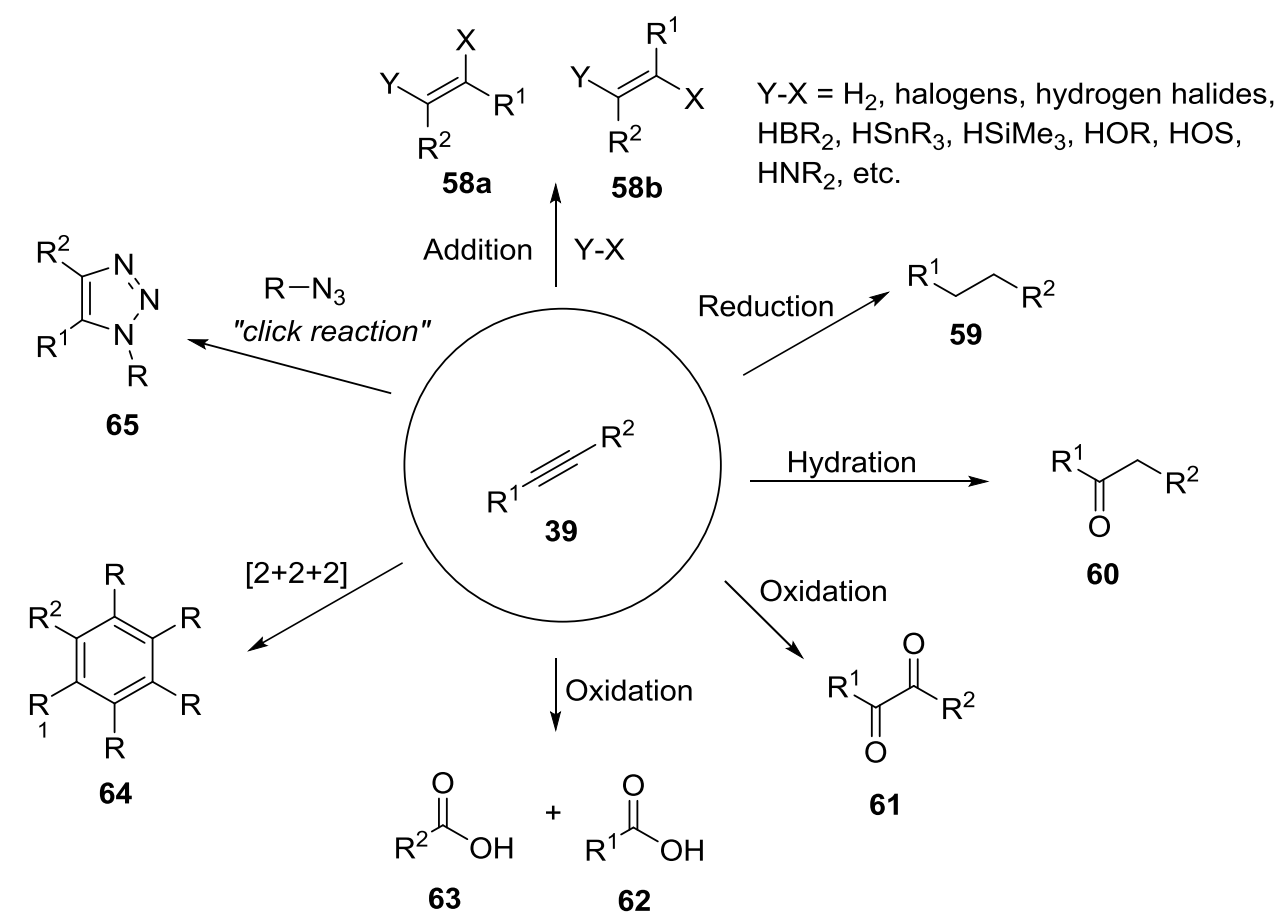

Figure 5 Selected products of alkynes common derivatization. 
Furthermore, it should be mentioned that there are several methods for the modification of alkynes that can be applied in the synthesis of complex structures. Such famous reactions as the alkyne zipper reaction $^{42}$ that is used for the transformation of internal to terminal alkynes or alkyne metathesis ${ }^{43}$ for the synthesis of polymeric, cyclic or terminal alkynes (Figure 6).
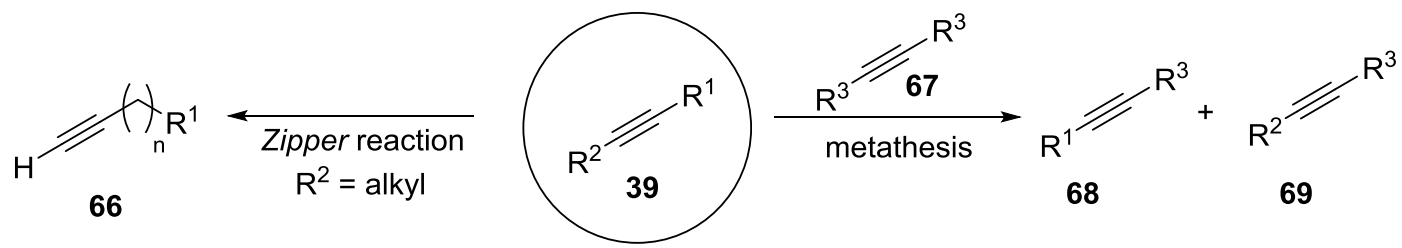

Figure 6 Common methods to modify alkynes. 


\subsubsection{Azide-alkyne cycloaddition ("click chemistry")}

The term "click chemistry" was introduced by Sharpless and coworkers in $2001 .^{44}$ Accordingly, a click-reaction should fulfill several requirements such as a high functional-group tolerance, mild and simple reaction conditions, an easy reaction work-up and the usage of environmental friendly or no solvents. Furthermore a high reaction yield, stereoselectivity, a broad substrate scope and a minimum of byproducts should be achieved.

Nowadays, the metal catalyzed 1,3-dipolar Huisgen cycloaddition for the formation triazoles from alkynes and azides is strongly related to the term click chemistry. ${ }^{45}$ The utilization of a metal catalyst in this reaction allows a significant reduction in temperature and affords the products with higher regioselectivity, when compared to the uncatalyzed Huisgen cycloaddition. Therefore, it fulfills nearly all the requirements of a click reaction. Particularly, the use of either copper of ruthenium catalysts for this reaction have emerged as powerful synthetic tools. These two systems elegantly either afford 1,4(73) or 1,5- disubstituted triazoles (70) with high selectivity. (Scheme 12).

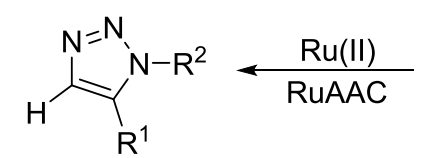

70

1,5-disubstituted

1,2,3-triazole

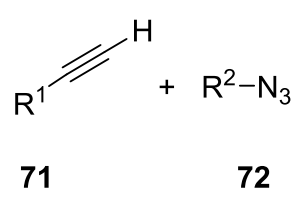

72

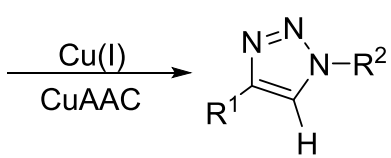

73

1,4-disubstituted

1,2,3-triazole

Scheme 12 Schematic reaction scheme of the copper- and the ruthenium-catalyzed click reactions.

In the proposed mechanism of the copper-catalyzed azide-alkyne cycloaddition (CuAAC, Figure 7A), the alkyne $\mathbf{7 1}$ and the copper catalyst initially form a $\pi$-complex $\mathbf{7 4} .^{46}$ Subsequent reaction with an additional molecule of copper catalyst affords the $\pi$-copper complex $\mathbf{7 5}$ of the copper acetylide. This complex coordinates the azide resulting in the formation of the intermediate 76. Subsequently, an internal rearrangement leads to the 6-membered metallacycle 77. The latter undergoes a ring contraction to afford the intermediate $\mathbf{7 8}$. Finally, the product $\mathbf{7 3}$ and the initial copper catalyst are obtained after protonolysis.

In the mechanism of ruthenium-catalyzed azide-alkyne cycloaddition (RuAAC, Figure 7B), an initial ligand exchange of the spectator ligands of the catalyst with the alkyne $\mathbf{7 1}$ and the azide $\mathbf{7 2}$ affords the complex 80. ${ }^{47}$ Subsequent regioselective oxidative coupling leads to the formation of the ruthenabicycle 81, which undergoes a reductive elimination to furnish the complex 82. Finally, the product $\mathbf{7 0}$ is obtained and the catalyst is regenerated through ligand replacement. 


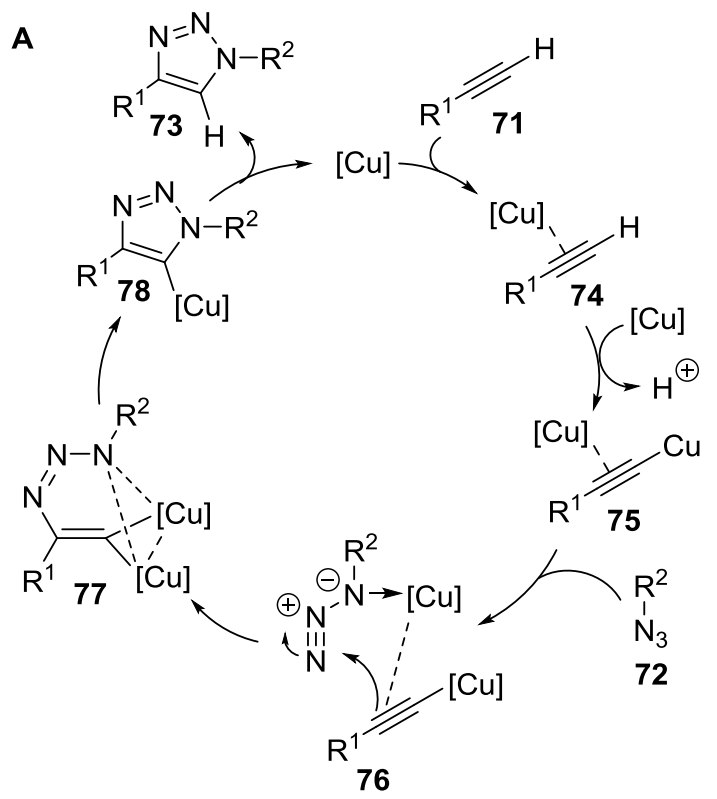

B

$B$

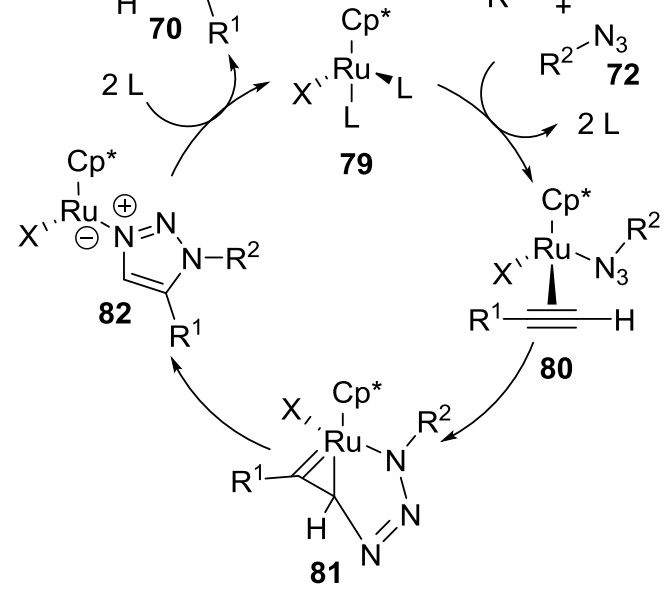

Figure 7 Proposed mechanisms for (A) the copper-catalyzed (CuAAC) $)^{46}$ and (B) the ruthenium-catalyzed (RuAAC) ${ }^{47}$ click reactions. 
In their publication from 2011, Nesterov and coworkers gave an illustrative example for the utilization of alkynes in organic electronics. ${ }^{48}$ They synthesized surface-bound semiconducting polymers with interesting spectroscopic and electronic properties. In the functionalization process, the polymerbonded alkyne 83 was treated successively with the diazide 84 and the dialkyne 86 in a coppermediated 1,3-dipolar cycloaddition (Scheme 14). After 34 steps, the solutions of compounds 84 and 86 were re-used without any significant loss of reactivity, thus illustrating the economic use of materials for the reported transformation.

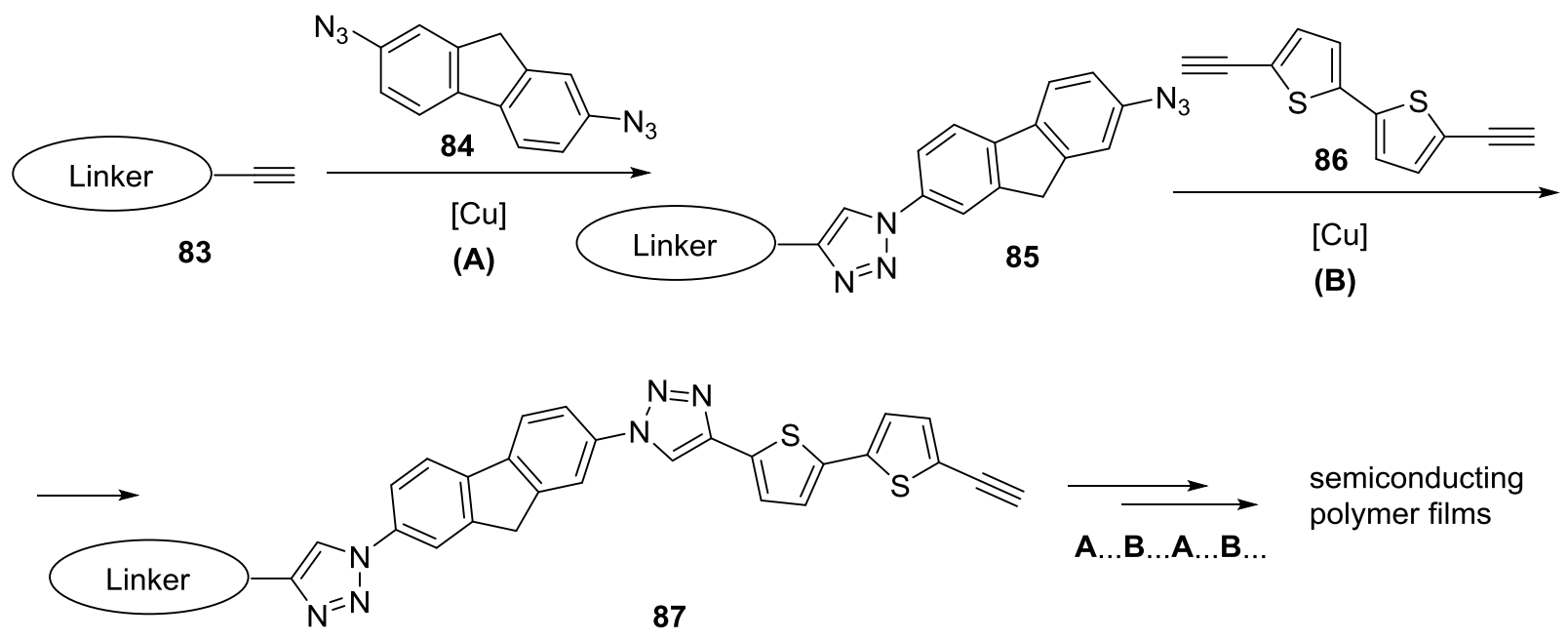

Scheme 13 Synthesis of surface-immobilized semiconducting polymers by Nesterov and coworkers. ${ }^{48}$ 
Recently, Mirkin and coworkers used DNA functionalized with dibenzylcyclooctyne (DBCO) to cover the surface of nanoparticles of a zirconium-based metal organic framework (MOF) (Figure 8A). ${ }^{49}$ The MOF-DNA conjugates 90 were obtained from the copper-free click reaction of the DBCO-labeled DNA 89 and azide group-containing metal organic-frameworks 88 (Figure 8B). Driving force of the reaction is the release of ring strain of the DNA-bounded alkynes. Later, the influence of the variation of the DNA length and the utilization of fluorescent DNA-residues was investigated in order to gain insight into the cell uptake of these compounds and to give important information towards drug delivery processes in cells.

A.

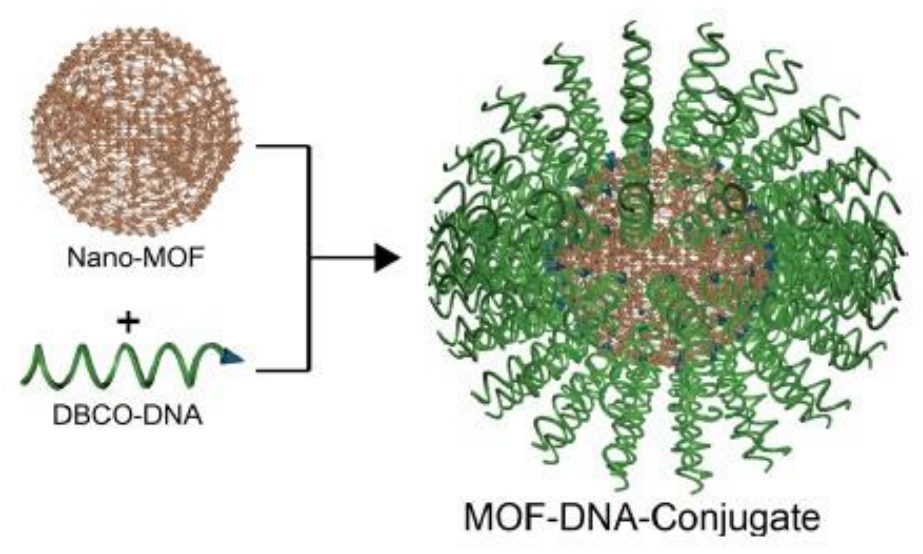

B. $\mathrm{Zr} \quad \mathrm{Zr}$<smiles>[Z7]OC([3H])c1ccc(C(O[Z7])O[Z7])cc1[NH3+]</smiles>

88<smiles>NOCC(=O)N1Cc2ccccc2C#Cc2ccccc21</smiles>

89 strained-alkyne click chemistry<smiles>[Z7]OC([Z7])c1ccc(C([Z7])O[Z7])c(-n2nnc3c2-c2ccccc2CN(C(=O)C[N+]([O-])O[CH2])c2ccccc2-3)c1</smiles>

90

Figure 8 Schematic surface attachment of DBCO-DNA to the Nano-MOF-surface (A) and reaction of DBCO-functionalized DNA 89 and azide-containing Nano-MOF 88. (B). ${ }^{49}$ 


\subsubsection{2 $[2+2+2]$ Cyclization}

The $[2+2+2]$-cyclization was first described by Reppe and coworkers in 1948 and over the years has become a versatile tool in the synthesis of complex molecules. ${ }^{50}$ Nowadays, polysubstituted cyclic molecules, such as pyridines or benzenes, can be easily accessed from this condensation reaction. A variety of unsaturated molecules, such as alkynes, alkenes, nitriles or isonitriles, can be applied as starting materials and the reaction tolerates other functional groups, including alcohols, amines, esters and halogens (Figure 9A). ${ }^{51}$ The cobalt complex $\left[\mathrm{CpCo}(\mathrm{CO})_{2}\right](\mathbf{9 2}$, Figure 9B) is a commonly used precatalyst in the $[2+2+2]$-cyclization, but also other cobalt, iridium, nickel or ruthenium catalysts can be applied. ${ }^{52}$

A.<smiles>[R]C#C[R]</smiles><smiles>[R]c1ccc([R])c([R])c1[R]</smiles>

91
B.<smiles>O=C1CCCC1CO</smiles>

92 $[\mathrm{M}]=\mathrm{Co}, \mathrm{Ni}, \mathrm{Ru}, \mathrm{Rh}$<smiles>[R]C#CC([R])=C[R]</smiles>

Figure 9 (A) General reaction scheme of the $[2+2+2]$-cycloaddition of alkynes and (B) the commonly used catalyst $\left[\mathrm{CpCo}(\mathrm{CO})_{2}\right](\mathbf{9 2})$.

Two general mechanisms have been proposed for the cobalt-catalyzed $[2+2+2]$ synthesis of benzene from acetylene (Figure 10). ${ }^{51}$ In both, the metal catalyst is coordinated by two alkynes and the 5membered intermediate 94 is subsequently formed through an oxidative addition. This intermediate 94 is then coordinated by another alkyne molecule, forming the intermediate $\mathbf{9 5}$. Two reaction pathways have been proposed from this intermediate to yield benzene. In the first case, the alkyne inserts into the carbon-metal bond of $\mathbf{9 5}$ to form the intermediate $\mathbf{9 6}$, and reductive elimination follows to form complex 98. Alternatively, it has been proposed that the intermediate 97 is initially formed by a [4+2]cycloaddition, which after isomerization affords the intermediate 98. Finally, release of benzene regenerates the catalyst. 


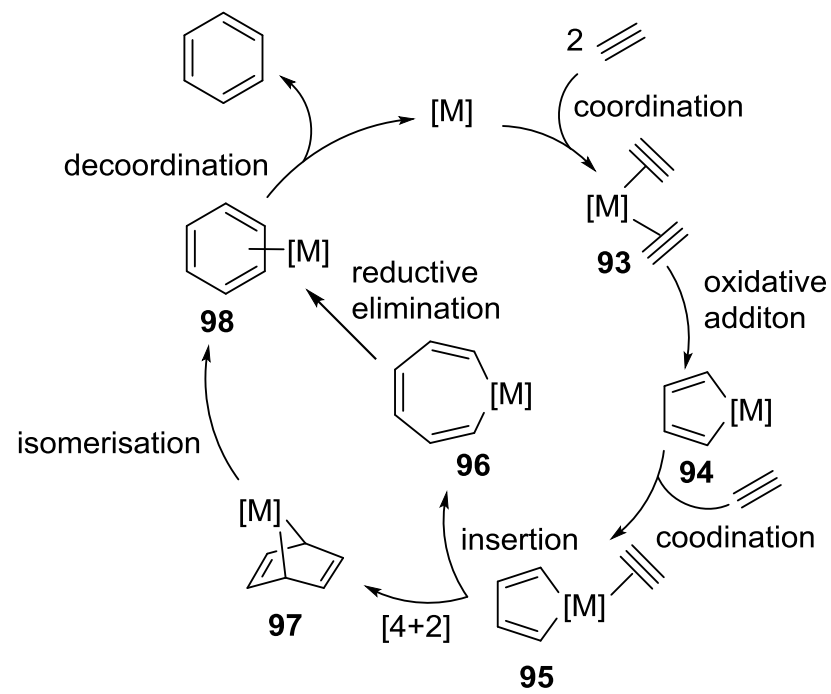

Figure 10 Proposed mechanism for the $[2+2+2]$-cyclization. ${ }^{51}$

Stará, Starý and coworkers have used a cobalt catalyzed [2+2+2]-cycloaddition in their synthesis of pyridohelicenes 101 (Scheme 14). ${ }^{53}$ These helically chiral structures can be potentially applied in variety of fields of chemistry including coordination chemistry ${ }^{54}$ and material science. ${ }^{55}$ Initially, the partially saturated helicene $\mathbf{1 0 0}$ was synthesized by a $\left[\mathrm{CpCo}(\mathrm{CO})_{2}\right]$-catalyzed $[2+2+2]$-cyclization of the triyne 99. In a second step, the compound $\mathbf{1 0 0}$ was completely aromatized to the pyridohelicene 101 in a microwave-assisted oxidation with manganese dioxide. This class of compounds was relatively unexplored before due to synthesis limitations regarding the basic pyridine group.

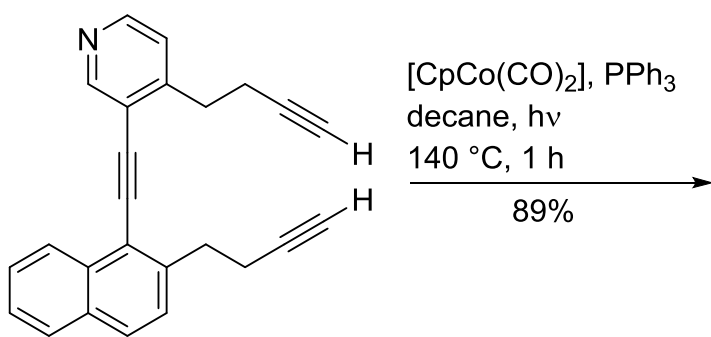

99

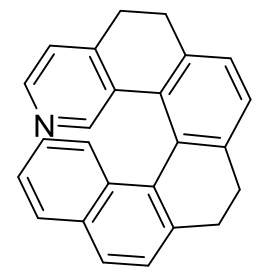

100

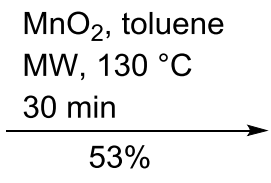

$\mathrm{MnO}_{2}$, toluene

MW, $130^{\circ} \mathrm{C}$

$53 \%$

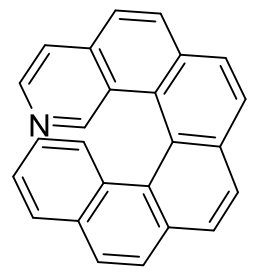

101

Scheme 14 Pyridohelicene synthesis by Stará, Starý and coworkers. ${ }^{53}$ 
Another recent example of a $[2+2+2]$ cyclization was presented by Wang and coworkers in the synthesis of 2,3,6-trisubstituted pyridines of the type 103 (Scheme 15). ${ }^{56 a}$ Pyridines 103 were synthesized in the reaction of alkylsubstituted cyanides and terminal arylalkynes under mild conditions. The chlorinated pyrylium salt $102[\mathrm{~T}(p-\mathrm{Cl}) \mathrm{PPT}]$ was utilized as a photocatalyst under visible light irradiation, and variously substituted pyridines were accessed in yields of up to $79 \%$. The authors proposed a single-electron-transfer process $^{56 \mathrm{~b}}$ as a key mechanistic step of the reaction.

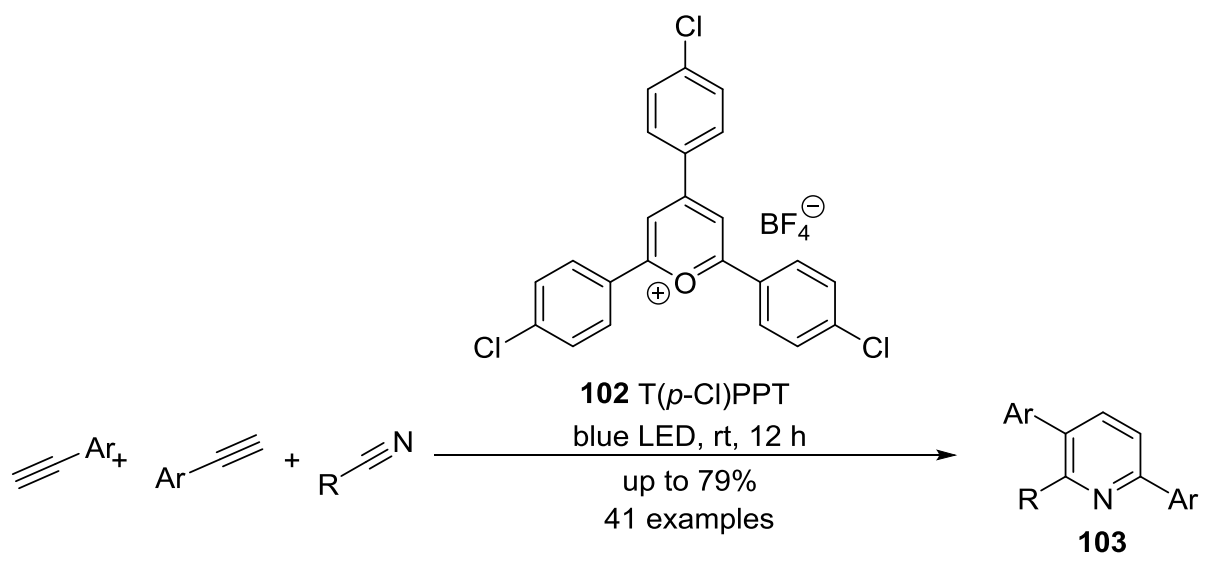

$\mathrm{R}=\mathrm{Me} ;$ Ar: flourinated, chlorinated, with alkene groups

Scheme 15 Synthesis of 2,3,6- trisubstituted pyridines 103 by Wang and coworkers. ${ }^{56}$ 


\subsubsection{Alkyne metathesis}

In the year 1968 Penella and coworkers observed that under high temperatures and in the presence of a tungsten catalyst, pent-2-yne (104) disproportionates affording a mixture of but-2-yne (105) and hex3-yne (Scheme 16). ${ }^{57}$ This observed reactivity was the foundation of the alkyne metathesis reaction, which is nowadays a powerful and versatile tool in the synthesis of complex molecules.

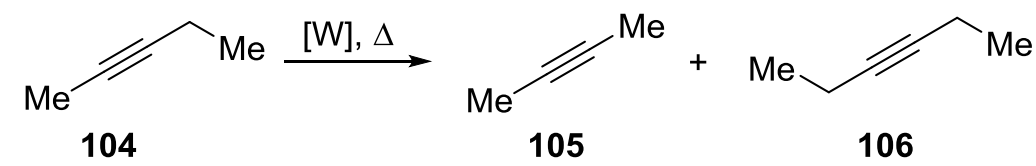

Scheme 16 Observations by Penella and coworkers towards the metal-catalyzed disproportionation of pent-2-yne (104). ${ }^{57}$

The alkyne metathesis is defined as a reaction where the alkylidyne constituents of two acetylene molecules are statistically redistributed in the presence of a metal catalyst (Scheme 17).

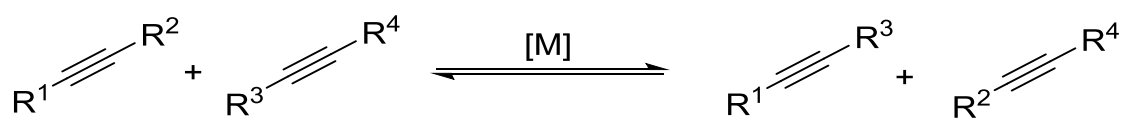

Scheme 17 Schematic reaction scheme for the alkyne metathesis.

Modern catalysts for the metathesis of alkynes comprise the systems based on molybdenum, such as the catalyst 107 or the bench stable precursor 108 (Figure 11). These catalysts distinguish themselves through a high stability, activity and selectivity in combination with a high functional group tolerance with respect to many common functional groups. ${ }^{58}$

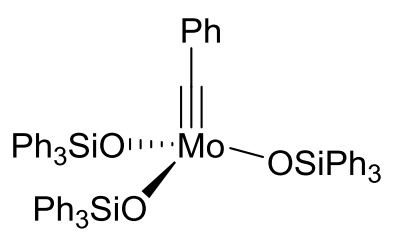

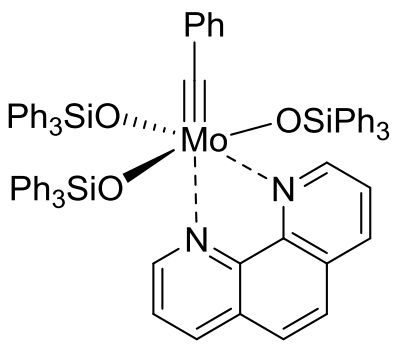

107 108

Figure 11 Common catalysts utilized in the alkyne metathesis. 
A mechanism for the alkyne metathesis was proposed by Katz and coworkers. ${ }^{59}$ Initially, the metallacyclobutane $\mathbf{1 1 1}$ is formed by a [2+2]-addition of the catalyst and the alkyne. A subsequent isomerization leads to the formation of the metallacyclobutane 112. Finally, the catalyst $\mathbf{1 1 4}$ and the new alkyne $\mathbf{1 1 3}$ are obtained through a cycloelimination (Figure 12).
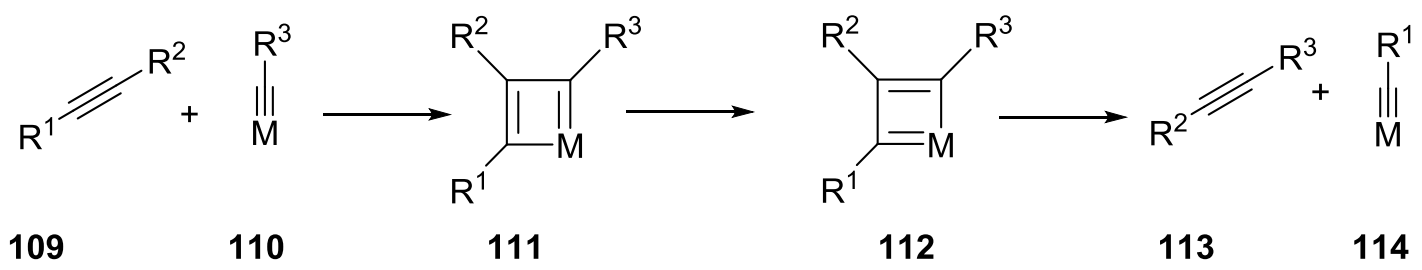

Figure 12 Proposed mechanism for the alkyne metathesis. ${ }^{59}$

Nowadays, other reaction formats of the alkyne metathesis rather than alkyne cross metathesis (ACM) are the focus of investigations. Ring closing metathesis (RCAM), which can be applied in the synthesis of cyclic alkynes or cyclic oligomers of dialkynes, is extensively investigated. Furthermore, polymerization techniques such as acyclic diyne metathesis polymerization (ADIMET) and ring opening polymerization are of high interest in the field of material science (Figure 13). ${ }^{58,60}$<smiles>[R][R]#CC(C)C(C)(C)C#[R]#[R]</smiles>
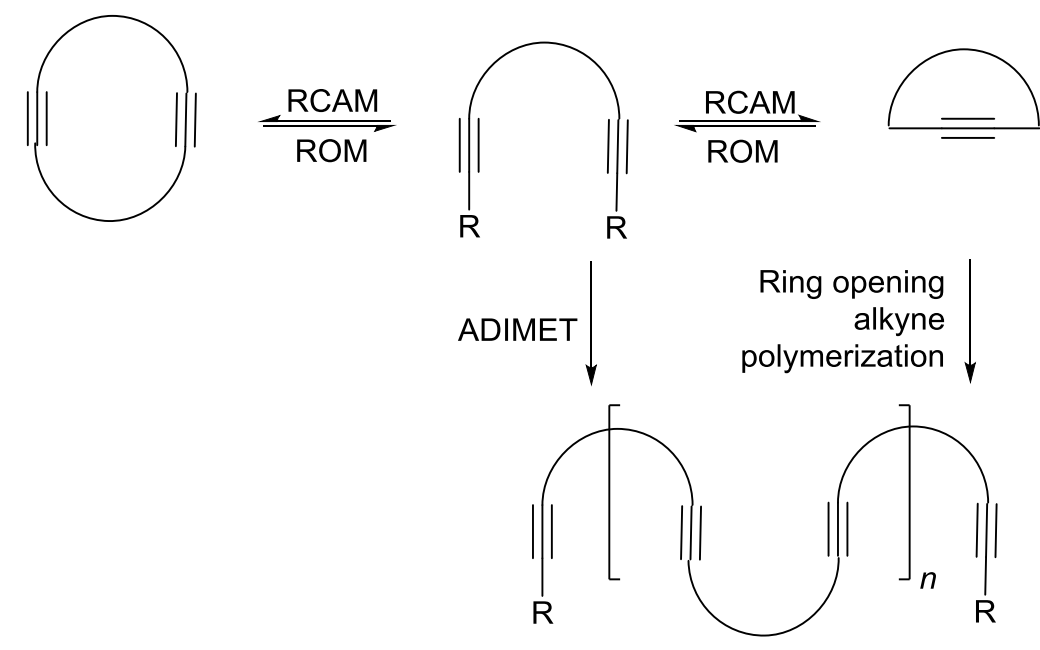

Figure 13 Typical reaction formats of alkyne metathesis: alkyne cross metathesis (ACM), ring closing metathesis (RCAM), ring opening metathesis (ROM), acyclic diyne metathesis polymerization (ADIMET) and the ring opening polymerization. ${ }^{60}$ 
Fürstner et al. presented a descriptive example for alkyne metathesis in the first total synthesis of Lactimidomycin (118) (Scheme 18). ${ }^{61}$ The latter exhibits anti-cancer activity in combination with a low cytotoxicity towards mammals and inhibits cell migration. Therefore, this macrolide is an attractive synthesis target. A high yielding ring closing alkyne metathesis (RCAM) was used as key step in the synthesis of the cyclic enyne $\mathbf{1 1 7}$ from the dialkyne $\mathbf{1 1 5}$. For this reaction, the molybdenum (VI) catalyst 116 was selected due to its strong Lewis acidity and resulting high reactivity. Afterwards, the cyclic alkyne 117 was transferred to Lactimidomycin (118). This methodology was also applied in the synthesis of a variety of biologically interesting derivatives. ${ }^{62}$

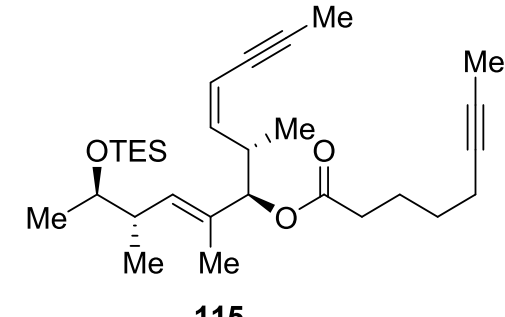

115
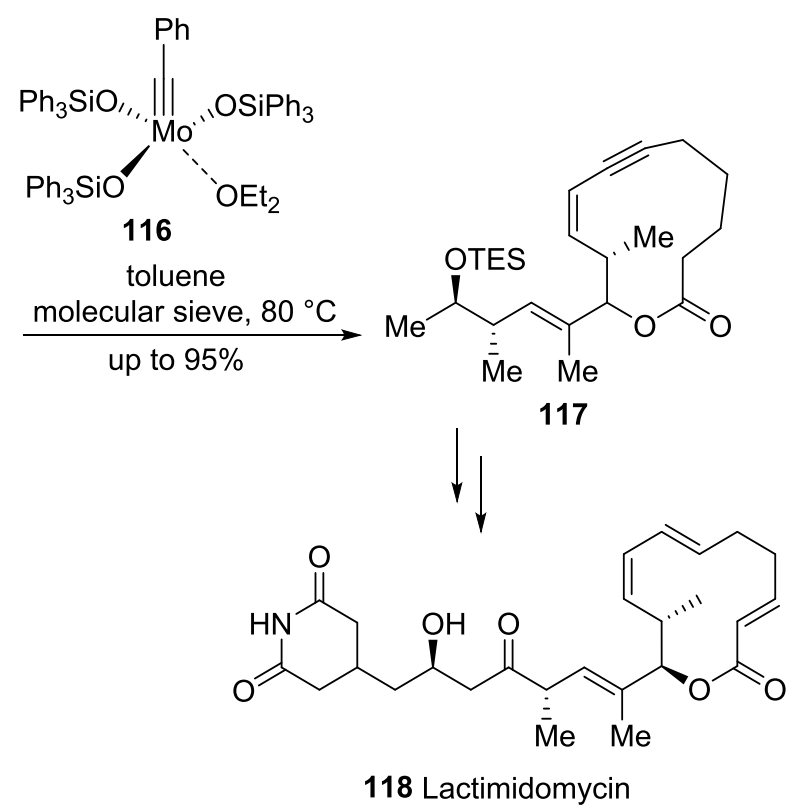

Scheme 18 First synthesis of Lactimidomycin 118 by Fürstner and Micoine utilizing ring closing alkyne metathesis (RCAM). ${ }^{59}$ 
An example of the formation of oligomers employing RCAM towards the synthesis of precursors of cycloparaphenyleneacetylene (CPPA) was published by Moore and coworkers (Scheme 19) ${ }^{63}$ CPPA's are completely conjugated molecular belts with interesting photophysical and electronic properties and capable of forming host-guest complexes. Therefore, they are intriguing targets in the field of supramolecular chemistry and material science. The compound $\mathbf{1 2 0}$ was synthesized through a high yielding macro-cyclization utilizing a molybdenum (VI) pre-catalyst. Molecular sieves were used to remove the byproduct but-2-yne, providing a driving force for the reaction. Afterwards, the desired compound [3] $\mathrm{CPP}^{3} \mathrm{~A} 121$ was obtained by a sodium naphthalenide-mediated reductive aromatization. Additionally, the potential application of CPPA 121 as a polymer linker applying the copper-free click-reaction with methyl azide as well as the physical properties of its host-guest complexes with $\mathrm{C}_{70}$ fullerene were examined

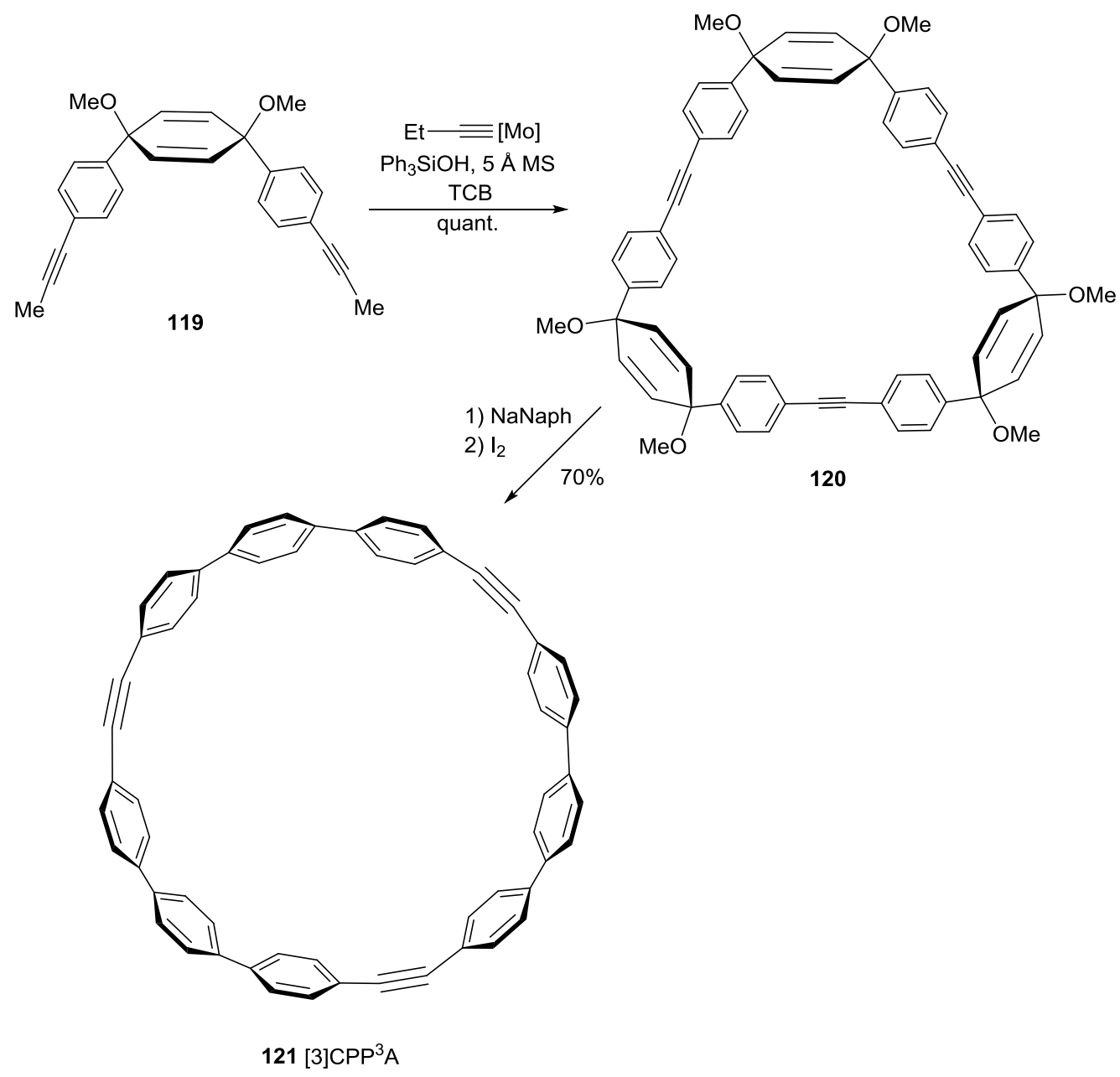

Scheme 19 Synthesis of [3]CPP ${ }^{3}$ A 121 by Moore and coworkers. ${ }^{63}$ 


\subsubsection{Alkyne zipper reaction}

The alkyne zipper reaction is a prototropic migration of an internal triple bond under the action of superbases producing metallated derivatives of terminal acetylenes (Scheme 20). ${ }^{42}$

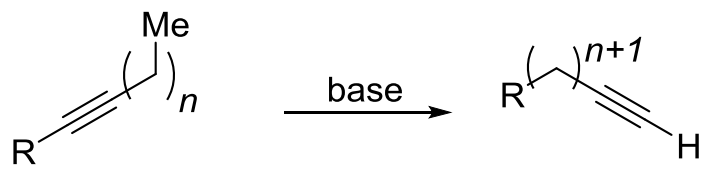

Scheme 20 Schematic scheme of the zipper reaction. ${ }^{42}$

This general reactivity was already described in the end of the 19th century, but the full synthetic potential of the transformation was revealed in 1975 with the discovery of potassium 3aminopropylamide (KAPA, 123) as an efficient base/acid system. ${ }^{64}$ KAPA allows the reaction to proceed at ambient temperature and in short reaction times. It fulfills a dual role as a base and an acid in the reaction mechanistic pathway. Initially, a KAPA mediated isomerization of the alkyne $\mathbf{1 2 2}$ leads to the formation of the allene 124 (Scheme 21). Afterwards, a second isomerization by KAPA affords the regioisomer 125. This prototropic migration continues further until the terminal acetylide $\mathbf{1 2 6}$ is formed. The final deprotonation is rather easy and represents the thermodynamic driving force of the reaction. A subsequent protonation leads to the formation of the final product $\mathbf{1 2 7}{ }^{64 a}$
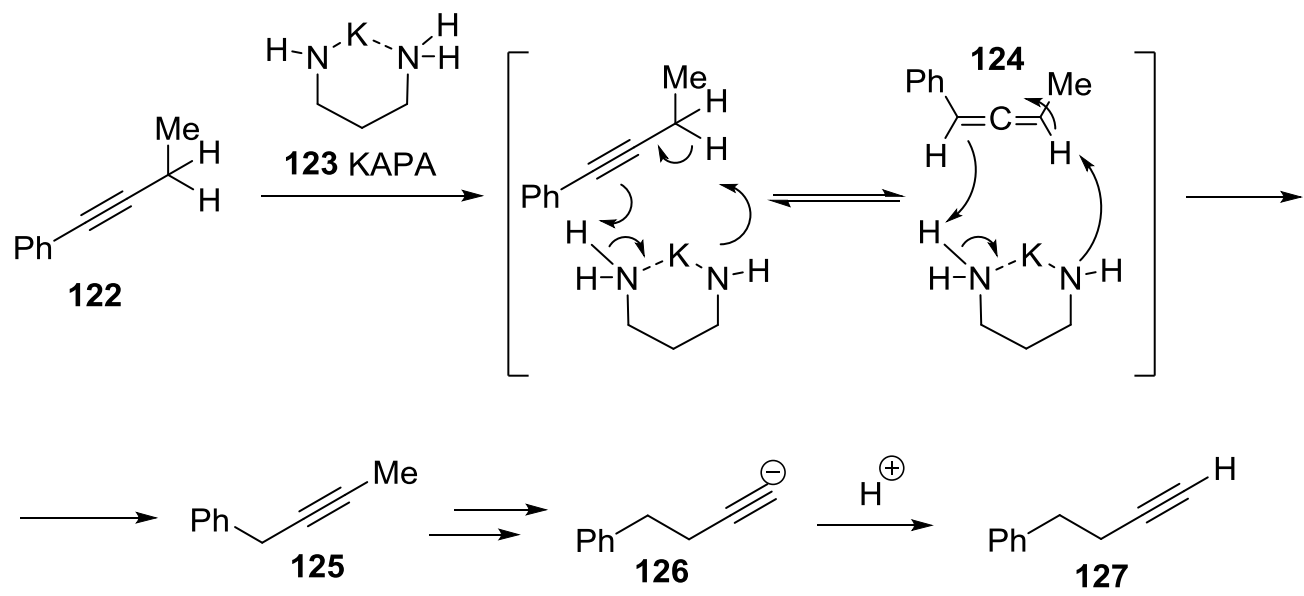

Scheme 21 Proposed mechanism for the KAPA-catalyzed zipper reaction ${ }^{64 a}$ 
An example of a zipper reaction was given by Trost et al. for the synthesis of (-)-Aspergillide B (Scheme 22). ${ }^{65}$ The class of the Aspergillide macrolactones shows biological activity against leukemia and human breast cancer. Representatives share the characteristic tetrahydropyran motif. Trost and coworkers used 1,3-diaminopropane to convert the internal alkyne $\mathbf{1 2 8}$ to its terminal isomer $\mathbf{1 2 9}$ by a zipper reaction in a yield of $81 \%$. The latter was used to synthesize the desired (-)-Aspergillide (130).<smiles>CCC#C[C@H](C)O</smiles>

128

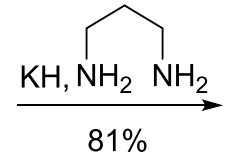

$81 \%$

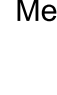

OH

129

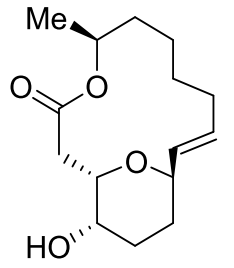

130 (-)-Aspergillide B

Scheme 22 Utilization of an alkyne zipper reaction in the synthesis of (-)-Aspergillide B $\mathbf{1 3 0}$ by Trost and coworkers. ${ }^{65}$ 


\subsubsection{Incorporation of alkyne moieties into organic molecules}

\subsubsection{Nucleophilic substitution with acetylides}

Acetylides, one of the oldest known family of organometallic compounds, are salts of metals and deprotonated alkynes. ${ }^{66}$ The first synthesis of silver acetylides was already reported in $1865 .{ }^{67}$ Deprotonated alkynes are isoelectronic to cyanide and carbon monoxide and can be described as pseudohalogenides. The metal salts show similar stoichiometry and magnetic properties compared to related cyanide compounds. ${ }^{68}$ Today a variety of metal acetylides is known in literature and include lithium, ${ }^{69}$ sodium, ${ }^{70}$ zinc, $^{71}$ silver $^{66}$ or copper acetylides. ${ }^{72}$ Acetylides act as nucleophiles and, therefore, can be utilized in nucleophilic substitution or addition reactions. Transition metal analogs, like silver or copper acetylides, tend to be explosive and should be only handled in solution of a limited concentration and with special precautions. Nevertheless, when handled accordingly these salts are quite stable. ${ }^{66,73}$ In solution acetylides tend to form dimers, oligomers or polymers. ${ }^{73,74}$ In general, acetylides react with electrophiles. Among others, nucleophilic substitution or addition reactions with different carbon-based electrophiles such as ketones or aldehydes, alkyl halides, imines, activated acids or the Michael-addition to $\alpha, \beta$-unsaturated carbonyl compounds are common examples (Figure $14)^{3}$

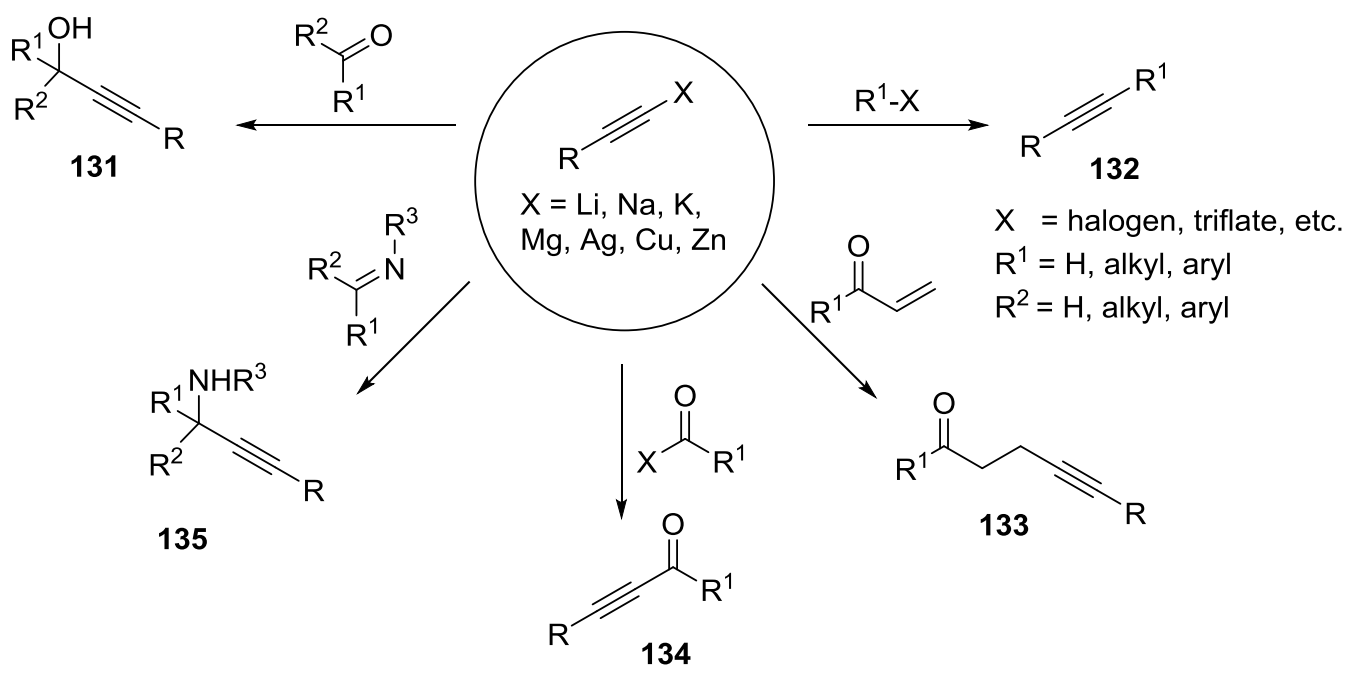

Figure 14 Typical reactions of acetylides with different electrophiles.3 
An example of a nucleophilic substitution with acetylides was given by Williams et al. ${ }^{75}$ The adamantyl bromide (136) was refluxed in $N$-methylmorpholine with silver(I) acetylide (137) to offer the alkyne $\mathbf{1 3 8}$ (Scheme 23). This illustrates the enhanced stability of silver acetylides in contrast to other organosilver(I) compounds.

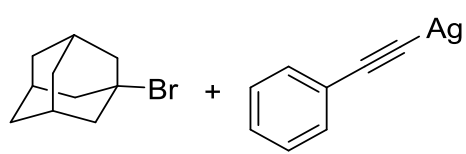

136

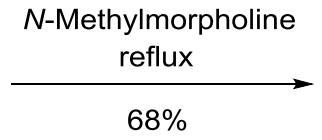

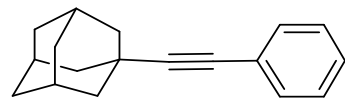

138

Scheme 23 Synthesis of adamantyl-alkynes with silver (I) acetylides by Williams et al. ${ }^{\mathbf{7 5}}$

Another example of a typical addition reaction with acetylides was reported by Corey and coworkers as a step in the total synthesis of Antheliolide A (143) ${ }^{76}$ This naturally occurring compound was first isolated from the marine coral Anthelia glauca. ${ }^{77}$ Furthermore, it is a synthetically challenging molecule with multiple stereo centers and a complex arrangement of functional groups. In the synthesis by Corey and coworkers, the lactone 139 was transferred to hemiacetal 142 in a three step reaction sequence. First, the intermediate enolate 140 was generated by addition of potassium bis(trimethylsilyl)amide as a base. Subsequently, the Davis oxaziridine was added, generating the intermediate lactone 141. Finally, nucleophilic attack of the lactone 141 with lithium acetylide afforded the hemiacetal 142, which was later utilized to synthesize Antheliolide A (143) (Scheme 24).

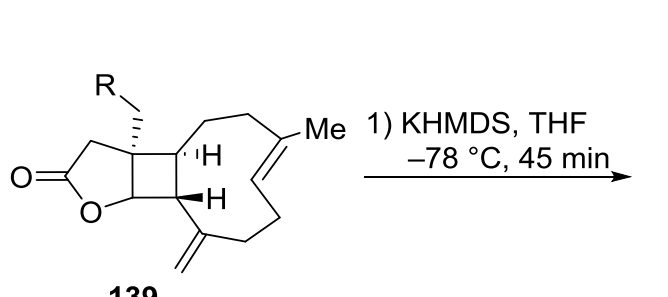

139

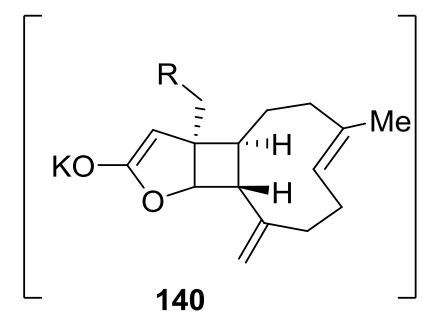

2) $\mathrm{PhCH}(\mathrm{O}) \mathrm{NSO}_{2} \mathrm{Ph}$

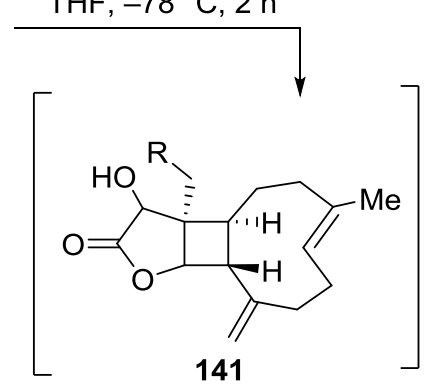

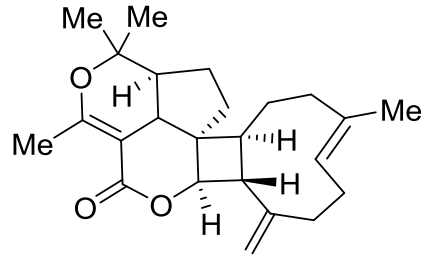

143 Antheliolide A

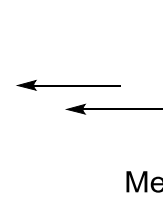

$\mathrm{Me}$

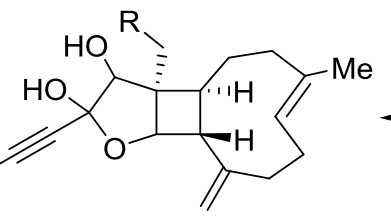

142
3) $\mathrm{CH}_{3} \mathrm{C} \equiv \mathrm{CLi}$, THF, $-78{ }^{\circ} \mathrm{C}, 12 \mathrm{~h}$ over 3 steps

Scheme 24 Synthesis of Antheliolide A (143) by Corey and coworkers. ${ }^{\mathbf{7 6}}$ 


\subsubsection{The Sonogashira reaction}

In their groundbreaking publication of 1975, Sonogashira and coworkers described their own modification of the Stephans-Castro coupling of an aryl iodide with terminal alkynes. ${ }^{78}$ They reported a cross-coupling reaction utilizing a palladium catalyst in combination with a copper co-catalyst and an amine base (Scheme 25). Particularly important was that this protocol could overcome the use of shock-sensitive copper acetylides, which were necessary in previous protocols.

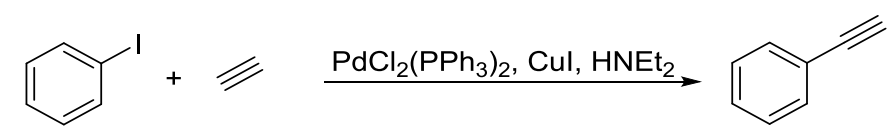

Scheme 25 Coupling of aryliodides with acetylene described by Sonogashira and coworkers. ${ }^{78}$

In general, the Sonogashira coupling can be performed under mild conditions, tolerating moisture and commonly used functional groups. Thus, the Sonogashira-reaction is an established and versatile tool for the introduction of alkyne moieties. ${ }^{19 a}$

A typical cross-coupling mechanism has been proposed for this transformation (Figure 15) ${ }^{79}$ Initial oxidative addition of the aryl halide to the palladium(0) catalyst $\mathbf{A}$ affords the intermediate $\mathbf{B}$. In a second catalyst cycle, the terminal alkyne is activated through the coordination of the copper cocatalyst $\mathbf{G}$ to the triple bond. The resulting alkyne $\pi$-complex $\mathbf{F}$ is deprotonated by the base to form the copper acetylide $\mathbf{E}$, which substitutes the counterion of the intermediate $\mathbf{B}$ through a transmetalation step. A subsequent cis/trans-isomerization results in the formation of the complex $\mathbf{D}$, which can undergo a reductive elimination to furnish the product and the initial palladium(0) complex.

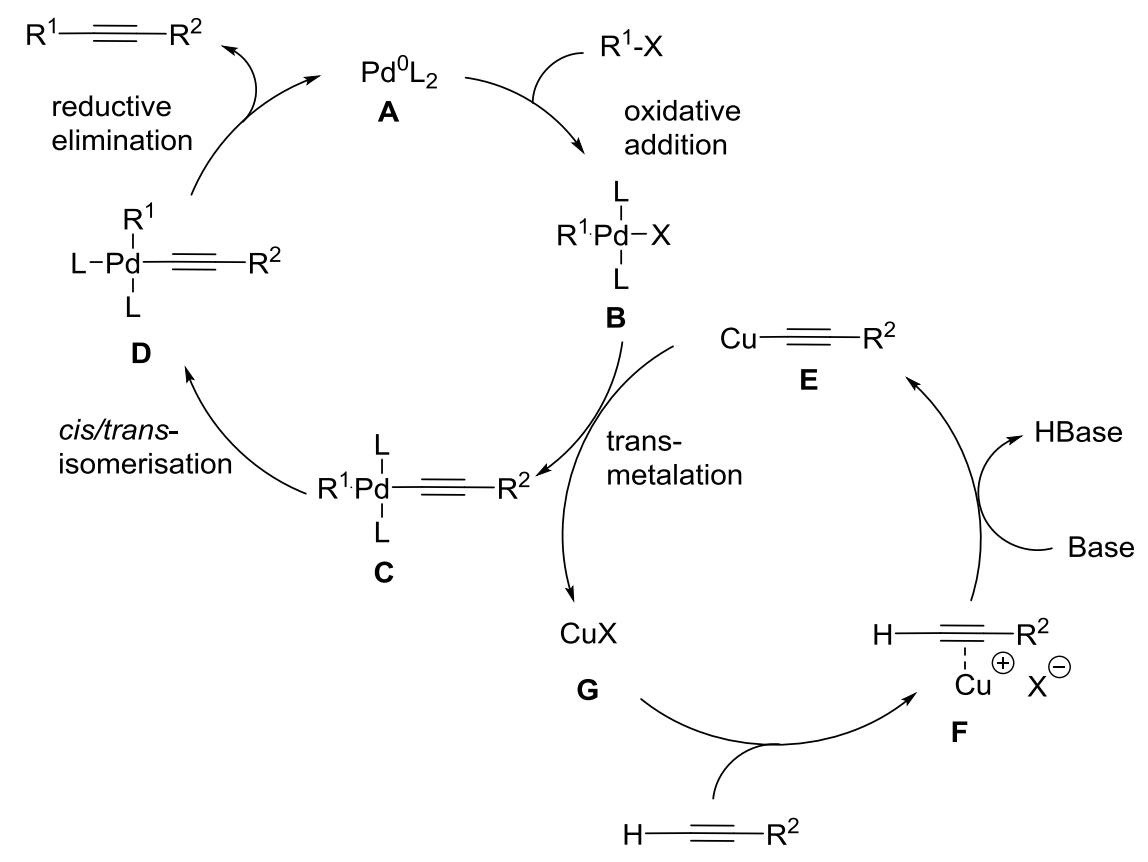

Figure 15 Proposed mechanism for the copper co-catalyzed Sonogashira coupling. ${ }^{79}$ 
Paterson et al. applied a late stage Sonogashira coupling in the first synthesis of the Callipeltoside Aglycon. ${ }^{80}$ Callipeltosides are an interesting class of natural macrolide polyketides isolated from the marine sponge Callipelte sp., which show activity in the proliferation of KB and P388 cells. The key structural feature of these polyketides is the trans-chlorocyclopropane ring adjacent to a dienyne moiety. Exactly this functionality of the molecule was addressed by Paterson and coworkers. Aglycon (146) was obtained through a high yielding Sonogashira coupling of the iodide 144 and the chlorocyclopropane-substituted alkyne $\mathbf{1 4 5}$, which was followed by deprotection of the TBS protective group (Scheme 26).
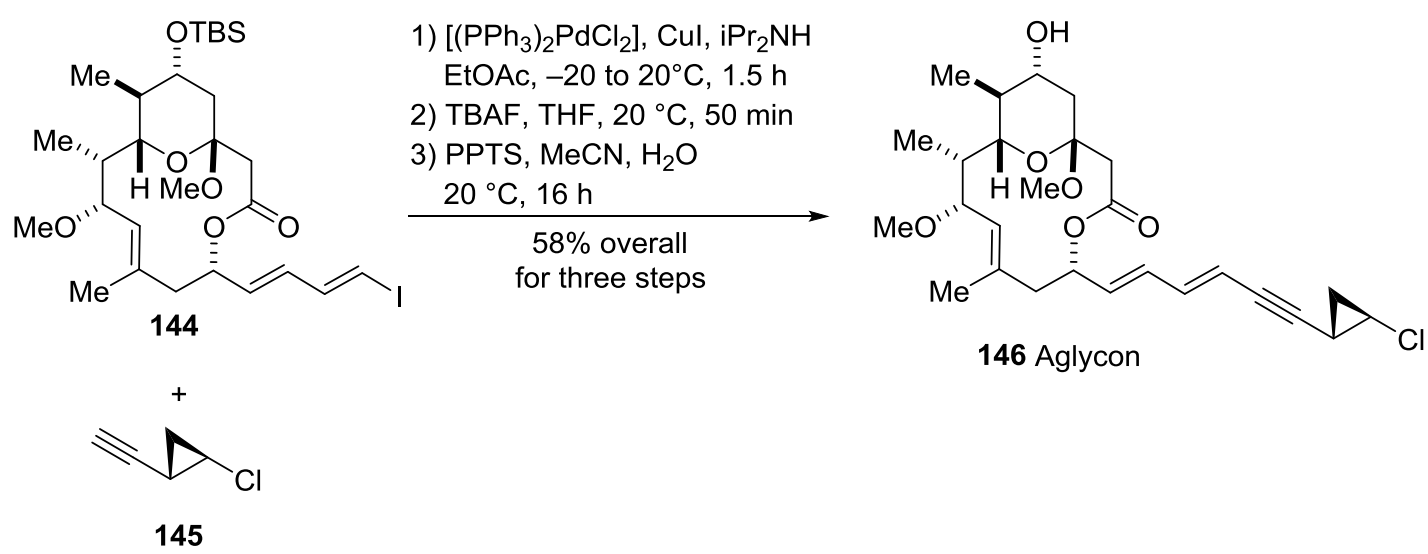

Scheme 26 Synthesis of Aglycon (146) by Paterson et al. ${ }^{80}$ 
Recently, a copper-free Sonogashira coupling was used in the functionalization of unprotected halotryptophans and halotryptophan containing peptides in water as a solvent. In their publication from 2017, Corr and coworkers presented this elegant methodology utilizing the water soluble Buchwald catalyst sXphos (149) (Scheme 27). ${ }^{81}$ Among others, the 6-bromocystargamide (147) smoothly underwent alkynylation to afford the corresponding product 148 in a microwave-assisted reaction. This methodology made these compounds accessible for labeling experiments and illustrates the potential of the Sonogashira coupling in the alkynylation of complex biological molecules.
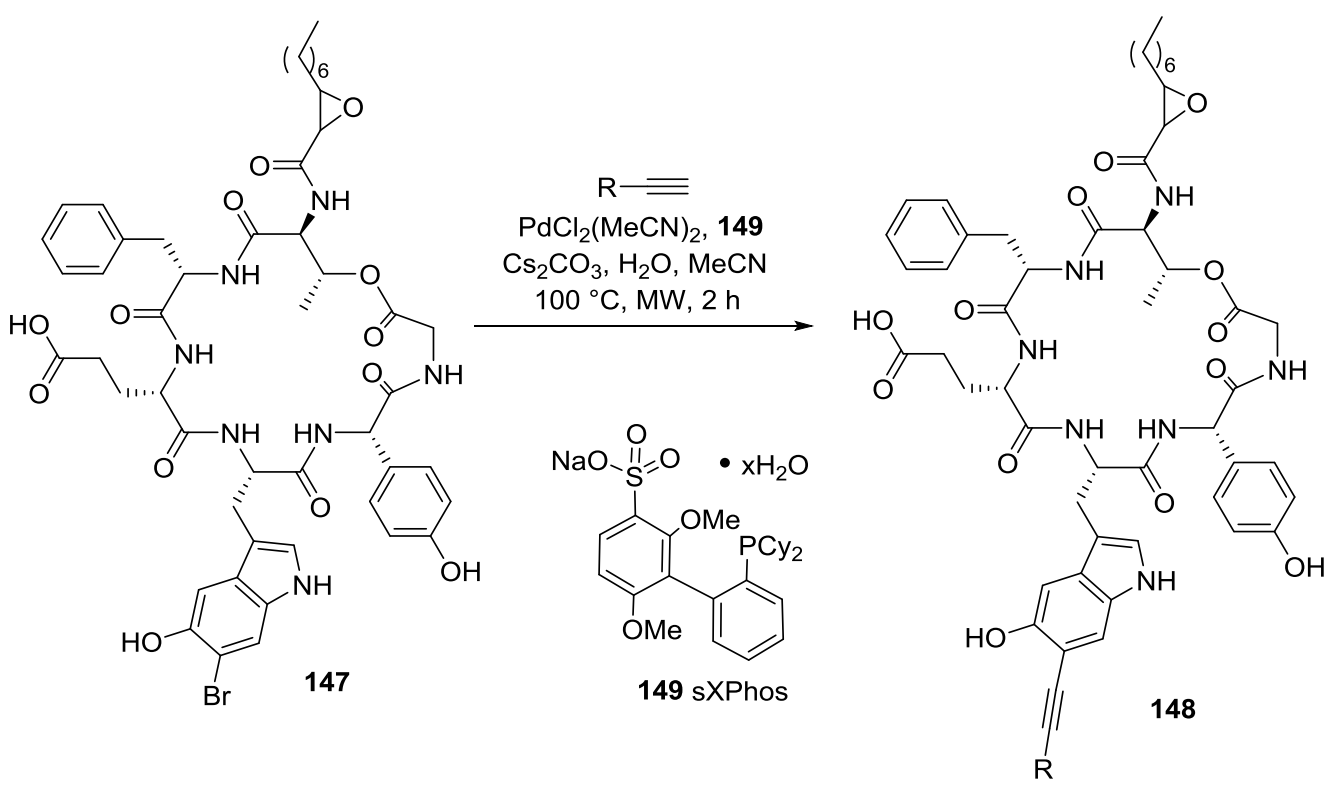

Scheme 27 Functionalization of bromocystargamide (147) employing a copper-free Sonogashira reaction. ${ }^{81}$ 


\subsubsection{Electrophilic umpolung}

The term "umpolung" is used to describe a process in which the polarity and reactivity of a structural unit (synthon) used for synthetic transformations is changed. ${ }^{82}$ Similarly, in the case of electrophilic group transfer, a compound is transformed into an electron acceptor, which contains a structural unit that acts naturally as an electron donor. Consequently, where conventionally the positively polarized residue $\mathrm{X}$ would possess affinity to a nucleophile and $\mathrm{Z}$ to an electrophile, in the case of an umpolung the now positively polarized structural group $\mathrm{Z}$ is attacked by a nucleophile (Figure 16). Common methods to access this reactivity are the introduction of neighboring electron withdrawing or delocalizing groups like halides, hypervalent iodine moieties or chalcogen salts. Groups which can be transferred as electrophiles in this way include the trifluoromethyl, ${ }^{83}$ azide, ${ }^{84}$ cyanide ${ }^{85}$ or acetylide functionality. ${ }^{66}$ In the several following representative examples of electrophilic group transfer, reactivities of different functional groups are given. Due to the large amount of publications in this field, these examples will mainly focus on reactions where no additional catalyst is needed.

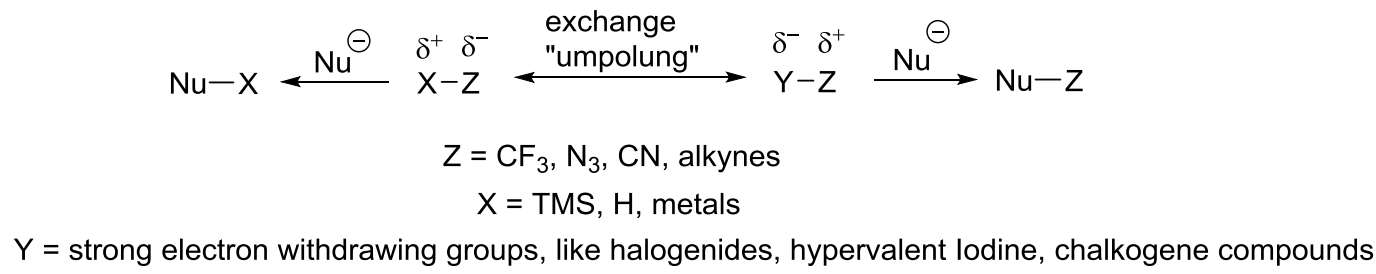

Figure 16 The principle of electrophilic group transfer by umpolung.

\subsection{Halogen compounds}

Halides are the simplest reagents imaginable to design an electrophilic group transfer. The utilization of these compounds would produce a minimum of waste. Nevertheless, to the best of our knowledge, no significant reactivity towards umpolung with nucleophiles is known for halogen azides, trifluoromethyl halides and halogen cyanides. Bromotrifluoromethane is usually transferred as corresponding zinc, aluminum or phosphorous nucleophiles or can be applied in metal-catalyzed radical transformations. ${ }^{86}$ Furthermore, cyanogen halogenides are extremely toxic reagents that should only be handled under special precautions and the showed just a low applicability in the electrophilicfunctionalization of complex molecules. ${ }^{87,88}$ Only a few examples for the utilization of haloalkynes in pure electrophilic transformations are known, ${ }^{89}$ yet they are commonly used in transition metalcatalyzed reactions. ${ }^{90}$ 


\subsection{Hypervalent iodine $\lambda^{3}$ compounds}

Hypervalent iodine compounds are a class of reagents that can be utilized for electrophilic group transfer. The first representation of these compounds was reported already in 1886 by C. J. Willgerodt. ${ }^{91}$ Later, in 1951, the hypervalent structure of these compounds was proposed by G. C. Pimentel and R. E. Rundel (Figure 17). ${ }^{92}$
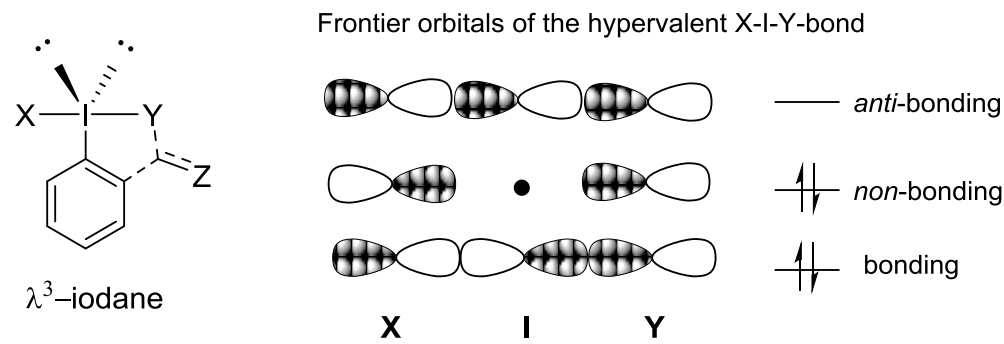

Figure 17 Characteristic structure of $\lambda^{3}$-iodine compounds and frontier orbitals of the hypervalent bond.

Polyvalent $\lambda^{3}$ iodine reagents exhibit pseudotrigonal bipyramidal geometry, where three substituents are arranged in a nearly T-shaped geometry around the central iodine-atom. Two lone pairs and one heteroatomic substituent are located in the equatorial positions. Likewise, a (3C-4e)-bond is present in the apical position and is formed by the non-hybridized 5p-orbital of the iodine and two adjacent substituents. As a result, the bonds of these substituents to the iodine are much longer and weaker compared to those in the equatorial position. The unique ability of hypervalent iodine reagents for electrophilic group transfer is directly related to this property. In many regards hypervalent I(III) reagents behave more like transition metal complexes than atoms of other lighter main group equivalents. As such, they are able to undergo characteristic reactions of transition metals such as oxidative addition, reductive elimination or ligand exchange. ${ }^{93}$ Most of these compounds can be synthesized from rather simple starting materials and thus, are easy accessible. However, it should be noted that these compounds should be handled with reasonable precautions, since several examples demonstrate an explosive nature at elevated temperatures or are shock sensitive. ${ }^{94}$

In the last two decades, a variety of different benziodoxolones and benziodoxoles were introduced and utilized for electrophilic group transfer in ground-breaking works by the groups of Togni, Waser or Zhdankin. In this regard, compounds 150-154 must be highlighted (Figure 18). They were utilized in the trifluoromethylation, ${ }^{94}$ alkynylation, ${ }^{95}$ azidation ${ }^{96}$ and cyanation ${ }^{97}$ of various nucleophiles<smiles>O=C1OI(C(F)(F)F)c2ccccc21</smiles>

150

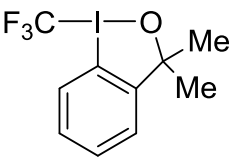

151<smiles>[R]C#C[I-]1OC(=O)c2ccccc21</smiles>

152<smiles>N#CI1OC(=O)c2ccccc21</smiles>

153<smiles>N#SI1OC(=O)c2ccccc21</smiles>

154

Figure 18 Modern polyvalent $\lambda 3$ iodine reagents. 


\section{Alkynylation with Iodine(III) Reagents}

Alkyne-substituted benziodioxolones (EBX reagents, Figure 19) are a group of electrophilic transfer reagents that deserve to be highlighted. ${ }^{95}$ These compounds were initially synthesized by Ochiai, Shira $^{98}$ and Zhdankin ${ }^{99}$ and later introduced as electrophilic transfer reagent by Waser and coworkers. ${ }^{100}$

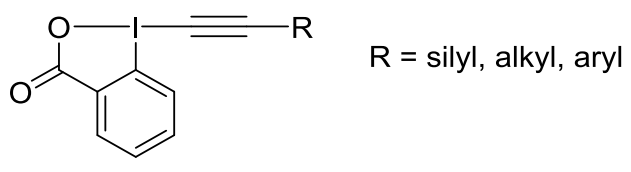

152

Figure 19 EBX-based electrophilic alkynylation reagents.

In their synthesis, Zhdankin and coworkers oxidized iodobenzoic acid (155) with sodium periodate. Afterwards the resulting compound $\mathbf{1 5 6}$ was activated by TMSOTf and subsequently treated with a TMS-protected alkyne. After basic work up with pyridine, the desired compound 152 was obtained (Scheme 28). ${ }^{99}$ Later, this procedure was scaled up by Waser and Brand. ${ }^{95 a, 101}$

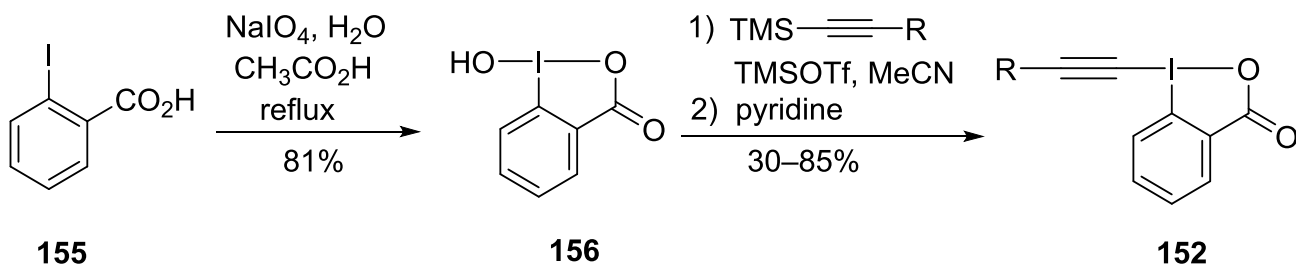

Scheme 28 Synthesis of the EBX-reagents by Zhdankin and coworkers. ${ }^{99,101}$

In their seminal paper of 2012, Olofsson and Bouma showed that these alkynylation reagents are also easily accessible in a one-pot synthesis. ${ }^{102}$ In their protocol, iodobenzoic acid $\mathbf{1 5 5}$ was oxidized by $m \mathrm{CPBA}$ and activated by $p \mathrm{TsOH}$. After substitution with either boronic esters 158 or 159 and cyclization with sodium bicarbonate, the desired compound 152 was obtained in yields of up to $90 \%$ (Scheme 29).

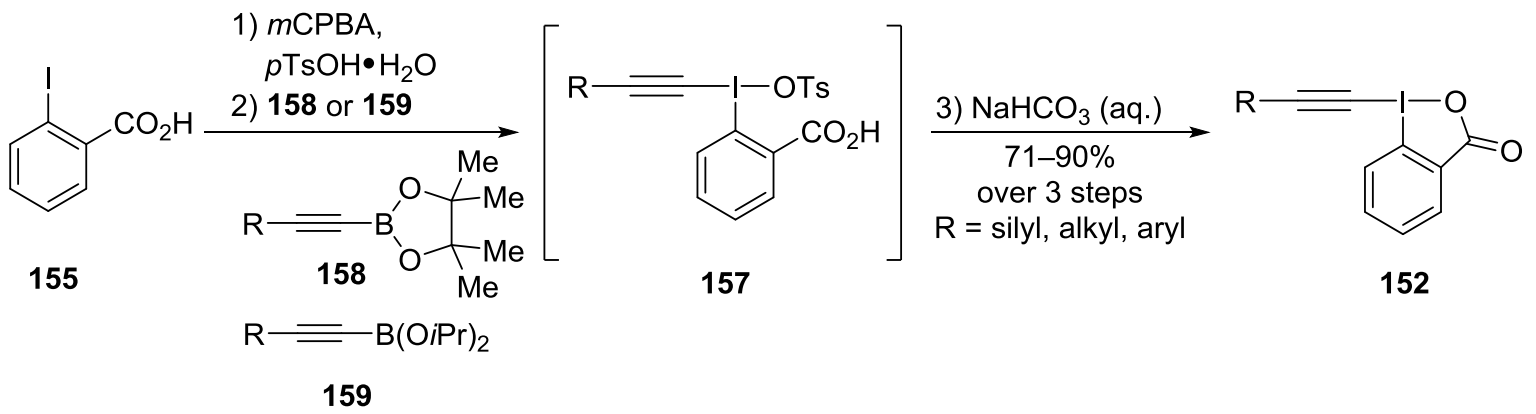

Scheme 29 Synthesis of the EBX-reagents by Olofsson and Bouma. ${ }^{102}$ 
Recent calculations carried out by Waser and coworkers indicated that the mechanism of alkynylation with hypervalent iodine reagents is nearly independent from the character of the iodine backbone and instead depends highly on the nature of the employed nucleophiles and the substituent on the alkynemoiety. ${ }^{103}$ If an iodine reagent with electron donating substituent is applied in the reaction with a sulfide, the authors propose that the reaction proceeds via the concerted transition state 160a, from which internal $\alpha$-addition results in the formation of intermediate 161a. Elimination offers the desired product. On the other hand, the application of reagents with an electron withdrawing substituents proceeds through concerted transition state $\mathbf{1 6 0 b}$ and leads to the formation of $\mathbf{1 6 1 b}$ through internal $\beta$-addition. Afterwards, $\alpha$-elimination gives the carbene 162, which can undergo a 1,2-shift to afford the desired product (Figure 20). Based on labeling experiments, Waser and coworkers concluded that in the case of the Ph-EBX and TIPS-EBX reagent both mechanisms are competing. ${ }^{103}$

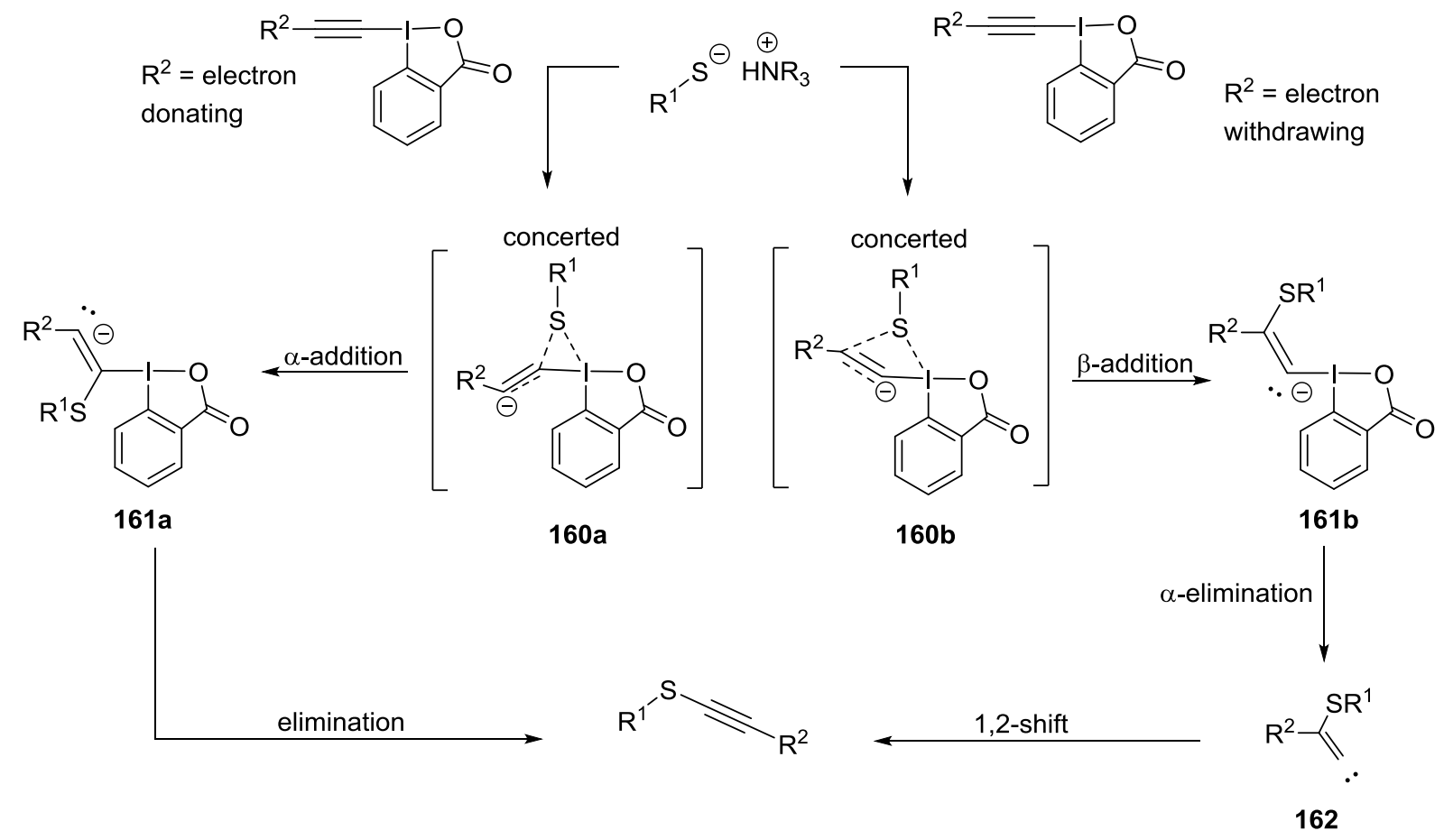

Figure 20 Proposed mechanism for the electrophilic transfer of alkynes by EBX-reagents. ${ }^{103}$ 
Several studies have been carried out towards the functionalization of different nucleophiles with the reagent 152 and the structurally similar alkynyl(phenyl)iodonium salts. Alkynes were transferred successfully to sulfides and carbothioic S-acids. ${ }^{104}$ Furthermore, it was possible to alkynylate sulfonamides, ${ }^{105}$ azlactones ${ }^{106}$ and $\beta$-ketoesters. ${ }^{107}$ Moreover, the alkynylation of H-phosphi(na)tes and secondary phosphine oxides was conducted (Figure 21). ${ }^{108}$ In summary, all reactions were conducted without additional metal catalyst in good to excellent yields, illustrating these reagents as useful tools for the functionalization of pharmaceutical products and other complex molecules.

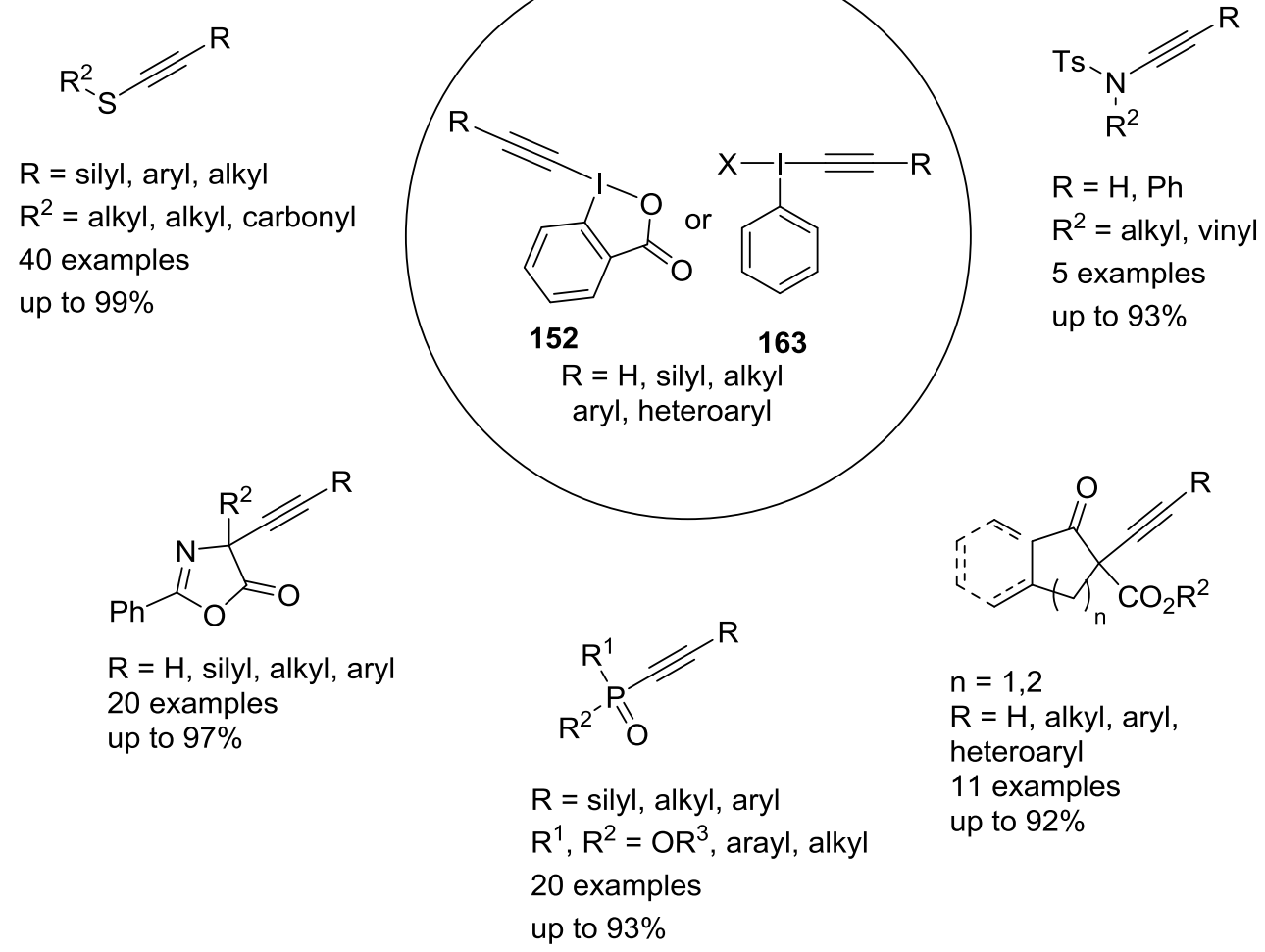

Figure 21 Typical reaction products of the direct, uncatalyzed alkynylations of nucleophiles by EBX-reagents. 
In 2015, Adibekian, Waser et al. showed the great potential for the utilization of alkyne-substituted benziodoxoles in proteomic profiling of cysteine residues for drug discovery. ${ }^{109}$ The authors investigated the applicability of the reagent 152a towards proteomes and living cells in aqueous phosphate buffered saline (PBS). Terminal cysteines of protein structures were functionalized selectively with the azide-substituted reagent 152a. Afterwards, these activated cysteine residues were utilized in the copper (I)-catalyzed "click"azide-alkyne cycloaddition (CuAAC) with alkynesubstituted TAMRA or biotin derivatives (Scheme 30). Moreover, this methodology was successfully applied for the investigation of the proteomic targets of the potential anticancer agent curcumin. ${ }^{110}$

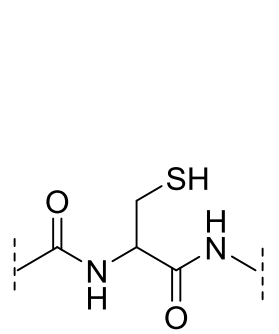

164

proteomes or living cells

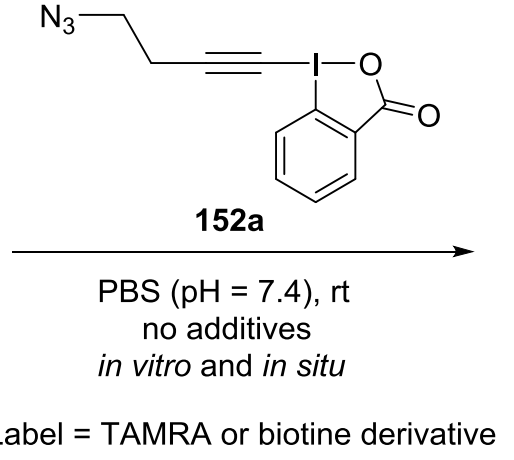<smiles>CC(=O)NC(CSC#CCCN)C(=O)NI</smiles>

165

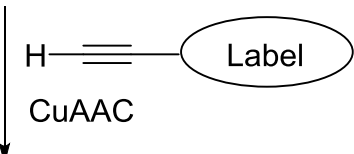

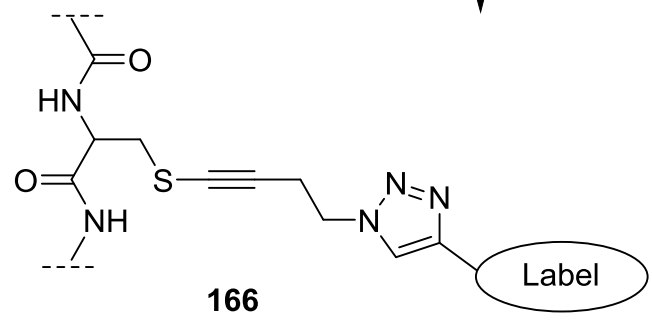

Scheme 30 Labeling of cysteine moieties of proteomes or living cells by alkynylation with hypervalent iodine compounds followed by CuAAC. 109 
Furthermore, EBX reagents have been employed as useful tools in the synthesis of complex molecules. Luo, Yang and coworkers utilized TMS-EBX in their investigations towards the synthesis of Azadirachtin derivatives. ${ }^{111}$ Azadirachtines are triterpenoids, which show anti-insect properties in combination with a low toxicity towards mammals. ${ }^{12}$ The authors conducted the alkynylation of compound 167 in a two-step procedure. Firstly, the $\beta$-ketoester 167 underwent Michael addition by addition of the in situ formed dimethyl(phenyl)silyl zincate, before alkynylation by the reagent $\mathbf{1 5 2 b}$ Finally, deprotection by TBAF afforded the desired building block 168 (Scheme 31).
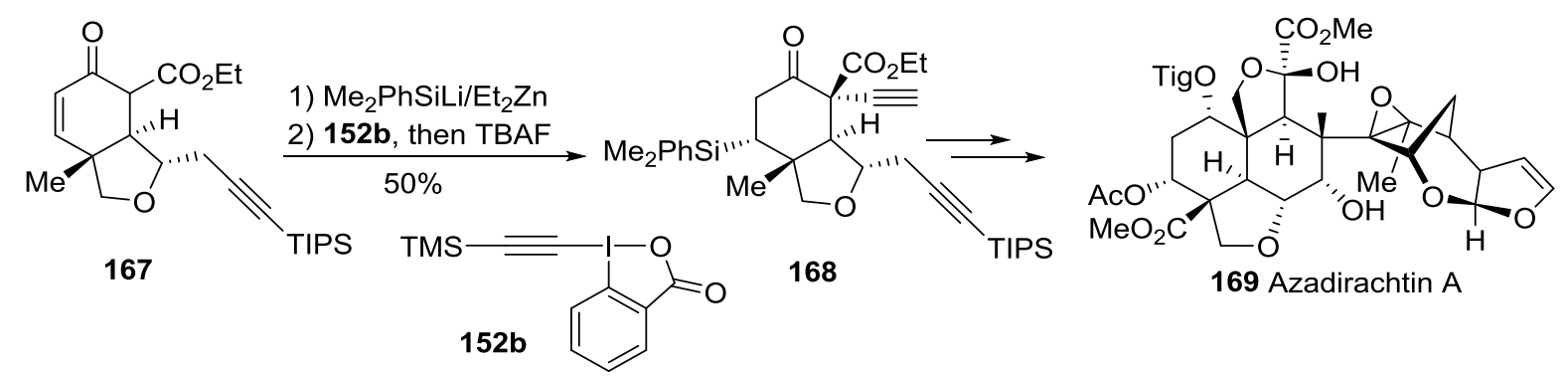

Scheme 31 Synthetic study towards Azadirachtin A (169) ultilizing an alkynylation with the reagent 152b, as reported by Luo, Yang and coworkers. ${ }^{111}$ 


\subsection{Chalcogen salts as transfer reagents}

In nature, SAM [S-(adenosylmethionine)] is a common methylation reagent in the biosynthesis of several important compounds. ${ }^{113}$ For example, 23S ribosomal RNA (rRNA) 171 originates from methylation by SAM 170 (Figure 23). ${ }^{114}$ Accordingly, the possibility of using chalcogen salts as transfer reagents for the synthesis has been known for a long time. However, these reactions are normally catalyzed by enzymes and proceed through radical pathways.

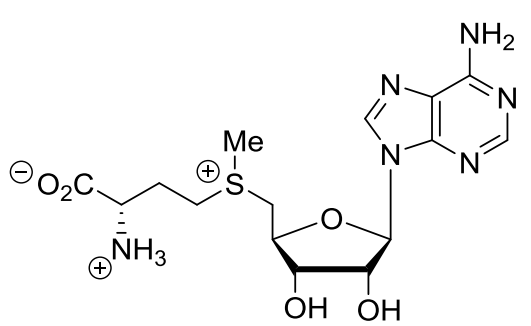

170

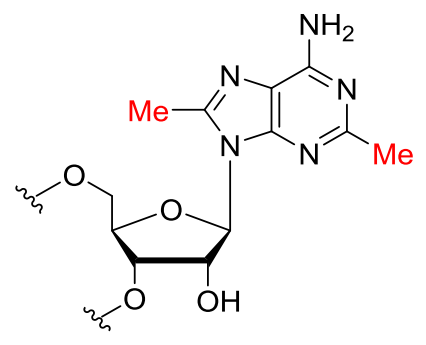

171235 rRNA

Figure 22 The electrophilic methylation reagent $S$-(adenosylmethionine) (SAM) 170 and methylated 23S ribosomal RNA 171. ${ }^{114}$ 


\subsubsection{Umemoto reagent}

(Trifluoromethyl)dibenzosulfonium salts are a well-known class of electrophilic transfer reagents, which were introduced by Umemoto and coworkers. ${ }^{115}$ These reagents show a high potential for electrophilic group transfer and better thermal stability in comparison to their hypervalent iodine equivalents. ${ }^{116}$ They can be accessed in a straightforward reaction sequence from the corresponding biaryl sulfide 172 with $m$ CPBA as oxidant under activation by triflic anhydride, ${ }^{117}$ or in the reaction of biphenyl (174) with potassium trifluoromethanesulfinate and triflic anhydride (Scheme 32). ${ }^{118}$

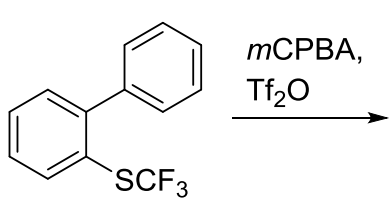

172<smiles>[X]c1ccccc1-c1ccccc1[Se]</smiles>

173

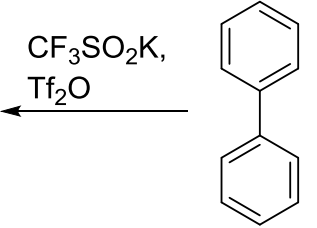

174

$\mathrm{X}=\mathbf{a} \mathrm{BF}_{4}, \mathbf{b} \mathrm{TfO}$

Scheme 32 Common synthetic methods for the Umemoto reagent 173. ${ }^{117,118}$

Investigations towards the mechanism of trifluoromethylation with dibenzothiophenium salts are still ongoing; however, presumably the mechanism strongly depends on the nature of the utilized nucleophile. ${ }^{119}$ There is no evidence for the participation of $\mathrm{CF}_{3}$-cation. Moreover, when certain nucleophiles, such as enolates, are used, radical trapping experiments indicate a SET-process. ${ }^{120}$ 
In 2003, Cahard and Ma reported the ability of the Umemoto reagent to trifluoromethylate different nucleophiles. ${ }^{121} \beta$-Ketoesters were functionalized under mild reaction conditions utilizing TBAI as a phase transfer catalyst. Additionally, in a fluoride-mediated trifluoromethylation trimethylsilyl enolates were converted to $\alpha$-trifluoromethyl ketones in good yields (up to 88\%) employing the dibenzothiophenium salt 173a (Scheme 33).

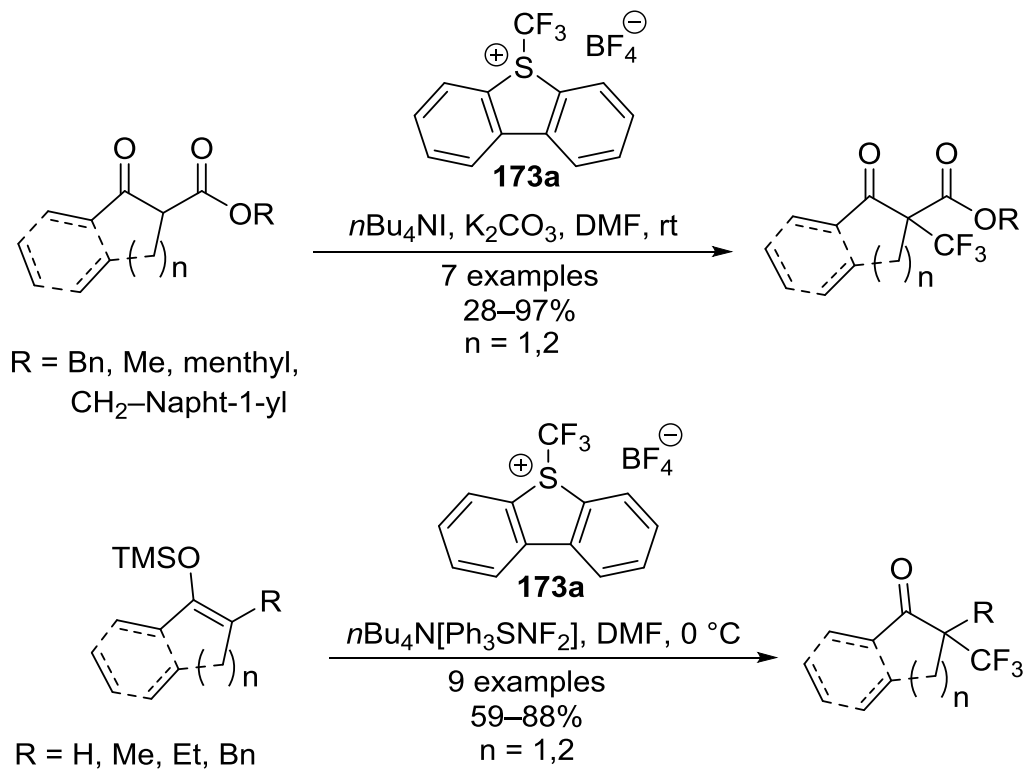

Scheme 33 Trifluoromethylation of $\beta$-ketoesters and silyl enol ethers with the Umemoto reagent 173a, as reported by Cahard and Ma. ${ }^{121}$

In addition, Umemoto and coworkers synthesized the thermally unstable dibenzofuranium salt $\mathbf{1 7 6}$ and employed it in the trifluoromethylation of different nucleophiles. ${ }^{122}$ The dibenzofuranium salt 176 was synthesized in situ from the diazonium salt $\mathbf{1 7 5}$ at $-100{ }^{\circ} \mathrm{C}$ in a light-induced Sandmeyer reaction (Scheme 34). Although it was not possible to isolate this highly reactive reagent, the presence of the desired compound 176 was confirmed by NMR experiments at low temperature, and a half-time of around $4.5 \mathrm{~h}$ at $-60{ }^{\circ} \mathrm{C}$ for the hexafluoroantimonate(V)-salt $\mathbf{1 7 6}$ was determined.

The unique reactivity of this reagent was demonstrated through trifluoromethylation of more challenging substrates. Among others, the aliphatic ether 178 and phenol ether 179 were functionalized in high yields. Furthermore, it was possible to functionalize different anilines and amines (Scheme 34). Pyridine derivatives were transformed to the corresponding pyridinium salts in good yields, as was showcased by the synthesis of the nicotine derivative 183. For comparison, only low yields could be achieved for the trifluoromethylation of phenols with hypervalent iodine compounds, probably due to radical reaction pathways. ${ }^{123}$ Therefore, the authors suggest that a $\mathrm{CF}_{3^{-}}$ cation must be transferred in the reaction. The wide substrate scope of the reagent $\mathbf{1 7 6}$ illustrates its huge potential. Nevertheless, its challenging synthesis and difficult handling are clearly limiting factors in its applications. 
<smiles>CO[C@@H](C)Oc1ccccc1-c1cc(C(C)(C)C)ccc1[N+](=O)[O-]</smiles>

175

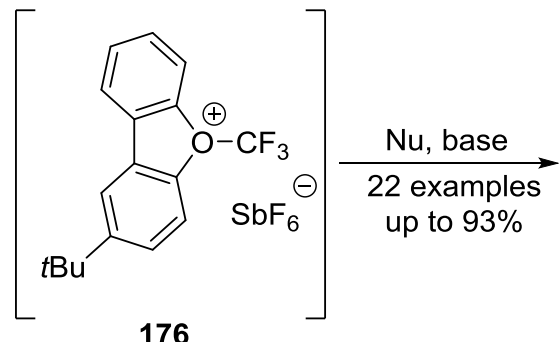

176<smiles>CC(C)(C)c1ccc2oc3ccccc3c2c1</smiles>

177<smiles>FC(F)(F)OCCc1ccccc1</smiles>

178

80

$\%$<smiles>FC(F)(F)NCc1ccccc1</smiles>

181

$46 \%$<smiles>FC(F)(F)Oc1ccccc1</smiles>

179

$75 \%$<smiles>FC(F)(F)N1CCc2ccccc21</smiles>

182

$68 \%$<smiles>FC(F)(F)Nc1ccccc1</smiles>

180

$93 \%$<smiles>COC(=O)c1ccc[n+](C(F)(F)F)c1</smiles>

183

Scheme 34 Synthesis of the dibenzofuranium salt 176 and the utilization in the trifluoromethylation of $N$ - and $O$-based nucleophiles by Umemoto and coworkers. ${ }^{122}$ 


\subsubsection{Thioimidazolium salts}

A thioimidazolium-based transfer reagent was presented recently by Alcarazo et al. ${ }^{124}$ In a straightforward procedure the thiourea 184 was transformed to the dibromide 185 via bromination with elemental bromine. Afterwards, a bromide atom was substituted by a cyanide group derived from TMSCN. Subsequent counterion exchange applying silver hexafluoroantimonate afforded the thioimidazolium salt $\mathbf{1 8 6}$ in an excellent yield of 95\% (Scheme 35).
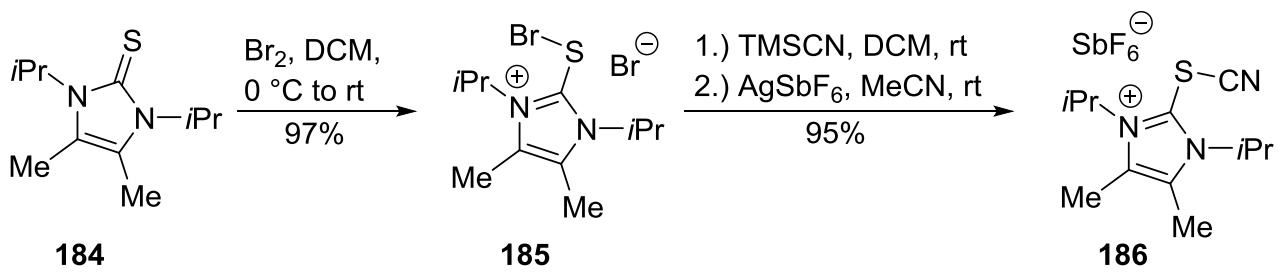

Scheme 35 Synthesis of the thioimidazolium salt $\mathbf{1 8 6} .^{124}$

The thioimidazolium salt $\mathbf{1 8 6}$ was used in the electrophilic cyanation of different nucleophiles. Two different methods were developed for the transfer reaction. Cyanamides, thiocyanates and $\beta$-amido- or ketonitriles were obtained in good to excellent yields using DIPEA as a base. The indole $\mathbf{1 9 1}$ and the dimethoxybenzonitrile 192 were prepared in a microwave-assisted reaction with a catalytic amount of boron trifluoride etherate as a Lewis acid. This method was also applied in the synthesis of the furan derivative 193 and the ketone 194 from the corresponding TMS-enolate and enamine, respectively (Scheme 36). These results highlight the broad applicability of the new reagent 186 towards electrophilic cyanation.

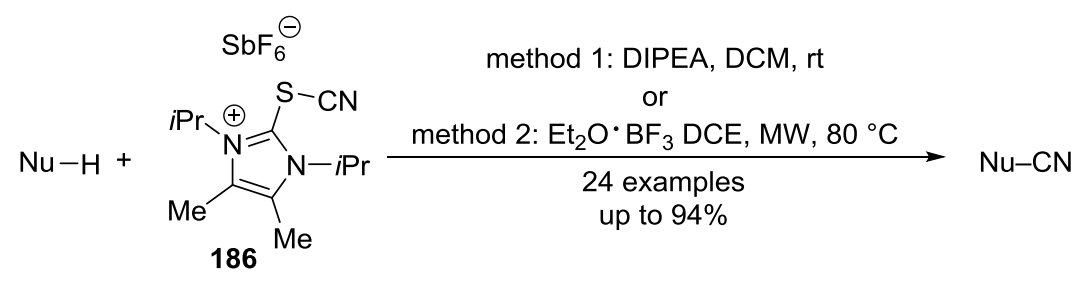<smiles>N#CNc1ccc(Br)cc1</smiles>

187 $79 \%$<smiles>N#Cc1cccn1-c1ccccc1</smiles>

$75 \%$<smiles>N#CN1CCCC1C(O)(c1ccccc1)c1ccccc1</smiles>

188 $84 \%$<smiles>COc1ccc(C#N)c(OC)c1</smiles>

192 $86 \%$<smiles>N#CSc1ccc([N+](=O)[O-])cc1</smiles>

189 $77 \%$<smiles>N#CCC(=O)c1ccco1</smiles>

193<smiles>CN1C(=O)C(C#N)(C#N)c2ccccc21</smiles>

190

$72 \%$<smiles>N#CC1CCCCC1=O</smiles>

194

$55 \%$

Scheme 36 Cyanation of $N$-, $C$ - and $S$-based nucleophiles by the thioimidazolium salt $186 .{ }^{124}$ 


\section{Design of the project}

\subsection{State of research}

\subsubsection{Alkyne-transferring reagents formerly developed in the Alcarazo group}

In their seminal publication of 2015, Alcarazo and coworkers presented the imidazolium-based alkyne transfer reagent 196a in line with the methodology applied for the formerly described cyanation reagent 186. ${ }^{124}$ 196a was easily accessible in a high yield of $92 \%$ employing the reaction of dibromide 185 with silver acetylide 195 (Scheme 37A). Moreover, it was shown that compound 195 is capable of alkynylateing different nucleophiles such as thiols, ketoesters or amides in high yields of up to $98 \%$ (Scheme 37B).

A.

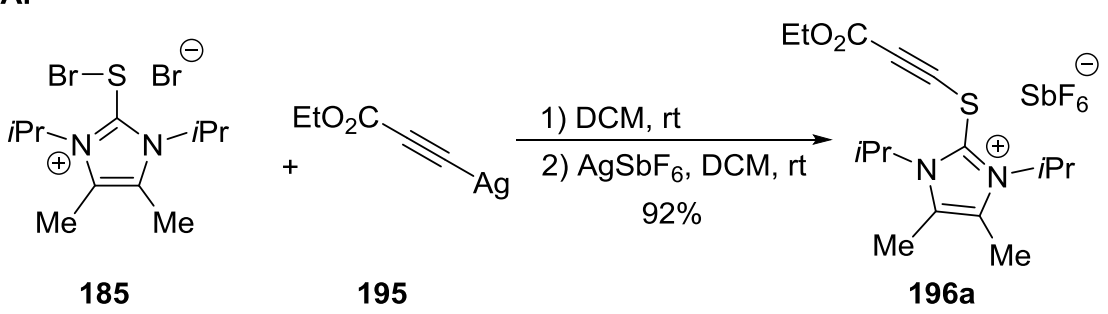

B.
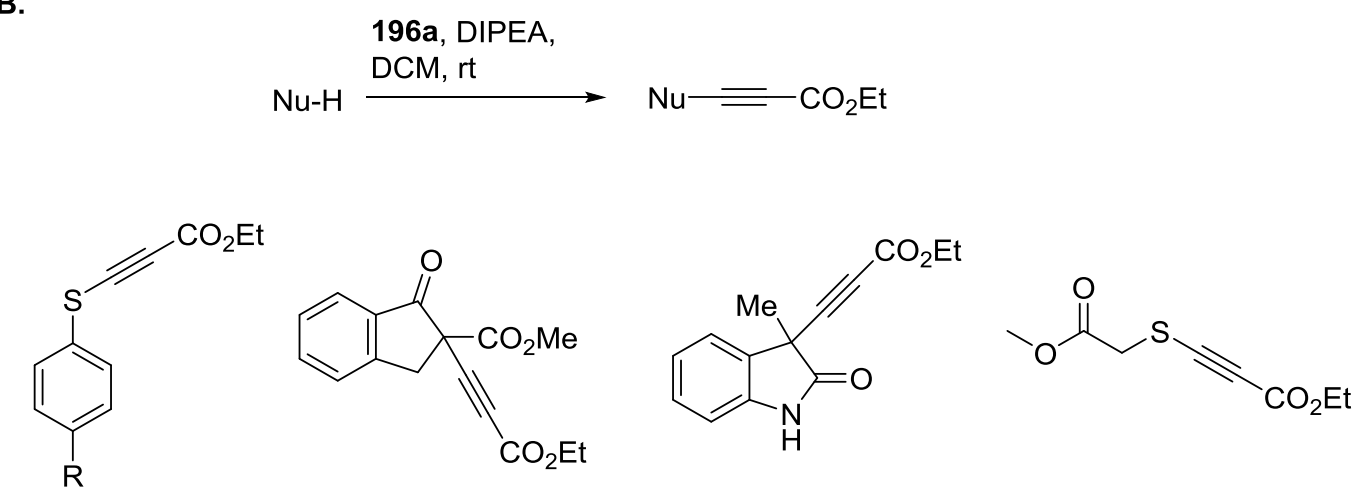

$$
\mathrm{R}=\mathrm{CF}_{3} \quad 19798 \%
$$$$
199
$$

$89 \%$

200

$79 \%$
201

$94 \%$

Scheme 37 (A) Synthesis of new thioimidazolium salts for alkynylation by Alcarazo and coworkers. (B) Substrate scope of the alkynylation. ${ }^{125}$ 
This desired reactivity was only observed for reagents with an electron withdrawing substituent on the alkyne moiety. The phenyl-substituted thioimidazolium salt 196b could be synthesized from dibromide 185 and a corresponding alkynyl zincate in a high yield (95\%). Interestingly, in attempted reactions with the $\beta$-ketoester $\mathbf{2 0 2}$ this alkynylating reagent exclusively formed the thioalkynylated derivative $\mathbf{2 0 3}$ as the main product instead of the targeted compound (Scheme 38). Undoubtedly, this unexpected reactivity demands further investigation.

A.

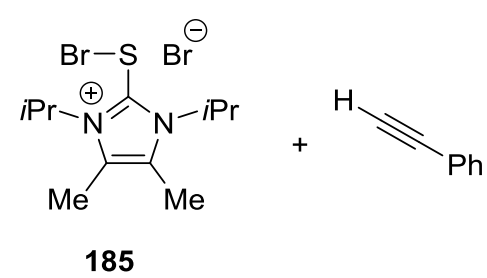

1) $n \mathrm{BuLi}, \mathrm{ZnBr}_{2}$, $\mathrm{THF},-78^{\circ} \mathrm{C}$ to $\mathrm{rt}$ 2) $\mathrm{NaSbF}_{6}$ $95 \%$ 196b, $\mathrm{Ag}_{2} \mathrm{CO}_{3}$,
$\stackrel{\mathrm{DCM}, \mathrm{rt}}{ }$ 202

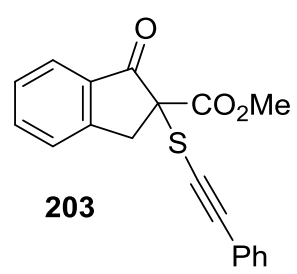

Scheme 38 Synthesis of a new phenyl-substituted thioimidazolium salt $196 \mathbf{b}$ and observed thioalkynylation of cyclic $\beta$ ketoester $202 .^{124}$ 


\subsubsection{Alkyne-based cationic polymerization initiators developed by Liska et al.}

In 2009, Liska et al. reported the synthesis and utilization of diphenylsulfonium- and -iodonium salts as initiators for cationic polymerization reactions of 4-epoxycyclohexenyl-methyl-3,4epoxycyclohexenyl carboxylate (ECHC). ${ }^{125}$ In a straightforward procedure, diphenyl sulfoxide $\mathbf{2 0 4}$ was treated successively with triflic anhydride and 1-phenyl-2-trimethylsilylacetylene to afford the compound 205. After counterion exchange with potassium hexafluorophosphate, the targeted diphenylsulfonium salt 206 was obtained (Scheme 39A). Subsequent steady state photolysis experiments revealed that the main decomposition pathway of these complexes is a heterolytic cleavage of the ethynyl carbon-sulfur bond (Scheme 39B). It was assumed that this is a direct consequence of the lower strength of the sulfur-alkyne bond. Thus, we considered the utilization of the salts 205 and 206 as potential transfer reagents that could possibly offer different reactivity to imidazolium-based system described above.

A.

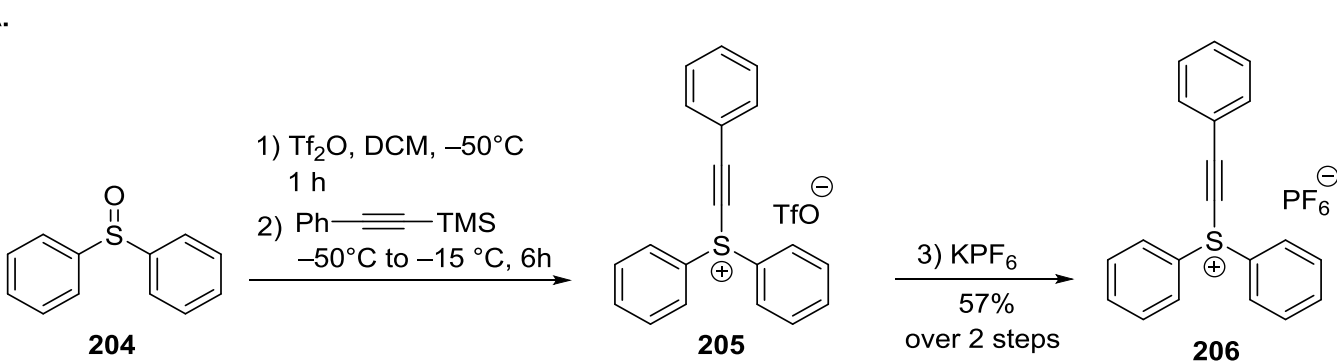

B.

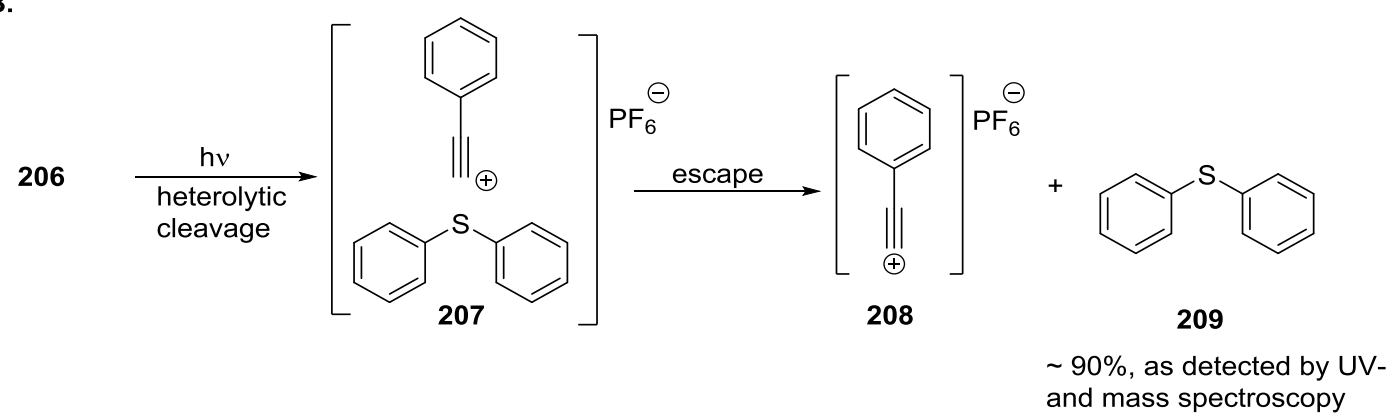

Scheme 39 (A) Synthesis of a new dibenzothiophenium-based initiator for cationic polymerization. (B) The mechanism for decomposition of the dibenzothiophenium salts, as proposed by Liska et al. ${ }^{\mathbf{1 2 5}}$ 


\subsection{Project aims}

The very recently discovered thioalkynylation with thioimidazolium-based reagents will be further investigated in collaboration with Dr. J. Peña and Dr. G. Talavera. The main focus of this study will be the introduction of differently substituted alkynes. Furthermore, suitable conditions will be examined to enhance the efficiency of the thioalkynylation protocol. The products obtained from these transformations will also be employed in further derivatization reactions (Figure 23).

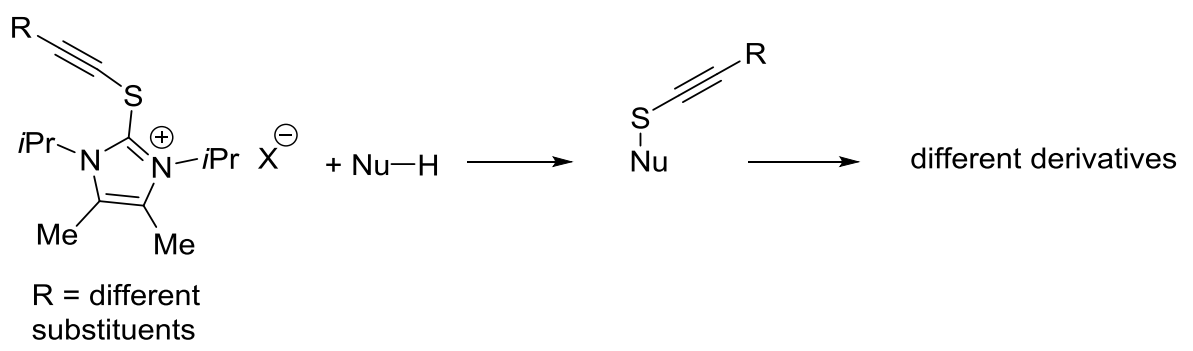

Figure 23 Proposed application of thioimidazolium reagents in the thioalkynylation of different nucleophiles with a perspective of further derivatization.

Additionally, based on the results of Liska and coworkers, ${ }^{125}$-the potential of diphenylsulfonium salts will be investigated as a platform for the transfer of alkynes or other functional groups. This approach will be evaluated in addition to the modification of derivatives with a dibenzothiophenium backbone. Although the dibenzothiophene backbone is already present in the commercially available Umemoto reagent (compare Chapter 1.3.1), to the best of our knowledge, no derivatives have been employed for the transfer of alkyne groups. One reason for this could be the complex synthesis of this reagent. The transfer of electron-rich or neutral alkyne groups could not be achieved with the previously developed thioimidazolium system. Therefore, these sulfur-based reagents could be considered as an alternative or complementary to the commercially available hypervalent iodine (EBX) reagents and/or other common methods to introduce alkynes to organic molecules (Figure 24).

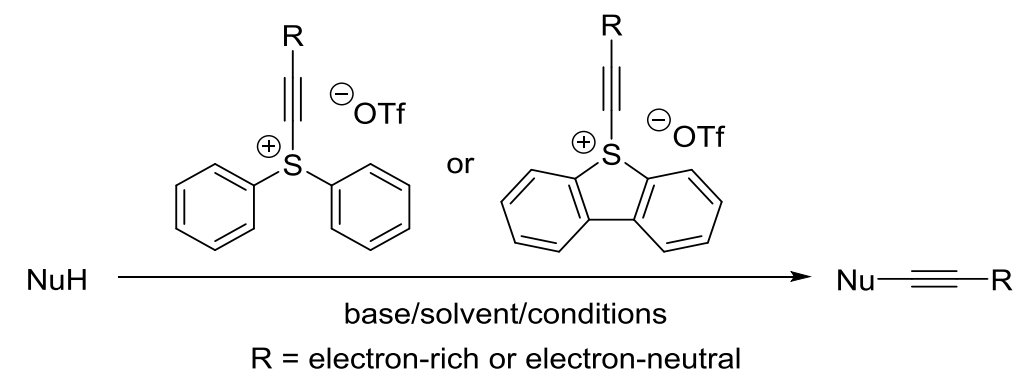

Figure 24 Proposed application of diphenylsulfonium- and dibenzothiophenium-reagents in the alkynylation of different nucleophiles. 
Electrophilic transfer reagents are valuable tools for the insertion not only of alkyne moieties into complex molecules, but of other functional groups as well. Particularly the thioimidazolium-based transfer reagents have a high potential to serve as a general platform for the umpolung of functional groups, as demonstrated by the recent results of Alcarazo and coworkers discussed above. ${ }^{124}$ Based on the success in establishing the thioimidazolium framework as a basis for very potent cyanating reagents, investigations on the ability of these reagents to facilitate the transfer of various functional groups will be conducted. In this connection, the most interesting targets are perfluoroalkylated molecules, as many pharmaceutically active or agrochemically useful compounds include fluorinecontaining groups. ${ }^{126}$ Accordingly, one part of the project will be the synthesis of reagents containing trifluoromethyl- or trifluoroethylene groups followed by investigation of their reactivity as group transfer reagents (Figure 25). These compounds are considered as a potential alternative or complement to commercially available systems developed by groups of Togni and Umemoto. ${ }^{122,123}$

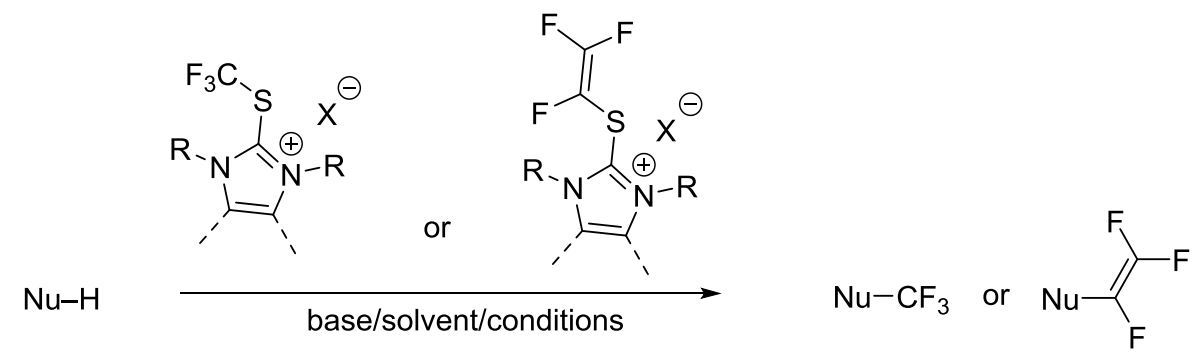

Figure 25 Proposed application of new thioimidazolium-based fluorine-containing transfer reagents. 


\section{Results and discussion}

\subsection{Further development of the newly discovered thioalkynylation reaction}

\subsubsection{Synthesis of new thioimidazolium-based alkynylation reagents}

The great interest in discovering new ways to introduce alkynes is spurred by the versatility of application and further derivatization possibilities of this functional group (compare Chapter 1.2.3). To begin with, the reactivity of harder and stronger nucleophiles, such as Grignard reagents, should thoroughly be studied in the reaction of either potential thioalkynylation or alkynylation with imidazolium salts (compare Scheme 37 and Scheme 38 in Chapter 2.1.1). For this purpose, a new series of prospective alkyne transfer reagents with electron donating or neutral substituents on the alkyne moiety was synthesized in collaboration with Dr. G. Talavera and Dr. J. Peña. Beginning with terminal alkynes, the corresponding zincates were prepared by deprotonation with $n \mathrm{BuLi}$ followed by transmetalation with zinc bromide. Subsequent addition of the dibromide $\mathbf{1 8 5}$ furnishes the desired alkyne reagents 196b-196o in good to very good yields, tolerating a variety of different functional groups. Thus, compounds 196d and 196e with substituted aromatic residues were synthesized in yields of up to 96\%, TBS- and PMB-protected reagents 196g and 196h were prepared in excellent yields of up to $92 \%$ as well, and challenging structures like the chloride 196i, enyne 196j or azide 196k were obtained in yields of $81 \%, 82 \%$ and $85 \%$, respectively. Additionally, complex reagents 196i-196n with a set of various protecting groups like TES, PMB, Bz, etc. were successfully prepared. Besides this, it was possible to synthesize the reagent $\mathbf{1 9 6 0}$ in good yield of $89 \%$ from the corresponding amide (Scheme 40). 


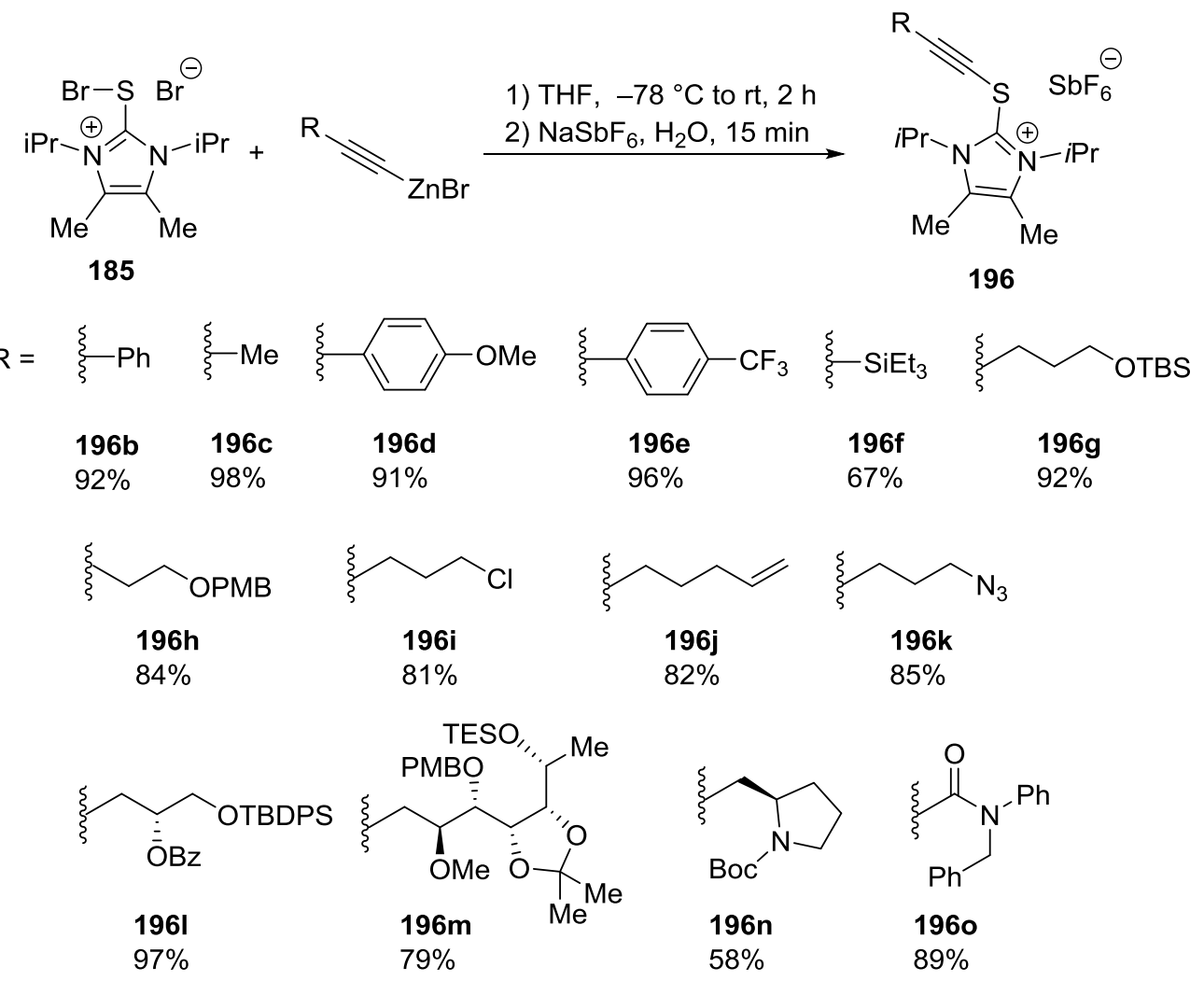

Scheme 40 Different imidazolium reagents prepared in cooperation with Dr. G. Talavera and Dr. J. Peña.

\subsubsection{Scope and limitations of the transfer reaction}

It was shown that organomagnesium reagents react with compounds 196 in an electrophilic thioalkynylation fashion as indicated above in Chapter 2.1.1 (Scheme 38B), smoothly affording the corresponding alkynyl sulfides 210-225, however, with better efficiency (Scheme 41). This reaction was utilized to synthesize a set of alkynyl sulfides in excellent yields. These results correspond to the formerly observed reactivity with weaker nucleophiles like $\beta$-ketoesters. With the established methodology, it was possible to perform reactions with alkyl, vinyl, aryl and alkynyl Grignards to generate a variety of different products.

The alkylsulfide 210 was obtained in a virtually quantitative yield (98\%). Furthermore, more challenging alkylsulfides, such as Boc-protected propargylpyrrolidine 211, compounds 214 and 215 were synthesized in 79, 88 and 98\% yield, respectively. The enyne $\mathbf{2 1 2}$ was obtained in a yield of $93 \%$, thus demonstrating that azide groups are tolerated by the reaction procedure. The isopropenylalkyne $\mathbf{2 1 3}$ was prepared in a yield of $92 \%$. Moreover, it was proven that this methodology is efficient in the presence of commonly used alcohol protecting groups with the synthesis of the enynes $\mathbf{2 1 6}$ and $\mathbf{2 1 7}$ in 75 and $91 \%$ yield, respectively. 
Furthermore, it was possible to obtain the TES-substituted arylsulfide $\mathbf{2 1 8}$ in an excellent yield of $96 \%$, thus illustrating the compatibility with silicon-based alkyne protective groups. The arylsulfides 219 and 222 were prepared in 98 and 86\% yield, respectively. Heteroaromatic Grignard reagents could be used as well, which was demonstrated by the synthesis of the alkyne $\mathbf{2 2 3}$ in a yield of $89 \%$. Additionally, a series of structurally interesting dialkynyl derivatives was synthesized. In a reaction of the compound 196b with a TES-protected Grignard reagent, the sulfide 220 was obtained in virtually quantitative yield (99\%). The sulfide 221 was synthesized in an excellent yield (97\%), whereas the sulfide 224 in a good yield (77\%). Besides, trifluoromethyl groups are tolerated in this reaction, as was demonstrated by the successful preparation of diyne $\mathbf{2 2 5}$ (97\% yield).

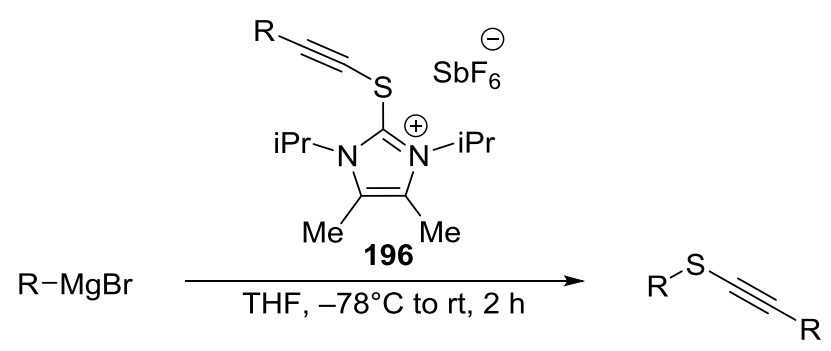

Scope with alkyl Grignards<smiles>C(#Cc1ccccc1)SC1CCCC1</smiles>

210

$98 \%$<smiles>C=CCCCC#CSCCc1ccc(OC)cc1</smiles>

214

$88 \%$

Scope with aryl Grignards

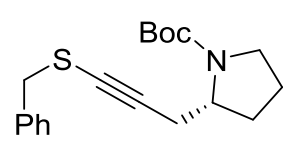

211

$79 \%$

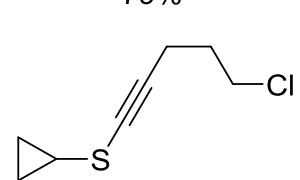

215

$98 \%$<smiles>Cc1ccc(SC#C[I-]S)cc1</smiles>

218

$96 \%$<smiles>CC#CSc1ccc(C)cc1</smiles>

222

$86 \%$<smiles>Cc1cc(C)c(SC#Cc2ccccc2)c(C)c1</smiles>

219

$98 \%$

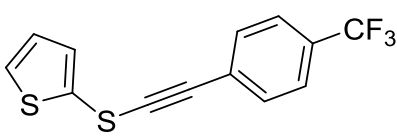

223

$89 \%$
Scope with vinyl Grignards
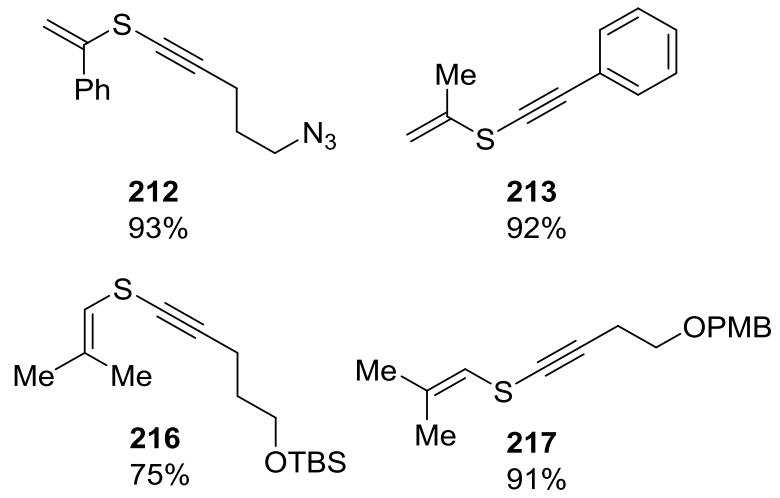

Scope with alkynyl Grignards
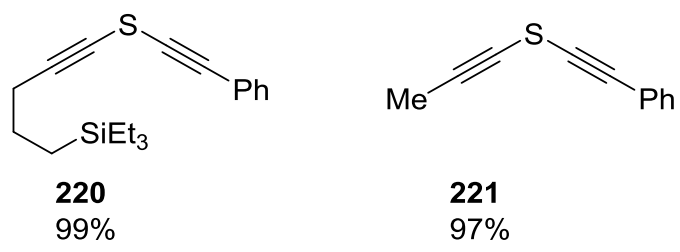

221

$97 \%$<smiles>CC#CSC#CC[C@H]1CCCN1C(=O)OC(C)(C)C</smiles>

224

225

$77 \%$

Scheme 41 Different disulfides prepared in cooperation with Dr. G. Talavera and Dr. J. Peña. 


\subsubsection{Further derivatization of the synthesized sulfides}

A set of illustrative examples of transformed products was prepared starting from the vinylsulfide $\mathbf{2 1 3}$ in order to emphasize the applicability of this alkynsulfides for further modification (Scheme 42). Accordingly, the sulfide $\mathbf{2 1 3}$ was converted to the sulfoxide $\mathbf{2 2 6}$ and to the sulfone $\mathbf{2 2 7}$ upon reaction with one or two equivalents of $m \mathrm{CPBA}$, in good yields of 70 and $86 \%$, respectively. The sulfone 227 was further functionalized under mild conditions to the cyclic enamine 228 in a Michael-type reaction in a yield of $26 \%$. Apart of these functionalizations, the cyclization of the sulfone 227 with $\mathrm{Na}_{2} \mathrm{~S}$ at elevated temperature gave access to the cyclic sulfide $\mathbf{2 3 0}$ ( $84 \%$ yield). Finally, the sulfide $\mathbf{2 1 3}$ was cyclized with $\mathrm{Na}_{2} \mathrm{~S}$ at ambient temperature into the thiophene $\mathbf{2 2 9}$ in a yield of $71 \%$.

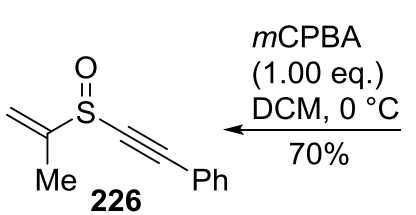

226

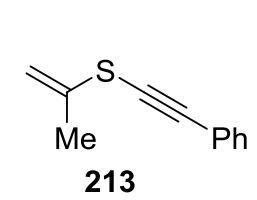

$71 \% \mid \begin{aligned} & \mathrm{Na}_{2} \mathrm{~S}, \mathrm{MeOH} \\ & \mathrm{rt}\end{aligned}$

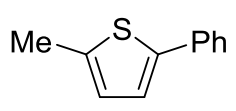

229

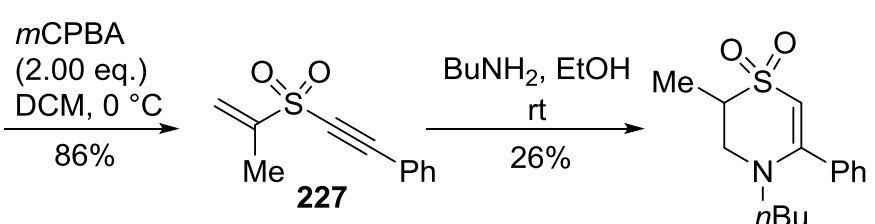

$84 \%\left\{\begin{array}{l}\mathrm{Na}_{2} \mathrm{~S}, \mathrm{EtOH} \\ 120^{\circ} \mathrm{C}\end{array}\right.$

228<smiles>CC1CSC(c2ccccc2)=CS1(=O)=O</smiles>

230

Scheme 42 Further derivatization of the synthesized sulfides. 


\subsection{The diphenylsulfonium-based reagent}

\subsubsection{Synthesis of the diphenylsulfonium reagent}

The inability of thioimidazolium salts to transfer electron-rich alkyne groups to nucleophiles was discussed above. To overcome this limitation, the possibility to utilize diphenylsulfonium salts as reagents for the alkynylation of nucleophiles based on the research of Liska and coworkers ${ }^{125}$ should be investigated. According to our optimized protocol, the intermediate sulfonium salt $\mathbf{2 3 1}$ was obtained by treatment of commercially available phenyl sulfoxide 204 with triflic anhydride. Subsequently, the final sulfonium salt $\mathbf{2 0 5}$ was synthesized from the intermediate $\mathbf{2 3 1}$ in a reaction with 1-phenyl-2-trimethylsilylacetylene in a yield of $60 \%$ (Scheme 43).

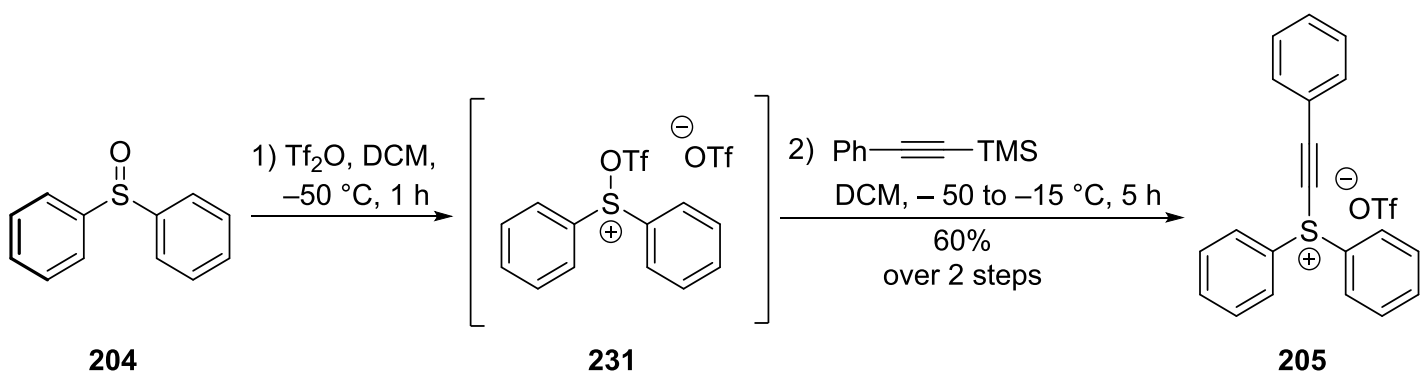

Scheme 43 Synthesis of the diphenylsulfonium salt 205.

\subsubsection{Scope and limitations of the transfer reaction}

After the optimization of synthesis of the salt $\mathbf{2 0 5}$, reactions with the $\beta$-ketoester $\mathbf{2 0 2}$ were performed in order to study the activity of this reagent towards nucleophiles (Table 1 and Scheme 44). With common bases for transfer reactions like DIPEA, $\mathrm{K}_{2} \mathrm{CO}_{3}$ or $\mathrm{K}_{3} \mathrm{PO}_{4}$ in dichloromethane as a solvent, the product 232 was obtained in low yields lying in the range of $7-14 \%$ (entries 1 and 2). Neither changing the solvent to the more polar acetonitrile nor applying the reagent 205 in excess did significantly increase the efficiency of the reaction. Reducing the reaction time or adding the base and reagent at $-78^{\circ} \mathrm{C}$ did not improve the product yield as well.

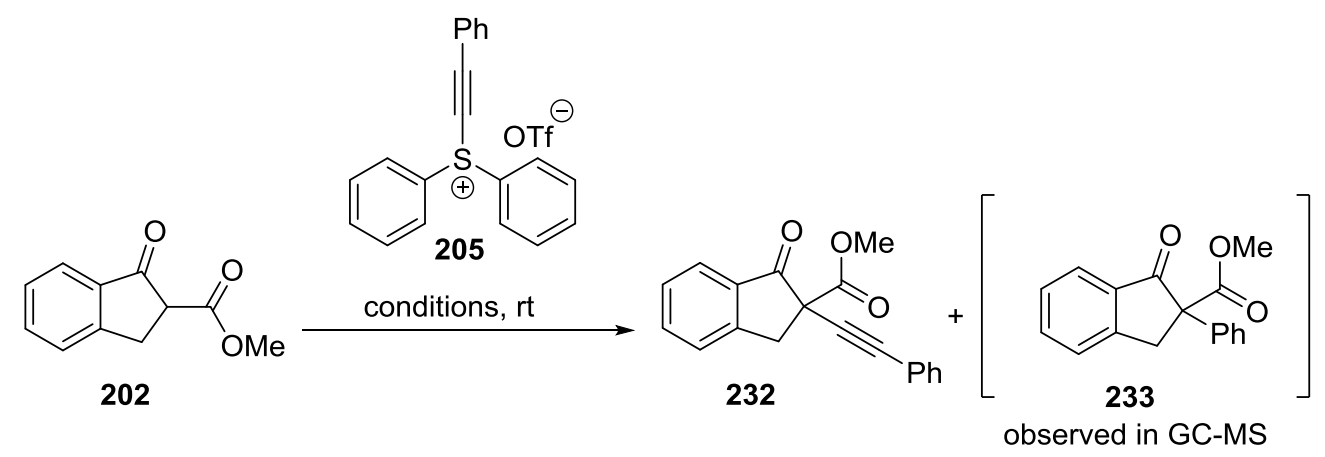

Scheme 44 Reaction of $\beta$-ketoester 202 with the diphenylsulfonium salt 205. 
Table 1 Alkynylation of the $\beta$-ketoester 202 with the diphenylsulfonium salt 205: screening for the conditions at ambient temperature.

\begin{tabular}{lllllccc}
\hline Entry & Equiv. 205 & Base & Equiv. & Solvent & Time (h) & Yield (\%) & Comment \\
\hline $\mathbf{1}$ & 1.20 & DIPEA & 1.10 & DCM & 12 & 7 & \\
$\mathbf{2}$ & 1.20 & $\mathrm{~K}_{2} \mathrm{CO}_{3}$ & 1.05 & $\mathrm{DCM}$ & 2 & 9 & \\
$\mathbf{3}$ & 1.50 & $\mathrm{~K}_{2} \mathrm{CO}_{3}$ & 1.05 & $\mathrm{MeCN}$ & 12 & 9 & \\
$\mathbf{4}$ & 1.50 & $\mathrm{~K}_{2} \mathrm{CO}_{3}$ & 1.10 & $\mathrm{DCM}$ & 50 & 13 & \\
$\mathbf{5}$ & 1.50 & $\mathrm{~K}_{3} \mathrm{PO}_{4}$ & 1.05 & $\mathrm{DCM}$ & 12 & 14 & \\
$\mathbf{6}$ & 1.50 & DIPEA & 1.05 & $\mathrm{DCM}$ & 2 & 11 & \\
$\mathbf{7}$ & 1.20 & DIPEA & 1.00 & $\mathrm{DCM}$ & 2 & 8 & $-78{ }^{\circ} \mathrm{C}$ to rt \\
\hline
\end{tabular}

Furthermore, the reaction with other nucleophiles like thiols did not lead to essential improvements. Nonetheless, for the reaction of the thiophenol 234 with the reagent 205 and DIPEA as a base, the desired product $\mathbf{2 3 5}$ was obtained in $3 \%$ yield (Scheme 45 ).

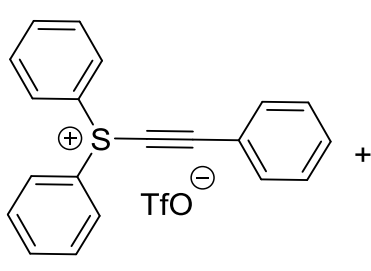

205<smiles>O=[N+]([O-])c1ccc(S)cc1</smiles>

234
DIPEA (1.20 eq.),

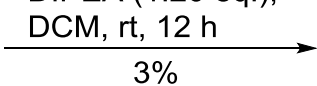<smiles>O=[N+]([O-])c1ccc(SC#Cc2ccccc2)cc1</smiles>

235

Scheme 45 Reaction of the thiol 234 with the diphenylsulfonium salt 205.

An explanation could be the direct decomposition of the reagent $\mathbf{2 0 5}$ because of its low stability under basic conditions. Moreover, other decomposition pathways are possible, as already discussed in the publication of Liska and coworkers. ${ }^{125}$ Thus reported on the formation of an unstable phenyl cation under the reaction conditions. As such, this illustrates that the nucleophile can also attack the phenyl cation, and indeed, the phenyl-substituted by-product was detected in GC-MS. 


\subsection{Searching for new dibenzothiophene-based reagents}

\subsubsection{Synthesis of the dibenzothiophene-based reagents}

As a consequence, we decided to address the problem of undesired side reactions through an additional modification of the backbone of the reagent. Thus, the well-known trifluoromethylation reagent - Umemoto reagent $\mathbf{1 7 3}$ - has a dibenzothiophene backbone (compare Chapter 1.3.1). Very probably, a dibenzothiophene-based alkynilating reagent should enhance the reactivity by enabling the charges to be localized in a larger conjugated system. On one hand, it should lower the frontier orbitals energies of the reagent and make the compound easier accessible for the nucleophilic attack. On the other hand, it should make the compound more stable due to the rigid backbone and the inclusion of the sulfur atom in the bigger aromatic system. Therefore, the methodology from Liska and coworkers $^{125}$ was employed to synthesize a new kind of dibenzothiophene-based reagent. In the straightforward synthesis, commercially available dibenzothiophene (236) was oxidized by hydrogen peroxide to the corresponding sulfoxide $\mathbf{2 3 7}$ in a yield of up to $76 \% .{ }^{127}$ Afterwards, the latter was activated by triflic anhydride and subsequently converted to the desired compound 238a with 1phenyl-2-trimethylsilylacetylene in $87 \%$ yield (Scheme 46 ).

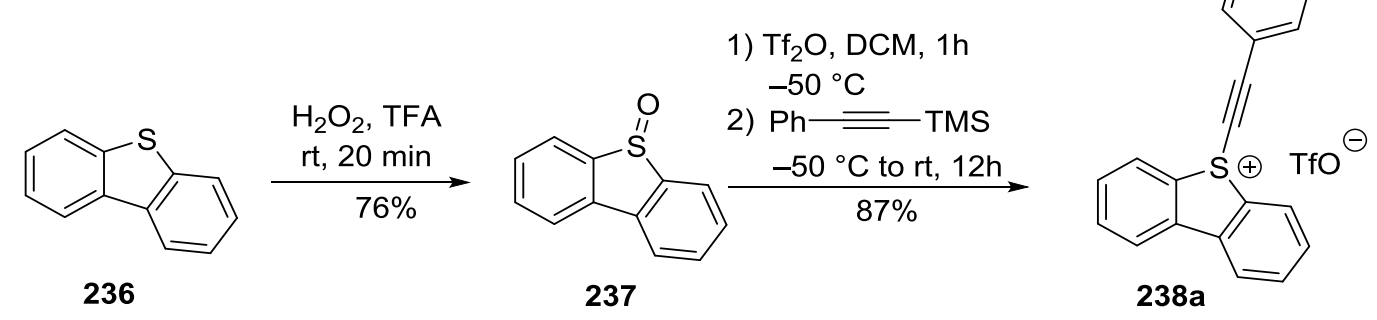

Scheme 46 Synthesis of a new dibenzothiophenium-based reagent 238a. 


\subsubsection{Expanding the scope towards different dibenzothiophenium salts}

A set of differently substituted dibenzothiophenium salts $\mathbf{2 3 8}$ was synthesized from the corresponding trimethylsilyl-protected alkynes and other TMS-bearing compounds to investigate the scope and limitations of this methodology (Scheme 47).
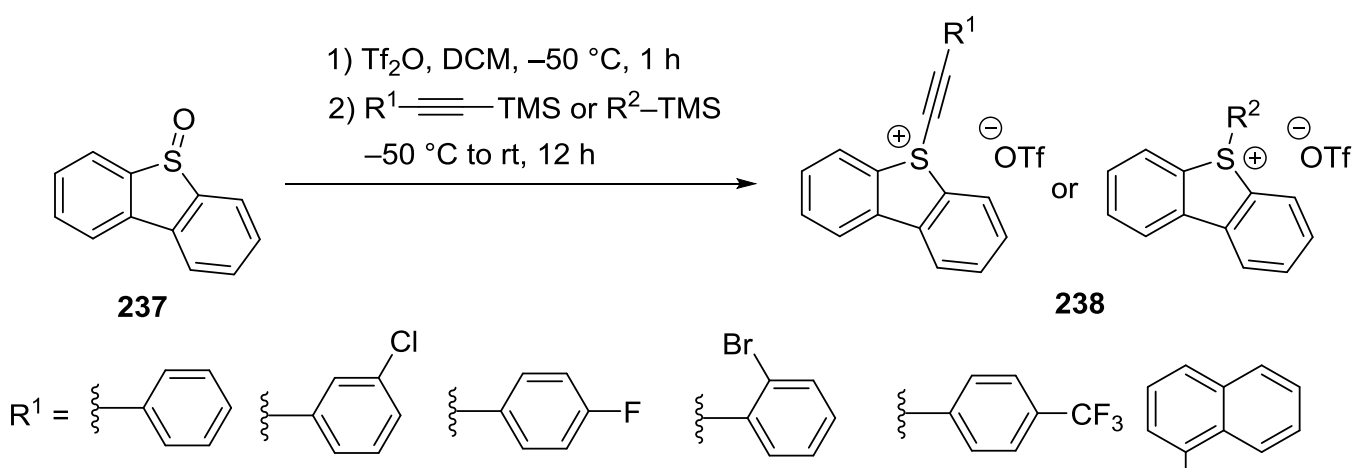

239

240

241<smiles>CCc1ccc(C(F)(F)F)cc1</smiles><smiles>Cc1cccc2ccccc12</smiles><smiles>CCc1ccc(C)cc1</smiles><smiles>CCc1cccs1</smiles><smiles>CCCc1ccc(OC)cc1</smiles><smiles>[13CH2][Te]=S</smiles>

242

243

244

245

246<smiles>CCOC(C)=O</smiles><smiles>CCCCCCCC</smiles>

$$
\mathrm{R}^{2}-\mathrm{TMS}=\mathrm{TMS}_{\mathrm{Tf}}^{\mathrm{Tf}} \underbrace{\mathrm{Tf}}_{\text {Tf }} \mathrm{TMS}-\mathrm{CN}
$$

251 252<smiles>CS(=O)(=O)C=Cc1ccccc1</smiles>

253
$248 \quad 249 \quad 250$<smiles></smiles>

Scheme 47 Attempted syntheses towards different dibenzothiophene-based reagents using various TMS-protected alkynes and other TMS-decorated molecules.

The reaction was working with different arylsubstituted alkynes. Thus, the reagents $\mathbf{2 3 8 b} \mathbf{- 2 3 8 f}$ were smoothly obtained in the reaction with the alkynes $\mathbf{2 3 9}, \mathbf{2 4 2}, \mathbf{2 4 0}, \mathbf{2 4 1}$ and $\mathbf{2 4 7}$, respectively, in 81, 99, 82 , 73 and $85 \%$ isolated yield, respectively 
Table 2 and Scheme 48). The same reactivity was observed for the reaction with the alkyne $\mathbf{2 4 4}$ as well, yet it appeared to be impossible to isolate the product $\mathbf{2 3 8 h}$ of an acceptable purity after several attempts. On the other hand, the reactions of the alkyne 243, TMS-protected acetylenes $\mathbf{2 4 5}, \mathbf{2 4 6}, \mathbf{2 4 8}$, 250 decorated with stronger coordinating functional groups and the trimethylsilylacetylene (249) led to the complete decomposition of the material. Presumably, the intermediately formed product underwent further reaction with rather active electron rich alkynes. Alternatively, activated dibenzothiophene $\mathbf{2 3 8}$ may be attacked by electron rich TMS sources to another reaction center, followed by direct decomposition of the resulting intermediates. 
Table 2 Attempted syntheses of differently substituted alkynylating reagents of type $\mathbf{2 3 8}$.

\begin{tabular}{lllcl}
\hline Entry & Product & $\mathbf{R}$ & Yield (\%). & Comments \\
\hline $\mathbf{1}$ & $\mathbf{2 3 8 a}$ & phenyl & 87 & \\
$\mathbf{2}$ & $\mathbf{2 3 8 b}$ & 3-chlorophenyl & 81 & \\
$\mathbf{3}$ & $\mathbf{2 3 8 c}$ & 4-trifluoromethylphenyl & 99 & \\
$\mathbf{4}$ & $\mathbf{2 3 8 d}$ & 4-fluorophenyl & 82 & \\
$\mathbf{5}$ & $\mathbf{2 3 8}$ & 2-bromophenyl & 73 & \\
$\mathbf{6}$ & $\mathbf{2 3 8 f}$ & TIPS & 85 & \\
$\mathbf{7}$ & $\mathbf{2 3 8}$ & 1-naphthyl & 0 & decomposition \\
$\mathbf{8}$ & $\mathbf{2 3 8 h}$ & 4-methylphenyl & 77 & purity $\sim 80-90 \%$ \\
$\mathbf{9}$ & $\mathbf{2 3 8 i}$ & 2-thienyl & 0 & decomposition \\
$\mathbf{1 0}$ & $\mathbf{2 3 8 j}$ & 4-methoxyphenyl & 0 & decomposition \\
$\mathbf{1 1}$ & $\mathbf{2 3 8 k}$ & ethoxycarbonyl & 0 & decomposition \\
$\mathbf{1 2}$ & $\mathbf{2 3 8 1}$ & H & 0 & decomposition \\
$\mathbf{1 3}$ & $\mathbf{2 3 8 m}$ & methyl & 0 & decomposition \\
\hline
\end{tabular}<smiles>O=S1C2=CC=C=C=C2c2ccccc21</smiles>

1) $\mathrm{Tf}_{2} \mathrm{O}, \mathrm{DCM},-50^{\circ} \mathrm{C}, 1 \mathrm{~h}$

2) $\mathrm{TMS}=\mathrm{R}$ $-50^{\circ} \mathrm{C}$ to rt, $12 \mathrm{~h}$

237<smiles>O=C[Se]1c2ccccc2-c2ccccc21</smiles>

238b

$81 \%$

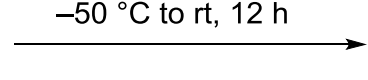<smiles>O=[S-]1(C#Cc2ccc(C(F)(F)F)cc2)c2ccccc2-c2ccccc21</smiles>

238c $99 \%$<smiles>[R]C#C[Se]c1ccccc1-c1ccccc1</smiles>

238

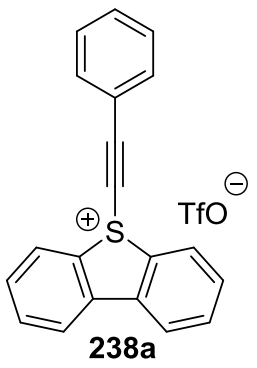

$87 \%$<smiles>O=C(C#Cc1ccccc1Br)[Se]1c2ccccc2-c2ccccc21</smiles>

238e

$73 \%$

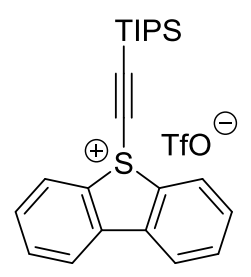

$238 f$

$85 \%$

Scheme 48 Substrate scope for the synthesis of novel dibenzothiophenium reagents 238 . 
The structures of the selected salts $\mathbf{2 3 8}$ were unambiguously established by X-ray diffraction analysis (Figure 29). Crystals suitable for X-ray diffractometry of the reagent $\mathbf{2 3 8 f}$ were obtained by slowly cooling down of a boiling, saturated toluene solution to rt. Furthermore, crystals of the reagent 238a were grown by slow evaporation of a saturated DCM solution. As expected, both compounds show a pyramidal geometry of the central sulfur atom (the sum of angles around $\mathrm{S} 1$ is $302.3^{\circ}$ for reagent $\mathbf{2 3 8 f}$ and $294.6^{\circ}$ for the salt 238a). The bonds between $\mathrm{S} 1$ and the neighboring carbons of the dibenzothiophene backbone $[\mathrm{S} 1-\mathrm{C} 3=1.7897(1) \AA$ in compound 238a and S1-C3 = 1.7933(8) $\AA$ in 238f] are lengthened due to the partial loss of the aromaticity, as compared to the parent dibenzothiophene $(1.740 \AA)$. ${ }^{128 a}$ This is a direct consequence of the reduction of the bonding order of the corresponding bond between sulfur and carbon in a dibenzothiophene backbone in $\mathbf{2 3 8}$. Besides, a strong coordination of the oxygen of the triflate counterion towards the sulfur-atom was observed. This can be interpreted as a consequence of the enhanced Lewis acidity of sulfur atom, resulting in a significant shortening of interatomic distances $[\mathrm{O} 1-\mathrm{S} 1=3.157(1) \AA$ in the salt 238a and O1-S1 2.972(2) $\AA$ in compound 238f] in comparison to the corresponding sum of the Van-der-Waals-radii $(3.32 \AA) .{ }^{129 b}$
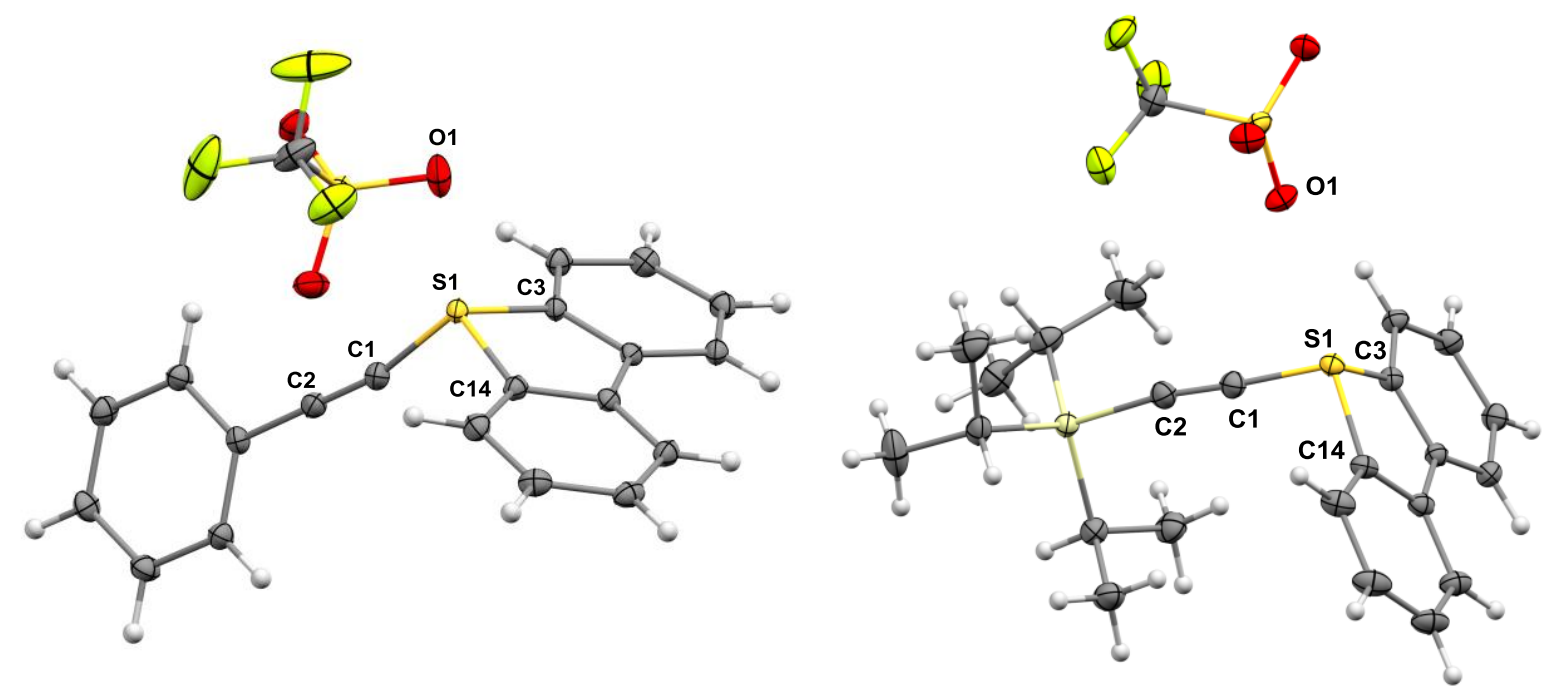

Figure 26 Molecular structures of compound 238a (left side) and 238f (right side) in the crystal. Thermal ellipsoids at $50 \%$ probability, the numbering does not correspond to the IUPAC rules. Selected bond lengths, distances ( $\mathrm{A})$ and angles $\left({ }^{\circ}\right)$ : Compound 238a: O1-S1 = 3.157(1), S1-C3 = 1.7878(1), S1-C14 = 1.7897(1), S1-C1 = 1.6871(1), C3-S1-O1 = 179.0(1); Compound 238f: S1-O1 = 2.972(1), S1-C3 = 1.7933(8), S1-C14 = 1.7935(8), S1-C1 = 1.6980(9), C6-S1-O1 = $177.3(1)$. 
Apart from TMS-protected alkynes, several other TMS-decorated molecules 251-254 (Scheme 47) were tested toward the synthesis of further dibenzothiophene-derived potential transfer reagents (Table 3). Whereas only decomposition products of the dibenzothiophene were obtained in the reaction with the TMS-sulfonamide 251, with TMS-cyanide (252) the corresponding reagent $\mathbf{2 3 8 0}$ was successfully synthesized in $83 \%$ yield. Also the $\beta$-trimethylsilylstyrene (253) was transferred to the dibenzothiophenium backbone. The reagent 238p was isolated with minor impurities in a yield around $87 \%$. In contrast, the use of 2-(trimethylsilyl)benzofurane (254) led to a complete decomposition of the reaction partners.

Table 3 Attempted syntheses of further dibenzothiophene-derived potential transfer reagents.

\begin{tabular}{lllrl}
\hline Entry & Product & TMS-R & Yield $(\boldsymbol{\%})$ & Comment \\
\hline $\mathbf{1}$ & $\mathbf{2 3 8 n}$ & TMS-N $(\text { Tf })_{2}$ & 0 & decomposition \\
$\mathbf{2}$ & $\mathbf{2 3 8 0}$ & TMS-cyanide & 83 & - \\
$\mathbf{3}$ & $\mathbf{2 3 8 p}$ & $(E)$-trimethyl(styryl)silane & $\sim 87$ & contain impurities \\
$\mathbf{4}$ & $\mathbf{2 3 8 q}$ & TMS-benzofuran-2-yl & 0 & decomposition \\
\hline
\end{tabular}

Furthermore, the structure of compound 238p was confirmed by X-ray crystal structure analysis (Figure 27). Single crystals suitable for X-ray diffraction were grown from over-layering a solution of the salt 238q in DCM with $\mathrm{Et}_{2} \mathrm{O}$. As in the previously discussed above structures, the bond length $\mathrm{C} 9$ S1 with $1.780(2) \AA$ is longer than in dibenzothiophene $(1.740 \AA)^{128 a}$ This is attributed to the partial loss of aromaticity in the dibenzothiophene backbone as well. The distance between the carbon atoms $\mathrm{C} 1-\mathrm{C} 2$ of the alkene moiety with 1.333 (3) $\AA$ is comparable to the length of a $\mathrm{C}=\mathrm{C}$ double bond in unsubstituted styrene in the solid phase $[1.3245(2) \AA] .{ }^{128 c}$ A significant shortening of interatomic distance C1-O1 [3.069(3) A vs. the sum of the Van-der-Waals-radii of $3.22 \AA]^{128 b}$ may be occurs due to the support of a strong hydrogen bonding $\mathrm{C} 1-\mathrm{H} \cdots \mathrm{O} 1$.

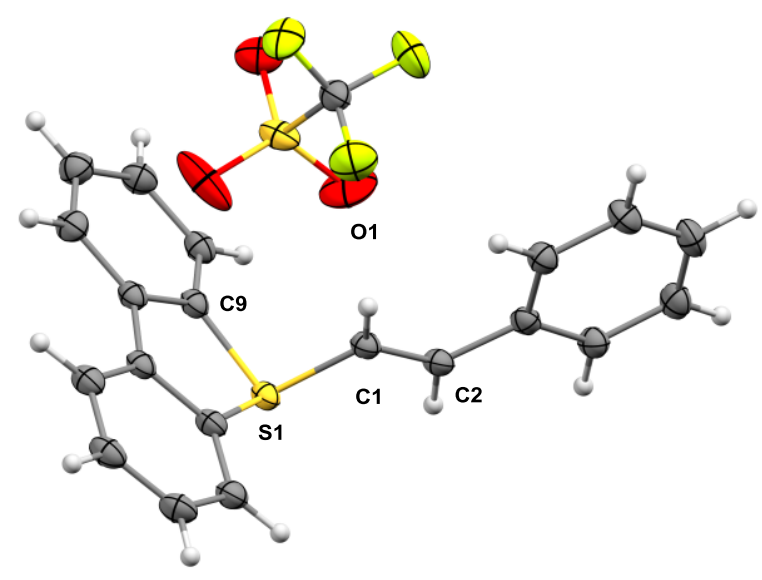

Figure 27 Molecular structure of compound 238q. Thermal ellipsoids at 50\% probability. Selected bond lengths and distances $(\AA)$ : $\mathrm{C} 1-\mathrm{C} 2=1.333(3), \mathrm{C} 1-\mathrm{O} 1=3.069(3), \mathrm{C} 9-\mathrm{S} 1=1.780(2), \mathrm{C} 1 \mathrm{H}-\mathrm{O} 1=3.069(3)$. 


\subsubsection{Optimization of the reaction conditions}

The reactivity of the reagents $\mathbf{2 3 8}$ was investigated by example of ethynylation of the $\beta$-ketoester 202 with the reagent 238a (Scheme 49 and Table 4). As believed, higher yields of compound 232 were observed for the reaction with the salt 238a as compared to the diphenylsulfonium salt $\mathbf{2 0 5}$ ( $c f$. Scheme 44 and Table 1). Compound 232 was isolated in up to $61 \%$ yield when applying $\mathrm{Cs}_{2} \mathrm{CO}_{3}$ or DIPEA as base and 1.20 equivalents of the reagent 238a in DCM (entries 1, 2). However, thus obtained product was contaminated with $10 \%$ of starting material as inseparable impurity. No unreacted $\beta$-ketoester 202 was observed, when the amount of the reagent 238a was increased to 1.50 equivalents while employing DIPEA as a base (entry 3). The same results were observed with $\mathrm{Cs}_{2} \mathrm{CO}_{3}$ (entries 4 and 5). Furthermore, no significant influence of the solvent was found, as the reaction exhibited similar efficiency utilizing MeCN, toluene and THF (entries 6-9). Surprisingly, no reaction was observed when silver carbonate was used as a base (entry 10). Solely starting material was isolated, when the reaction was run without a base in $\mathrm{MeCN}$ (entry 11). The yield increased up to 69\% by lowering the reactants concentration by factor 2 (entries 12 and 13). The dropwise addition of the reagent solution utilizing DIPEA as a base afforded the desired product 232 in $62 \%$ yield (entry 14). Finally, a screening of the temperature in the range from 40 to $70{ }^{\circ} \mathrm{C}$ (entries 15-20) revealed that $60{ }^{\circ} \mathrm{C}$ was the optimal one giving $\mathbf{2 3 2}$ in the best yield of $79 \%$ (entry 18).

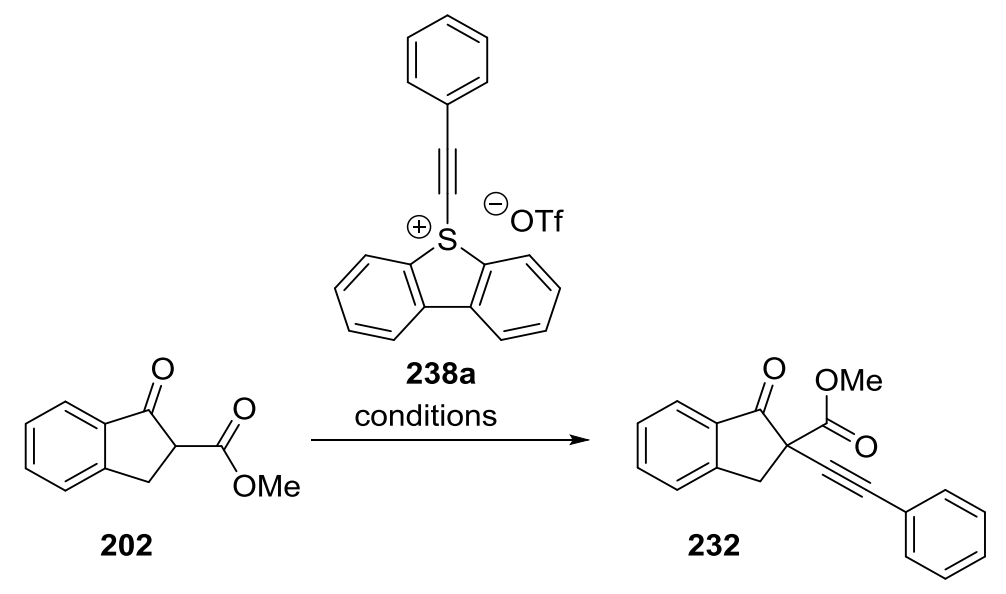

Scheme 49 Alkynylation of the $\beta$-ketoester 202 with the reagent 238a as a test reaction. 
Table 4 Alkynylation of the $\beta$-ketoester 202 with the dibenzothiophenium salt $\mathbf{2 3 8 a}$ : screening for the better conditions.

\begin{tabular}{|c|c|c|c|c|c|c|c|}
\hline Entry & Equiv. & Base & Solvent & $\mathbf{T}\left({ }^{\circ} \mathbf{C}\right)$ & Concentration. & Yield (\%) & Comment \\
\hline 1 & 1.20 & $\mathrm{Cs}_{2} \mathrm{CO}_{3}$ & DCM & $\mathrm{rt}$ & $0.14 M$ & 57 & $+10 \% \mathrm{SM}^{*}$ \\
\hline 2 & 1.20 & DIPEA & DCM & $\mathrm{rt}$ & $0.14 M$ & 61 & $+10 \% \mathrm{SM}$ \\
\hline 3 & 1.50 & DIPEA & DCM & $\mathrm{rt}$ & $0.14 M$ & 58 & - \\
\hline 4 & 1.50 & $\mathrm{Cs}_{2} \mathrm{CO}_{3}$ & $\mathrm{DCM}$ & $\mathrm{rt}$ & $0.14 M$ & 58 & - \\
\hline 5 & 1.50 & $\mathrm{Cs}_{2} \mathrm{CO}_{3}$ & DCM & $\mathrm{rt}$ & $0.07 M$ & 67 & - \\
\hline 6 & 1.20 & $\mathrm{Cs}_{2} \mathrm{CO}_{3}$ & $\mathrm{MeCN}$ & $\mathrm{rt}$ & $0.14 M$ & 67 & $+10 \% \mathrm{SM}$ \\
\hline 7 & 1.20 & $\mathrm{Cs}_{2} \mathrm{CO}_{3}$ & THF & $\mathrm{rt}$ & $0.14 M$ & 58 & - \\
\hline 8 & 1.20 & $\mathrm{Cs}_{2} \mathrm{CO}_{3}$ & Toluene & $\mathrm{rt}$ & $0.14 M$ & 52 & Isolated $40 \% \mathrm{SM}$ \\
\hline 9 & 1.50 & $\mathrm{Cs}_{2} \mathrm{CO}_{3}$ & $\mathrm{MeCN}$ & $\mathrm{rt}$ & $0.14 M$ & 66 & - \\
\hline 10 & 1.20 & $\mathrm{Ag}_{2} \mathrm{CO}_{3}$ & DCM & $\mathrm{rt}$ & $0.14 M$ & 0 & Isolated only SM \\
\hline 11 & 1.20 & - & $\mathrm{MeCN}$ & $\mathrm{rt}$ & $0.14 M$ & 0 & Isolated only SM \\
\hline 12 & 1.50 & $\mathrm{Cs}_{2} \mathrm{CO}_{3}$ & $\mathrm{MeCN}$ & $\mathrm{rt}$ & $0.07 M$ & 69 & - \\
\hline 13 & 1.50 & $\mathrm{Cs}_{2} \mathrm{CO}_{3}$ & DCM & $\mathrm{rt}$ & $0.07 M$ & 67 & - \\
\hline 14 & 1.50 & DIPEA & $\mathrm{DCM}$ & $\mathrm{rt}$ & $0.07 M$ & 62 & $\begin{array}{l}\text { Reagent solution } \\
\text { added dropwise }\end{array}$ \\
\hline 15 & 1.50 & $\mathrm{Cs}_{2} \mathrm{CO}_{3}$ & DCE & 40 & $0.07 M$ & 71 & - \\
\hline 16 & 1.50 & $\mathrm{Cs}_{2} \mathrm{CO}_{3}$ & DCE & 50 & $0.07 M$ & 73 & - \\
\hline 17 & 1.50 & $\mathrm{Cs}_{2} \mathrm{CO}_{3}$ & DCE & 55 & $0.07 M$ & 66 & - \\
\hline 18 & 1.50 & $\mathrm{Cs}_{2} \mathrm{CO}_{3}$ & DCE & 60 & $0.07 M$ & 79 & - \\
\hline 19 & 1.50 & $\mathrm{Cs}_{2} \mathrm{CO}_{3}$ & DCE & 65 & $0.07 M$ & 74 & - \\
\hline 20 & 1.50 & $\mathrm{Cs}_{2} \mathrm{CO}_{3}$ & DCE & 70 & $0.07 M$ & 69 & - \\
\hline
\end{tabular}

$* \mathrm{SM}=$ starting material 202. 


\subsubsection{Scope and limitations of the transfer reaction}

Reactions with $N$-, $S,-C$ - and $P$-benchmark nucleophiles were performed to demonstrate the scope of this transfer reaction (Scheme 50). The reactions with the reagents 238a-238e were performed under the optimized conditions described above (A), but the excess of used reagent $\mathbf{2 3 8 f}$ could be reduced to 1.20 equivalents, whereas all reactions with this salt were conducted at room temperature (B).

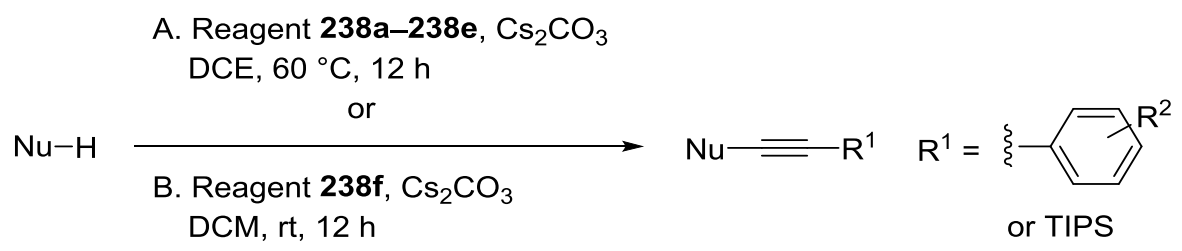

Scheme 50 Applied reaction conditions for the investigations towards the alkynylation of nucleophiles with newly developed reagents 238 .

Additionally, all reactions with thiols were accomplished at room temperature because of the possibility of disulfide formation. Different aliphatic and aromatic, electron rich and electron poor thiols were functionalized (Figure 28). For example, the products 255 and 256 were obtained in a yield of 70 and 67\%, respectively, by reacting (4-methoxyphenyl)methanethiol with reagents $\mathbf{2 3 8 f}$ or $\mathbf{2 3 8 a}$. respectively. In addition, upon treatment with the salts $\mathbf{2 3 8 f}$ or $\mathbf{2 3 8 a}$, ethyl 2-mercaptoacetate was converted into sulfides $\mathbf{2 5 7}$ or $\mathbf{2 5 8}$ in $\mathbf{8 7}$ or $91 \%$ yield, respectively. The reaction of 4nitrobenzenethiol with the reagent $\mathbf{2 3 8 f}$ resulted in the formation of product $\mathbf{2 5 9}$ with a yield of $76 \%$. With 4-methoxybenzenethiol, compound $\mathbf{2 6 0}$ was received from the reaction with the reagent $\mathbf{2 3 8 f}$ in 73\% yield, whereas the transfer of a phenylacetylene moiety from reagent 238a appeared to be slightly less efficient, as the product $\mathbf{2 6 1}$ in a yield of 64\%. The examined conversions of naphthalene-1-thiol into the corresponding thioether $\mathbf{2 6 2}$ using the reagent 238a (49\% yield), of benzo[ $d]$ thiazole-2-thiol into compound $\mathbf{2 6 3}$ employing the salt $\mathbf{2 3 8 f}$ (99\% yield), of thiobenzoic acid into the corresponding ester 264 (66\% yield) and of protected cysteine into its derivative 266 using the same reagent (80\%) appeared to be successful as well. On the other hand, no product formation was observed in the attempted alkynylations of the latter two starting materials with the reagent 238a. Unfortunately, all attempts to synthesize the bromide 267 or the selenoether 268 failed. Presumably, both products possess a low stability and decompose under the reaction conditions. 
<smiles>[R]C#CSCc1ccc(OC)cc1</smiles>

$\mathrm{MeO}$<smiles>[R]C#CSCC(C)=O</smiles>

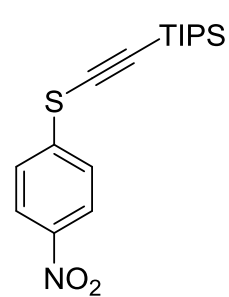

259

260, $R=$ TIPS, $73 \%$

261, $\mathrm{R}=\mathrm{Ph}, \quad 64 \%$

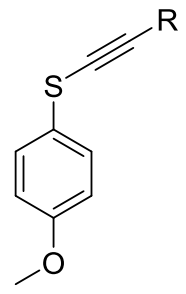<smiles>C(#Cc1ccccc1)Sc1cccc2ccccc12</smiles>

262

$49 \%$ 256, $R=P h, \quad 67 \%$

258, $\mathrm{R}=\mathrm{Ph}, \quad 91 \% \quad 76 \%$<smiles>Brc1ccccc1SC#Cc1ccccc1</smiles><smiles>C(#Cc1ccccc1)c1ccccc1</smiles>

263

$99 \%$<smiles>[R]C#CSC(=O)c1ccccc1</smiles>

$264 \mathrm{R}=$ TIPS $66 \%$

$265 \mathrm{R}=\mathrm{Ph} \quad 0 \%$
TIPS<smiles>CC#CSC[C@H](N)C(=O)OC(=O)OC</smiles>

266

$80 \%$
267

$0 \%$
268

$0 \%$

Figure 28 Reaction scope of the transfer reaction with different sulfur-based nucleophiles.

Also twofold-activated methyne compounds were examined as nucleophiles in the alkynylation reaction (Figure 29). The $\beta$-ketoester 202 was functionalized under the optimizing reaction conditions with the reagents $\mathbf{2 3 8 a}-\mathbf{2 3 8 f}$. This reaction tolerates a wide range of substituents on the aromatic ring upon transferring arylacetylene moieties. Thus, the products 232 (79\% yield) 269 (79\% yield), 270 (74\% yield), $\mathbf{2 7 1}$ (65\% yield) and $\mathbf{2 7 2}$ (81\% yield) were obtained in the reactions of compound $\mathbf{2 0 2}$ with reagents 238a, 238e, 238c, 238d and 238b, respectively. The TIPS-substituted reagent $238 f$ appeared to be synthetically useful in alkynylation of several twofold-activated methyne compounds such as cyclic $\beta$-ketoester 202, its analogue 2-phenyl-1H-indene-1,3(2H)-dione or ring-opened 2cyano-3-phenylpropanoate. Reactions with $\mathbf{2 3 8 f}$ afforded acetylenes 273-275 in 88, 95 and 79\% isolated yield. Surprisingly, the attempted preparation of the closest analogue of the latter - ring opened $\beta$-ketoester 277 from methyl 2-methyl-3-oxo-3-phenylpropanoate - failed because of unknown reasons. Likewise, only solely starting material was isolated in the reaction of the reagent $238 f$ with methylated Meldrum's acid. Most probably, this is a result of enhanced acidity of Meldrum's acid: the two carbonyl groups in the six-membered ring are better conjugated and exert stronger electronwithdrawing effect. As result, this compound is 8 orders of magnitude more $\mathrm{C}-\mathrm{H}$ acidic than the closely related dimethyl malonate. On the other hand, products like compounds $\mathbf{2 7 8 , 2 7 9}$ or 280 could not be synthesized from single activated starting materials with low $\mathrm{C}-\mathrm{H}$ acidity applying elaborated methodology as well. Following the HSAB-concept, the generated nucleophiles are presumably too hard, what led to a decomposition of the reagent instead. 

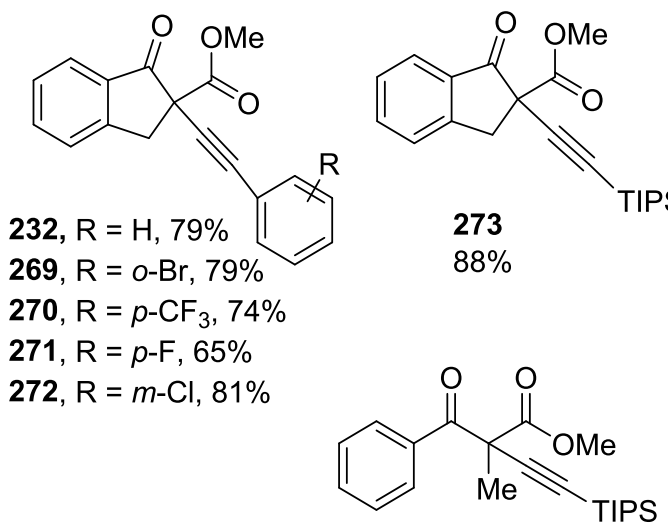

$0 \%$
277

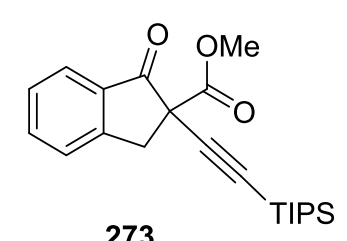

$88 \%$

IPS

$$
277
$$
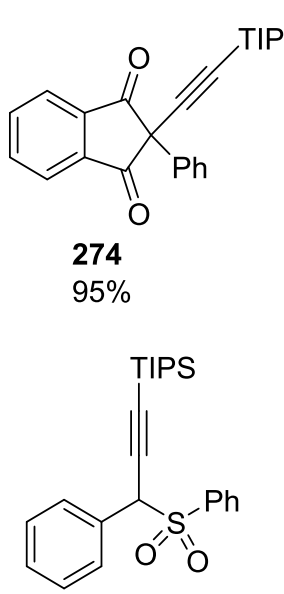

278

$0 \%$

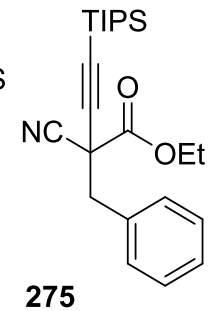

$70 \%$

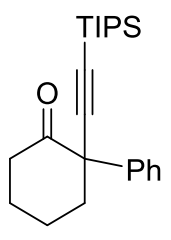

279

$0 \%$
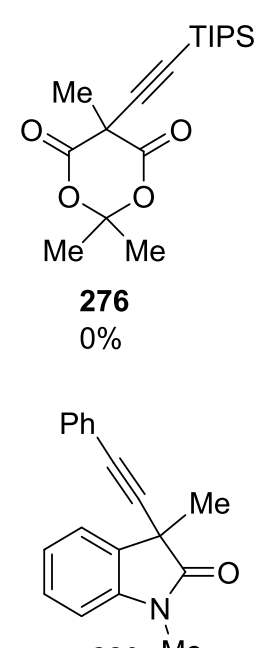

$280 \mathrm{Me}$

$0 \%$

Figure 29 Reaction scope of the alkyne transfer reaction with different carbon-based nucleophiles.

Among nitrogen-based nucleophiles, sulfonamides were working in the alkyne transfer reaction as well (Figure 30). Thus, N,4-dimethylbenzenesulfonamide was functionalized with the salts 238a and $238 f$ affording products 282 and 281 in 55 and 67\% yield, respectively. Derivatives of differently substituted anilines were also alkynylated in good yields. Proceeding from the tosylated anilines, the compound 283 (77\% (bsrm, 55\%) yield), 284 (50\% yield), 285 in a of (61\% yield) and 286 (53\% yield) were successfully synthesized, thus demonstrating the reaction tolerance towards ethoxycarbonyl, methoxy and iodine substituents on an aniline aromatic moiety.

Sulfonamides with other structural motifs were probed as well. Accordingly, compound 287 was obtained in a yield of 60\%, and the derivatives of camphorsulfonic acid $\mathbf{2 8 8}$ and $\mathbf{2 8 9}$ - in a yield of $60 \%$ and 58\%, respectively. Furthermore, the pharmacologically active compounds and veterinary antibiotic Sulfadimidine ${ }^{129}$ was selectively converted to the alkyne 290 in a yield of $60 \%$. A completely new reactivity, which, as far as we know, has not yet been described in the literature, was found upon the functionalization of diamides with alkyne transfer reagents. Naphthalimide and phthalimide were transformed into their $N$-alkynylated derivatives $\mathbf{2 9 1}$ and $\mathbf{2 9 2}$ in 60 and 33\% yield, respectively. In contrast, maleimide or succinimide could not be functionalized with the reagent $\mathbf{2 3 8 f}$. This looks surprising, as structural differences between compounds 292 and 293 seem to be negligible. On the other hand, the general degree of conjugation in a molecule drops in the sequence $\mathbf{2 9 1} \rightarrow \mathbf{2 9 2} \rightarrow \mathbf{2 9 3} \rightarrow \mathbf{2 9 4}$. This could result in dropping in stability of the products and lead to decomposition under the reaction conditions. A number of other cyclic and open-chained functionalized amides, such as the compounds 295-296, could not be synthesized as well. Most likely, only compounds with a Lewis basicity that lie within a certain range can be alkynylated with the dibenzothiophenium reagents. This is in line with HSAB-concept and the reported results on the reactivity of amides with the hypervalent iodine equivalent TIPX-EBX. ${ }^{105}$ As well, the tert-amine 298 was not obtained due to the expected low stability of the product. 
<smiles>[R]C#CN(C)S(=O)(=O)c1ccc(C)cc1</smiles>

$281 \mathrm{R}=\mathrm{TIPS}, 67 \%$ $282 \mathrm{R}=\mathrm{Ph}, 55 \%$<smiles>Cc1ccc(S(C)(=O)=O)cc1</smiles>

$283 \mathrm{R}=\mathrm{CO}_{2} \mathrm{Et}, 77 \%$ (brsm)

$284 \mathrm{R}=\mathrm{OMe}, 50 \%$

$285 \mathrm{R}=\mathrm{I}, 61 \%$

$286 R=H, 53 \%$<smiles>O=S(=O)(c1ccc2c(c1)OCCO2)N(C#C[Al])c1ccccc1</smiles>

287

$62 \%$

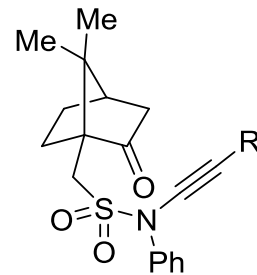

$288 \mathrm{R}=$ TIPS, $60 \%$

$289 \mathrm{R}=\mathrm{Ph}, 58 \%$<smiles>Cc1cc(C)nc(N(C#CSC(C)C)S(=O)(=O)c2ccc(N)cc2)n1</smiles>

$60 \%$<smiles></smiles>

295

$0 \%$<smiles>O=C1c2cccc3cccc(c23)C(=O)N1C#CC(F)(F)F</smiles>

291 $60 \%$

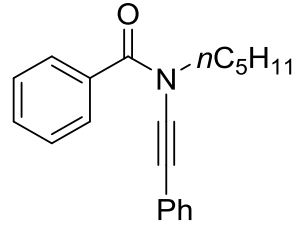

296

$0 \%$<smiles></smiles>

292

$33 \%$<smiles>CC(F)SC#CN1C(=O)C=CC1=O</smiles>

293<smiles>O=C1CCC(=O)N1C#CS[In]</smiles>

294

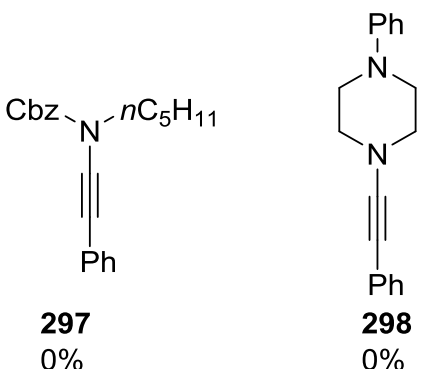

Figure 30 Reaction scope of the alkyne transfer reaction with different nitrogen-based nucleophiles.

In contrast to amines, alcoholates did not react with these reagents 238 in the desired manner. Neither benzylic (299 and 300) nor phenolic ethers 301 and 302 could be synthesized with the newly developed transfer reagents (Figure 31). Presumably, salts 238 only react properly with soft nucleophiles, while alcoholates can act on the reagent in an undesirable position, forming unstable products.<smiles>[R]C#COCc1cccc(OC)c1</smiles>

$299 \mathrm{R}=\mathrm{TIPS} 0 \%$ $300 \mathrm{R}=\mathrm{Ph} \quad 0 \%$<smiles>Pc1cccc(OC#Cc2ccccc2)c1</smiles>

301

$0 \%$<smiles>COc1ccc(OC#CSP)cc1</smiles>

302

$0 \%$

Figure 31 Attempted alkynylation of different alcoholates with reagents 238 . 
The posphonium salt $\mathbf{3 0 3}$ was synthesized by the direct ethynylation of triphenylphosphine with the reagent $\mathbf{2 3 8 f}$ in a yield of $88 \%$ without additional base (Figure 32). Also the diyne $\mathbf{3 0 4}$ could be obtained from the reaction of the salt $\mathbf{2 3 8 f}$ with 1-ethynyl-4-methoxybenzene after deprotonation with and $n \mathrm{BuLi}$ in a yield of $19 \%$. In contrast, the reaction of the enol ether $\mathbf{3 0 6}$ and the Grignard reagent $\mathbf{3 0 8}$ with reagents $\mathbf{2 3 8 f}$ or $\mathbf{2 3 8 a}$, respectively, did not afford the desired product $\mathbf{3 0 5}$ and $\mathbf{3 0 7}$, respectively. The alkynylated indole derivatives $\mathbf{3 0 9}$ and $\mathbf{3 1 0}$ and the dimethoxybezene derivative $\mathbf{3 1 1}$ were not accessed under base-free conditions as well, even in microwave-assisted reactions. Furthermore, in the attempted alkynylations with the salt 238a, the products 312 and 314 could not be obtained from enamine $\mathbf{3 1 3}$ or from Grignard reagent 315, respectively. As indicated above, only specific nucleophiles appeared to be functionalized with the elaborated system.

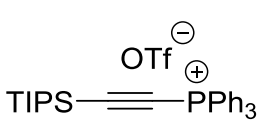

303

$88 \%$<smiles>[R]C#Cc1c(-c2ccccc2)n(C)c2ccccc12</smiles>

$309 \mathrm{R}=$ TIPS $0 \%$ $310 \mathrm{R}=\mathrm{Ph} \quad 0 \%$
TIPS

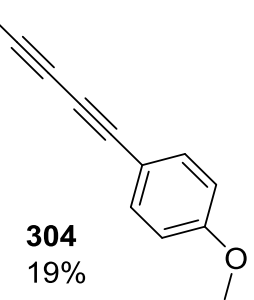<smiles>COc1cccc(OC)c1C#Cc1ccccc1</smiles>

311

$0 \%$<smiles>COC(=O)CC#C[AsH2]</smiles>

305

$0 \%$

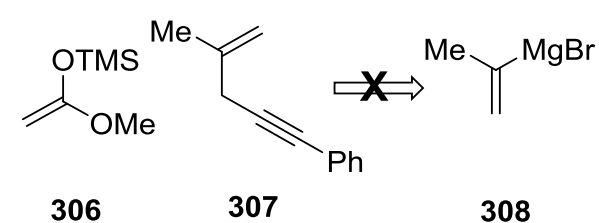

$0 \%$

308

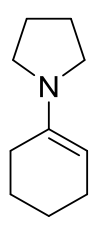

313

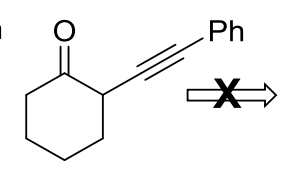

312

$0 \%$
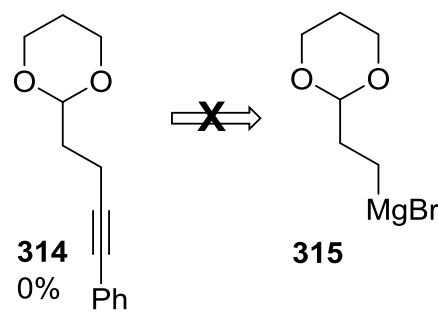

Figure 32 Reaction scope of the transfer reaction with selected various nucleophiles.

To verify structural identity of the selected representative products, their single crystals suitable for Xray diffraction were grown by slow evaporation of a saturated solution in DCM or hexane. The results of X-ray crystal structure analysis are presented in Figure 33. 

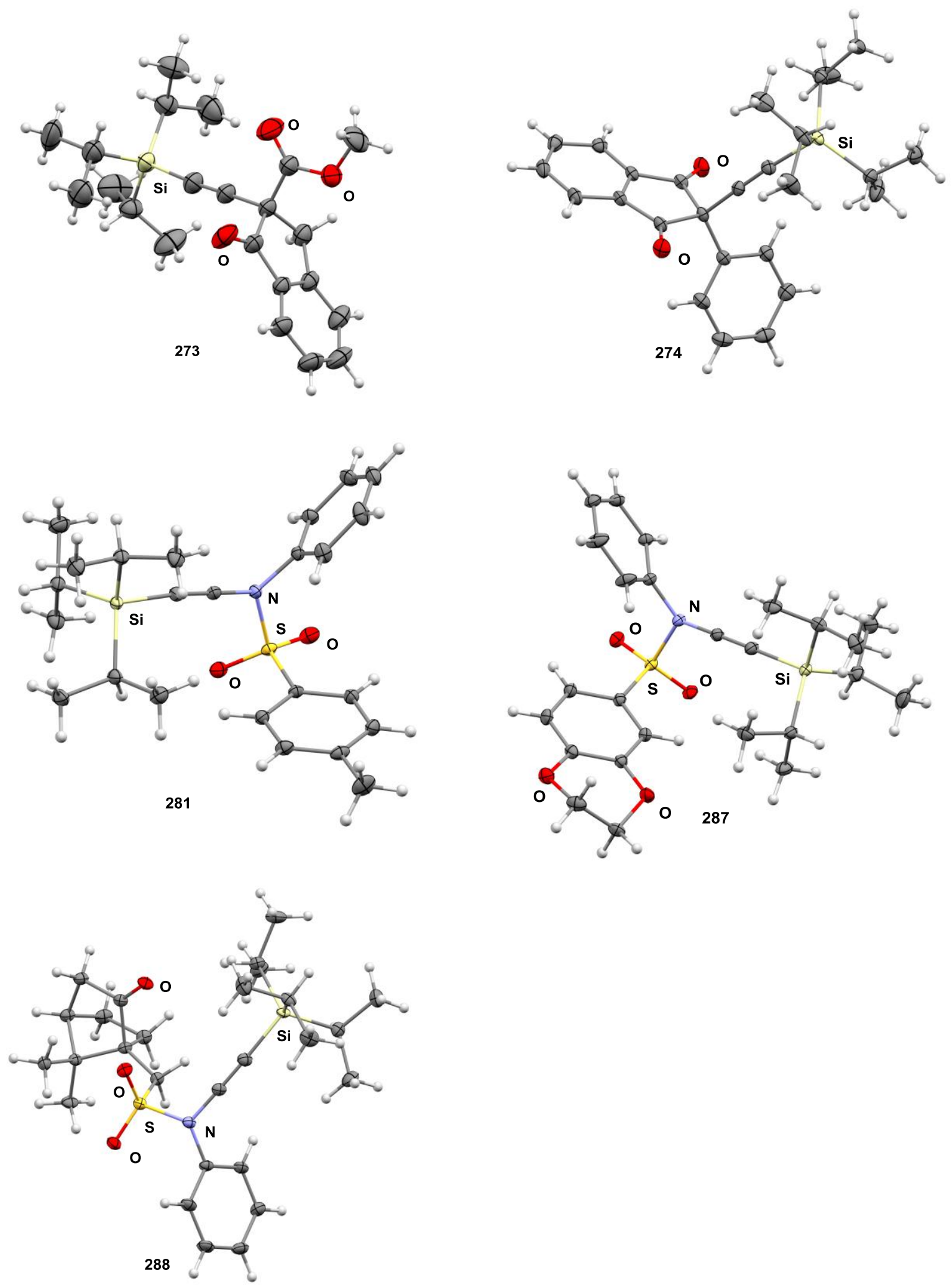

Figure 33 Molecular structure of the alkynylated compounds 273 (top left), 274 (top right), 281 (middle left), 287 (middle right) and $\mathbf{2 8 8}$ (bottom). Thermal ellipsoids at $50 \%$ probability. 


\subsubsection{Comparison of the new reagents with TIPS-EBX}

It is known that hypervalent iodine compounds can undergo a strong exothermic decomposition; some of them even show explosive nature. ${ }^{130}$ Hence, estimation of decomposition energy of the compound 238a and 238f by differential scanning calorimetry (DSC) was performed to compare with the values for corresponding hypervalent iodine reagents. With $449 \mathrm{~J} \cdot \mathrm{g}^{-1}$, the decomposition energy of the phenyl reagent was around $100 \mathrm{~J} \cdot \mathrm{g}^{-1}$ lower than that of Ph-EBX 152c. Moreover, the decomposition of dibenzothiophenium salts $\mathbf{2 3 8}$ appeared to be a non-explosive slow process. ${ }^{131}$

Furthermore, competition experiments with NMR monitoring were performed applying equimolar mixtures of aromatic thiol $\mathbf{3 1 6}$ and the aliphatic thiol $\mathbf{3 1 7}$ with either the reagent $\mathbf{2 3 8 f}$ or the commercially available TIPX-EBX 152d. When the reagent $\mathbf{2 3 8 f}$ was used under basic conditions, the thioether 259 was formed selectively (Scheme 51 and Figure 34).

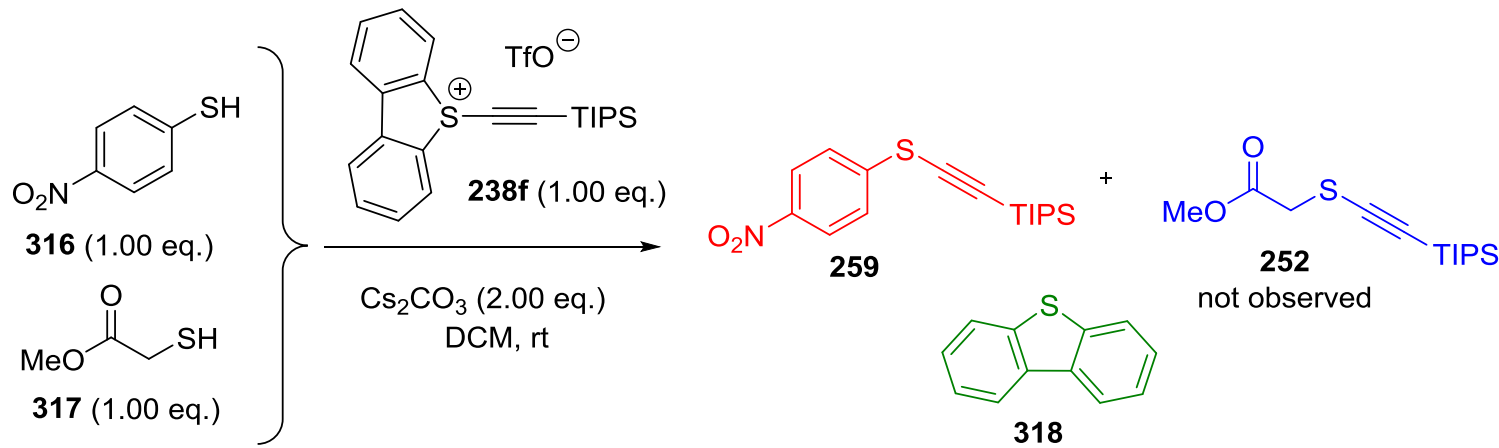

Scheme 51 Competition reaction of a 1:1 mixture of the thiol $\mathbf{3 1 6}$ and $\mathbf{3 1 7}$ with the dibenzothiophenium salt $\mathbf{2 3 8 f}$.

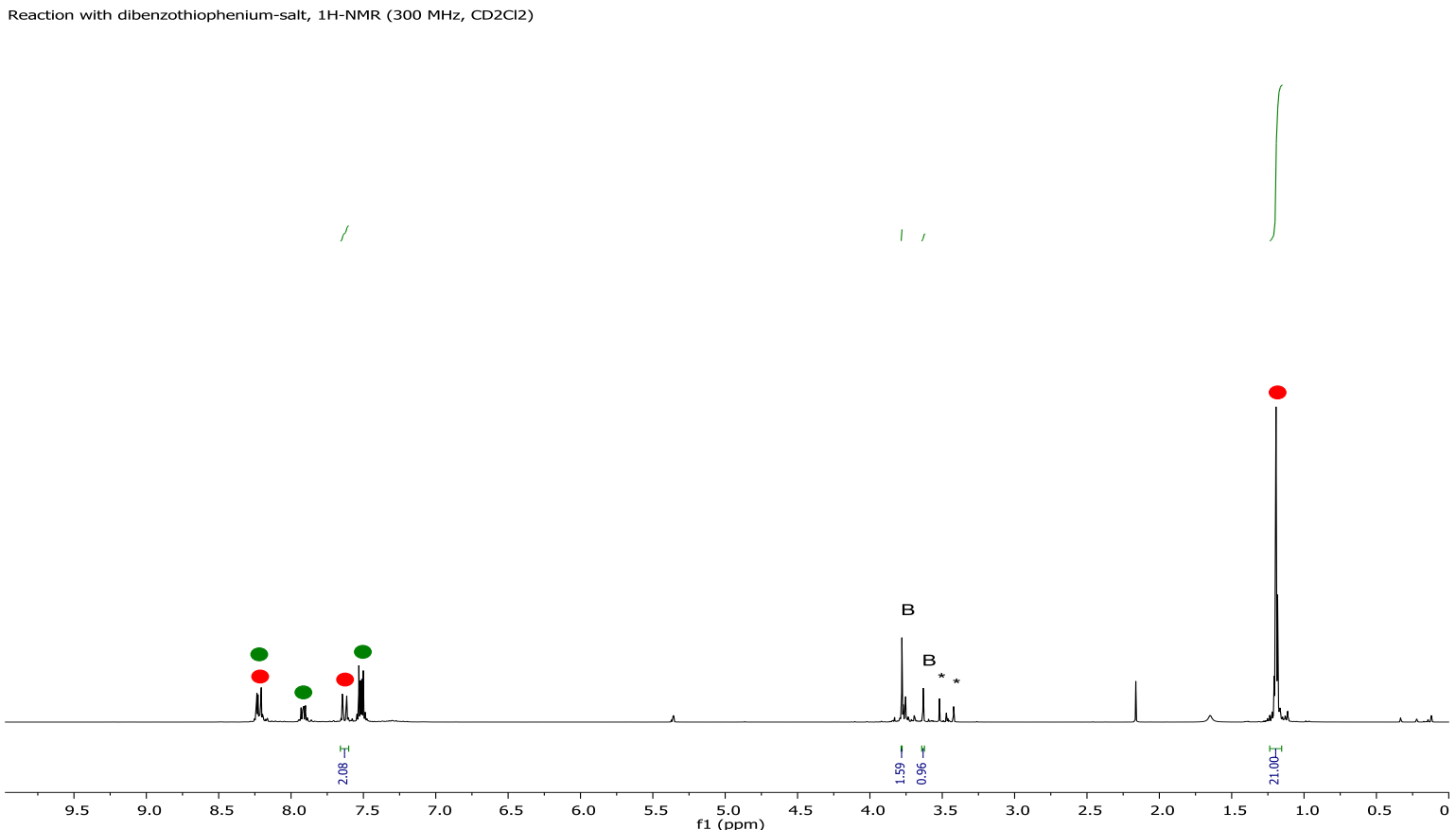

Figure $34{ }^{1} \mathrm{H}$ NMR spectrum of the reaction mixture obtained from dibenzothiophenium salt $238 \mathrm{f}$ and equimolar mixture of thiols $\mathbf{3 1 6}$ and $\mathbf{3 1 7}$. 
Under the same conditions, a 40:60 mixture of both products was obtained with the commercially available TIPS-EBX 152d instead, favoring the formation of the thioether 252 (Scheme 52 and Figure 35). This result could be explained by the enhanced reactivity of the iodine reagent $\mathbf{1 5 2 d}$ in comparison to $\mathbf{2 3 8 f}$ and, as result, unselectively in the alkynylation. Therefore, this proves that the new dibenzothiophenium reagents can be a valuable alternative to iodine-based reagents, especially in research fields were high selectivity is required, i.e. the late stage functionalization of challenging and complex substrates. Besides, the products can easy be purified due to the stability of the formed byproduct dibenzothiophene $\mathbf{3 1 8}$ and its high solubility in most organic solvents.

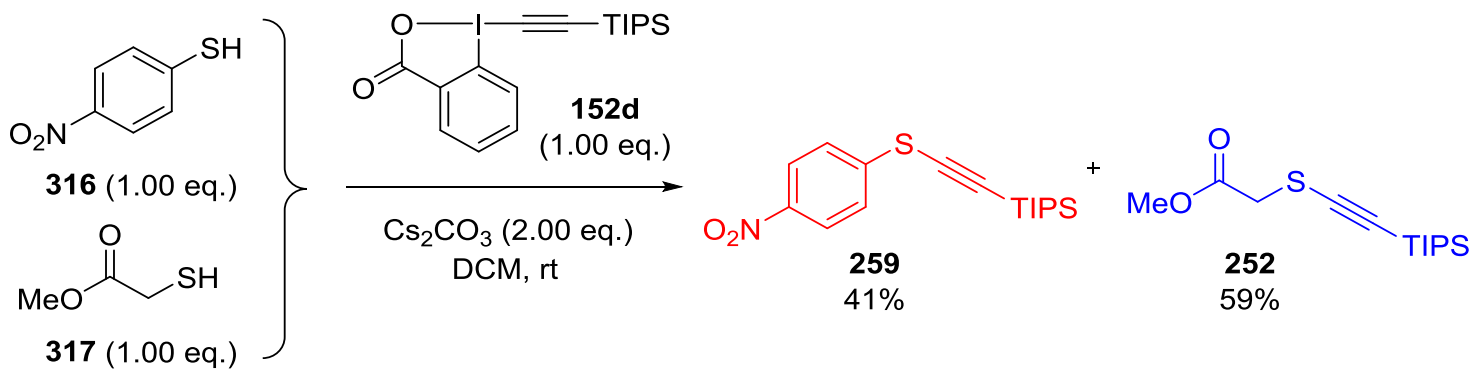

Scheme 52 Competition reaction of a 1:1 mixture of the thiol $\mathbf{3 1 6}$ and $\mathbf{3 1 7}$ with TIPX-EBX 152d.

Reaction with EBX $1 \mathrm{H}-\mathrm{NMR}(300 \mathrm{MHz}, \mathrm{CD} 2 \mathrm{Cl} 2)$
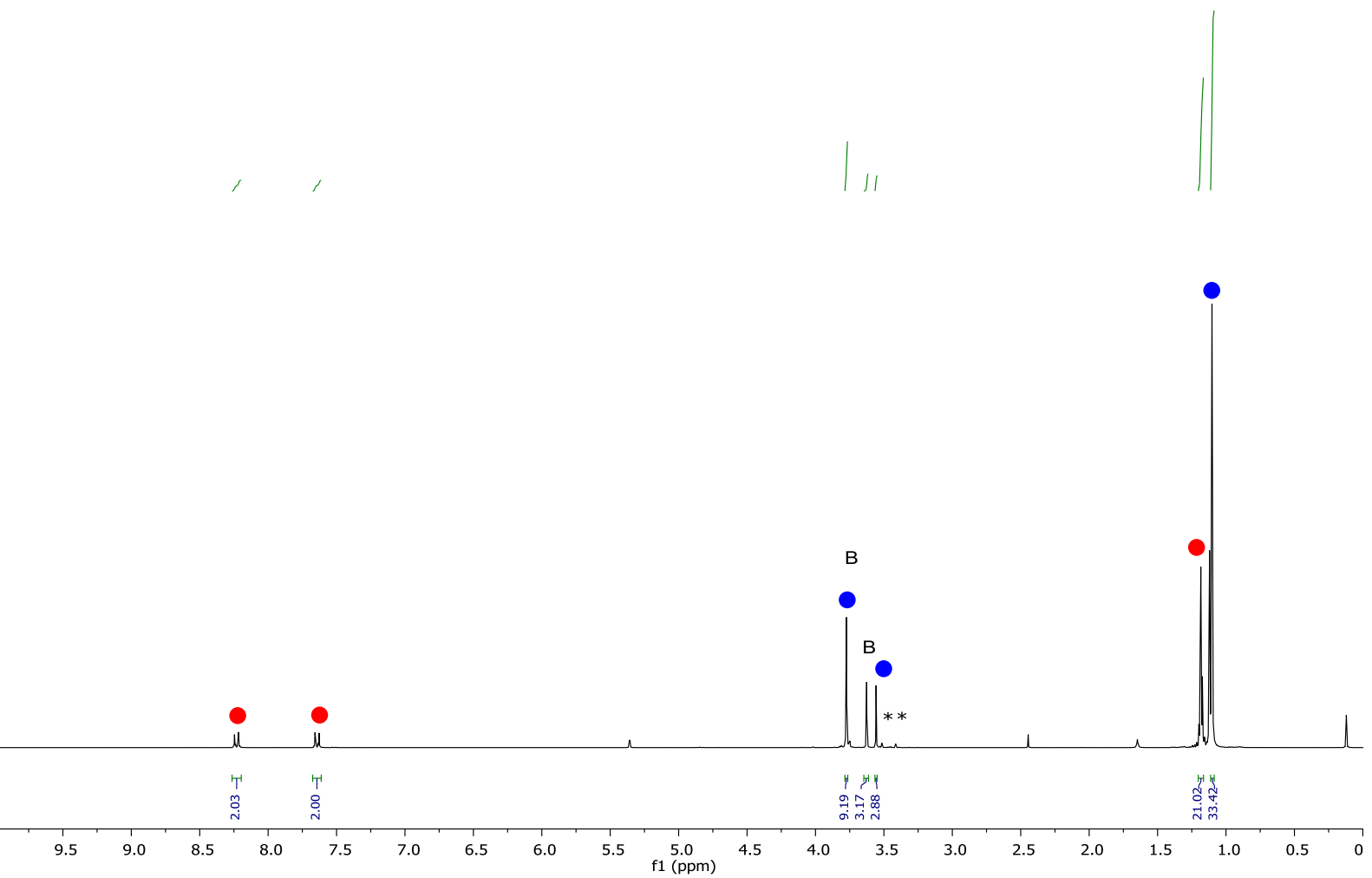

Figure $35{ }^{1} \mathrm{H}$ NMR spectrum of the reaction mixture obtained from dibenzothiophenium-salt 152d and equimolar mixture of thiols $\mathbf{3 1 6}$ and $\mathbf{3 1 7}$. 
In several cases, the new reagents $\mathbf{2 3 8}$ demonstrate a reactivity which differs from those of the hypervalent iodine compounds. For example, the reagent $\mathbf{2 3 8 f}$ allows functionalization of naphthalimide 319, which, to the best of our knowledge, was not achieved applying the commercially available TIPS-EBX 152d. In our hands, when the reaction of reagent 152d with the naphthalimide 319 was performed under the developed reaction conditions, only the unreacted naphthalimide 319 was re-isolated from the reaction mixture, whereas $60 \%$ of the desired product $\mathbf{2 9 1}$ was isolated upon employment of the reagent $\mathbf{2 3 8 f}$ (Scheme 53).<smiles>O=C1NC(=O)c2cccc3cccc1c23</smiles>

319 reagent, $\mathrm{Cs}_{2} \mathrm{CO}_{3}$ $\mathrm{DCM}, \mathrm{rt}, 12 \mathrm{~h}$<smiles>CCN1C(=O)c2cccc3cccc(c23)C1=O</smiles>

291

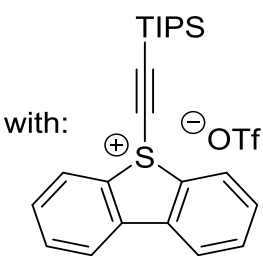

$60 \%$<smiles>CC(C)SC#CI1OC(=O)c2ccccc21</smiles>

$0 \%$

Scheme 53 Reaction of naphthalimide $\mathbf{3 1 9}$ with the newly developed dibenzothiophene reagent $\mathbf{2 3 8 f}$, as compared to the commercially available TIPS-EBX reagent 152d. 


\subsubsection{Investigations towards mechanistic rationalization of the transfer reaction}

Experiments with ${ }^{13} \mathrm{C}$-labeled substrates were performed addressing further investigations on the mechanism of the transfer reaction. Basing on the results of former investigations by Waser et al,. ${ }^{104}$ we suggest that the reagent 238a and 238 could react in different ways, as compared to the corresponding hypervalent iodine reagents. Therefore, labeled equivalents of reagent 238a (Scheme 54) and reagent $\mathbf{2 3 8 f}$ were synthesized. Initially, the ${ }^{13} \mathrm{C}$-labeled alkyne $\mathbf{3 2 2}$ was prepared over two steps using a Corey-Fuchs reaction according to a protocol by Yoshikai et al.. ${ }^{132}$ In the first step, ${ }^{13} \mathrm{C}$ labeled benzaldehyde $\mathbf{3 2 0}$ was treated with tetrabromomethane and triphenylphosphine to synthesize the dibromide $\mathbf{3 2 1}$ in a yield of $91 \%$. Subsequently, the alkyne $\mathbf{3 2 2}$ was obtained by treatment of the dibromide 321 with $n \mathrm{BuLi}$ followed by the addition of trimethylsilyl chloride in $93 \%$ yield. Finally, the desired labeled compound 238a* was received by the activation of the sulfoxide $\mathbf{2 3 7}$ with triflic anhydride and subsequent nucleophilic substitution with the alkyne 322 (63\% overall yield).

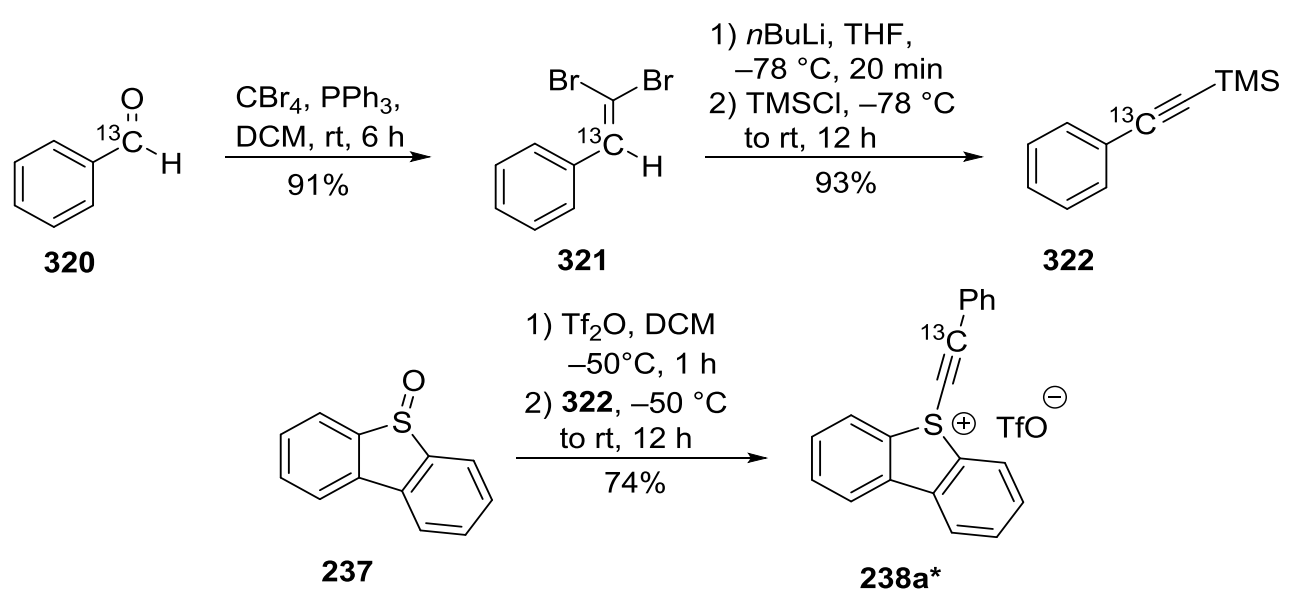

Scheme 54 Synthesis of the labeled reagent $238 a^{*}$.

In addition, the labeled reagent $238 f^{*}$ was synthesized according to a protocol by Waser et al. (Scheme 55). ${ }^{160}$ First, ethylene glycol was protected with a $p$-methoxybenzyl group in a yield of $85 \%$. The resulting alcohol $\mathbf{3 2 4}$ was oxidized by Dess-Martin periodinane to the corresponding aldehyde $\mathbf{3 2 5}$ in $97 \%$ yield. The latter was converted to the alkyne $\mathbf{3 2 7}$ by a Corey-Fuchs reaction: the dibromide $\mathbf{3 2 6}$ was synthesized in a yield of 55\% with labeled tetrabromomethane and triphenylphosphine. Afterwards, alkyne $\mathbf{3 2 7}$ was obtained in a yield of $87 \%$ by treatment of $\mathbf{3 2 6}$ with $n \mathrm{BuLi}$ and subsequent quenching the reaction with TIPS chloride. The $p$-methoxybenzyl group in $\mathbf{3 2 7}$ was first oxidatively deprotected with DDQ, and the resulting propagylic alcohol was cleaved using manganese dioxide to obtain the unprotected alkyne $\mathbf{3 2 8}$ in a total yield of $77 \%$ over two steps. The terminal alkyne $\mathbf{3 2 8}$ was protected with TMS chloride (66\% yield). Finally, the sulfoxide $\mathbf{2 3 7}$ was activated by triflic anhydride, and the desired labeled transfer reagent $\mathbf{2 3 8} *$ was synthesized in the reaction with the labeled alkyne $\mathbf{3 2 9}$ in a yield of $85 \%$. 

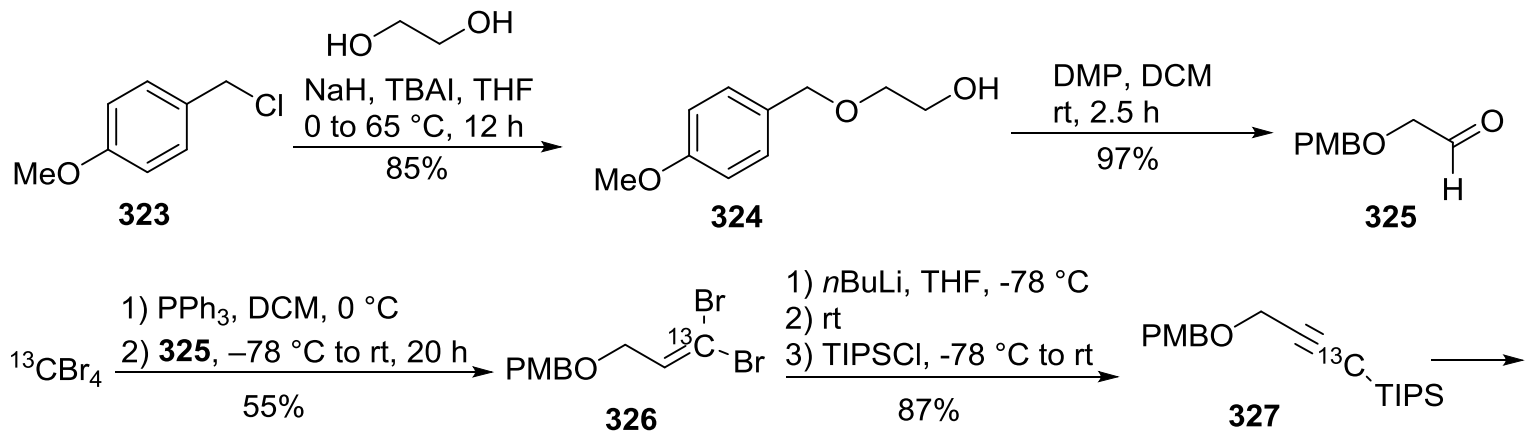

1) $\mathrm{DDQ}, \mathrm{DCM}, \mathrm{H}_{2} \mathrm{O}$

$\underset{77 \%}{\stackrel{\mathrm{MnO}_{2}, \mathrm{KOH}, \mathrm{Et}_{2} \mathrm{O}}{\longrightarrow}}$<smiles></smiles>

328

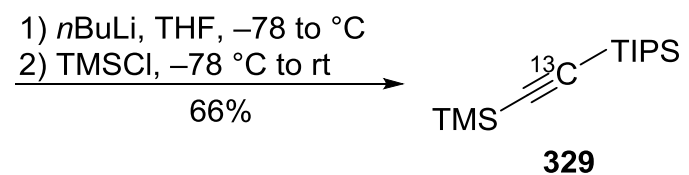<smiles>O=S1c2ccccc2-c2ccccc21</smiles>

237

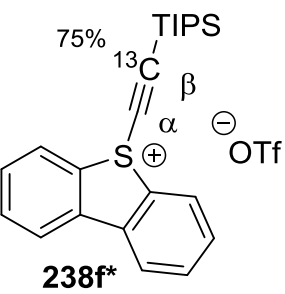

$238 f^{*}$

Scheme 55 Synthesis of the labeled TIPS-substituted dibenzothiophenium reagent 238**.

Unexpectedly, an isotopic scrambling was observed in the final step of the synthesis of the reagent 238f*. An enrichment of $75 \%$ was obtained for the desired position instead of the expected ratio of 20:1. To our delight, after completion of the reaction, the isotopic ratio did not changed anymore, as was proven in NMR experiments over 3 days (Experimental part 5.7). Furthermore, the consistency of this result was proven by a second synthesis attempt. Consequently, this observation must have a mechanistic reason. Our suggestion is that it could be a direct result of the direction in which the alkyne attacks the reactive intermediate $\mathbf{3 3 0}$ (Scheme 56). Accordingly to this, both $\boldsymbol{\alpha}$ and $\boldsymbol{\beta}$ carbon atoms of the alkyne $\mathbf{3 2 9}$ (in respect to the TIPS moiety) possess similar reactivity and can attack the sulfonium salt 330. After initial attack with the carbon atom in $\boldsymbol{\beta}$-position, the carbenium ion 331a would be formed, which would undergo an elimination to form the product $238 f^{*} \boldsymbol{\beta}$. Alternatively, if sulfonium intermediate is attacked by the carbon atom in $\boldsymbol{\alpha}$-position, the resulting carbenium ion $\mathbf{3 3 1 b}$ would undergo an elimination to form the terminal carbene 332. Afterwards, the isomer 238f* $\alpha$ would be obtained by a 1,2-migration. However, an attack of $\alpha$ carbon atom should be less favored because of the bigger steric bulk of the TIPS group, what explains the observed isotopic distribution. 
Route of the formation of the main product $238 f^{*} \beta$

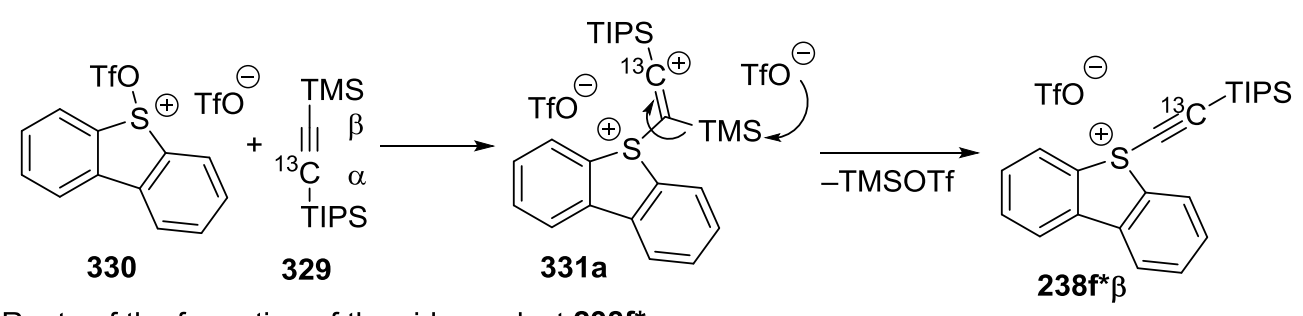

Route of the formation of the side product $238 f^{*} \alpha$
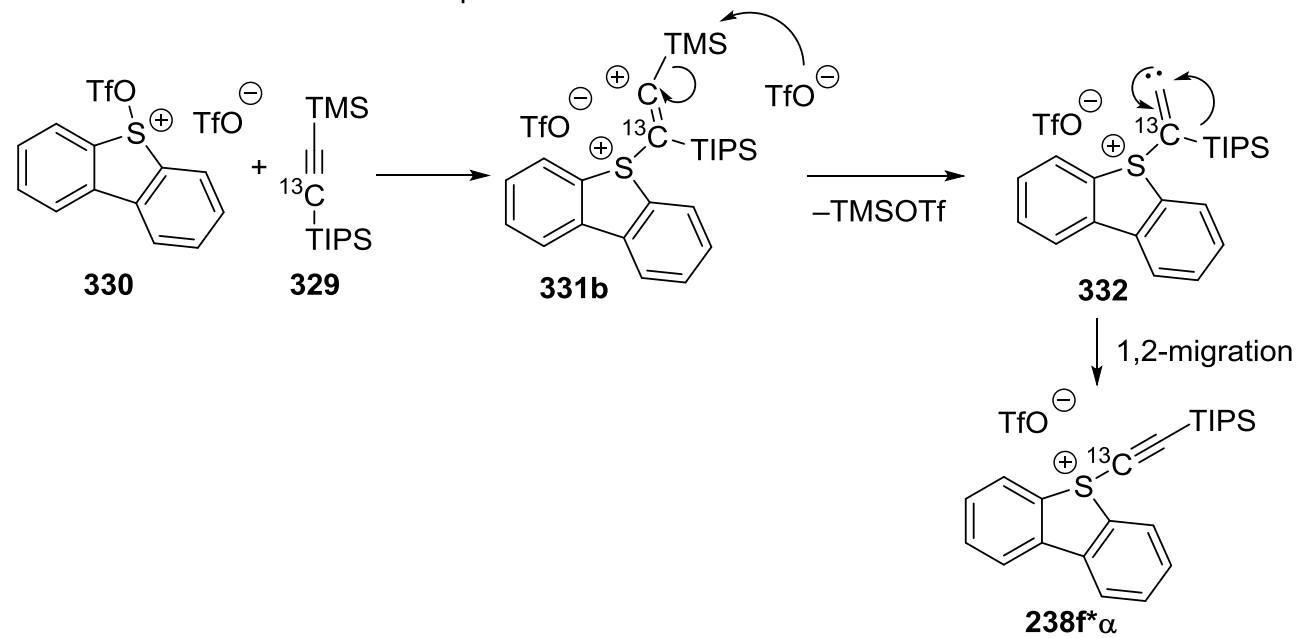

Scheme 56 Proposed mechanism of the formation of unexpected label distribution in TIPS-substituted dibenzothiophenium reagent $238 f^{*}$.

Reactions of the labeled reagents 238a* and 238f* with different nucleophiles were performed (Figure 36 and Scheme 57). The product $\mathbf{2 5 6}^{*}$ was obtained from the reaction of (4methoxyphenyl)methanethiol with 238a*. This could be a result of a direct attack of the alkyne to the $\boldsymbol{\alpha}$-position of the reagent, followed by an elimination of dibenzothiophene moiety (pathway $\mathbf{A}$ ). Another possibility would be a $\boldsymbol{\beta}$-attack of the thiol with a subsequent 1,2-migration of the thiogroup ( $c f$. Scheme 57, pathway B). The compound 286* with alternative label distribution was exclusively obtained for the reaction with $N$-tosylanilide and reagent $238 a^{*}$. A plausible explanation would be a $\boldsymbol{\beta}$ attack of the amide to the transfer reagent and concomitant 1,2-migration of a phenyl group. In case of the product $232^{*}$, the $\boldsymbol{\alpha}$ - and $\boldsymbol{\beta}$-position in the corresponding product were equally labeled. An explanation could be a $\boldsymbol{\beta}$-attack on the transfer-reagent with subsequent 1,2-migration. Both substituents should be able to undergo the following 1,2-migration with a similar probability because of the very similar migratory aptitudes for tert-butyl and phenyl groups. Nevertheless, the possibility of an $\boldsymbol{\alpha}$-attack of the nucleophile towards the reagent cannot be completely excluded. 


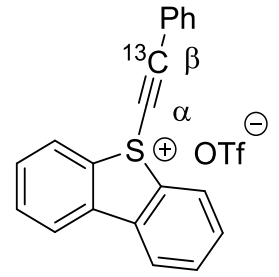

$238 a^{*}$<smiles>COc1ccc(CSC#C[As]c2ccccc2)cc1</smiles>

$256^{*}$<smiles>COC(=O)C1(C#Cc2ccccc2)Cc2ccccc2C1=O</smiles>

232*<smiles>Cc1ccc(S(=O)(=O)N(C#CPc2ccccc2)c2ccccc2)cc1</smiles>

286*

Figure 36 Results of the alkynylations experiments with labeled compound 238a*.
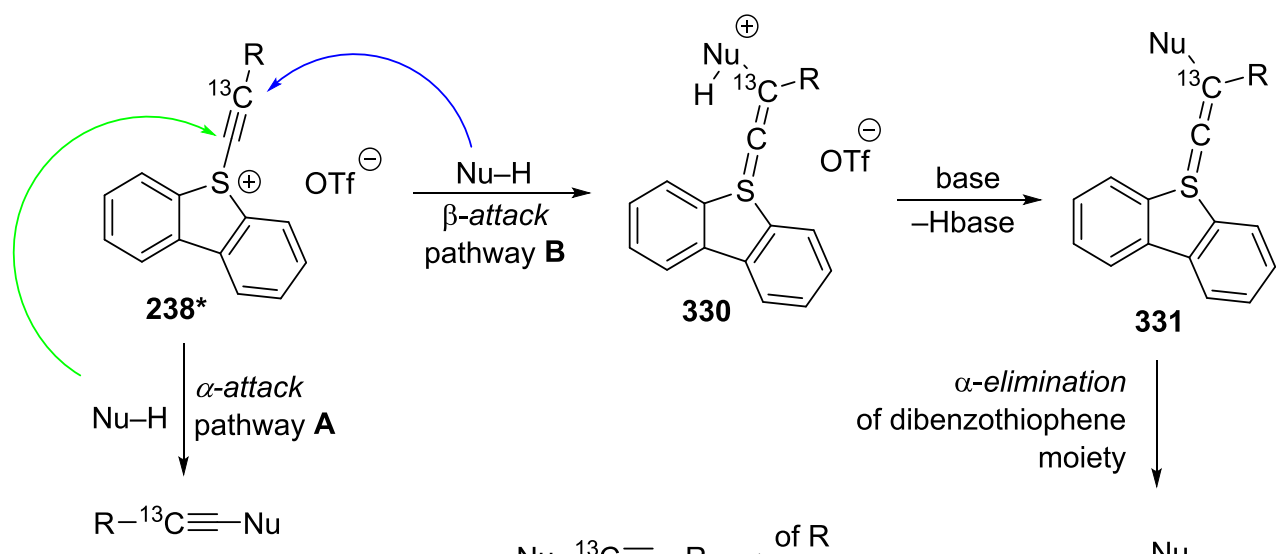

$$
\begin{array}{r}
\alpha \text {-elimination } \\
\text { of dibenzothiophene } \\
\text { moiety }
\end{array}
$$

$$
\mathrm{Ru}-{ }^{13} \mathrm{C} \equiv \mathrm{R} \stackrel{\text { of } \mathrm{R}}{\text { of } \mathrm{Nu}} \overbrace{332}^{1,2-\text { migration }}:{ }^{13} \mathrm{C}_{\mathrm{R}}^{\mathrm{Nu}}
$$

Scheme 57 Proposed mechanism for the transfer reaction.

However, no ${ }^{13} \mathrm{C}$ scrambling was observed for the reactions with the reagent 238f*: solely the compounds 255*, 273* and 281* were selectively obtained (Figure 37). Most likely, the steric bulk of the TIPS group favors a direct $\boldsymbol{\alpha}$-attack of the nucleophiles, thus resulting in the formation of the observed products.

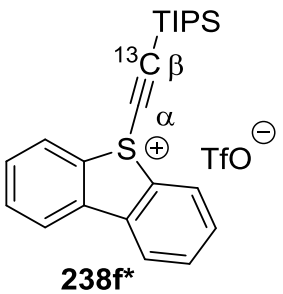

$238 f^{*}$

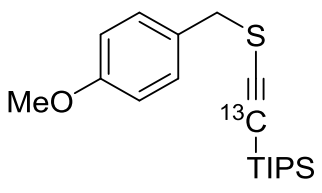

255*

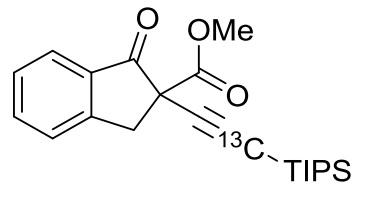

273*<smiles>Cc1ccc(S(=O)(=O)N(C#C[Al]C(=O)[O-])c2ccccc2)cc1</smiles>

281*

Figure 37 Results of the experiments with labeled compound 238f*.

Calculations regarding the mechanism are conducted in collaboration with Dr. R. Mata, which are currently ongoing. These will give a better understanding and a deeper insight towards the mechanism of the transfer reaction. 


\subsubsection{Investigation towards metal-catalyzed reactions}

\subsubsection{Investigations towards reactions with metal-based Lewis acids}

As reported by Waser et al., ${ }^{133}$ indoles can be functionalized with alkynes applying gold- and silverbased metal catalysts. Normally, these catalysts enhance the reactivity of the alkyne reagent towards the attack of nucleophiles by coordination of the reagents as Lewis acids. Hence, newly prepared transfer reagents $\mathbf{2 3 8}$ were tested in the alkynylation of indoles in the presence of metal-based Lewis acids. Unexpectedly, no reactivity was observed for the functionalization of the 3-position in indoles. Instead, the indole $\mathbf{3 3 7}$ was selectively obtained (Scheme 58).

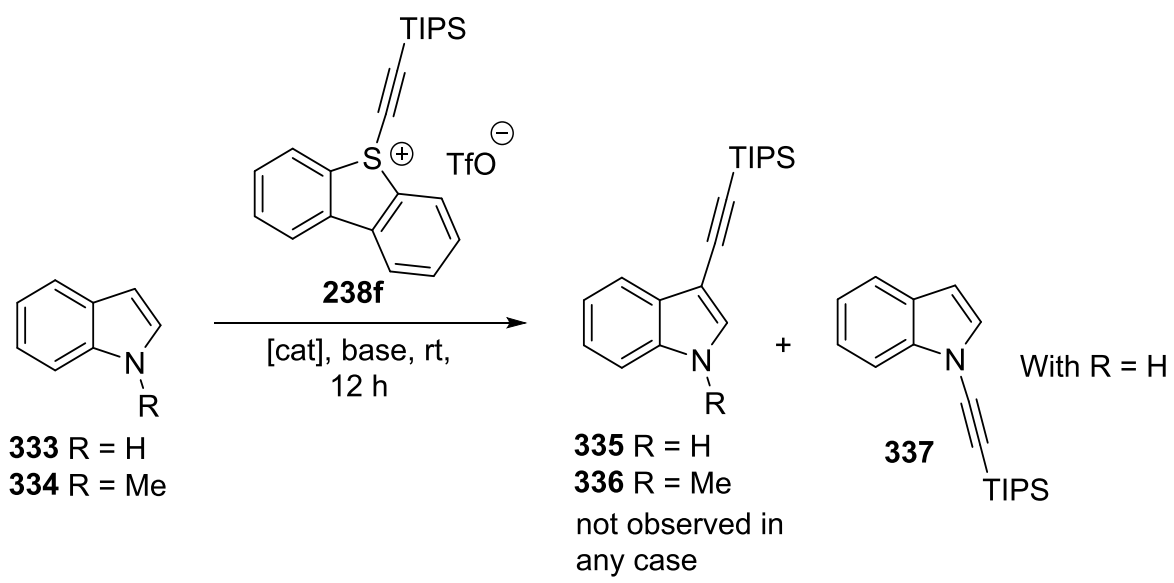

Scheme 58 Attempted metal-catalyzed functionalization of indoles with the salt $\mathbf{2 3 8 f}$.

First, chloro(triphenylphosphine)gold(I) and silver hexafluoroantimonate(V) were tested as catalysts in presence of different bases. $N$-Functionalized indole $\mathbf{3 3 7}$ was obtained from indole (333) in $38 \%$ yield with cesium carbonate as base and DCM as solvent (Table 5, entry 1). On the contrary, only the unreacted indole $\mathbf{3 3 3}$ was obtained using stronger bases such as potassium phosphate, tetrabutylammonium acetate or potassium acetate (entries 2-4). This result could originate from the fast decomposition of the reagent in the presence of these bases. The yield of product $\mathbf{3 3 7}$ decreased to $23 \%$ at an elevated temperature of $60{ }^{\circ} \mathrm{C}$ (entry 5), probably because of limited thermal stability of the reagent. Furthermore, only the unreacted starting material was re-isolated, if $N$-methylindole $\mathbf{3 3 4}$ was used instead of indole (333) (entry 6). A slightly reduced yield (23-25\%) of the $N$-alkynylated product 337 was observed via the addition of silver chloride (entries 7-9), whereas varying of the solvent had no significant influence on the isolated yield, unlike the absence of a base (entry 10). If platinum(II) chloride was used as a catalyst, neither utilizing bases like $N, N$-diisopropylethylamine or cesium carbonate (entries 11 and 12), nor running the reaction at higher temperatures without addition of base (entry 13) led to any product formation. No product formation was observed with gold(III) chloride as well (entry 14). A final control experiment showed that the reaction proceeds even without additional Lewis acid in a yield of $30 \%$ (entry 16). The low yields of indole $\mathbf{3 3 3}$ can be attributed to its reduced stability as well as partial decomposition during the purification process. 
Table 5 Screening of conditions for the alkynylation of indoles 333,334 with the dibenzothiophenium salt $238 f$.

\begin{tabular}{|c|c|c|c|c|c|c|}
\hline Entry & Catalyst & Additive & Base & Solvent & Yield (\%) & Comments \\
\hline 1 & $\mathrm{AuClPPh}_{3}$ & $\mathrm{AgSbF}_{6}$ & $\mathrm{Cs}_{2} \mathrm{CO}_{3}$ & DCM & 38 & $N$-alkynylated product $\mathbf{3 3 7}$ \\
\hline 2 & $\mathrm{AuClPPh}_{3}$ & $\mathrm{AgSbF}_{6}$ & $\mathrm{~K}_{3} \mathrm{PO}_{4}$ & DCM & 0 & Isolated starting material $\mathbf{3 3 3}$ \\
\hline 3 & $\mathrm{AuClPPh}_{3}$ & $\mathrm{AgSbF}_{6}$ & TBAOAC & DCM & 0 & Isolated starting material $\mathbf{3 3 3}$ \\
\hline 4 & $\mathrm{AuClPPh}_{3}$ & $\mathrm{AgSbF}_{6}$ & KOAC & $\mathrm{DCM}$ & 0 & Isolated starting material $\mathbf{3 3 3}$ \\
\hline 5 & $\mathrm{AuClPPh}_{3}$ & $\mathrm{AgSbF}_{6}$ & $\mathrm{Cs}_{2} \mathrm{CO}_{3}$ & DCE & 23 & Reaction at $60^{\circ} \mathrm{C}$ \\
\hline 6 & $\mathrm{AuClPPh}_{3}$ & $\mathrm{AgSbF}_{6}$ & $\mathrm{Cs}_{2} \mathrm{CO}_{3}$ & DCM & 0 & $\begin{array}{l}N \text {-Methylindole } \mathbf{3 3 4} \text { as a } \\
\text { substrate; re-isolated }\end{array}$ \\
\hline 7 & $\mathrm{AgCl}$ & - & $\mathrm{Cs}_{2} \mathrm{CO}_{3}$ & DCM & 23 & $N$-alkynylated product 337 \\
\hline 8 & $\mathrm{AgCl}$ & - & $\mathrm{Cs}_{2} \mathrm{CO}_{3}$ & $\mathrm{Et}_{2} \mathrm{O}$ & 25 & $N$-alkynylated product 337 \\
\hline 9 & $\mathrm{AgCl}$ & - & $\mathrm{K}_{2} \mathrm{CO}_{3}$ & THF & 23 & $N$-alkynylated product 337 \\
\hline 10 & $\mathrm{AgCl}$ & - & - & DCM & 0 & Isolated starting material $\mathbf{3 3 3}$ \\
\hline 11 & $\mathrm{PtCl}_{2}$ & - & $\mathrm{Cs}_{2} \mathrm{CO}_{3}$ & $\mathrm{DCM}$ & 0 & No reaction \\
\hline 12 & $\mathrm{PtCl}_{2}$ & - & DIPEA & $\mathrm{DCM}$ & 0 & $\begin{array}{l}\text { Reaction at } 60^{\circ} \mathrm{C} \text {, Isolated } \\
\text { starting material } \mathbf{3 3 3}\end{array}$ \\
\hline 13 & $\mathrm{PtCl}_{2}$ & - & - & DCE & 0 & $\begin{array}{l}\text { Reaction at } 80{ }^{\circ} \mathrm{C} \text {, Isolated } \\
\text { starting material } \mathbf{3 3 3}\end{array}$ \\
\hline 14 & $\mathrm{AuCl}_{3}$ & - & $\mathrm{Cs}_{2} \mathrm{CO}_{3}$ & DCM & 0 & No reaction \\
\hline 15 & $\mathrm{AuCl}_{3}$ & - & - & DCM & 0 & $N$-Methylindole as a substrate \\
\hline 16 & - & - & $\mathrm{Cs}_{2} \mathrm{CO}_{3}$ & $\mathrm{DCM}$ & 30 & + Isolated starting material $\mathbf{3 3 3}$ \\
\hline
\end{tabular}

Summarizing the results discussed above, it can be concluded that the utilization of a Lewis acid only slightly influences the formation of $\mathrm{N}$-alkynylated product 337 in this reaction, whereas the $\mathrm{C}-\mathrm{H}$ bond alkynylation of indoles with the reagent $\mathbf{2 3 8 f}$ was not detected. 


\subsubsection{Investigations towards directing group based $\mathrm{C}-\mathrm{H}$-alkynylation with metal catalysts}

The TIPS-EBX reagent $\mathbf{1 5 2 d}$ is reported to be applied in rhodium- or iridium-catalyzed $\mathrm{C}-\mathrm{H}$ alkynylation of 2-phenylpyridine (338). ${ }^{134}$ In this regard, commercially available catalysts and additives were examined in the reaction with the reagent $\mathbf{2 3 8 f}$ (Scheme 59).

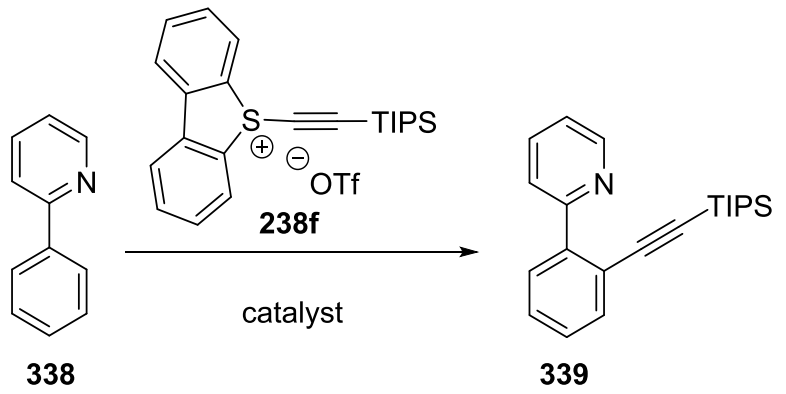

Scheme 59 Attempted metal-catalyzed C-H alkynylations of 2-phenylpyridine (338).

Only traces of the desired product $\mathbf{3 3 9}$ were detected in alkynylations utilizing $\left[\mathrm{RhCp} * \mathrm{Cl}_{2}\right]_{2}$, silver hexafluoroantimonate(V) or zinc triflate as a catalyst (Table 6, entries 1 and 2). An increase in temperature (entries 3 and 4 ) to $80{ }^{\circ} \mathrm{C}$ resulted in formation of the desired product in up to $34 \%$ yield. No formation of the product was observed with $\left[\mathrm{IrCp}^{*} \mathrm{Cl}_{2}\right]_{2}$ and silver hexafluoroantimonate(V) (entry 5). With acetonitrile as a solvent (entry 6), $4 \%$ of the product was isolated. Traces of the product were obtained when $\operatorname{MnBr}(\mathrm{CO})_{5}$ and dicyclohexylamine (entry 7) were used as a catalytic system. ${ }^{135}$ Variation of the dilution or equivalents of the catalyst components (entries 8-12) did not lead to an increase of the product yield. From the results of the mass spectrometric analysis it can be concluded that a large amount of the starting material $\mathbf{3 3 8}$ in the reaction under investigation was acting as a base. Therefore, an external base would be necessary to achieve complete conversion. 
Table 6 Screening of the conditions for C-H alkynylation of 2-phenylpyridine (338) with the reagent $\mathbf{2 3 8 f}$.

\begin{tabular}{|c|c|c|c|c|c|}
\hline Entry & Catalyst & Additive & Solvent & $\mathbf{T}\left({ }^{\circ} \mathbf{C}\right)$ & Yield (\%) \\
\hline 1 & $\begin{array}{l}{\left[\mathrm{RhCp}^{*} \mathrm{Cl}_{2}\right]_{2}} \\
(2 \%)\end{array}$ & $\mathrm{AgSbF}_{6}(10 \%)$ & DCM & $\mathrm{rt}$ & Traces of the product $\mathbf{3 3 9}$ \\
\hline 2 & $\begin{array}{l}{\left[\mathrm{RhCp}^{*} \mathrm{Cl}_{2}\right]_{2}} \\
(2 \%)\end{array}$ & $\mathrm{Zn}(\mathrm{OTf})_{2}(10 \%)$ & DCE & $\mathrm{rt}$ & $\begin{array}{l}\mathrm{SM}^{*}+\text { traces of the product } \\
\mathbf{3 3 9}\end{array}$ \\
\hline 3 & $\begin{array}{l}{\left[\mathrm{RhCp} * \mathrm{Cl}_{2}\right]_{2}} \\
(2 \%)\end{array}$ & $\mathrm{AgSbF}_{6}(10 \%)$ & DCE & 80 & 34 \\
\hline 4 & $\begin{array}{l}{\left[\mathrm{RhCp} * \mathrm{Cl}_{2}\right]_{2}} \\
(2 \%)\end{array}$ & $\mathrm{Zn}(\mathrm{OTf})_{2}(10 \%)$ & DCE & 80 & 32 \\
\hline 5 & $\begin{array}{l}{\left[\mathrm{IrCp} * \mathrm{Cl}_{2}\right]_{2}} \\
(4 \%)\end{array}$ & $\mathrm{AgSbF}_{6}(10 \%)$ & DCM & $\mathrm{rt}$ & $0(\mathrm{SM})$ \\
\hline 6 & $\begin{array}{l}{\left[\mathrm{RhCp} * \mathrm{Cl}_{2}\right]_{2}} \\
(2 \%)\end{array}$ & $\operatorname{AgSbF}_{6}(10 \%)$ & $\mathrm{MeCN}$ & 80 & 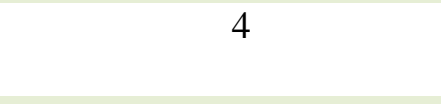 \\
\hline 7 & $\mathrm{MnBr}(\mathrm{CO})_{5}$ & $\mathrm{HNCy}_{2}(20 \%)$ & DCE & 80 & Traces of the product $\mathbf{3 3 9}$ \\
\hline 8 & $\begin{array}{l}{\left[\mathrm{RhCp}^{*} \mathrm{Cl}_{2}\right]_{2}} \\
(4 \%)\end{array}$ & $\mathrm{AgSbF}_{6}(10 \%)$ & DCE & 80 & Mixture of SM and product \\
\hline 9 & $\begin{array}{l}{\left[\mathrm{RhCp}^{*} \mathrm{Cl}_{2}\right]_{2}} \\
(2 \%)\end{array}$ & $\mathrm{AgSbF}_{6}(10 \%)$ & $\begin{array}{l}\text { DCE (twice } \\
\text { diluted) }\end{array}$ & 80 & 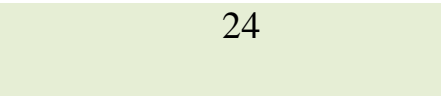 \\
\hline 10 & $\begin{array}{l}{\left[\mathrm{RhCp} * \mathrm{Cl}_{2}\right]_{2}} \\
(2 \%)\end{array}$ & $\operatorname{AgSbF}_{6}(20 \%)$ & DCE & 80 & Mixture of SM and product \\
\hline 11 & $\begin{array}{l}{\left[\mathrm{RhCp}^{*} \mathrm{Cl}_{2}\right]_{2}} \\
(8 \%)\end{array}$ & $\mathrm{AgSbF}_{6}(10 \%)$ & DCE & 80 & Mixture of SM and product \\
\hline 12 & $\begin{array}{l}{\left[\mathrm{RhCp} * \mathrm{Cl}_{2}\right]_{2}} \\
(4 \%)\end{array}$ & $\mathrm{AgSbF}_{6}(5 \%)$ & DCE & 80 & Mixture of SM and product \\
\hline
\end{tabular}

Consequently, the effect of different bases on the reaction was investigated (Table 7). The reaction was performed in DCM at ambient temperature or in DCE at $80^{\circ} \mathrm{C}$. By using rhodium and iridium catalysts in combination with cesium carbonate, only starting material $\mathbf{3 3 8}$ or traces of the product $\mathbf{3 3 9}$ were observed (entries 1-3). The same result was obtained when tetrabutylammonium acetate was used (entry 4). Furthermore, a complete decomposition of the starting material was observed with cesium pivalate as a base (entry 5). Similarly, only starting material $\mathbf{3 3 8}$ was isolated when potassium phosphate or water were used (entries 6 and 7). No conversion was observed by utilizing potassium pyrophosphate (entry 8). The same result was obtained from the reaction with pyridine or 2,6-lutidine (entries 9 and 10), whereas employment of 2,6-di-tert-butylpyridine led to formation of the desired product in $4 \%$ yield (entry 11). Variation of the temperature or the equivalents of the base resulted in solely traces of product (entries 12 and 13). The same holds true for the reaction catalyzed by bromopentacarbonylmanganese(I) in the presence of stoichiometric quantity of dicyclohexylamine (entry 14). Strong bases like DMAP or DIPEA (entries 15 and 16) led to traces of the desired product 339 as well. Starting material was re-isolated for the utilization of 1,8 -bis $(N, N-$ dimethylamino)naphthaline (proton sponge, entry 17). At last, DBU (entry 18) completely decomposed the alkynylating agent $\mathbf{2 3 8 f}$. 
Table 7 Screening of conditions for the C-H alkynylation of 2-phenylpyridine (338) with the reagent $\mathbf{2 3 8 f}$ in the presence of an additional base.

\begin{tabular}{|c|c|c|c|c|c|c|}
\hline Entry & Catalyst & Additive & Base & Solvent & $\mathbf{T}\left({ }^{\circ} \mathbf{C}\right)$ & $\begin{array}{l}\text { Yield }(\%) / \\
\text { Comment }\end{array}$ \\
\hline 1 & $\begin{array}{l}{\left[\mathrm{RhCp} * \mathrm{Cl}_{2}\right]_{2}} \\
(2 \%)\end{array}$ & $\mathrm{AgSbF}_{6}(10 \%)$ & $\mathrm{Cs}_{2} \mathrm{CO}_{3}$ & DCM & $\mathrm{rt}$ & $0\left(\mathrm{SM}^{*}\right)$ \\
\hline 2 & $\begin{array}{l}{\left[\mathrm{IrCp} * \mathrm{Cl}_{2}\right]_{2}} \\
(4 \%)\end{array}$ & $\operatorname{AgSbF}_{6}(10 \%)$ & $\mathrm{Cs}_{2} \mathrm{CO}_{3}$ & DCM & $\mathrm{rt}$ & $0(\mathrm{SM})$ \\
\hline 3 & $\begin{array}{l}{\left[\mathrm{RhCp} * \mathrm{Cl}_{2}\right]_{2}} \\
(4 \%)\end{array}$ & $\operatorname{AgSbF}_{6}(5 \%)$ & $\begin{array}{l}\mathrm{Cs}_{2} \mathrm{CO}_{3}(2.00 \\
\text { equiv.) }\end{array}$ & DCE & 80 & $\begin{array}{l}\text { Traces of the } \\
\text { product } \mathbf{3 3 9}\end{array}$ \\
\hline 4 & $\begin{array}{l}{\left[\mathrm{RhCp} * \mathrm{Cl}_{2}\right]_{2}} \\
(2 \%)\end{array}$ & $\mathrm{AgSbF}_{6}(10 \%)$ & TBAOAc & DCM & $\mathrm{rt}$ & $0(\mathrm{SM})$ \\
\hline 5 & $\begin{array}{l}{\left[\mathrm{RhCp} * \mathrm{Cl}_{2}\right]_{2}} \\
(2 \%)\end{array}$ & $\operatorname{AgSbF}_{6}(10 \%)$ & Cesium pivalate & DCE & 80 & $\begin{array}{l}\text { Decomposition } \\
\text { of } \mathbf{2 3 8 f}\end{array}$ \\
\hline 6 & $\begin{array}{l}{\left[\mathrm{RhCp} * \mathrm{Cl}_{2}\right]_{2}} \\
(2 \%)\end{array}$ & $\mathrm{AgSbF}_{6}(10 \%)$ & $\mathrm{K}_{3} \mathrm{PO}_{4}$ & DCE & $\mathrm{rt}$ & $\begin{array}{l}\text { Traces of the } \\
\text { product } 339\end{array}$ \\
\hline 7 & $\begin{array}{l}{\left[\mathrm{RhCp} * \mathrm{Cl}_{2}\right]_{2}} \\
(2 \%)\end{array}$ & $\mathrm{AgSbF}_{6}(10 \%)$ & $\mathrm{H}_{2} \mathrm{O}$ & DCE & 80 & $\begin{array}{l}\text { Traces of the } \\
\text { product } \mathbf{3 3 9}\end{array}$ \\
\hline 8 & $\begin{array}{l}{\left[\mathrm{RhCp} * \mathrm{Cl}_{2}\right]_{2}} \\
(2 \%)\end{array}$ & $\mathrm{AgSbF}_{6}(10 \%)$ & $\mathrm{K}_{4} \mathrm{P}_{2} \mathrm{O}_{7}$ & DCE & $\mathrm{rt}$ & SM \\
\hline 9 & $\begin{array}{l}{\left[\mathrm{RhCp} * \mathrm{Cl}_{2}\right]_{2}} \\
(2 \%)\end{array}$ & $\mathrm{AgSbF}_{6}(10 \%)$ & Pyridine & DCE & 80 & SM \\
\hline 10 & $\begin{array}{l}{\left[\mathrm{RhCp} * \mathrm{Cl}_{2}\right]_{2}} \\
(2 \%)\end{array}$ & $\mathrm{AgSbF}_{6}(10 \%)$ & Lutidine & DCE & 80 & SM \\
\hline 11 & $\begin{array}{l}{\left[\mathrm{RhCp} * \mathrm{Cl}_{2}\right]_{2}} \\
(2 \%)\end{array}$ & $\mathrm{AgSbF}_{6}(10 \%)$ & $\begin{array}{l}\text { 2,6-Di-tert- } \\
\text { butylpyridine }\end{array}$ & DCE & 80 & Product $339(4 \%)$ \\
\hline 12 & $\begin{array}{l}{\left[\mathrm{RhCp} * \mathrm{Cl}_{2}\right]_{2}} \\
(2 \%)\end{array}$ & $\mathrm{AgSbF}_{6}(10 \%)$ & $\begin{array}{l}\text { 2,6-Di-tert- } \\
\text { butylpyridine }\end{array}$ & DCE & $\mathrm{rt}$ & $\begin{array}{l}\text { Traces of the } \\
\text { product } \mathbf{3 3 9}\end{array}$ \\
\hline 13 & $\begin{array}{l}{\left[\mathrm{RhCp} * \mathrm{Cl}_{2}\right]_{2}} \\
(2 \%)\end{array}$ & $\mathrm{AgSbF}_{6}(10 \%)$ & $\begin{array}{l}2,6 \text {-Di-tert- } \\
\text { butylpyridine } \\
(0.50 \mathrm{eq})\end{array}$ & DCE & $\mathrm{rt}$ & $\begin{array}{l}\text { Traces of the } \\
\text { product } \mathbf{3 3 9}\end{array}$ \\
\hline 14 & $\mathrm{MnBr}(\mathrm{CO})_{5}$ & & $\mathrm{HNCy}_{2}$ & DCE & 80 & $\begin{array}{l}\text { Traces of the } \\
\text { product } \mathbf{3 3 9}\end{array}$ \\
\hline 15 & $\begin{array}{l}{\left[\mathrm{RhCp} * \mathrm{Cl}_{2}\right]_{2}} \\
(2 \%)\end{array}$ & $\mathrm{AgSbF}_{6}(10 \%)$ & DMAP & DCE & 80 & $\begin{array}{l}\text { Traces of the } \\
\text { product } 339\end{array}$ \\
\hline 16 & $\begin{array}{l}{\left[\mathrm{RhCp} * \mathrm{Cl}_{2}\right]_{2}} \\
(2 \%)\end{array}$ & $\operatorname{AgSbF}_{6}(10 \%)$ & DIPEA & DCE & 80 & $\begin{array}{l}\text { Traces of the } \\
\text { product } \mathbf{3 3 9}\end{array}$ \\
\hline 17 & $\begin{array}{l}{\left[\mathrm{RhCp} * \mathrm{Cl}_{2}\right]_{2}} \\
(2 \%)\end{array}$ & $\operatorname{AgSbF}_{6}(10 \%)$ & Proton sponge & DCE & $\mathrm{rt}$ & $0(\mathrm{SM})$ \\
\hline 18 & $\begin{array}{l}{\left[\mathrm{RhCp}^{*} \mathrm{Cl}_{2}\right]_{2}} \\
(2 \%)\end{array}$ & $\mathrm{AgSbF}_{6}(10 \%)$ & DBU & DCE & 80 & $\begin{array}{l}\text { Decomposition } \\
\text { of } \mathbf{2 3 8 f}\end{array}$ \\
\hline
\end{tabular}

*SM = Starting material 338.

In summary, the application of an additionally base did not improve the product yield. The problem seems to be the low stability of the reagent $\mathbf{2 3 8 f}$ in the presence of different bases. Correspondingly, the decomposition caused by a base is faster than the desired transfer towards the phenylpyridine (338). Presumably, an internal base such as in EBX-systems might help to improve the efficiency. 


\subsubsection{Synthesis attempts towards a system with internal base}

In analogy to EBX-reagents 152, a synthesis of a compound with an internal basic amine moiety was attempted in order to increase the stability of the reagents $\mathbf{2 3 8}$ by a chelating effect. Also it is possible that this amine acts as base in transfer reactions. An additional advantage of such a reagent would be a reduction of waste by avoiding any external base, if the compound is reusable like the dibenzothiophene system. Thus, an equivalent of the diphenylsulfide with a coordinating group in the backbone was synthesized utilizing a modified literature procedure (Scheme 60). ${ }^{136}$ Starting from the acid 340, esterification with methanol led to the corresponding ester $\mathbf{3 4 1}$ in $83 \%$ yield. Subsequently, the ester 341 was transformed into the unsymmetrical diary sulfide $\mathbf{3 4 3}$ by an Ullmann-type reaction with copper(I) oxide as catalyst (56\% yield). Then, compound 343 was converted to the corresponding amide 344 in a two-step procedure in a yield of $84 \%$. Afterwards, the amide 344 was activated by phosphorus pentachloride and reduced to the aminoalcohol $\mathbf{3 4 5}$ with lithium aluminum hydride in a yield of $58 \%$ over two steps. Finally, compound $\mathbf{3 4 5}$ was chlorinated using thionyl chloride to enable the cyclization towards the cyclic thioether $\mathbf{3 4 6}$.<smiles>O=C(O)c1ccccc1S</smiles>

340

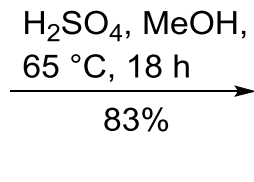

$\mathrm{H}_{2} \mathrm{SO}_{4}, \mathrm{MeOH}$,
$65^{\circ} \mathrm{C}, 18 \mathrm{~h}$
$\underset{83 \%}{\longrightarrow}$<smiles>COC(=O)c1ccccc1S</smiles>

341

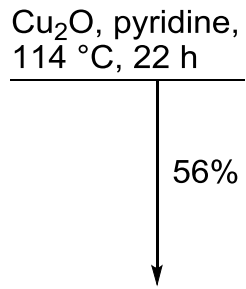<smiles>O=C(O)c1ccccc1I</smiles>

342<smiles>CNC(=O)c1ccccc1Sc1ccccc1C(=O)OC</smiles>

344

1) $\mathrm{SOCl}_{2}, 80{ }^{\circ} \mathrm{C}, 3 \mathrm{~h}$

2) $\mathrm{NEt}_{3}$, methylamine (1.2 equiv.), THF, $0{ }^{\circ} \mathrm{C}$ to rt, $12 \mathrm{~h}$ $84 \%$<smiles>COC(=O)c1ccccc1Sc1ccccc1C(=O)O</smiles>

343<smiles>CNCc1ccccc1Sc1ccccc1CO</smiles>

345<smiles>CN1Cc2ccccc2Sc2ccccc2C1</smiles>

Scheme 60 Synthesis of the cyclic aminosulfide 346. 
It is known that oxidation of the thioether $\mathbf{3 4 6}$ with $\mathrm{H}_{2} \mathrm{O}_{2}$ affords the respective sulfone, whereas reaction with $\mathrm{NaIO}_{4}$ furnishes the corresponding $N$-Oxide. ${ }^{136}$ Within our synthetic goal, the bromination of the compound $\mathbf{3 4 6}$ was investigated. Surprisingly, in the attempted reaction with bromine a complete decomposition of the starting material 346 was observed. The same results were obtained upon oxidation of $\mathbf{3 4 6}$ with $m$ CPBA or with sodium hypochlorite (Scheme 61).
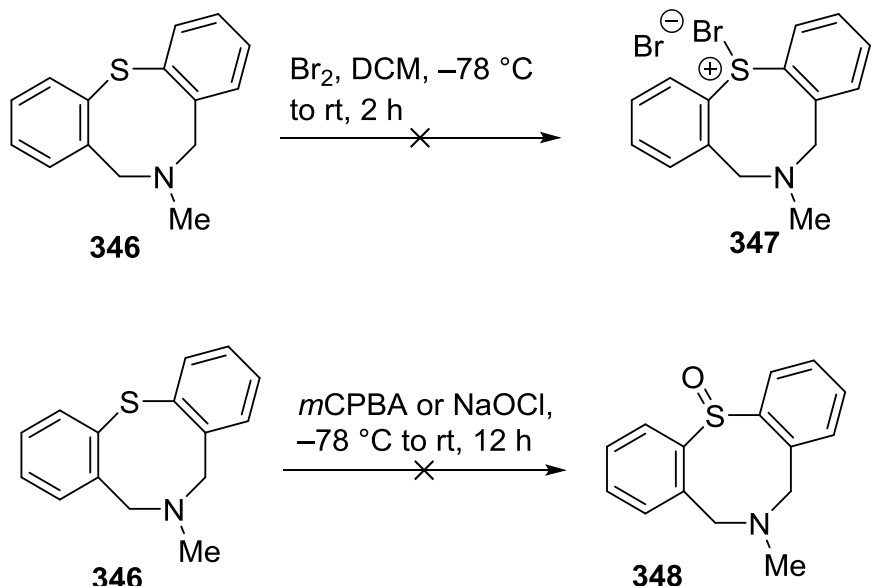

Scheme 61 Investigations towards the activation of the cyclic aminosulfide 346.

After such a daunting result, no further synthetic investigations were conducted on this potential transfer reagent backbone. 


\subsection{Investigations towards potential trifluoromethylation reagents based on the thioimidazolium backbone.}

\subsubsection{Synthesis of the new potentially trifluoromethylating reagent 355}

To further expand the observed reactivity of the thioimidazolium based reagents different fluorine bearing compounds were synthesized._A new family of potentially useful trifluoromethylation reagent was synthesized in a straightforward reaction sequence. At first, the silver thiolate $\mathbf{3 5 0}$ was prepared in a good yield of 54\% following the published protocol. ${ }^{137}$ Then, the iodinated imidazole 352 was obtained in a high yield (84\%) by treating methylimidazol 351 with $n \mathrm{BuLi}$ and subsequent reaction with iodine. Afterwards, compound $\mathbf{3 5 2}$ was methylated to afford the imidazolium salt $\mathbf{3 5 4}$ in a yield of $73 \% .{ }^{138}$ Finally, nucleophilic substitution in the imidazolium salt $\mathbf{3 5 4}$ via treatment with the silver thiolate $\mathbf{3 5 0}$ in a microwave-assisted reaction offered the desired product $\mathbf{3 5 5}$ in a yield of $76 \%$ (Scheme 62).

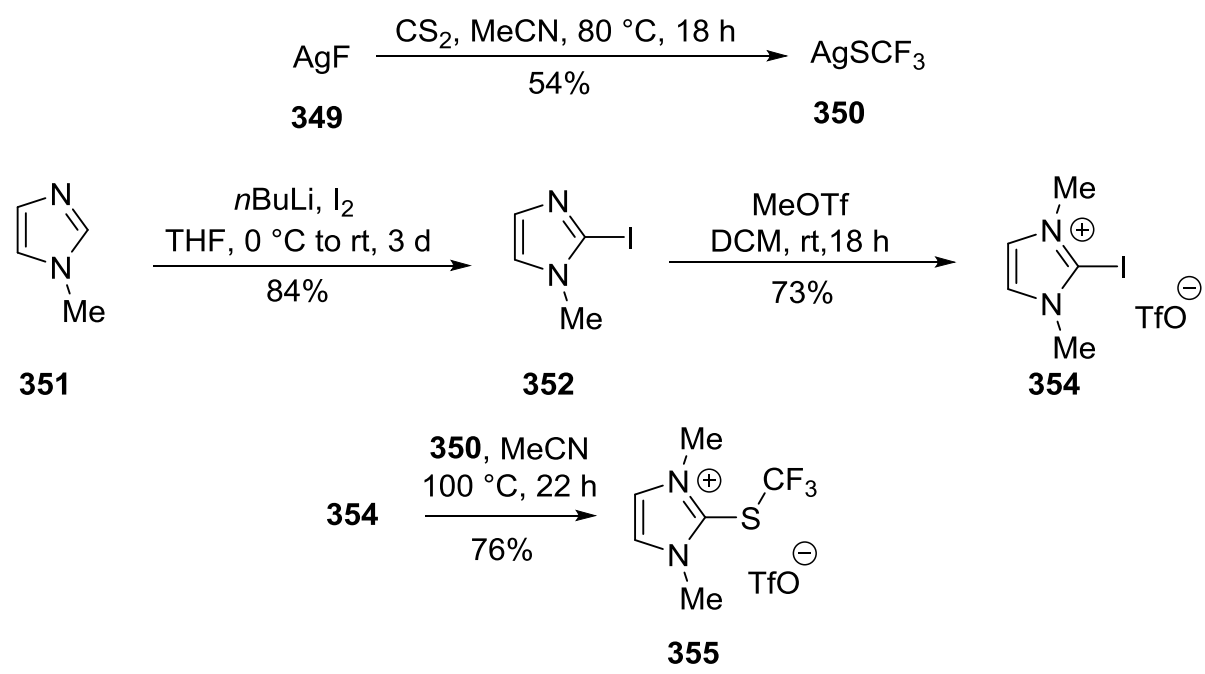

Scheme 62 Synthesis of a new potential trifluoromethylation reagent 355.

The structural identity of the compound $\mathbf{3 5 5}$ was confirmed by X-ray crystallography (Figure 38). Single crystals suitable for $\mathrm{X}$-ray diffraction were grown by overlayering a saturated solution of the reagent 355 in $\mathrm{MeCN}$ with diethyl ether. As expected, the structure of the compound shows an angular geometry of $\mathrm{C}-\mathrm{S}-\mathrm{CF}_{3}$ with an angle of $97.3(9)^{\circ}$. With $2.913(2) \AA$, the $\mathrm{S} 3-\mathrm{O} 1$ bond is significantly shortened as compared to the corresponding sum of Van-der-Waals radii $\left(3.32 \AA^{128 b}\right)$, thus illustrates a strong coordinative bonding between the Lewis-acidic sulfur atom and the oxygen atom of the triflate counterion. Furthermore, with a bond length of 1.747(3) $\AA$ the S1-C2 bond shows clearly the characteristics of a single bond. ${ }^{139}$ 


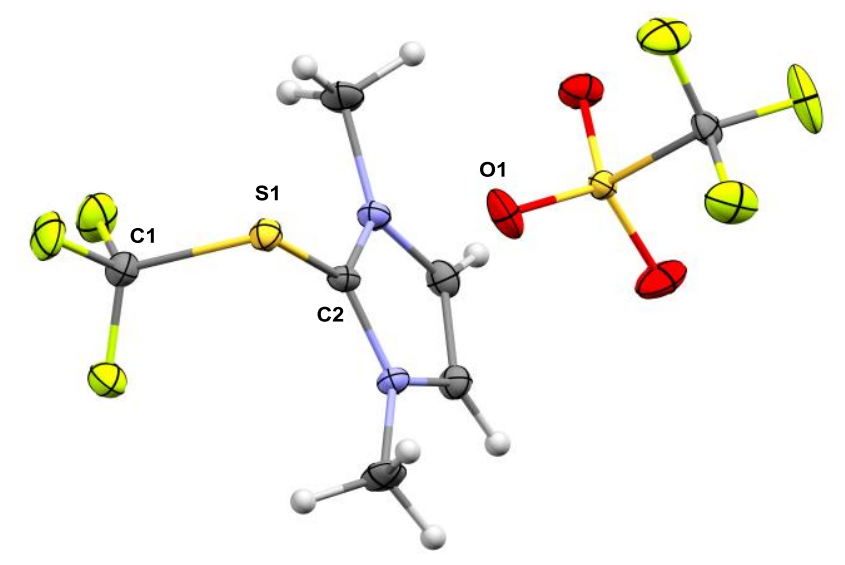

Figure 38 Molecular structure of reagent 355. Thermal ellipsoids at 50\% probability. Selected bond lengths and distances $(\AA): \mathrm{S} 1-\mathrm{O} 1=2.913(2), \mathrm{C} 2-\mathrm{S} 1=1.747(3)$; angle of the sulfide moiety $\left(^{\circ}\right)$ : $\mathrm{C} 1-\mathrm{S} 1-\mathrm{C} 2=97.29(2)$.

\subsubsection{Investigations towards reactions with different nucleophiles}

The reactivity of newly prepared compound 355 with respect to various nucleophiles has been investigated to understand its synthetic utility. Unfortunately, in contrast to hypervalent iodine compounds ${ }^{94}$ or Umemoto reagent, ${ }^{119}$ no nucleophiles were reacting with the salt $\mathbf{3 5 5}$ in the desired way (Scheme 63). Only the starting material could be isolated from the reactions with $\beta$-ketoester 202, 2,4,6-trimethylphenol (356), electron-rich aromatics like 1-methylindole (357), 1,3-dimethoxybenzene (359) or sec-amine 360, all of which were successively cyanated with the previously developed reagent 186 ( $c f$. Scheme 36). ${ }^{124}$ The modification of the reaction conditions such as temperature, solvent and reaction time did not lead to any observable reactivity as well. When stronger nucleophiles like Grignard reagent 365 or zincate 366 were utilized, a complete decomposition of the salt $\mathbf{3 5 5}$ was observed. The reaction with enol ether $\mathbf{3 6 4}$ also did not lead to the formation of the expected product. Another possibility would be the transfer of a trifluoromethyl radical. But only starting material was obtained employing theophylline $\mathbf{3 6 7}$ as a nucleophile in combination with a radical initiator. ${ }^{140}$ 


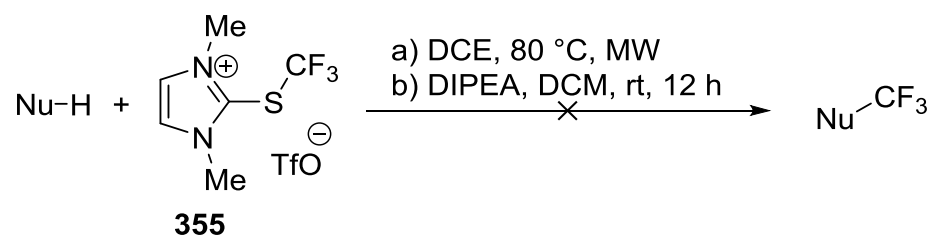<smiles>COC(=O)C1Cc2ccccc2C1=O</smiles>

202<smiles>Cc1cc(C)c(O)c(C)c1</smiles>

356<smiles>Cn1ccc2ccccc21</smiles>

357<smiles>Cn1c(-c2ccccc2)cc2ccccc21</smiles>

358<smiles>COc1cccc(OC)c1</smiles>

359<smiles>COc1cc2c(cc1OC)CNCC2</smiles>

360<smiles>Sc1cccc2ccccc12</smiles>

361<smiles>O=[N+]([O-])c1ccc(S)cc1</smiles>

362<smiles>Cc1ccc(S[18O])cc1</smiles>

363<smiles>COC(OC)=C(C)C</smiles>

364<smiles>CCCCCCCCCCCCCCCCCCCCCCCCCC</smiles>

367

Scheme 63 Investigations towards the reaction of the thioimidazolium-based reagent 355 with different nucleophiles.

Only with thiols 361, 362 any reactivity was observed. However, instead of the desired product, an inseparable mixture of trithiocarbonates 369 and the corresponding disulfides 370 was obtained (Scheme 64A). An explanation of this undesired reaction pathway could consist in the initial attack of the imidazolium moiety in $\alpha$-position to the sulfur atom with a sulfur nucleophilic center of thiol $\mathbf{3 6 2}$ (Scheme 64B). The released carbonothioic difluoride could undergo a subsequent attack of additional thiols to form the observed product. The side product of this reaction, the thioimidazolium salt $\mathbf{3 6 8}$, was crystallized, and the structural identity was confirmed by X-ray crystallography (Figure 39). 
A.

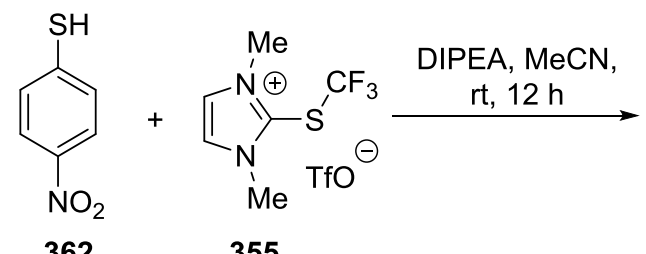

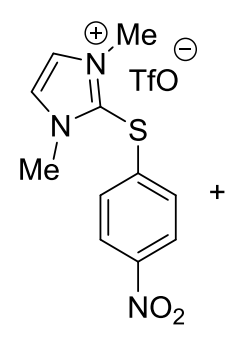

368<smiles>O=[N+]([O-])c1ccc(SC(=S)Sc2ccc([N+](=O)[O-])cc2)cc1</smiles>

369<smiles>O=[N+]([O-])c1ccc(SSc2ccc([N+](=O)[O-])cc2)cc1</smiles>

370

B.

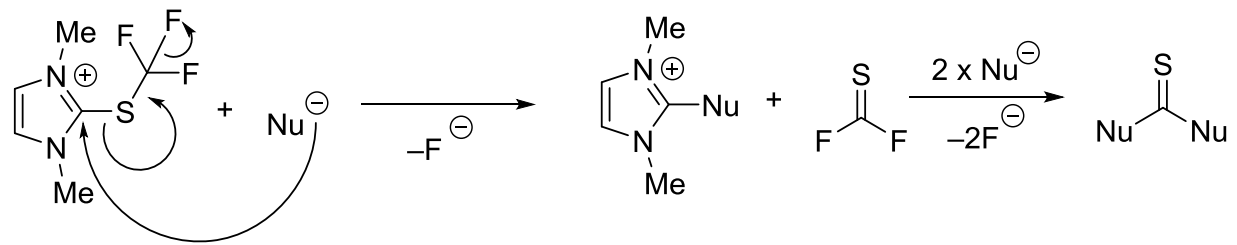

Scheme 64 (A) Reaction of thiol 362 with the new thioimidazolium reagent 355 and (B) proposed mechanistic rationalization of the results.

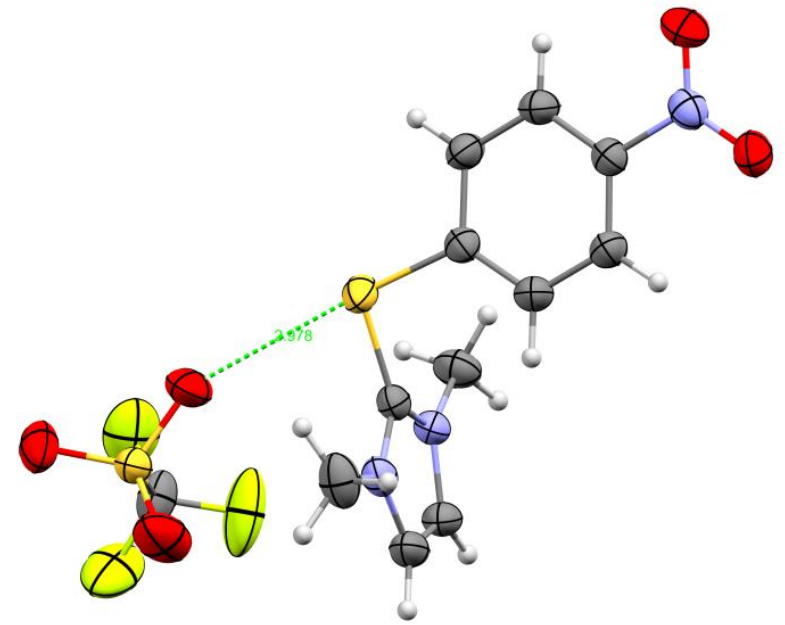

Figure 39 Molecular structure of side product 368. Thermal ellipsoids at 50\% probability. 


\subsubsection{Investigations towards metal-catalyzed reactions}

Several examples of metal-catalyzed trifluoromethylation reactions have been reported in literature using group transfer reagents. ${ }^{141}$ Regarding this, copper salts seem to be an excellent choice for stabilizing trifluoromethyl radicals. ${ }^{142}$ Test reactions with different copper catalysts and starting materials were examined (Scheme 65). In no case any reactivity towards trifluoromethylation was observed. Following a publication by Huang, Weng et al.,${ }^{143}$ the reaction of benzo[h]quinoline (371) with the reagent $\mathbf{3 5 5}$ was probed applying copper trifluoroacetate and palladium acetate as catalyst; unfortunately, the unreacted quinoline $\mathbf{3 7 1}$ was re-isolated. The same result was obtained by employing trifluroborate $\mathbf{3 7 3}$ as a substrate: neither copper iodide nor $\mathrm{Cu}(\mathrm{TFA})_{2}{ }^{143}$ appeared to be a suitable catalyst for the desired reaction. Furthermore, only starting material was obtained using boronic acid $\mathbf{3 7 5}$ and copper iodide/bipy as a catalyst. ${ }^{144}$ Summarizing these experimental results, this indicates that reagent $\mathbf{3 5 5}$ exhibit no expected reactivity with copper catalysts under the investigated conditions.<smiles></smiles>

371

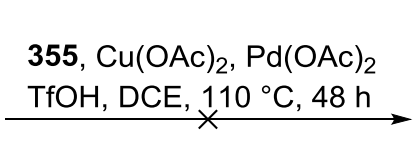

355, $\mathrm{Cu}(\mathrm{TFA})_{2}$

2,2'-di-4-picolyl, $\mathrm{MeCN}, \mathrm{rt}, 12 \mathrm{~h}$

355, Cul, 2,2'-di-4-picolyl $\stackrel{\text { diglyme, rt, } 15 \mathrm{~h}}{\longrightarrow}$

355, Cul, bipy, $\mathrm{Li}_{2} \mathrm{CO}_{3}$ $\stackrel{\text { diglyme, } 60^{\circ} \mathrm{C}, 15 \mathrm{~h}}{\times}$<smiles>COc1ccccc1B(O)O</smiles>

375<smiles>FC(F)(F)c1cccc2ccc3cccnc3c12</smiles>

372<smiles>FC(F)(F)c1ccc2c(c1)OCO2</smiles><smiles>COc1ccccc1C(F)(F)F</smiles>

376

Scheme 65 Investigations towards metal-catalyzed reactions with reagent 355. 


\subsubsection{Application of thioimidazolium salts as phase transfer catalyst by Mizuta and coworkers}

During our investigations, a thioimidazolium-based reagent similar to $\mathbf{3 5 5}$ was published by Mizuta et al., ${ }^{145}$ who trifluoromethylated the thiourea $\mathbf{1 8 4}$ using the commercially available Umemoto reagent $\mathbf{1 7 3}$ to obtain the corresponding imidazolium salts $\mathbf{3 7 7}$ in good yields (Scheme 66). The authors utilized the resulting imidazolium salts as phase transfer catalysts in the alkylation of different compounds possessing an active methylene moiety, whereas applying of the compounds $\mathbf{3 7 7}$ for the trifluoromethylation of nucleophiles was not examined.

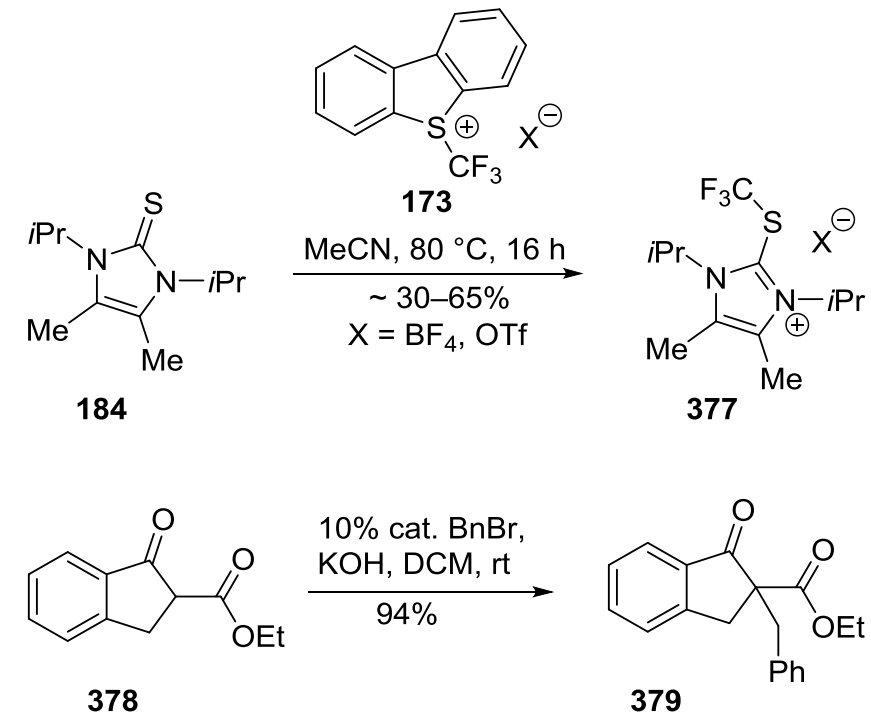

Scheme 66 Synthesis of a new thioimidazolium-based reagent 377 by Mizuta and coworkers and its application as phase transfer catalyst.

Based on preliminary NMR studies, the authors suggest that in the beginning of the reaction carbanion $\mathbf{3 8 0}$ is formed by deprotonation of the $\beta$-ketoester $\mathbf{3 7 8}$ with potassium hydroxide. The low solubility of this carbanion would normally lead to a low reaction rate. They assumed that the reactive imidazolium intermediate 377d is formed via counterion exchange. This complex is more soluble and allows achieving higher reaction rate of the alkylation reaction. A subsequent attack of benzyl bromide with the imidazolium salt-stabilized carbanion $\mathbf{3 7 7 d}$ would release the product 379 and the imidazolium salt 377e, which undergoes the cycle again (Figure 40). 

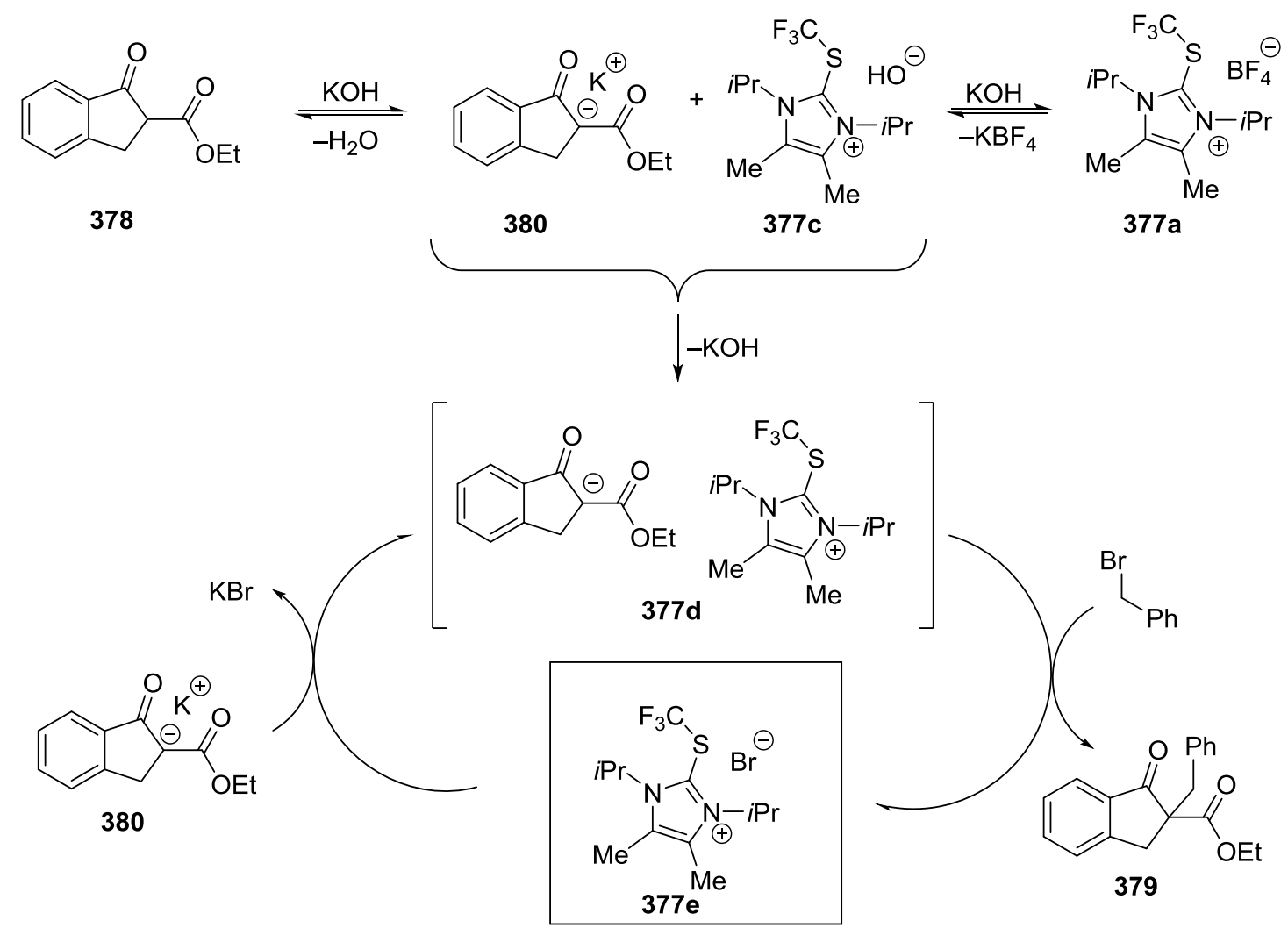

Figure 40 Mechanism for the phase transfer catalysis as proposed by Mizuta and coworkers.

Considering the chosen substrates and reaction conditions, it can be assumed that Mizuta and coworkers were also interested in the trifluoromethylation instead of the presented phase-transfer catalysis. As a result of the high similarity to the presented results, no further resources were spent on this project part. 


\subsection{Investigations towards a new trifluoroethylenating reagent}

\subsubsection{Synthesis of the new reagent 385}

An imidazolium-based fluorinated alkene derivative would be another desirable synthesis target. To the best of our knowledge, no metal-free alkenylation method for the functionalization of nucleophiles with transfer reagents by umpolung was reported. However, fluorinated alkenes could be useful tools in the synthesis of partly fluorinated heteroaromatics or other perfluoroalkylated molecules.

In fact, it was possible to synthesize the corresponding alkene reagent 385 (Scheme 63). First, the imidazothione 184 was synthesized by the condensation of acetoin (381) and 1,3-diisopropylthiourea (382) in a yield of $61 \%$. Subsequent bromination of the reagent $\mathbf{1 8 4}$ led to the corresponding dibromide $\mathbf{1 8 5}$ in a yield of $98 \%$. The formation of the zincate 384 was accessed by dehydrofluorination of tetrafluoroethane $\mathbf{3 8 3}$, deprotonation initiated by LDA and subsequent transmetalation with zinc chloride. ${ }^{146}$ The concentration of the zincate $\mathbf{3 8 4}$ was determined by a method of Knochel and coworkers. ${ }^{147}$ After reaction of zincate 384 with the dibromide 185, a counterion exchange with sodium hexafluoroantimonate $(\mathrm{V})$ was performed to obtain the desired product $\mathbf{3 8 5}$ in a yield of $97 \%$.
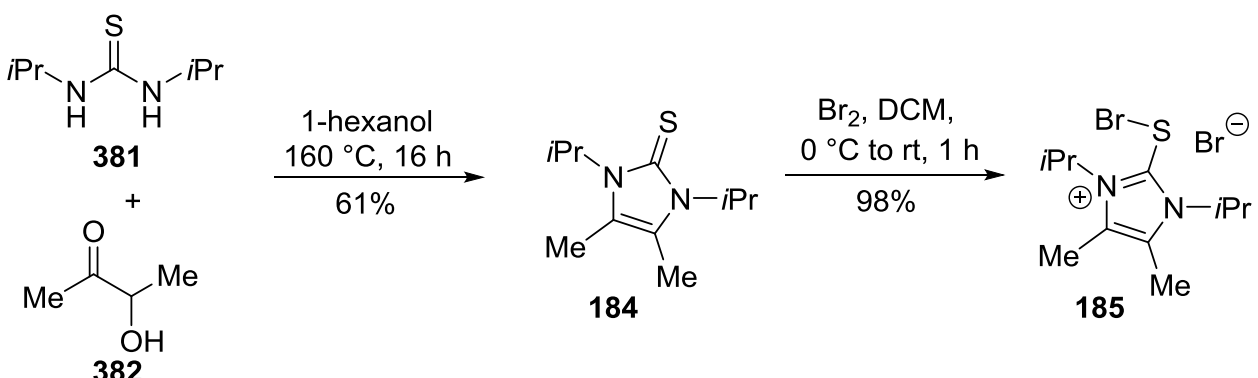

382

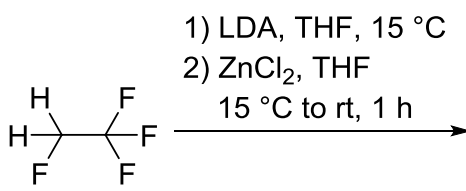

383

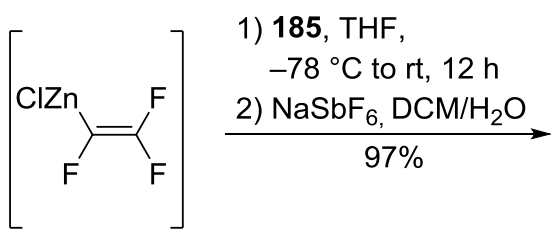

384

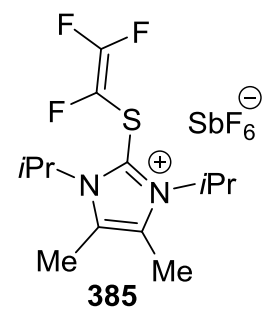

385

Scheme 67 Synthesis of a new potential trilfluoroethylating reagent $\mathbf{3 8 5}$.

Single crystals of the compound $\mathbf{3 8 5}$ suitable for X-Ray diffraction were obtained by slow evaporation of a saturated solution of the compound in DCM. The expected structural connectivity was confirmed (Figure 41). Similarly to the compound 355, the structure of the compound $\mathbf{3 8 5}$ shows an angular geometry C1-S1-C3 with an angle value of $99.50(1)^{\circ}$. Similarly as in chase for compound $\mathbf{3 5 5}$, the S1-C3 bond is with 1.749(3) A in the range of a single bond. 


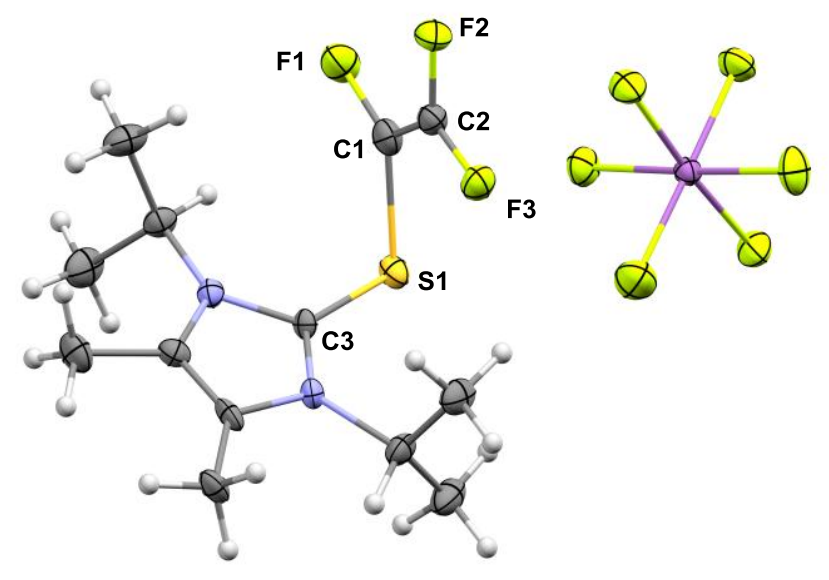

Figure 41 Molecular structure of compound 385. Thermal ellipsoids at 50\% probability. Selected bond lengths and distances $(\AA)$ : C1-C2 1.316(4), S1-C1 1.721(9), S1-C3 1.749(3); angle of the sulfide moiety $\left(^{\circ}\right)$ : C1-S1-C3 = 99.50(1).

\subsubsection{Investigations towards reactions with different nucleophiles}

No electrophilic transfer of the trifluoroethylene group was observed in the course of investigations of the reactivity of the reagent $\mathbf{3 8 5}$ under various conditions (Scheme 68). In fact, only unreacted starting material was isolated in the reactions with the beta-keto ester 202, indole derivatives $\mathbf{3 5 7}$ and $\mathbf{3 5 8}$, and the dimethoxyphenol 386. The reaction with the thiol $\mathbf{3 6 2}$ led to a complete decomposition of the reagent 385. Furthermore, reactivities of 1,3-dimethoxybenzene (359) and the enamine 313 were tested in a microwave-assisted reaction with reagent $\mathbf{3 8 5}$ without any additional base. Likewise, only the starting materials were isolated.

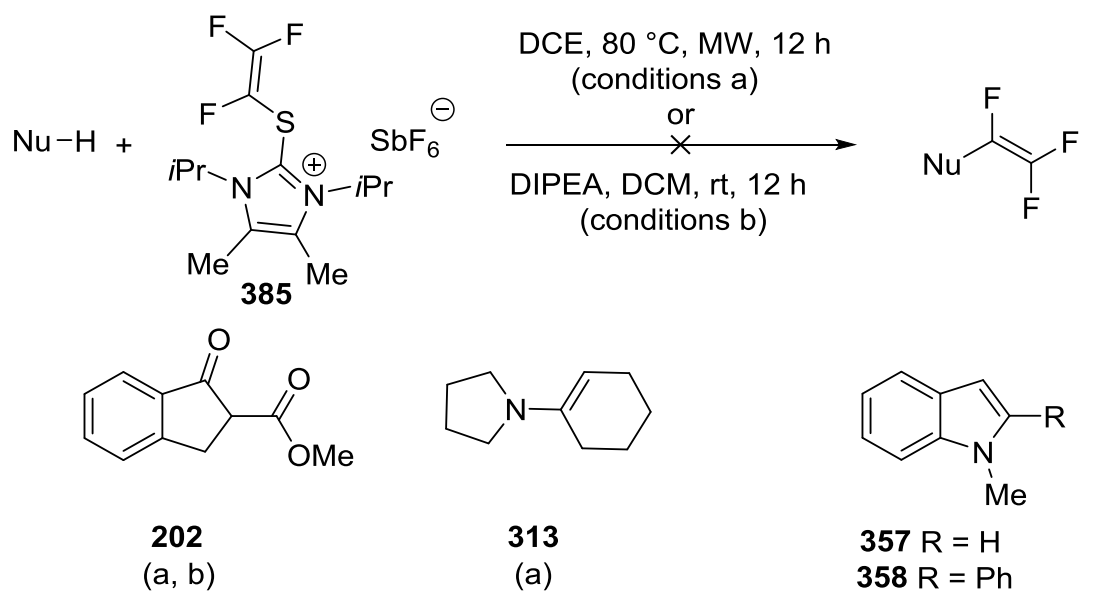

(a)<smiles>COc1cccc(OC)c1</smiles>

(a)<smiles>O=[N+]([O-])c1ccc(S)cc1</smiles>

362

(a, b)<smiles>COc1cccc(OC)c1O</smiles>

386

(a)

Scheme 68 Investigations towards the reactivity of the reagent 385 with different nucleophiles. 
The further study of the chemistry of the salt $\mathbf{3 8 5}$ remains a matter of the nearest future. In this regards, most interesting would be reactions with metal-catalysts or/and the possible radical transfer of the ethylene-group. 


\section{Summary}

In collaboration with the colleagues Dr. G. Talavera and Dr. J. Peña, the recently discovered thioalkynylation reaction was further investigated. A set of different alkyne reagents was prepared, and their reactivity towards thioalkynylation with Grignard reagents and zincates was examined. The products of these reactions were used for further derivatization, thus enabling easy access to different kind of compounds such as sulfones or sulfoxides (Scheme 69).

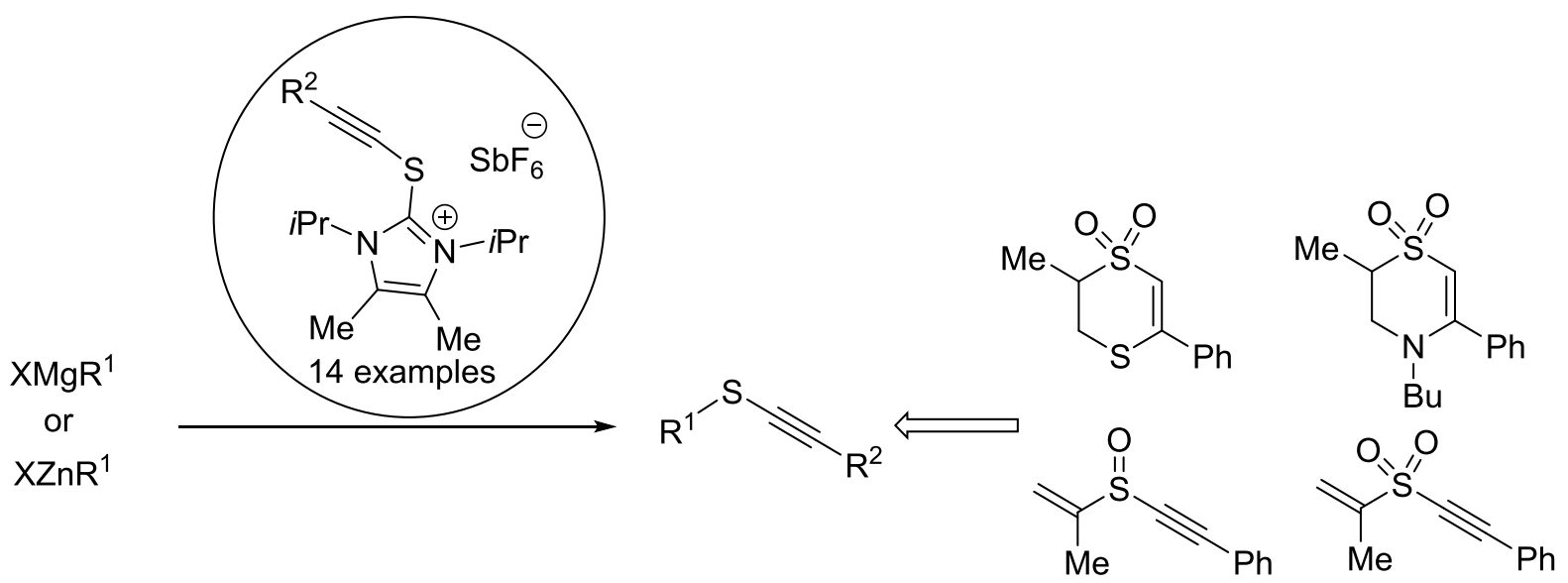

Scheme 69 Results of the investigations towards the thioalkynylation with thioimidazolium-based alkyne transfer reagents.

Additionally, a set of new dibenzothiophenium-based alkynylation reagents was prepared and their structural identity was confirmed by X-ray crystallography. The versatile reactivity of the new reagents was demonstrated in their reactions with benchmark $C$-, $S$-, $N$ - and $P$-nucleophiles (Scheme 70). Straightforward experiments applying ${ }^{13} \mathrm{C}$-labeled reagents were proceeded to give a first insight in the reaction mechanism. Finally, the reagents were directly compared with their commercially available EBX analogues highlighting them as powerful and safe alternative to hypervalent iodine reagents.

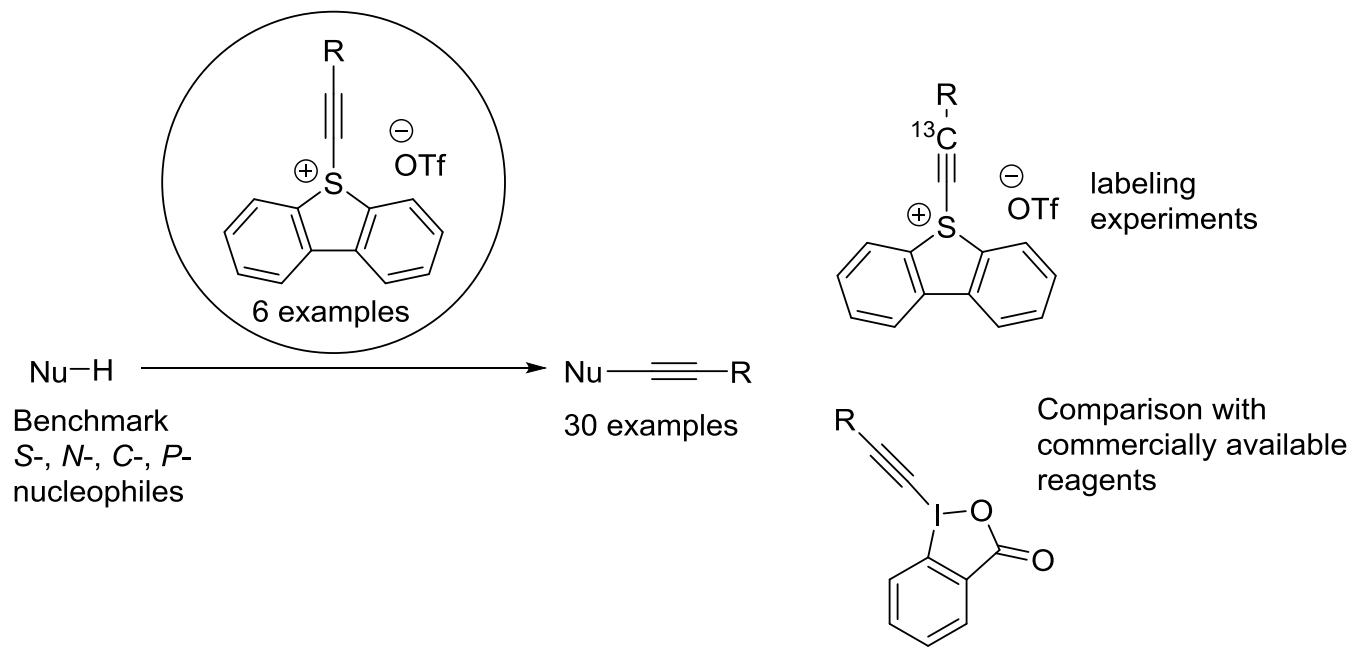

Scheme 70 Results of the investigations towards the synthesis of a new set of dibenzothiophenium-based alkyne transfer reagents. 
The thioimidazolium salt $\mathbf{3 5 5}$ and the salt $\mathbf{3 8 5}$ were synthesized in a straightforward reaction sequence. Their structural identity was confirmed by spectral methods as well as by X-ray crystallography. Moreover, the reactivity of these compounds in the reaction with benchmark nucleophiles was investigated as well (Scheme 71), albeit with negative results. For reagent 355, an unexpected decomposition process was observed affording the product $\mathbf{3 6 8}$, which structure was confirmed by crystallographic study.

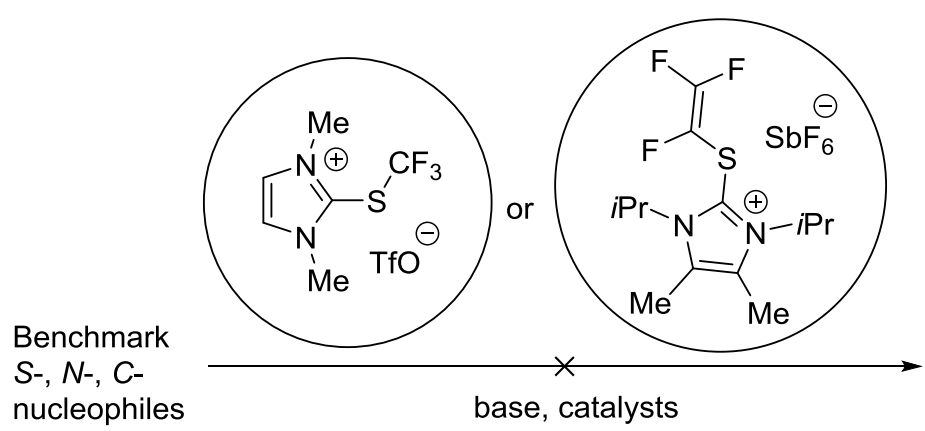

Scheme 71 Results of the investigations towards synthesis and application of thioimidazolium-based fluorine-containing transfer reagents. 


\section{Experimental}

\subsection{General remarks}

Unless otherwise stated, all reactions were carried out in flame-dried glassware under nitrogen atmosphere. Solvents were dried by an MBraun MB-SPS-800 solvent purification system (tetrahydrofuran, diethyl ether, toluene, pentane, dichloromethane, acetonitrile) or by distillation with appropriate drying agents. The water content of the solvent was determined by Karl Fischer titrator TitroLine R 7500 KF trace from SI Analytics. Reactions were monitored by thin layer chromatography (TLC) polygram SIL G/UV254 from Macherey Nagel, UV irradiation $(\lambda=254 \mathrm{~nm})$ and/or phosphomolybdic acid or $\mathrm{KMnO}_{4}$ dip. Flash chromatography was performed on Macherey Nagel $60(40-63 \mu \mathrm{m})$ silica gel.

Chemicals: Unless otherwise stated, all reagents were used as received from commercial suppliers (ABCR, Acros Organics, Alfa Aesar, Chempur GmbH, J and K Scientific, Sigma Aldrich, Thermo Fisher Scientific, Tokyo Chemical Industry). 1-(trifluoromethyl)-4-[2-(trimethylsilyl)ethynyl]benzene, ${ }^{148}$ 1-chloro-3-[2-(trimethylsilyl)ethynyl]-benzene, ${ }^{149}$ 1-bromo-2-[2-(trimethylsilyl)ethynyl]benzene, ${ }^{150}$ 1-fluoro-4-[2-(trimethylsilyl)ethynyl]-benzene, ${ }^{151}$ trimethyl[2-[tris(1-methylethyl)silyl]ethynyl]-silane, ${ }^{152} \quad \mathrm{~N}$-(4-methoxyphenyl)-4-methyl-benzenesulfonamide and $\mathrm{N}$-(4-Iodophenyl)-4methyl-Benzenesulfonamide, ${ }^{153} \alpha$-cyano-benzenepropanoic acid ethyl ester, ${ }^{154} 2,3$-dihydro-1-oxo- $1 H$ Indene-2-carboxylic acid methyl ester, ${ }^{155}$ 1,3-diisopropyl-4,5-dimethyl-1,3-dihydro-2H-imidazole-2thione $^{124}$ were prepared according to the literature reports. Compounds 196d-196n, 210-212, 214-221, 223-225 were prepared and analyst by Dr. G. Talavera and Dr. J. Peña.

NMR: NMR spectra were recorded on a Bruker AV600, AV500, AV400, DPX300, Varian Mercury 300 or Varian Inova 500. The ppms of ${ }^{1} \mathrm{H}$ - and ${ }^{13} \mathrm{C}-\mathrm{NMR}$-spectras were measured relative to TMS. Coupling constants $(J)$ were given in Hz. All NMR solvents were used as received from commercial suppliers.

Mass analysis: Mass spectrometry analysis was performed by the department of mass spectrometry of the chemistry department of the Georg-August University utilizing a Finnigan MAT 95 (70 eV, EI), Finnigan LCQ (ESI) and APEX IV 7T FTICR, Bruker Daltonic (HRMS). 
Single crystal X-ray diffraction analysis: Data collection was done on a Bruker D 8 Venture fourcircle-diffractometer from Bruker AXS GmbH; used detector: Photon II from Bruker AXS GmbH; used X-ray sources: microfocus $I \mu S \mathrm{Cu} / \mathrm{Mo}$ from Incoatec $\mathrm{GmbH}$ with mirror optics HELIOS and singlehole collimator from Bruker AXS GmbH.

Used programs: APEX3 Suite (v2017.3-0) and therein integrated programs SAINT (Integration) und $S A D A B S$ (Absorption correction) from Bruker AXS GmbH; structure solution was done with SHELXT, refinement with $S H E L X S^{156}$; OLEX ${ }^{2}$ was used for data finalization. ${ }^{157}$

Special Utilities: SMZ1270 stereomicroscope from Nikon Metrology GmbH was used for sample preparation; crystals were mounted on MicroMounts or MicroLoops from MiTeGen; for sensitive samples the X-TEMP 2 System was used for picking of crystals; ${ }^{158}$ crystals were cooled to given temperature with Cryostream 800 from Oxford Cryosystems.

IR: FT-IR spectra were measured by the utilization of a FT/IR-4100 (Jasco). The wavenumbers ( $\tilde{\mathrm{V}})$ were recorded in $\mathrm{cm}^{-3}$.

Differential scanning calorimetry (DSC): The DSC measurements were performed in a MettlerToledo TGA/DSC 3+, using the method 25_650_20K/min_N2 -b. 


\subsection{Reactions towards the newly discovered thioalkynylation reaction}

\subsubsection{Synthesis of new thioimidazolium-based alkynylation reagents General procedure A (GPA)}

To a solution of a terminal alkyne $(0.50 \mathrm{mmol}, 1.00$ equiv. $)$ in THF $(2 \mathrm{~mL})$ was added $n \mathrm{BuLi}(1.6 \mathrm{M}$ in hexanes, 1.05 equiv.) at $-78^{\circ} \mathrm{C}$. After stirring for 1 hour, a solution of $\mathrm{ZnBr}_{2}$ (1.05 equiv.) in THF (1 M) was added at $-78{ }^{\circ} \mathrm{C}$ and the whole mixture stirred for another hour. Then the dibromide 185 (1.00 equiv.) was added in one portion to the reaction mixture at $-78^{\circ} \mathrm{C}$ and after 30 minutes the reaction was let to warm up to room temperature. The solvents were removed in vacuo to afford a crude mixture which was washed with dry diethyl ether $(3 x)$ and pentane $(2 x)$. The obtained solid was dissolved in DCM $(0.1 \mathrm{M})$ and treated with an aqueous solution of $\mathrm{NaSbF}_{6}$ (3.00 equiv.). Extraction of the aqueous layer with DCM (3x) and subsequent removal of all solvents in vacuo afforded the desired products as white to pale yellow-orange solids.

Synthesis of the compound 2-(bromothio)-1,3-diisopropyl-4,5-dimethyl-1 $H$-imidazol-3-ium bromide (185)<smiles></smiles>

To a solution of 1,3-diisopropyl-4,5-dimethyl-1,3-dihydro-2 $H$-imidazole-2thione (4.00 g, $18.8 \mathrm{mmol}, 1.00$ equiv.) in DCM (20 mL) was added bromine ( $0.97 \mathrm{~mL}, 18.8 \mathrm{mmol}, 1.00$ equiv.) at $0{ }^{\circ} \mathrm{C}$ and the solution was stirred for $1 \mathrm{~h}$ at $0^{\circ}{ }^{\circ} \mathrm{C}$ and $2 \mathrm{~h}$ at $\mathrm{rt}$. The solvent was removed under reduced pressure and the residue was washed with ether $(2 \times 20 \mathrm{~mL})$ to afford the desired compound $\mathbf{1 8 5}$ as orange solid (6.90 g, $18.5 \mathrm{mmol}, 98 \%) .{ }^{1} \mathbf{H}$ NMR (300 MHz, $\left.\mathrm{CDCl}_{3}\right) \delta$ $=3.81(6 \mathrm{H}, \mathrm{s}), 2.27 \mathrm{ppm}(6 \mathrm{H}, \mathrm{s}) \cdot{ }^{13} \mathbf{C} \mathbf{~ N M R}\left(75 \mathrm{MHz}, \mathrm{CDCl}_{3}\right) \delta=127.8,33.8$, 9.7 ppm. IR $\left(\right.$ ATR): $\widetilde{v}\left(\mathrm{~cm}^{-1}\right)=783,855,1032,1230,1372,1429,1490,1624,2944$. HRMS: calcd. for $\mathrm{C}_{7} \mathrm{H}_{12} \mathrm{~N}_{2} \mathrm{BrS}[\mathrm{M}]^{+}=234.9898$; found $=234.9899$. Analytical data corresponded to those described in the literature. ${ }^{124}$ 
Synthesis of 1,3-diisopropyl-4,5-dimethyl-2-((phenylethynyl)thio)-1 $H$-imidazol-3-ium hexafluoroantimonate(V) (196b)

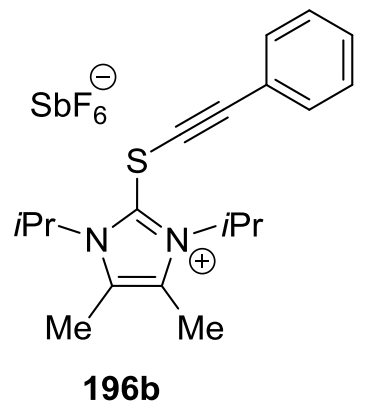

Using the general procedure GPA, compound (196b) was prepared from phenyl acetylene (1.70 mL, $15.3 \mathrm{mmol}), n \mathrm{BuLi}(10 \mathrm{~mL}, 16.0 \mathrm{mmol}), \mathrm{ZnBr}_{2}$ (3.62 g, $16.0 \mathrm{mmol})$ and dibromide $185(5.70 \mathrm{~g}, 15.3 \mathrm{mmol})$. The desired compound was obtained as pale white solid (7.7 g, 92\%). ${ }^{1}$ H NMR (500 $\mathrm{MHz}, \mathrm{CDCl}_{3}$, $\delta=7.28-7.47(5 \mathrm{H}, \mathrm{m}), 5.31(2 \mathrm{H}$, hept., $J=7.0 \mathrm{~Hz}), .2 .43$ $(6 \mathrm{H}, \mathrm{s}), 1.73 \mathrm{ppm}(12 \mathrm{H}, \mathrm{d}, J=7.0 \mathrm{~Hz}) .{ }^{13} \mathbf{C ~ N M R}\left(126 \mathrm{MHz}, \mathrm{CDCl}_{3},\right) \delta=$ 132.0, 131.0, 130.0, 129.8, 128.5, 120.4, 95.3, 69.2, 53.7, 20.7, 10.0 ppm. IR (ATR): $\widetilde{v}\left(\mathrm{~cm}^{-1}\right)=653,691,754,906,1114,1219,1378,1459,1618,2943,2996$. HR-MS: calcd. for $\mathrm{C}_{19} \mathrm{H}_{25} \mathrm{~N}_{2} \mathrm{~S}[\mathrm{M}]^{+}=313.1732$; found $=313.1732$.

Synthesis of 1,3-diisopropyl-4,5-dimethyl-2-(prop-1-yn-1-ylthio)-1H-imidazol-3-ium hexafluoroantimonate $(\mathrm{V})(\mathbf{1 9 6 c})$

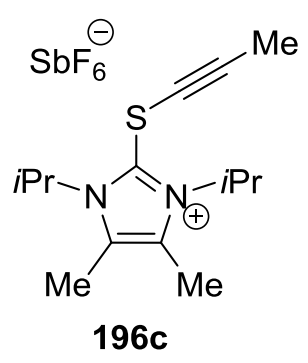

Using the general procedure GPA, compound 196c was prepared from propynyl lithium (29.6 mg, $0.64 \mathrm{mmol}$ ), $\mathrm{ZnBr}_{2}(151.3 \mathrm{mg}, 0.67 \mathrm{mmol}$ ) and dibromide 185 (238.8 $\mathrm{mg}, 0.64 \mathrm{mmol})$. The desired compound was obtained as pale yellow solid (307.9 mg, 99\%); ${ }^{1} \mathbf{H}$ NMR (300 MHz, $\mathrm{CDCl}_{3}$, $\delta=5.15(2 \mathrm{H}$, hept, $J=$ $7.1 \mathrm{~Hz}), 2.35$ (6 H, s), $1.90(3 \mathrm{H}, \mathrm{s}), 1.63 \mathrm{ppm}(12 \mathrm{H}, \mathrm{d}, J=7.1 \mathrm{~Hz}) .{ }^{13} \mathbf{C}$ NMR $\left(75 \mathrm{MHz}, \mathrm{CDCl}_{3}\right) \delta=131.1,130.8,94.4,58.5,53.7,20.9,10.1,4.6$ ppm. IR $\left(\right.$ ATR): $\widetilde{v}\left(\mathrm{~cm}^{-1}\right)=652,754,844,1065,1136,1164,1219,1321,1371,1458,1615,2943,2994$. HRMS: calcd. for $\mathrm{C}_{14} \mathrm{H}_{23} \mathrm{~N}_{2} \mathrm{~S}[\mathrm{M}]^{+}=251.1577$; found $=251.1576$. 


\subsubsection{Synthesis of sulfides}

\section{General procedure B (GPB)}

The thioalkynyl imidazolium salt $(0.05-0.25 \mathrm{mmol})$ was dissolved in THF $(0.2 \mathrm{M})$ at the indicated temperature and the Grignard reagent solution (1.00 equiv.) was added dropwise. After $2 \mathrm{~h}$ a saturated aqueous $\mathrm{NH}_{4} \mathrm{Cl}$ solution was added and reaction mixture was extracted with EtOAc $(3 \mathrm{x} 15 \mathrm{~mL})$. The combined organic layers were dried over anhydrous $\mathrm{Na}_{2} \mathrm{SO}_{4}$, filtered, and the volatiles were removed under vacuum. Purification of the crude product by flash chromatography on silica gel (hexane/EtOAc) afforded the desired substances.

Synthesis of (phenylethynyl)(prop-1-en-2-yl)sulfane (213)

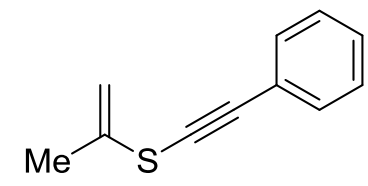

213

Using the general procedure GPB, compound 213 was prepared from isopropenylmagnesium bromide $(0.5 \mathrm{M}$ in THF, $1.80 \mathrm{~mL}, 0.85 \mathrm{mmol})$ and compound 196b (496 mg, $0.90 \mathrm{mmol}$ ). The Grignard reagent was added at $78^{\circ} \mathrm{C}$. Flash chromatography purification (hexane/EtOAc 9/1) afforded 213 as a pale yellow oil (155 mg, 99\%). ${ }^{1} \mathbf{H}$ NMR $\left(300 \mathrm{MHz}, \mathrm{CDCl}_{3}\right.$, $\delta=7.41-7.54$ $(2 \mathrm{H}, \mathrm{m}), 7.28-7.38(3 \mathrm{H}, \mathrm{m}), 5.30-5.42(1 \mathrm{H}, \mathrm{m}), 5.23(1 \mathrm{H}, \mathrm{q}, J=1.5 \mathrm{~Hz}), 2.09 \mathrm{ppm}(3 \mathrm{H}, \mathrm{dd}, J=$ 1.5, 0.8 Hz). ${ }^{13} \mathbf{C}$ NMR (75 MHz, CDCl, $) \delta=136.9,131.7,128.6,128.5,123.2,111.3,98.7,75.9,22.0$ ppm. IR (ATR): $\widetilde{v}\left(\mathrm{~cm}^{-1}\right)=693,736,751,801,917,1028,1072,1175,1263,1357,1444,1490,1596$, 1687, 2186, 2922, 3027, 3057. HRMS: calcd. for $\mathrm{C}_{11} \mathrm{H}_{10} \mathrm{~S}[\mathrm{M}]^{+}=174.0501$; found $=174.0503$.

Synthesis of (phenylethynyl)(prop-1-yn-1-yl)sulfane (221)

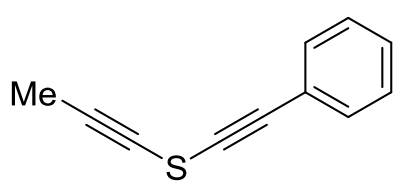

221

Using the general procedure GPA, compound 221 was prepared from propynylmagnesium bromide $(0.5 \mathrm{M}$ in THF, $1.08 \mathrm{~mL}, 0.51 \mathrm{mmol})$ and the compound 196b (297 mg, $0.54 \mathrm{mmol}$ ). The Grignard reagent was added at $-78^{\circ} \mathrm{C}$. Flash chromatography purification (hexane/EtOAc 9/1) afforded 221 as a pale yellow oil (85.4 mg, 97\%). ${ }^{1} \mathbf{H}$ NMR $\left(300 \mathrm{MHz}, \mathrm{CDCl}_{3}\right) \delta=7.43-7.52$ (2 H, m), 7.287.36 (3 H, m), $2.00 \mathrm{ppm}(3 \mathrm{H}, \mathrm{s},) .{ }^{13} \mathbf{C} \mathbf{N M R}\left(75 \mathrm{MHz}, \mathrm{CDCl}_{3}\right) \delta=132.0,129.0,128.5,122.5,94.5$, 92.5, 73.1, 60.8, 5.2 ppm. IR (ATR): $\widetilde{v}\left(\mathrm{~cm}^{-1}\right)=729,803,905,1014,1260,1443,1487,2252,2853$, 2924, 2959. HRMS: calcd. for $\mathrm{C}_{11} \mathrm{H}_{8} \mathrm{~S}[\mathrm{M}]^{+}=172.0345$; found $=172.0346$. 


\subsubsection{Synthesis of derivatization products of the synthesized sulfides}

Synthesis of ((prop-1-en-2-ylsulfinyl)ethynyl)benzene (226)

To a solution of the compound 213 (110 mg, $0.63 \mathrm{mmol}, 1.00$ equiv.) in DCM (6.5 mL) was slowly added $m$ CPBA (141 mg, $0.63 \mathrm{mmol}, 1.00$ equiv.) over $1 \mathrm{~h}$. The solution was stirred for another $12 \mathrm{~h}$ at $0{ }^{\circ} \mathrm{C}$. Then the white solid was removed by filtration and the solution was washed with a saturated aqueous solution of $\mathrm{NaS}_{2} \mathrm{O}_{3}$, a saturated aqueous solution of $\mathrm{NaHCO}_{3}$ and water. Afterwards the solution was dried over $\mathrm{MgSO}_{4}$, the solvent was removed by evaporation and the residue was purified by flash-chromatography (hexane/ether : $3 / 2)$ to afford the product as yellow oil $(81 \mathrm{mg}, 68 \%) .{ }^{1} \mathbf{H}$ NMR $\left(600 \mathrm{MHz}, \mathrm{CDCl}_{3}\right) \delta=7.50-7.52(1 \mathrm{H}, \mathrm{m})$; 7.41-7.44 $(1 \mathrm{H}, \mathrm{m}), 7.34-7.37(2 \mathrm{H}, \mathrm{m}), 5.92(1 \mathrm{H}$, $\left.\mathrm{m}_{\mathrm{C}}\right), 5.67\left(1 \mathrm{H}, \mathrm{m}_{\mathrm{C}}\right), 2.22 \mathrm{ppm}(3 \mathrm{H}, \mathrm{dd} J=1.1) .{ }^{13} \mathbf{C} \mathbf{N M R}\left(125 \mathrm{MHz}, \mathrm{CDCl}_{3}\right) \delta=148.5,132.2$, 130.5, 128.5, 120.0, 118.3, 101.0, 84.6, 14.7 ppm. IR (ATR): $\widetilde{v}\left(\mathrm{~cm}^{-1}\right)=527,534,629,688,756,921$, 1066, 1442, 1487, 1636, 2159, 2956, 3082. HRMS: calcd. for $\mathrm{C}_{11} \mathrm{H}_{10} \mathrm{SO}[\mathrm{M}+\mathrm{H}]^{+}=191.0525$; found $=$ 191.0528.

Synthesis of ((prop-1-en-2-ylsulfonyl)ethynyl)benzene (227)

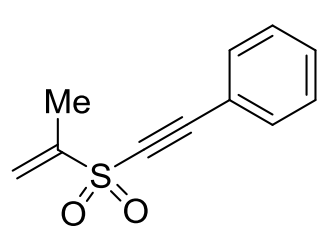

227

To a solution of the compound 213 (305 mg, $1.75 \mathrm{mmol}, 1.00$ equiv.) in DCM (6.5 mL) was slowly added $m$ CPBA (141 mg, $3.68 \mathrm{mmol}, 2.00$ equiv.) over $1 \mathrm{~h}$. The solution was stirred for another $12 \mathrm{~h}$ at $0{ }^{\circ} \mathrm{C}$ and $1 \mathrm{~h}$ at $\mathrm{rt}$. Then the white solid was removed by filtration and the solution was washed with a saturated aqueous solution of $\mathrm{NaS}_{2} \mathrm{O}_{3}$, a saturated aqueous solution of $\mathrm{NaHCO}_{3}$ and water. Afterwards the solution was dried over $\mathrm{MgSO}_{4}$, the solvent was removed by evaporation and the residue was purified by flash-chromatography (hexane/ether : $3 / 2$ ) to afford the product as colorless oil (309 mg, $86 \%) .{ }^{1} \mathbf{H}$ NMR (500 MHz, $\left.\mathrm{CDCl}_{3}\right) \delta=, 6.30\left(15.81\left(1 \mathrm{H}, \mathrm{m}_{\mathrm{C}}\right), 2.26 \mathrm{ppm}(3 \mathrm{H}, \mathrm{dd}, J=0.5\right.$, $0.8 \mathrm{~Hz})^{13} \mathbf{C}$ NMR $\left(125 \mathrm{MHz}, \mathrm{CDCl}_{3}\right) \delta=146.3,132.9,131.7,128.8,124.9,117.8,93.0,83.1,16.1$ ppm. IR (ATR): $\widetilde{v}\left(\mathrm{~cm}^{-1}\right)=531,633,684,726,756,846,923,952,1127,1220,1319,1444,1488$, 1636, 2177, 3061. HRMS: calcd. for $\mathrm{C}_{11} \mathrm{H}_{10} \mathrm{O}_{2} \mathrm{~S}[\mathrm{M}+\mathrm{H}]^{+}=207.0474$; found $=207.0472$. 
Synthesis of 4-butyl-2-methyl-5-phenyl-3,4-dihydro-2H-1,4-thiazine 1,1-dioxide (228)<smiles>CCCCN1CC(C)S(=O)(=O)C=C1c1ccccc1</smiles>

228

To a solution of butan-1-amine (48.9 mg, $0.67 \mathrm{mmol}, 2.00 \mathrm{eq}$,) in methanol (7 $\mathrm{mL}$ ) was added a solution of the compound $227(69.0 \mathrm{mg}, 0.33 \mathrm{mmol}, 1.00$ equiv.) in one drop at RT. The solution was stirred for $20 \mathrm{~h}$ at $\mathrm{rt}$ and added then to a saturated aqueous solution of $\mathrm{NaHCO}_{3}$. The aqueous solution was extracted three times with DCM, the combined organic phases were dried over $\mathrm{MgSO}_{4}$ and the solvent was removed by evaporation. Flash chromatography (hexane/EE+ 1\% $\mathrm{NEt}_{3}: 3 / 1$ to $1 / 1$ ) afford the desired product as white solid (22 $\mathrm{mg}, 26 \%$ ). ${ }^{1} \mathbf{H}$ NMR $\left(300 \mathrm{MHz}, \mathrm{CDCl}_{3},\right) \delta=7.29-7.38(3 \mathrm{H}, \mathrm{m}), 7.20-7.26(2 \mathrm{H}, \mathrm{m}), 4.93(1 \mathrm{H}, \mathrm{s}), 3.57-3.74(2 \mathrm{H}, \mathrm{m})$, 3.09-3.20 (1 H, m), 2.90-2.95 (2 H, m), $1.37\left(5 \mathrm{H}, \mathrm{m}_{\mathrm{C}}\right), 1.03(2 \mathrm{H}, \mathrm{hex}, J=7.6 \mathrm{~Hz}), 0.68 \mathrm{ppm}(3 \mathrm{H}, \mathrm{t}, J$ $=7.2 \mathrm{~Hz}) .{ }^{13} \mathrm{C}$ NMR $\left(125 \mathrm{MHz}, \mathrm{CDCl}_{3}\right) \delta=155.3,135.7,129.4,128.5,127.7,95.1,52.4,52,3,50.8$, 30.7, 13.6, 9.8 ppm. IR (ATR): $\widetilde{v}\left(\mathrm{~cm}^{-1}\right)=510,536,563,666,693,728,769,1042,1079,1110,1162$, 1216, 1260, 1315, 1364, 1376, 1442, 1465, 1551, 1579, 2859, 2918, 2983, 3071; HRMS: calcd. for $\mathrm{C}_{15} \mathrm{H}_{21} \mathrm{NO}_{2} \mathrm{~S}[\mathrm{M}+\mathrm{H}]^{+}=280.1366 ;$ found $=280.1367$.

Synthesis of 2-methyl-5-phenylthiophene (229)<smiles>Cc1ccc(-c2ccccc2)s1</smiles>

229

To a solution of compound 213 (60.1 mg, $0.34 \mathrm{mmol}, 1.00$ equiv.) in EtOH $(10 \mathrm{~mL})$ was added $\mathrm{Na}_{2} \mathrm{~S} \cdot 9 \mathrm{H}_{2} \mathrm{O}(82.0 \mathrm{mg}, 0.34 \mathrm{mmol}, 1.00$ equiv.). The reaction mixture was stirred under microwave irradiation for $20 \mathrm{~h}$ at $120{ }^{\circ} \mathrm{C}$. Water was added to the reaction mixture and the reaction mixture was extracted by EtOAc. The combined org. phases were washed with brine and the solvent was removed in vacuo. Column chromatography (hexane) afforded the desired product as white solid $(41.4 \mathrm{mg}, 70 \%) .{ }^{1} \mathbf{H}$ NMR (300 MHz, $\left.\mathrm{CDCl}_{3}, \mathrm{ppm}\right) \delta=7.50-7.62(2 \mathrm{H}, \mathrm{m}), 7.30-7.43(2 \mathrm{H}, \mathrm{m}), 7.20-7.29(1 \mathrm{H}, \mathrm{m}), 7.11$ $(1 \mathrm{H}, \mathrm{d}, J=3.5 \mathrm{~Hz}), 6.73(1 \mathrm{H}, \mathrm{dq}, J=3.4,1.1 \mathrm{~Hz}), 2.51 \mathrm{ppm}(3 \mathrm{H}, \mathrm{d}, J=1.1 \mathrm{~Hz}) .{ }^{13} \mathbf{C} \mathbf{N M R}(126$ $\left.\mathrm{MHz}, \mathrm{CDCl}_{3}\right) \delta=141.8,139.4,134.6,128.7,126.9,126.0,125.4,122.8,15.5$ ppm. IR (ATR): $\widetilde{v}\left(\mathrm{~cm}^{-}\right.$ $\left.{ }^{1}\right)=682,747,798,900,944,1026,1072,1210,1259,1440,1468,1496,1596,2851,2913,3020$, 3056. HRMS: calcd. for $\mathrm{C}_{11} \mathrm{H}_{10} \mathrm{~S}\left[\mathrm{M}^{+}\right]=174.0530$; found $=174.0494$. Analytical data corresponded to that described in the literature. ${ }^{159}$ 
Synthesis of 2-methyl-5-phenyl-2,3-dihydro-1,4-dithiine 1,1-dioxide (230)<smiles>CC1CSC(c2ccccc2)=CS1(=O)=O</smiles>

To a solution of sodium sulfide nonahydrate ( $316 \mathrm{mg}, 1.32 \mathrm{mmol}, 2.00$ equiv.) in methanol $(10 \mathrm{~mL})$ was added a solution of the compound $227(135 \mathrm{mg}$, $0.66 \mathrm{mmol}, 2.00$ equiv.) in one drop at rt. The solution was stirred for another $15 \mathrm{~min}$ at $\mathrm{rt}$ and then was added to a water/ice-mixture. Afterwards the suspension was extracted three times with DCM. The combined organic phases 230 were dried over $\mathrm{MgSO}_{4}$ and the solvent was removed by evaporation. After purification by flash chromatography (hexane/ether : 1/1) the product was isolated as white solid (132 mg, 84\%). ${ }^{1} \mathbf{H}$ NMR $\left(300 \mathrm{MHz}, \mathrm{CDCl}_{3}\right) \delta=7.35-7.50(5 \mathrm{H}, \mathrm{m}), 6.54(1 \mathrm{H}, \mathrm{s}), 3.52(1 \mathrm{H}, \mathrm{s}), 3.50(1 \mathrm{H}$, d, $J=1.4 \mathrm{~Hz}), 3.30-3.40(1 \mathrm{H}, \mathrm{m}), 1.55 \mathrm{ppm}(3 \mathrm{H}, \mathrm{d}, J=3.4 \mathrm{~Hz}) .{ }^{13} \mathbf{C} \mathbf{N M R}\left(75 \mathrm{MHz}, \mathrm{CDCl}_{3}\right) \delta=$ 150.2, 130.8, 128.9, 126.7, 119.0, 51.0, 32.5, 11.2 ppm. IR (ATR): $\widetilde{v}\left(\mathrm{~cm}^{-1}\right)=513,540,573,642$, 691,.702, 746, 774, 821, 915, 943, 1026, 1072, 1098, 1118, 1220, 1267, 1293, 1445, 1489, 1556, 3018. HRMS: calcd. for $\mathrm{C}_{11} \mathrm{H}_{12} \mathrm{O}_{2} \mathrm{~S}_{2}[\mathrm{M}+\mathrm{H}]^{+}=241.0351$; found $=241.0343$. 


\subsection{Synthesis of new diphenylsulfane and dibenzothiophene based reagents}

\subsubsection{Synthesis of starting materials}

Synthesis of dibenzo[b,d]thiophene 5-oxide (237)

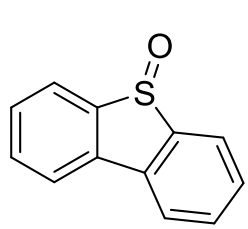

237

Compound 237 was synthesized according to a modified literature procedure. ${ }^{127}$ To a suspension of dibenzothiophene ( $2.00 \mathrm{~g}, 10.9 \mathrm{mmol}, 1.00$ equiv.) in TFA $(8 \mathrm{~mL})$ was added dropwise $\mathrm{H}_{2} \mathrm{O}_{2}\left(1.24 \mathrm{~mL}, 30 \%, 1.20\right.$ equiv.) at $0{ }^{\circ} \mathrm{C}$. Afterwards the reaction was allowed to warm up to r.t. Upon complete consumption of the starting material (monitored by TLC), the reaction was stirred for additional 20 mininutes and then neutralized with $\mathrm{H}_{2} \mathrm{O}$ (ca. $100 \mathrm{~mL}$ ) to precipitate a white solid. The solid was washed with $\mathrm{H}_{2} \mathrm{O}$ (ca. $30 \mathrm{~mL}$ ) and dried in vacuo. The crude product was then purified by column chromatography using DCM/MeOH $\left(50: 1 ; \mathrm{R}_{\mathrm{F}}=0.5\right)$ as the eluent. Removal of the solvents in vacuo afforded 237 as a white solid $(1.66 \mathrm{~g}, 8.26 \mathrm{mmol}, 76 \%)$. Analytical data corresponded to that described in the literature. ${ }^{127}{ }^{1} \mathbf{H}$ NMR $\left(300 \mathrm{MHz}, \mathrm{CDCl}_{3}\right) \delta=7.95$ (ddd, $\left.J=7.6,1.2,0.6 \mathrm{~Hz}, 2 \mathrm{H}\right), 7.76$ (ddd, $J=7.7$, $1.2,0.6 \mathrm{~Hz}, 2 \mathrm{H}), 7.56(\mathrm{td}, J=7.6,1.2 \mathrm{~Hz}, 2 \mathrm{H}), 7.46 \mathrm{ppm}(\mathrm{td}, J=7.5,1.2 \mathrm{~Hz}, 2 \mathrm{H}) .{ }^{13} \mathbf{C}$ NMR $(126$ $\left.\mathrm{MHz}, \mathrm{CDCl}_{3}\right) \delta 145.11,137.02,132.50,129.49,127.46,121.91 \mathrm{ppm}$. IR (ATR): $\widetilde{v}\left(\mathrm{~cm}^{-1}\right)=3055$, 1591, 1578, 1477, 1443, 1220, 1124, 1066, 1042, 1020, 987, 947, 871, 762, 750, 712, 691, 650, 613, 579, 569, 554, 506. HR-MS for $\mathrm{C}_{12} \mathrm{H}_{8}$ OS: calc.: 200.03, found: 200.0293 [M] ${ }^{+}$(EI-HRMS).

\subsubsection{Synthesis of transfer reagents}

\section{General procedure C (GPC)}

These compounds were synthesized by the modification of a literature procedure. ${ }^{125}$ Triflic anhydride (1.00 equiv.) was slowly added at $-50{ }^{\circ} \mathrm{C}$ to a solution of the sulfoxide (1.00 equiv.) in dry DCM (8 $\mathrm{mL} / \mathrm{mmol}$ ). The reaction was stirred for $1 \mathrm{~h}$ at that temperature and then a solution of the desired TMS-alkyne (1.00 equiv.) in DCM (1 mL/mmol) was added dropwise. After this, the reaction was slowly warmed to $-15{ }^{\circ} \mathrm{C}$ and stirred for another $6 \mathrm{~h}$ at this temperature. Removal of the solvents in vacuo afforded crude salts, which were washed with dry $\mathrm{Et}_{2} \mathrm{O}(5 \times 3 \mathrm{~mL} / \mathrm{mmol})$ and dry pentane $(2 \times 3 \mathrm{~mL} / \mathrm{mmol})$ to obtain the desired products as a powder. 
Synthesis of diphenyl(phenylethynyl)sulfonium trifluoromethanesulfonate (205)<smiles>O=S(C#Cc1ccccc1)c1ccccc1</smiles>

205

Using the general procedure GPC, compound 205 was prepared from diphenylsulfoxid $(0.77 \mathrm{~g}, 3.83 \mathrm{mmol}, 1.00$ equiv.), trifluoromethanesulfonic anhydride (0.65 ml, 3.83 mmol, 1.00 equiv.) and 1-phenyl-2trimethylsilylacetylene $(0.44 \mathrm{~g}, 2.50 \mathrm{mmol}, 1.25$ equiv.). The product was obtained as an orange resin $(1.03 \mathrm{~g}, 2.30 \mathrm{mmol}, 60 \%) .{ }^{1} \mathbf{H}-\mathbf{N M R}(500 \mathrm{MHz}$, $\left.\mathrm{CDCl}_{3}\right): \delta[\mathrm{ppm}]=8.218 .18(\mathrm{~m}, 4 \mathrm{H}), 7.80-7.79(\mathrm{~m}, 2 \mathrm{H}) ; 7.747 .68(\mathrm{~m}, 6 \mathrm{H})$, $7.61(\mathrm{tt}, J=7.5,1.2 \mathrm{~Hz}, 1 \mathrm{H}), 7.48(\mathrm{tt}, J=7.9,1.4 \mathrm{~Hz}, 2 \mathrm{H}) \mathrm{ppm} .{ }^{13} \mathbf{C}-\mathbf{N M R}(126$ $\left.\mathrm{MHz}, \mathrm{CDCl}_{3}\right): \delta[\mathrm{ppm}]=135.1,133.9,133.4,132.0,129.8,129.2,128.0,117.0,111.6 \mathrm{ppm} .{ }^{\mathbf{1 9}} \mathbf{F}-\mathbf{N M R}$ $\left(282 \mathrm{MHz}, \mathrm{CDCl}_{3}\right): \delta[\mathrm{ppm}]=-78.1 . \mathbf{I R}(\mathrm{ATR}): \widetilde{v}\left(\mathrm{~cm}^{-1}\right)=3088,3063,2182,2102,1474,1446,1305$, $1259,1222,1028,1012,997,932,872,842,744,681,660,634,587,572,535,514,501$. HR-MS for $\mathrm{C}_{20} \mathrm{H}_{15} \mathrm{~S}^{+}$: calc.: 287.0889; found: $287.0894[\mathrm{M}]^{+}$(ESI-HRMS).

Synthesis of 5-(phenylethynyl)-5H-dibenzo[ $b, d]$ thiophen-5-ium trifluoromethanesulfonate (238a)

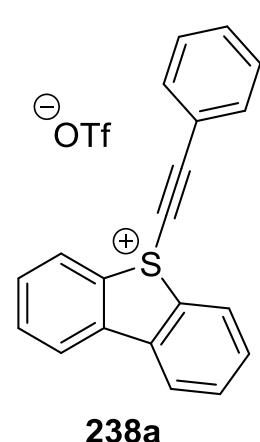

Using the general procedure GPC, compound 238a was prepared from 237 ( $0.77 \mathrm{~g}$, $3.83 \mathrm{mmol}, 1.00$ equiv.), $\mathrm{Tf}_{2} \mathrm{O}(0.65 \mathrm{~mL}, 3.83 \mathrm{mmol}, 1.00$ equiv.) and trimethyl(phenylethynyl)silane ( $0.75 \mathrm{ml}, 3.83 \mathrm{mmol}, 1.00$ equiv.), obtaining after washing a white powder (1.52 g, $3.59 \mathrm{mmol}, 94 \%) .{ }^{1} \mathbf{H}$ NMR $\left(300 \mathrm{MHz}, \mathrm{CD}_{2} \mathrm{Cl}_{2}\right) \delta=8.43$ (ddd, $J=8.1,1.1,0.5 \mathrm{~Hz}, 2 \mathrm{H}$ ), 8.20 (ddd, $J=7.8,1.3,0.5 \mathrm{~Hz}, 2 \mathrm{H}$ ), 7.95 (ddd, $J=$ 7.5, 1.1 Hz, $2 \mathrm{H}), 7.80$ (ddd, $J=8.1,7.5,1.3 \mathrm{~Hz}, 2 \mathrm{H}), 7.72-7.62(\mathrm{~m}, 2 \mathrm{H}), 7.63-$ $7.51(\mathrm{~m}, 1 \mathrm{H}), 7.50-7.35 \mathrm{ppm}(\mathrm{m}, 2 \mathrm{H}) .{ }^{13} \mathbf{C} \mathbf{N M R}\left(101 \mathrm{MHz}, \mathrm{CD}_{2} \mathrm{Cl}_{2}\right) \delta=139.6$, $135.6,134.2,133.5,132.7,130.5,129.5,128.9,125.0,117.8,108.2,64.4 \mathrm{ppm}$. ${ }^{19}$ F NMR (376 MHz, $\left.\mathrm{CD}_{2} \mathrm{Cl}_{2}\right) \delta=-78.74$ ppm. IR (ATR): $\widetilde{v}\left(\mathrm{~cm}^{-1}\right)=3104,3088,3065,3011,2174$, 2121, 2090, 1593, 1574, 1484, 1462, 1449, 1441, 1427, 1257, 1221, 1156, 1151, 1073, 1059, 1026, 998, 952, 936, 884, 867, 785, 760, 702, 689, 658, 635, 612. HR-MS calc. for $\mathrm{C}_{20} \mathrm{H}_{13} \mathrm{~S}: 285.0732$; found: $285.0740[\mathrm{M}]^{+}$(ESI-HRMS). 
Synthesis of 5-((3-chlorophenyl)ethynyl)-5H-dibenzo[ $b, d]$ thiophen-5-ium trifluoromethanesulfonate $(\mathbf{2 3 8 b})$

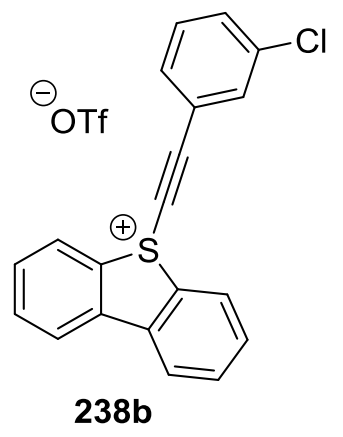

Using the general procedure GPC, compound $\mathbf{2 3 8 b}$ was prepared from $\mathbf{2 3 7}$ (1.15 g, $5.75 \mathrm{mmol}, 1.00$ equiv.), $\mathrm{Tf}_{2} \mathrm{O}$ (0.96 mL, $5.75 \mathrm{mmol}, 1.00$ equiv.) and , 1-chloro-3-[2-(trimethylsilyl)ethynyl]-benzene $(1.26 \mathrm{~g}, \quad 5.75 \mathrm{mmol}$, 1.00 equiv.), obtaining after washing a white powder $(2.18 \mathrm{~g}, 4.65 \mathrm{mmol}$, $81 \%) .{ }^{1} \mathbf{H}$ NMR $\left(300 \mathrm{MHz}, \mathrm{CD}_{2} \mathrm{Cl}_{2}\right) \delta=8.46(\mathrm{ddd}, J=8.1,1.1,0.5 \mathrm{~Hz}, 2 \mathrm{H})$, 8.20 (ddd, $J=7.9,1.3,0.5 \mathrm{~Hz}, 2 \mathrm{H}), 7.95$ (ddd, $J=7.5,1.1 \mathrm{~Hz}, 2 \mathrm{H}), 7.81$ (ddd, $J=8.1,7.5,1.3 \mathrm{~Hz}, 2 \mathrm{H}), 7.63-7.51(\mathrm{~m}, 3 \mathrm{H}), 7.38 \mathrm{ppm}(\mathrm{t}, J=8.2 \mathrm{~Hz}$, $1 \mathrm{H}) .{ }^{13} \mathrm{C}$ NMR $\left(75 \mathrm{MHz}, \mathrm{CD}_{2} \mathrm{Cl}_{2}\right) \delta=139.7,135.6,135.3,133.7,133.6,132.8,132.5,130.9,130.4$, 129.2, 125.0, 119.7, 105.6, 66.0 ppm. ${ }^{19} \mathbf{F}$ NMR $\left(282 \mathrm{MHz}, \mathrm{CD}_{2} \mathrm{Cl}_{2}\right) \delta=-78.78$ ppm. IR (ATR): $\widetilde{v}\left(\mathrm{~cm}^{-1}\right)=1587,1447,1247,1218,1146,1025,905,791,753,633$. HR-MS calc. for $\mathrm{C}_{20} \mathrm{H}_{12} \mathrm{ClS}$ : 319.0348; found: $319.0345[\mathrm{M}]^{+}$(ESI-HRMS).

Synthesis of 5-((4-(trifluoromethyl)phenyl)ethynyl)-5H-dibenzo[b,d]thiophen-5-ium trifluoromethanesulfonate $(\mathbf{2 3 8 c})$

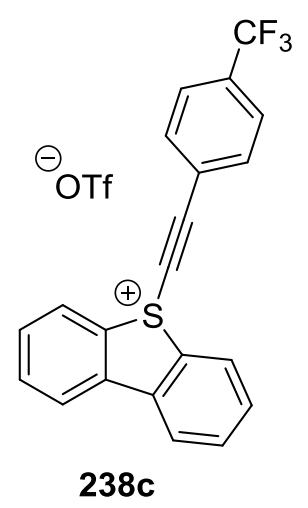

Using the general procedure GPC, compound 238c was prepared from $237(0.50$ g, $2.50 \mathrm{mmol}, 1.00$ equiv.), $\mathrm{Tf}_{2} \mathrm{O}(0.42 \mathrm{~mL}, 2.50 \mathrm{mmol}, 1.00$ equiv.) and 1(trifluoromethyl)-4-[2-(trimethylsilyl)ethynyl]-benzene (0.60 g, $2.50 \mathrm{mmol}, 1.00$ equiv.), obtaining after washing a pale yellow powder $(0.89 \mathrm{~g}, 2.50 \mathrm{mmol}$, quant.). ${ }^{1} \mathbf{H}$ NMR (300 MHz, $\left.\mathrm{CD}_{2} \mathrm{Cl}_{2}\right) \delta=8.49$ (ddd, $J=8.1,1.1,0.5 \mathrm{~Hz}, 2 \mathrm{H}$ ), 8.20 (ddd, $J=7.8,1.3,0.5 \mathrm{~Hz}, 2 \mathrm{H}), 7.96$ (ddd, $J=7.5,1.1 \mathrm{~Hz}, 2 \mathrm{H}), 7.87-7.77$ $(\mathrm{m}, 4 \mathrm{H}), 7.67 \mathrm{ppm}(\mathrm{dt}, J=8.2,0.7 \mathrm{~Hz}, 2 \mathrm{H}) .{ }^{13} \mathbf{C} \mathbf{N M R}\left(75 \mathrm{MHz}, \mathrm{CD}_{2} \mathrm{Cl}_{2}\right) \delta=$ $139.8,139.7,135.7,134.6,134.1,132.8,130.2,129.3,126.4(\mathrm{q}, J=3.8 \mathrm{~Hz})$, 125.0, 121.8, 119.2, 105.1 ppm. ${ }^{19} \mathbf{F}$ NMR $\left(282 \mathrm{MHz}, \mathrm{CD}_{2} \mathrm{Cl}_{2}\right) \delta=-63.80$, $-78.82 \mathrm{ppm}$. IR (ATR): $\widetilde{v}\left(\mathrm{~cm}^{-1}\right)=3094,2185,1450,1405,1319,1247,1153,1066,1025,849,755$, 703, 635, 612. HR-MS calc. for $\mathrm{C}_{21} \mathrm{H}_{12} \mathrm{~F}_{3} \mathrm{~S}$ : 353.0606; found: 353.0607 [M] ${ }^{+}$(ESI-HRMS). 
Synthesis of 5-((4-fluorophenyl)ethynyl)-5H-dibenzo[b,d]thiophen-5-ium trifluoromethanesulfonate (238d)

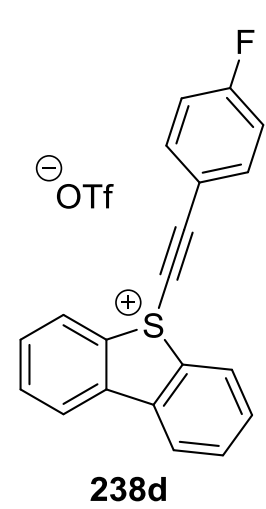

Using the general procedure GPC, compound 238d was prepared from 237 ( $0.37 \mathrm{~g}$, $1.87 \mathrm{mmol}, 1.00$ equiv.), $\mathrm{Tf}_{2} \mathrm{O}(0.32 \mathrm{~mL}, 3.90 \mathrm{mmol}, 1.00$ equiv.) and 1-fluoro-4[2-(trimethylsilyl)ethynyl]-benzene $(0.36 \mathrm{~g}, 1.87 \mathrm{mmol}, 1.00$ equiv.), obtaining after washing a pale yellow powder $(0.65 \mathrm{~g}, 1.44 \mathrm{mmol}, 77 \%) .{ }^{1} \mathbf{H}$ NMR (300 $\left.\mathrm{MHz}, \mathrm{CD}_{2} \mathrm{Cl}_{2}\right) \delta=8.42(\mathrm{~d}, J=8.2 \mathrm{~Hz}, 2 \mathrm{H}), 8.20(\mathrm{ddd}, J=7.7,1.1 \mathrm{~Hz}, 2 \mathrm{H}), 7.94$ $(\mathrm{dt}, J=7.7,0.9 \mathrm{~Hz}, 2 \mathrm{H}), 7.79(\mathrm{dt}, J=8.0,1.1,2 \mathrm{H}), 7.72-7.67(\mathrm{~m}, 2 \mathrm{H}), 7.14-$ $7.08(\mathrm{~m}, 2 \mathrm{H}) .{ }^{13} \mathbf{C}$ NMR $\left(75 \mathrm{MHz}, \mathrm{CD}_{2} \mathrm{Cl}_{2}\right) \delta=166.1(\mathrm{~d}, J=287.8 \mathrm{~Hz}), 139.6$, $137.9(\mathrm{~d}, J=10.0 \mathrm{~Hz}), 135.6,132.7,130.4,129.0,125.0,117.5(\mathrm{~d}, J=20.7 \mathrm{~Hz})$, $114.1(\mathrm{~d}, J=3.5 \mathrm{~Hz}), 107.1,64.5(\mathrm{~d}, J=2.3 \mathrm{~Hz}) \mathrm{ppm} .{ }^{19} \mathbf{F}$ NMR $\left(282 \mathrm{MHz}, \mathrm{CD}_{2} \mathrm{Cl}_{2}\right) \delta=-78.87$, 102.44 ppm. IR (ATR): $\widetilde{v}\left(\mathrm{~cm}^{-1}\right)=3087,3066,2972,2868,2180,2133,2112,1598,1506,1482$, $1465,1449,1427,1282,1255,1242,1221,1151,1114,1077,1062,1026,999,875,842,822,798$, 842, 822, 797, 765, 706, 669, 634, 612. HR-MS calc. for $\mathrm{C}_{20} \mathrm{H}_{12} \mathrm{FS}: 303.0638$; found: $303.0630[\mathrm{M}]^{+}$ (ESI-HRMS).

Synthesis of 5-((2-bromophenyl)ethynyl)-5H-dibenzo[b,d]thiophen-5-ium trifluoromethanesulfonate (238e)

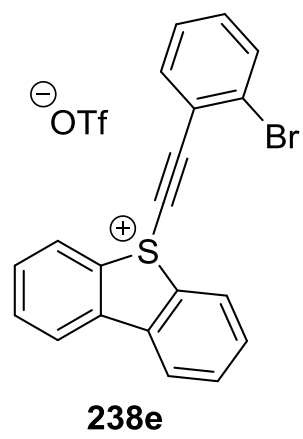

Using the general procedure GPC, compound 238e was prepared from 237 ( 0.78 g, $3.90 \mathrm{mmol}, 1.00$ equiv.), $\mathrm{Tf}_{2} \mathrm{O}(0.66 \mathrm{~mL}, 3.90 \mathrm{mmol}, 1.00$ equiv. $)$ and 1bromo-2-[2-(trimethylsilyl)ethynyl]-benzene ( $0.60 \mathrm{~g}, 3.90 \mathrm{mmol}, 1.00$ equiv.), obtaining after washing a pale yellow powder (1.45 g, $2.83 \mathrm{mmol}, 73 \%)$. ${ }^{1} \mathbf{H}$ NMR $\left(300 \mathrm{MHz}, \mathrm{CD}_{2} \mathrm{Cl}_{2}\right) \delta=8.46(\mathrm{ddd}, J=8.1,1.1,0.5 \mathrm{~Hz}, 2 \mathrm{H}), 8.20$ (ddd, $J=7.9,1.3,0.5 \mathrm{~Hz}, 2 \mathrm{H}), 7.96$ (ddd, $J=7.5,1.1 \mathrm{~Hz}, 2 \mathrm{H}), 7.82$ (ddd, $J=$ 8.1, 7.5, 1.3 Hz, $2 \mathrm{H}), 7.77$ - $7.72(\mathrm{~m}, 1 \mathrm{H}), 7.65$ - $7.59(\mathrm{~m}, 1 \mathrm{H}), 7.44-$ $7.37 \mathrm{ppm}(\mathrm{m}, 2 \mathrm{H}){ }^{\mathbf{1 3}} \mathbf{C}$ NMR $\left(126 \mathrm{MHz}, \mathrm{CD}_{2} \mathrm{Cl}_{2}\right) \delta=139.7,135.7,135.3,133.7,133.6,132.8,132.5$, 130.9, 130.4, 129.2, 125.0, 119.6, 105.6, 66.0 ppm. ${ }^{19} \mathbf{F}$ NMR $\left(282 \mathrm{MHz}, \mathrm{CD}_{2} \mathrm{Cl}_{2}\right) \delta=-78.77 \mathrm{ppm} . \mathbf{I R}$ $(\mathrm{ATR}): \widetilde{v}\left(\mathrm{~cm}^{-1}\right)=3091,1576,1447,1270,1248,1222,1149,1025,868,754,702,634,612,571,515$, 420. HR-MS calc. for $\mathrm{C}_{20} \mathrm{H}_{12} \mathrm{BrS}$ : 362.9843; found: 362.9838 [M] $]^{+}$(ESI-HRMS). 
Synthesis of 5-((triisopropylsilyl)ethynyl)-5H-dibenzo[ $b, d]$ thiophen-5-ium trifluoromethanesulfonate (238f)

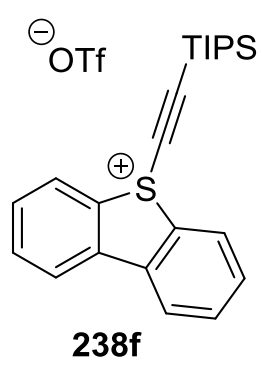

Using the general procedure GPC, compound 238f was prepared from 237 (2.00 g, $10.0 \mathrm{mmol}, 1.00$ equiv.), $\mathrm{Tf}_{2} \mathrm{O}$ (1.68 mL, $10.0 \mathrm{mmol}, 1.00$ equiv.) and trimethyl[2[tris(1-methylethyl)silyl]ethynyl]-silane (3.14 mL, $10.0 \mathrm{mmol}, 1.00$ equiv.), obtaining after washing a white powder $(4.36 \mathrm{~g}, 8.47 \mathrm{mmol}, 85 \%)$. ${ }^{\mathbf{1}} \mathbf{H}$ NMR (300 $\left.\mathrm{MHz}, \mathrm{CD}_{2} \mathrm{Cl}_{2}\right) \delta=8.33(\mathrm{ddd}, J=8.1,1.0,0.5 \mathrm{~Hz}, 2 \mathrm{H}), 8.20(\mathrm{ddd}, J=7.8,1.3,0.5$ $\mathrm{Hz}, 2 \mathrm{H}), 7.94(\mathrm{dt}, J=7.7,1.1 \mathrm{~Hz}, 2 \mathrm{H}), 7.82(\mathrm{ddd}, J=8.6,8.1,1.3 \mathrm{~Hz}, 2 \mathrm{H})$. ${ }^{13} \mathbf{C ~ N M R}\left(75 \mathrm{MHz}, \mathrm{CD}_{2} \mathrm{Cl}_{2}\right) \delta=139.6,135.5,132.7,131.1,128.4,125.1,118.6,78.9,18.6,11.5$ ppm. ${ }^{19}$ F NMR (282 MHz, $\left.\mathrm{CD}_{2} \mathrm{Cl}_{2}\right) \delta=-78.77 \mathrm{ppm}$. IR (ATR): $\widetilde{v}\left(\mathrm{~cm}^{-1}\right)=2945,2924,2865,1461$, 1448, 1273, 1249, 1226, 1154, 1130, 1072, 1062, 1029, 997, 966, 921, 880, 822, 767, 757, 704, 685, 657, 636, 614, 605,. HR-MS calc. for $\mathrm{C}_{23} \mathrm{H}_{29} \mathrm{SiS:} 365.1754$; found: 365.1754 [M] ${ }^{+}$(ESI-HRMS).

Synthesis of (E)-5-styryl-5H-dibenzo[b,d]thiophen-5-ium trifluoromethanesulfonate (238p)

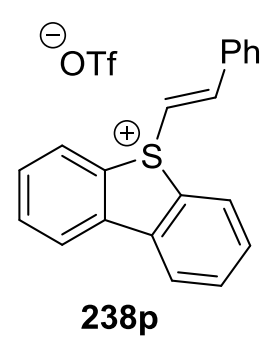

Using the general procedure GPC, compound 238p was prepared from dibenzothiophene sulfoxide $\mathbf{2 3 7}$ (0.40 g, $2.00 \mathrm{mmol}, 1.00$ equiv.), trifluoromethanesulfonic anhydride $(0.34 \mathrm{ml}, 2.00 \mathrm{mmol}, 1.00$ equiv.) and trimethyl-(styryl)-silane $(0.44 \mathrm{~g}, 2.50 \mathrm{mmol}, 1.25$ equiv.). The product was obtained as a green powder (0.76 g, $1.74 \mathrm{mmol}, 87 \%) .{ }^{1} \mathbf{H}-\mathbf{N M R}(300 \mathrm{MHz}$, $\left.\mathrm{CD}_{2} \mathrm{Cl}_{2}\right): \delta[\mathrm{ppm}]=8.49(\mathrm{~d}, J=15.0 \mathrm{~Hz}, 1 \mathrm{H}), 8.25(\mathrm{dd}, J=18.3,7.9 \mathrm{~Hz}, 4 \mathrm{H}), 7.98$ $-7.91(\mathrm{~m}, 2 \mathrm{H}), 7.82-7.74(\mathrm{~m}, 2 \mathrm{H}), 7.66-7.59(\mathrm{~m}, 2 \mathrm{H}), 7.50(\mathrm{dt}, J=14.3,7.0 \mathrm{~Hz}, 3 \mathrm{H})$, $6.33(\mathrm{~d}, J=15.0 \mathrm{~Hz}, 1 \mathrm{H}) \mathrm{ppm} .{ }^{13} \mathrm{C}-\mathbf{N M R}\left(125 \mathrm{MHz}, \mathrm{CD}_{2} \mathrm{Cl}_{2}\right): \delta[\mathrm{ppm}]=155.0,139.2,134.44,132.6$, 132.4, 131.6, 130.0, 129.3, 129.0, 128.5, 124.0, 111.5 ppm. ${ }^{19} \mathbf{F}-\mathbf{N M R}\left(282 \mathrm{MHz}, \mathrm{CD}_{2} \mathrm{Cl}_{2}\right): \delta[\mathrm{ppm}]=$ -78.8 ppm. IR (ATR): $\widetilde{v}\left(\mathrm{~cm}^{-1}\right)=3487.3084,3054,1598,1569,1484,1448,1430,1251,1221,1150$, 1075, 1025, 1000, 967, 856, 748, 704, 688, 633, 586, 571, 514. HR-MS for $\mathrm{C}_{20} \mathrm{H}_{15} \mathrm{~S}^{+}$: calc.: 287.0889; found: $287.0886[\mathrm{M}]^{+}$(ESI-HRMS). 


\subsubsection{Synthesis of labeled reagents}

Synthesis of (2,2-dibromovinyl-1- $\left.{ }^{13} \mathrm{C}\right)$ benzene (321)<smiles>BrC(Br)=Cc1ccccc1</smiles>

For the synthesis of (2,2-dibromovinyl-1- $\left.{ }^{13} \mathrm{C}\right)$ benzene a slightly modified literature procedure was used. ${ }^{132}$ To a solution of $\mathrm{CBr}_{4}(3.33 \mathrm{~g}, 10.0 \mathrm{mmol}, 2.00$ equiv.) and $\mathrm{PPh}_{3}$ (5.25 g, $20.0 \mathrm{mmol}, 4.00$ equiv.) in DCM $(20 \mathrm{~mL})$ was added dropwise a 321 solution of labeled benzaldehyde $(0.50 \mathrm{~mL}, 5 \mathrm{mmol}, 1.00 \mathrm{eq}, 20 \%$ enriched) in DCM $(6 \mathrm{~mL})$ at $0{ }^{\circ} \mathrm{C}$. The reaction mixture was stirred for $3 \mathrm{~h}$ at $\mathrm{rt}$ and subsequently the reaction mixture was filtered through a short pad of silica. The solvent was removed under reduced pressure and after column chromatography (pure hexane) the labeled product could be obtained as colorless oil (1.14 g, $4.35 \mathrm{mmol}, 87 \%)$. Analytical data corresponded to those described in the literature. ${ }^{132}$

Synthesis of compound trimethyl(phenylethynyl-2- ${ }^{13} \mathrm{C}$ )silane (322)

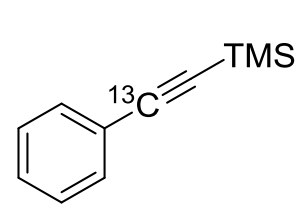

322

For the synthesis of labeled trimethyl(phenylethynyl-2- ${ }^{13} \mathrm{C}$ ) silane a slightly modified literature procedure was used. ${ }^{132}$ To a solution of the dibromide 321 ( $1.14 \mathrm{~g}, 4.35 \mathrm{mmol}, 1.00$ equiv.) in THF (30 mL) was added $n \mathrm{BuLi}(2.5 \mathrm{M}$ in hexane, $4.35 \mathrm{~mL}, 10.9 \mathrm{mmol}, 2.50$ equiv.) at $-78^{\circ} \mathrm{C}$. The solution was stirred for

$1 \mathrm{~h}$ at $-78^{\circ} \mathrm{C}$ and subsequently TMSCl (1.18 g, $10.9 \mathrm{mmol}, 2.50$ equiv.) was added to the reaction mixture. The reaction mixture was warmed up to $\mathrm{rt}$ and stirred for another hour at this temperature. A saturated aqueous solution of $\mathrm{NH}_{4} \mathrm{Cl}$ was added and the reaction mixture was extracted with diethylether $(2 \times 20 \mathrm{~mL})$. The combined org. phases were dried over $\mathrm{Na}_{2} \mathrm{SO}_{4}$ and after purification by flash chromatography the desired product could be obtained as colorless oil $(550 \mathrm{mg}$, $3.16 \mathrm{mmol}, 73 \%$ ). Analytical data corresponded to those described in the literature. ${ }^{132}$ 
Synthesis of labeled 5-(phenylethynyl)-5H-dibenzo[b,d]thiophen-5-ium trifluoromethanesulfonate $\left(238 a^{*}\right)$

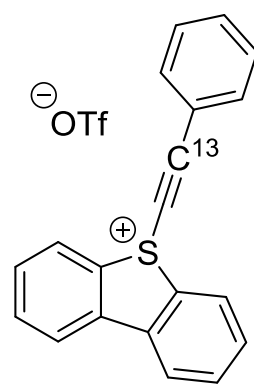

238a*

Using the general procedure GPC, compound 238a* was prepared from 237 (674 mg, $3.34 \mathrm{mmol}, 1.00$ equiv.), $\mathrm{Tf}_{2} \mathrm{O}$ (0.56 mL, $3.34 \mathrm{mmol}, 1.00$ equiv.) and trimethyl(phenylethynyl-2- ${ }^{13} \mathrm{C}$ ) silane (582 mg, $3.34 \mathrm{mmol}, 1.00$ equiv.), obtaining a white powder (1.26 g, $2.99 \mathrm{mmol}, 90 \%)$ after washing. ${ }^{1} \mathbf{H}$ NMR $(300 \mathrm{MHz}$, $\left.\mathrm{CD}_{2} \mathrm{Cl}_{2}\right) \delta=8.60(\mathrm{~d}, J=8.6 \mathrm{~Hz}, 2 \mathrm{H}), 8.21(\mathrm{~d}, J=8.2 \mathrm{~Hz}, 2 \mathrm{H}), 7.94(\mathrm{dd}, J=8.2$, $7.8 \mathrm{~Hz}, 2 \mathrm{H}), 7.78$ (dd, $J=8.5,7.8 \mathrm{~Hz}, 2 \mathrm{H}), 7.63$ (d, $J=7.9 \mathrm{~Hz}, 2 \mathrm{H}), 7.55$ (tt, $J=$ 7.9, $1.7 \mathrm{~Hz}, 1 \mathrm{H}), 7.40(\mathrm{~d}, J=7.9 \mathrm{~Hz}, 2 \mathrm{H}) .{ }^{13} \mathbf{C} \mathbf{N M R}\left(101 \mathrm{MHz}, \mathrm{CD}_{2} \mathrm{Cl}_{2}\right) \delta=$ $139.6,135.6,134.2,133.5,132.7,130.5,129.5,129.1,125.0,117.9,108.2\left({ }^{13} \mathrm{C}-\right.$ enriched), 64.4, ppm. ${ }^{19} \mathbf{F}$ NMR (287 MHz, $\left.\mathrm{CD}_{2} \mathrm{Cl}_{2}\right) \delta=-78.79 \mathrm{ppm}$. IR (ATR): $\widetilde{v}\left(\mathrm{~cm}^{-1}\right)=3106$, 3086, 2175, 2143, 1484, 1449, 1442, 1427, 1258, 1221, 1157, 1072, 1059, 1028, 998, 952, 936, 905884, 867, 785, 861, 734, 702, 761, 734, 702, 689, 659, 635,612. HR-MS calc. for $\mathrm{C}_{20} \mathrm{H}_{13} \mathrm{~S}$ : 285.0732; found: $285.0730[\mathrm{M}]^{+}$(ESI-HRMS)

Synthesis of the compound 2-((4-methoxybenzyl)oxy)ethan-1-ol (324)<smiles>COc1ccc(COCCO)cc1</smiles>

324

For the synthesis of compound $\mathbf{3 2 4}$ a slightly modified literature procedure was used. ${ }^{160}$ To a solution of glycol $(11.4 \mathrm{~mL}, 228 \mathrm{mmol}$, 6.00 equiv.) in THF (65 mL) was added dropwise $\mathrm{NaH}(60 \%, 1.35 \mathrm{~g}$, $33.8 \mathrm{mmol}, 1.00$ equiv.) at $0{ }^{\circ} \mathrm{C}$. After stirring for $15 \mathrm{~min}$ at $0{ }^{\circ} \mathrm{C}$ TBAI (1.25 g, $3.38 \mathrm{mmol}, 0.10$ equiv.) was added, followed by the dropwise addition of the chloride (4.60 ml, $33.8 \mathrm{mmol}, 1.00$ equiv.). The mixture was stirred at $65{ }^{\circ} \mathrm{C}$ for $12 \mathrm{~h}$ and subsequently $\mathrm{s}$ saturated aqueous solution of $\mathrm{NH}_{4} \mathrm{Cl}(150 \mathrm{~mL})$ was added to the reaction mixture. The organic phase was extracted with diethylether and the combined organic phases were dried over $\mathrm{Na}_{2} \mathrm{SO}_{4}$. After flash chromatography (hexane: EtOAc $=1: 1)$ the desired product could be obtained as yellow oil $(5.24 \mathrm{~g}$, $28.7 \mathrm{mmol}, 85 \%$ ). Analytical data corresponded to those described in the literature. ${ }^{160}$ 
<smiles>COc1ccc(COCC=O)cc1</smiles>

325

For the synthesis of $\mathbf{3 2 5}$ a slightly modified literature procedure was used. $^{100}$ To a solution of the alcohol $324(630 \mathrm{mg}, 3.60 \mathrm{mmol}$, 1.00 equiv. $)$ in DCM $(27 \mathrm{~mL})$ was added DMP $(1.59 \mathrm{mmol}$, $3.90 \mathrm{mmol}, 1.00$ equiv.) and the suspension was stirred for $2.5 \mathrm{~h}$ at $\mathrm{rt}$. A saturated aqueous solution of $\mathrm{NaHCO}_{3}(30 \mathrm{~mL})$ and a saturated aqueous solution of $\mathrm{Na}_{2} \mathrm{~S}_{2} \mathrm{O}_{3}(30 \mathrm{ml})$ was added to the reaction mixture and the resulting biphasic mixture was stirred for $10 \mathrm{~min}$ until a clear mixture occurred. The layers were separated and the organic phase was washed with water $(30 \mathrm{~mL})$ and brine $(30 \mathrm{~mL})$. The organic phases were dried over $\mathrm{Na}_{2} \mathrm{SO}_{4}$. After removal of the solvent under reduced pressure the desired product could be obtained as yellow oil $(630 \mathrm{mg}, 3.49 \mathrm{mmol}$, $97 \%$ ). Analytical data corresponded to those described in the literature. ${ }^{100}$

Synthesis of 1-(((3,3-dibromoallyl-3- $\left.{ }^{13} \mathrm{C}\right)$ oxy)methyl)-4-methoxybenzene (326)

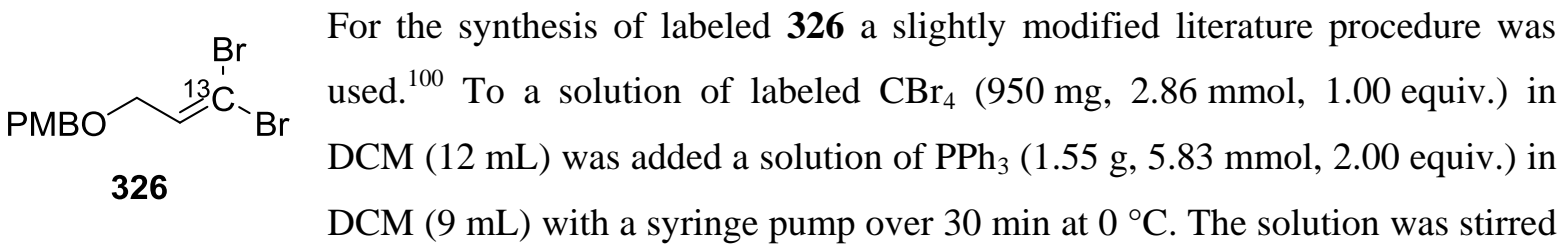
for another $15 \mathrm{~min}$ at $0{ }^{\circ} \mathrm{C}$ and then cooled to $-78{ }^{\circ} \mathrm{C}$. Subsequently a solution of the aldehyde 325 (630 mg, $3.49 \mathrm{mmol}, 1.20$ equiv.) was added with a syringe pump to the reaction mixture at $-78{ }^{\circ} \mathrm{C}$. The solution was stirred for another $12 \mathrm{~h}$, slowly warming up to rt. A saturated aqueous solution of $\mathrm{NaHCO}_{3}(30 \mathrm{ml})$ was added to the reaction mixture. Phases were separated and the aqueous phase was extracted by DCM ( $3 \times 20 \mathrm{~mL})$. The combined org. phases were washed water $(30 \mathrm{~mL})$, brine $(30 \mathrm{~mL})$ and dried over $\mathrm{Na}_{2} \mathrm{SO}_{4}$. After column chromatography (pure hexane) the product could be obtained as colorless oil (530 mg, $1.58 \mathrm{mmol}, 55 \%)$. Analytical data corresponded to those described in the literature. ${ }^{100}$ 
Synthesis of labeled labeled triisopropyl(3-((4-methoxybenzyl)oxy)prop-1-yn-1-yl)silane (327)

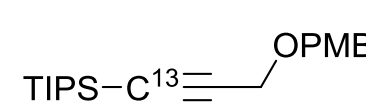

327

For the synthesis of labeled $\mathbf{3 2 7}$ a slightly modified literature procedure was used. $^{100}$ To a solution of the dibromide 326 (530 $\mathrm{mg}, 1.58 \mathrm{mmol}$, 1.00 equiv.) in THF (10.5 mL) was added $n \operatorname{BuLi}(2.5 \mathrm{M}$ in hexane, $1.40 \mathrm{~mL}$, $3.48 \mathrm{mmol}, 2.20$ equiv.) at $-78^{\circ} \mathrm{C}$ and the solution was stirred for $1 \mathrm{~h}$ at $78{ }^{\circ} \mathrm{C}$. The solution was warmed up to $\mathrm{rt}$ and stirred for another hour at this temperature. Then the solution was cooled back to $-78^{\circ} \mathrm{C}$ and TIPSCl $(0.44 \mathrm{~mL}, 2.05 \mathrm{mmol}, 1.30$ equiv. $)$ was added. The reaction mixture was stirred for $12 \mathrm{~h}$, slowly was warming up to $\mathrm{rt}$. A saturated aqueous solution of $\mathrm{NaHCO}_{3}(30 \mathrm{~mL})$ was added and the mixture was extracted with $\mathrm{Et}_{2} \mathrm{O}(3 \times 20 \mathrm{~mL})$. The combined organic phases were washed with brine and dried over $\mathrm{Na}_{2} \mathrm{SO}_{4}$. After flash chromatography the desired product could be isolated as colorless oil (456 mg, $1.37 \mathrm{mmol}, 87 \%)$. Analytical data corresponded to those described in the literature. ${ }^{100}$

Synthesis of (ethynyl- $\left.{ }^{13} \mathrm{C}\right)$ triisopropylsilane (328)

13.TIPS For the synthesis of labeled compound $\mathbf{3 2 8}$ a slightly modified literature procedure was used. ${ }^{100}$ To a suspension of the ether 327 (472 mg, $1.42 \mathrm{mmol}, 1.00$ equiv.) in DCM

$328(10 \mathrm{~mL})$ and water $(1 \mathrm{~mL})$ was added DDQ (484 mg, $2.13 \mathrm{mmol}, 1.50$ equiv.) at $0{ }^{\circ} \mathrm{C}$ and the reaction was stirred for 15 in at $0{ }^{\circ} \mathrm{C}$ and $3 \mathrm{~h}$ at $\mathrm{rt}$. Then a saturated aqueous solution of $\mathrm{NaHCO}_{3}(30 \mathrm{~mL})$ was adding to the reaction mixture and the reaction mixture was extracted by DCM $(3 \times 15 \mathrm{~mL})$. The combined org. phases were washed with brine $(2 \times 30 \mathrm{~mL})$ and dried over $\mathrm{Na}_{2} \mathrm{SO}_{4}$. The solvent was removed under reduced pressure and the resulting residue was dissolved in diethylether ( $25 \mathrm{~mL})$. Manganese dioxide (1.85 g, $21.3 \mathrm{mmol}, 15.00$ equiv.) and potassium hydroxide (599 mg, $10.7 \mathrm{mmol}, 7.50$ equiv.) were added to reaction in four portions over $3 \mathrm{~h}$. Afterwards the reaction mixture was stirred for another $4 \mathrm{~h}$ at $\mathrm{rt}$. The excess of manganese dioxide was removed by filtration over a short pad of silica. Column chromatography (pentane) afforded the product as colorless oil (200 mg, $1.10 \mathrm{mmol}, 77 \%)$. Analytical data corresponded to those described in the literature. $^{100}$ 
Synthesis of triisopropyl((trimethylsilyl)ethynyl-1- $\left.{ }^{13} \mathrm{C}\right)$ silane (329)

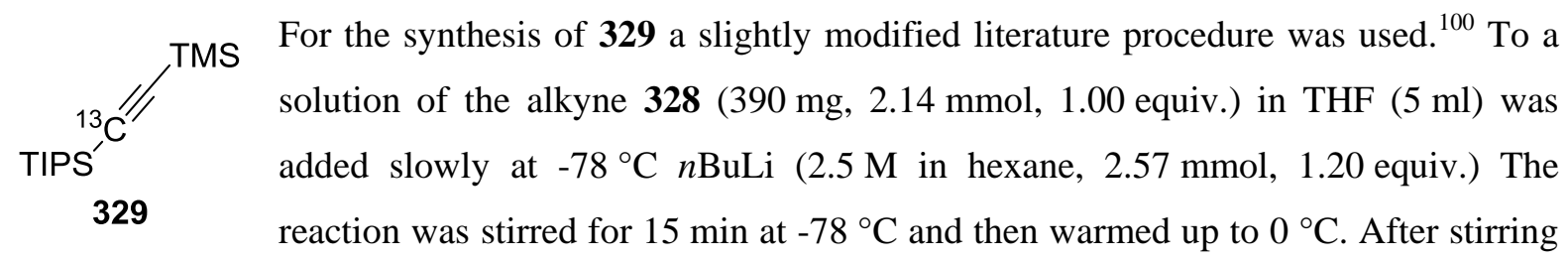
for another $5 \mathrm{~min}$ at $0{ }^{\circ} \mathrm{C}$ the solution was cooled back to $-78{ }^{\circ} \mathrm{C}$ and $\mathrm{TMSCl}(0.35 \mathrm{~mL}, 2.78 \mathrm{mmol}$, 1.30 equiv.) was added to the reaction mixture. The reaction mixture was stirred for another $12 \mathrm{~h}$, slowly warming up to rt. A saturated aqueous solution of $\mathrm{NH}_{4} \mathrm{Cl}$ was added to the reaction mixture. The reaction mixture was extracted with diethylether $(3 \times 20 \mathrm{~mL})$ and the combined organic phases were washed with brine and subsequently dried over $\mathrm{Na}_{2} \mathrm{SO}_{4}$. Column chromatography (pure pentane) offered the product as colorless oil (361 mg, $1.42 \mathrm{mmol}, 66 \%$ ). Analytical data corresponded to those described in the literature. ${ }^{100}$

Synthesis of compound labeled 5-((triisopropylsilyl)ethynyl)-5H-dibenzo[b, $d]$ thiophen-5-ium trifluoromethanesulfonate (238f*)

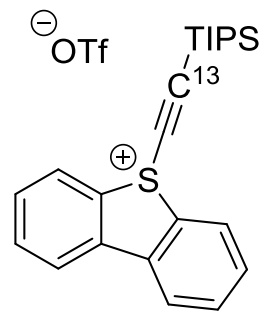

238f*

Using the general procedure GPC, compound 238f* was prepared from 329 (280 mg, $1.42 \mathrm{mmol}, 1.00$ equiv.), $\mathrm{Tf}_{2} \mathrm{O}$ (0.24 mL, $1.42 \mathrm{mmol}, 1.00$ equiv.) and labeled trimethyl[2-[tris(1-methylethyl)silyl]ethynyl]silane (361 mg, $1.42 \mathrm{mmol}$, 1.00 equiv.), obtaining after washing a white powder (607 mg, $1.21 \mathrm{mmol}, 85 \%)$. ${ }^{1} \mathbf{H}$ NMR $\left(300 \mathrm{MHz}, \mathrm{CD}_{2} \mathrm{Cl}_{2}\right) \delta=8.32(\mathrm{~d}, J=8.5 \mathrm{~Hz}, 2 \mathrm{H}), 8.19(\mathrm{dd}, J=7.7$, $1.3 \mathrm{~Hz}, 2 \mathrm{H}), 7.94(\mathrm{dt}, J=7.7,1.0 \mathrm{~Hz}, 2 \mathrm{H}), 7.79(\mathrm{dt}, J=7.7,1.2 \mathrm{HZ}, 2 \mathrm{H})$, 1.21-1.07 (m, $3 \mathrm{H}), 1.02-1.00$ (m, $18 \mathrm{H}) .{ }^{13} \mathbf{C} \mathbf{~ N M R}\left(126 \mathrm{MHz}, \mathrm{CD}_{2} \mathrm{Cl}_{2}\right) \delta=139.5,135.4,132.6,131.0$, 128.3, 125.0, 118.6 (enriched, major), 78.8 (enriched, minor), 18.6, 11.5. ppm. ${ }^{\mathbf{1 9}} \mathbf{F}$ NMR $(282 \mathrm{MHz}$, $\left.\mathrm{CD}_{2} \mathrm{Cl}_{2}\right) \delta=-78.87 \mathrm{ppm}$. IR (ATR): $\widetilde{v}\left(\mathrm{~cm}^{-1}\right)=2945,2866,1462,1448,1271,1249,1226,1153$, 1072, 1062, 1028, 997, 966, 921, 880, 821, 766, 757, 704. HR-MS calc. for $\mathrm{C}_{20} \mathrm{H}_{12} \mathrm{BrS}: 365.1754$; found: $365.1747[\mathrm{M}]^{+}$(ESI-HRMS). 


\subsection{Electrophilic group transfer to nucleophiles}

\subsubsection{Reactions with benchmark nucleophiles}

General procedure D (GPD)

To a suspension of a the desired nucleophile (1.00 equiv.) and $\mathrm{Cs}_{2} \mathrm{CO}_{3}$ (1.10 equiv.) in dry DCM/DCE $(14 \mathrm{~mL} / \mathrm{mmol})$, was added the corresponding dibenzothiophenium salt (1.20-1.50 equiv.). The reaction was stirred for $12 \mathrm{~h}$. at the specified temperature. After quenching with water $(8 \mathrm{~mL})$, the mixture was extracted using DCM $(3 \times 10 \mathrm{~mL})$, the organic layers were combined, dried over $\mathrm{MgSO}_{4}$ and the solvents were removed in vacuo. The crude products were purified by column chromatography.

Synthesis of triisopropyl(((4-methoxybenzyl)thio)ethynyl)silane (255)

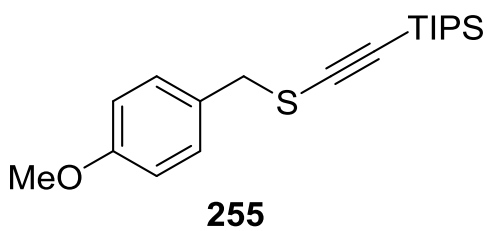

chromatography using (hexane/EtOAc : 20/1) compound 255 was obtained as a yellow oil (66.8 mg, 72\%). ${ }^{1} \mathbf{H}$ NMR $\left(300 \mathrm{MHz}, \mathrm{CDCl}_{3}\right) \delta=7.26(\mathrm{td}, J=8.7,3.1 \mathrm{~Hz}, 2 \mathrm{H}), 6.84(\mathrm{td}, J=8.7,3.1 \mathrm{~Hz}, 2 \mathrm{H})$, 3.92 (s, $2 \mathrm{H}), 3.80$ (s, $3 \mathrm{H}), 1.04$ ppm (m, $21 \mathrm{H}) .{ }^{13} \mathbf{C}$ NMR $\left(126 \mathrm{MHz}, \mathrm{CDCl}_{3}\right) \delta=159.2,130.3,128.9$, 114.1, 98.7, 95.7, 55.5, 40.4, 18.8, 11.6 ppm. IR (ATR): $\widetilde{v}\left(\mathrm{~cm}^{-1}\right)=2992,2941,2863,2836,2721$, 2557, 2087, 1881, 1610, 1584, 1510, 1462, 1441, 1423, 1383, 1365, 1317, 1302, 1250, 1236, 1205, 1174, 1123, 1105, 1072, 1036, 1016, 995, 919, 881, 855, 828, 807, 745, 727, 674, 654. HR-MS calc. for $\mathrm{C}_{19} \mathrm{H}_{30} \mathrm{OSSi}$ : 334.1787 ; found: 334.1781 [M] $]^{+}$(EI-HRMS). Analytical data corresponded to those previously reported. ${ }^{161}$

Synthesis of (4-methoxybenzyl)(phenylethynyl)sulfane (256)

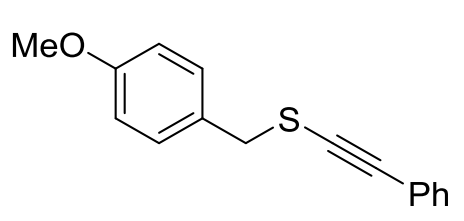

Using the general procedure GPD, compound 256 was prepared from (4-methoxyphenyl)methanethiol (34.0 mg, $0.22 \mathrm{mmol}, 1.00$ equiv.), $\mathrm{Cs}_{2} \mathrm{CO}_{3}$ (78 mg, $0.24 \mathrm{mmol}, 1.10$ equiv.) and $\mathbf{2 3 8 a}(115 \mathrm{mg}, 0.55$ mmol, 1.50 equiv. $)$ in dry DCM $(3 \mathrm{~mL})$. The reaction was carried out 256 at RT for $12 \mathrm{~h}$. After flash chromatography using (hexane/EtOAc 5/1) compound 256 was obtained as a yellow oil $(76.1 \mathrm{mg}, 70 \%) .{ }^{1} \mathbf{H}$ NMR $\left(300 \mathrm{MHz}, \mathrm{CDCl}_{3}\right) \delta=$ $7.347 .23(\mathrm{~m}, 7 \mathrm{H}), 6.85$ (td, $J=8.6,2.0 \mathrm{~Hz}, 2 \mathrm{H}, 3.97$ (s, $2 \mathrm{H}), 3.78 \mathrm{ppm}(\mathrm{s}, 3 \mathrm{H}) .{ }^{13} \mathbf{C}$ NMR $(75$ $\left.\mathrm{MHz}, \mathrm{CDCl}_{3}\right) \delta=159.4,131.4,130.4,128.7,128.9,128.1,123.6,114.1,94.6,79.6,55.4,40.2$ ppm. IR (ATR): $\widetilde{v}\left(\mathrm{~cm}^{-1}\right)=3061,2953,2931,2906,2834,2359,2332,2164,1885,1734,1608,1595,1583$, 1509, 1486, 1462, 1440, 1421, 1317, 1302, 1248, 1236, 1205, 1174, 1236, 1205, 1174, 1105, 1068, 
1031, 913, 883, 829, 752, 689, 653, 544, 530, 514. HR-MS for $\mathrm{C}_{16} \mathrm{H}_{14} \mathrm{OS}$ : calc.: 255.0838; found: $255.0834[\mathrm{M}+\mathrm{H}]^{+}($ESI-HRMS $)$.

Synthesis of methyl 2-(((triisopropylsilyl)ethynyl)thio)acetate (257)

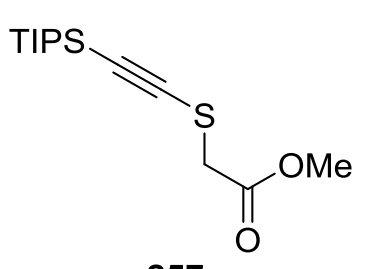

257

Using the general procedure GPD, compound 257 was prepared from the methyl 2-mercaptoacetate (71.6 mg, $0.29 \mathrm{mmol}, 1.00$ equiv.), $\mathrm{Cs}_{2} \mathrm{CO}_{3}$ (103 $\mathrm{mg}, \quad 0.32 \mathrm{mmol}, \quad 1.10$ equiv.) and $\mathbf{2 3 8 f}(162 \mathrm{mg}, 0.65 \mathrm{mmol}$, 1.20 equiv.) in dry DCM (4 mL). The reaction was carried out at RT for 12 h. After flash chromatography (hexane/EtOAc : 25/1) compound 257 was obtained as a yellow oil (71.6 mg, $87 \%$ ). ${ }^{1} \mathbf{H}$ NMR $\left(300 \mathrm{MHz}, \mathrm{CDCl}_{3}\right) \delta=3.77$ (s, $\left.3 \mathrm{H}\right), 3.51$ (s, $2 \mathrm{H}$ ), $1.06 \mathrm{ppm}(\mathrm{s}, 21 \mathrm{H}) .{ }^{13} \mathbf{C}$ NMR $\left(126 \mathrm{MHz}, \mathrm{CDCl}_{3}\right) \delta=168.7,99.5,93.5,52.9$, 38.0, 18.8, 11.5. ppm. IR (ATR): $\widetilde{v}\left(\mathrm{~cm}^{-1}\right)=2943,2865,2093,1742,1462,1435,1406,1384,1273,1193,1130,1072$, 1012, 996, 919, 881, 854, 675, 659. HR-MS calc. for $\mathrm{C}_{14} \mathrm{H}_{26} \mathrm{O}_{2} \mathrm{SSi}$ : 287.1496; found: 287.1497 $[\mathrm{M}+\mathrm{H}]^{+}(\mathrm{ESI}-\mathrm{HRMS})$.

Synthesis of methyl 2-((phenylethynyl)thio)acetate (258)

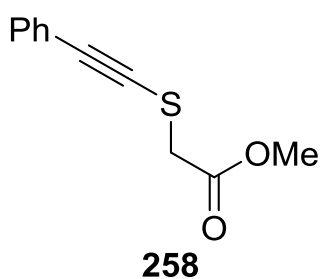

Using the general procedure GPD, compound 258 was prepared from methyl 2-mercaptoacetate (45.6 mg, $0.43 \mathrm{mmol}, 1.00$ equiv.), $\mathrm{Cs}_{2} \mathrm{CO}_{3}$ (151.1 mg, $0.47 \mathrm{mmol}, 1.10$ equiv.) and $238 \mathrm{a}$ ( $283 \mathrm{mg}, 0.65 \mathrm{mmol}, 1.50$ equiv.) in dry DCM. The reaction was carried out at RT for $12 \mathrm{~h}$. After flash chromatography (hexane/EtOAc : 20/1) compound 258 was obtained as a yellow oil (45.6 mg, $91 \%)$. ${ }^{\mathbf{1}} \mathbf{H}$ NMR (300 MHz, $\left.\mathrm{CDCl}_{3}\right) \delta=7.43-7.39$ (m, 2 ppm ${ }^{\mathbf{1 3}} \mathbf{C}$ NMR (126 $\left.\mathrm{MHz}, \mathrm{CDCl}_{3}\right) \delta=168.9,131.8,128.6,128.4,123.0,100.2$, 94.7, 53.0, 37.7 ppm. IR (ATR): $\widetilde{v}\left(\mathrm{~cm}^{-1}\right)$ $=3078,3058,3031,3001,2951,2843,2168,1571,1486,1435,1404,1271,1194,1155,1128,1007$, 900, 880, 842, 753, 689, 645, 622, 604. HR-MS calc. for $\mathrm{C}_{11} \mathrm{H}_{10} \mathrm{O}_{2} \mathrm{~S}: 207.0474$; found: 207.0689 $[\mathrm{M}+\mathrm{H}]^{+}($ESI-HRMS). 
Synthesis of triisopropyl(((4-nitrophenyl)thio)ethynyl)silane (259)

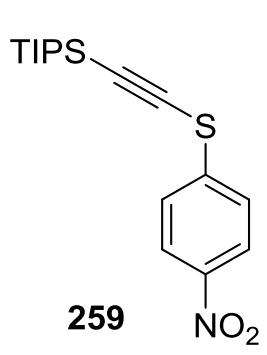

Using the general procedure GPD, compound $\mathbf{2 5 9}$ was prepared from 4nitrobenzenethiol $\quad(34.1 \mathrm{mg}, \quad 0.22 \mathrm{mmol}, \quad 1.00$ equiv. $), \quad \mathrm{Cs}_{2} \mathrm{CO}_{3} \quad(78.0 \mathrm{mg}$, $0.24 \mathrm{mmol}, 1.10$ equiv.) and $\mathbf{2 3 8 f}$ ( $136 \mathrm{mg}, 0.26 \mathrm{mmol}, 1.20$ equiv.) in dry DCM $(3 \mathrm{~mL})$. The reaction was carried out at RT for $12 \mathrm{~h}$. After flash chromatography using (pure hexane) compound 259 was obtained as a yellow oil $(56.6 \mathrm{mg}, 76 \%)$. ${ }^{1} \mathbf{H}$ NMR $\left(300 \mathrm{MHz}, \mathrm{CDCl}_{3}\right) \delta=8.20(\mathrm{td}, J=8.6,2.8 \mathrm{~Hz}, 2 \mathrm{H}), 7.57(\mathrm{td}, J=8.6$, $2.8 \mathrm{~Hz}, 2 \mathrm{H}), 1.15 \mathrm{ppm}(\mathrm{m}, 21 \mathrm{H}) .{ }^{13} \mathbf{C} \mathbf{~ N M R}\left(126 \mathrm{MHz}, \mathrm{CDCl}_{3}\right) \delta=146.3,142.9,125.8,124.3,106.8$, 88.2, 18.9, 11.6 ppm. IR (ATR): $\widetilde{v}\left(\mathrm{~cm}^{-1}\right)=2943,2863,2096,1597,1581,1515,1467,1461,1383$, 1353, 1336, 1315,1254, 1233, 1107, 1081, 1016, 992, 917, 880, 851, 837, 738, 721, 676, 652, 627. HR-MS calc. for $\mathrm{C}_{17} \mathrm{H}_{25} \mathrm{NO}_{2} \mathrm{SSiNa}$ 358.1269; found: 358.1269 [M+Na] ${ }^{+}$(ESI-HRMS).

Synthesis of triisopropyl(((4-methoxyphenyl)thio)ethynyl)silane (260)

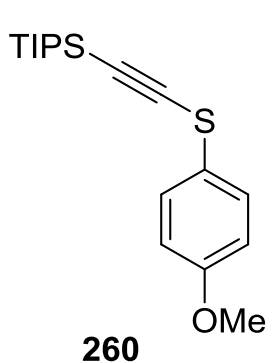

Using the general procedure GPD, compound 260 was prepared from the 4methoxy-benzenethiol (30.8 mg, $0.22 \mathrm{mmol}, 1.00$ equiv.), $\mathrm{Cs}_{2} \mathrm{CO}_{3}$ (78.0 mg, 0.24 mmol, 1.10 equiv.) and $\mathbf{2 3 8 f}$ ( $136 \mathrm{mg}, 0.26 \mathrm{mmol}, 1.20$ equiv.) in dry DCM ( $3 \mathrm{~mL}$ ). The reaction was carried out at RT for $12 \mathrm{~h}$. After flash chromatography using (pure hexane) compound $\mathbf{2 6 0}$ was obtained as a yellow oil (52.0 $\mathrm{mg}, 73 \%)$. ${ }^{1}$ H NMR $(300 \mathrm{MHz}, \mathrm{CDCl} 3) \delta=7.37(\mathrm{td}, J=8.9,2.2 \mathrm{~Hz}, 2 \mathrm{H}), 6.89(\mathrm{td}, J=9.0$, $2.2 \mathrm{~Hz}, 2 \mathrm{H}), 3.80$ (s, $3 \mathrm{H}), 1.11 \mathrm{ppm}(\mathrm{s}, 21 \mathrm{H}) .{ }^{13} \mathbf{C}$ NMR $\left(126 \mathrm{MHz}, \mathrm{CDCl}_{3}\right) \delta=158.7,128.2,122.9$, 114.9, 101.4, 92.7, 55. 4, 18.7, 11.5 ppm. IR (ATR): $\widetilde{v}\left(\mathrm{~cm}^{-1}\right)=2940,2803,2090,1592,1576,1488$, 1461, 1383, 1290, 1244, 1174, 1104, 1086, 1071, 1033, 1017, 995, 881, 857, 821, 802, 675, 658, 636, 622, 591, 573, 515. HR-MS for $\mathrm{C}_{18} \mathrm{H}_{28} \mathrm{OSSi}$ : calc.: 320.1630; found: 320.1632 [M] ${ }^{+}$(EI-HRMS).

Synthesis of (4-methoxyphenyl)(phenylethynyl)sulfane (261)

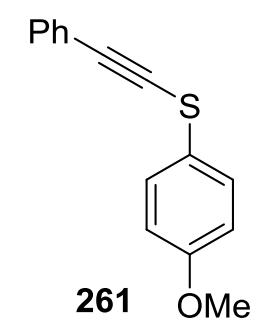

Using the general procedure GPD, compound 261 was prepared from 4-methoxybenzenethiol (60.0 mg, $0.43 \mathrm{mmol}, 1.00$ equiv.), $\mathrm{Cs}_{2} \mathrm{CO}_{3}$ (151 mg, $0.47 \mathrm{mmol}$, 1.10 equiv.) and $\mathbf{2 3 8 a}$ ( $283 \mathrm{mg}, 0.65 \mathrm{mmol}, 1.50$ equiv.) in dry DCM. The reaction was carried out at RT for $12 \mathrm{~h}$. After flash chromatography using (hexane/EtOAc : 20/1) compound 261 was obtained as a yellow oil (66.5 mg, $64 \%) .{ }^{1} \mathbf{H}$ NMR (300 $3.81 \mathrm{ppm}(\mathrm{s}, 3 \mathrm{H}) .{ }^{13} \mathbf{C}$ NMR $\left(126 \mathrm{MHz}, \mathrm{CDCl}_{3}\right) \delta=159,132,128,123,115,96,55 \mathrm{ppm} . \mathbf{I R}$ (ATR): $\widetilde{v}\left(\mathrm{~cm}^{-1}\right)=3061,3030,3002,2955,2938,2904,2834,2167,1590,1574,1490,1459,1440$, 1289, 1243, 1173, 1027, 1005, 914, 821, 797, 752, 718, 689, 655, 635, 621. HR-MS calc. for $\mathrm{C}_{15} \mathrm{H}_{12} \mathrm{OS}$ : 241.0682; found: $241.0689[\mathrm{M}+\mathrm{H}]^{+}$(ESI-HRMS). Analytical data corresponded to those previously reported. ${ }^{162}$ 


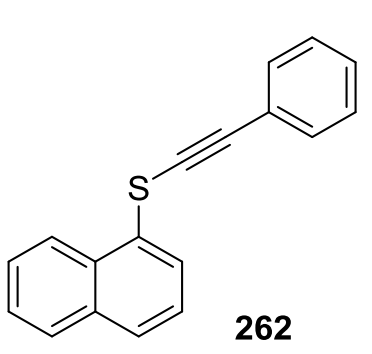

Using the general procedure GPD, compound 262 was prepared from naphthalene-1-thiol (68.8 mg, $0.43 \mathrm{mmol}, 1.00$ equiv.), $\mathrm{Cs}_{2} \mathrm{CO}_{3}$ (151 mg, $0.47 \mathrm{mmol}, 1.10$ equiv.) and $238 \mathrm{a}$ ( $283 \mathrm{mg}, 0.65 \mathrm{mmol}, 1.50$ equiv.) in dry DCM. The reaction was carried out at RT for $12 \mathrm{~h}$. After flash chromatography using (hexane/EtOAc 50/1) compound 262 was obtained as a yellow oil (54.5 mg, $49 \%)$. ${ }^{1} \mathbf{H}$ NMR $\left(300 \mathrm{MHz}, \mathrm{CDCl}_{3}\right) \delta=8.18(\mathrm{qd}$, $J=7.7,1.0 \mathrm{~Hz}, 1 \mathrm{H}), 7.97(\mathrm{dd}, J=7.42,1.3 \mathrm{~Hz}, 1 \mathrm{H}), 7.91\left(\mathrm{~m}_{\mathrm{C}}, 1 \mathrm{H}\right), 7.79(\mathrm{~d}, J=8.5 \mathrm{~Hz}, 1 \mathrm{H})$, 7.64-7.49 (m, $5 \mathrm{H}), 7.39-7.36 \mathrm{ppm}(\mathrm{m}, 3 \mathrm{H}) .{ }^{13} \mathbf{C} \mathbf{~ N M R}\left(126 \mathrm{MHz}, \mathrm{CDCl}_{3}\right) \delta=133.9,131.8,130.8$, $129.8,128.7,128.7,128.4,127.6,126.7,126.6,126.0,125.66,123.6,123.1,97.9,75.8$ ppm. IR (ATR): $\widetilde{v}\left(\mathrm{~cm}^{-1}\right)=3852,3054,3031,2987,2954,2941,2888,2863,2163,1738,1697,1684,1591$, $1563,1503,1487,1456,1442,1414,1369,1336,1166,766$. MS calc. for $\mathrm{C}_{18} \mathrm{H}_{12} \mathrm{~S}: 260.1$; found: $260.1[\mathrm{M}]^{+}(\mathrm{EI}-\mathrm{MS})$.

Synthesis of 2-(((triisopropylsilyl)ethynyl)thio)benzo[d]thiazole (263)

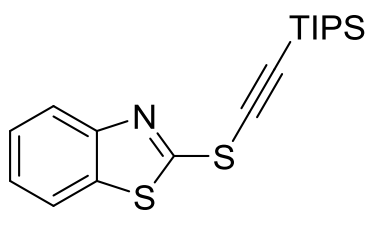

263

Using the general procedure GPD, compound 263 was prepared from benzo[d]thiazole-2-thiol $(36.8 \mathrm{mg}, 0.22 \mathrm{mmol}, 1.00$ equiv. $), \mathrm{Cs}_{2} \mathrm{CO}_{3}$ (78.0 mg, $0.24 \mathrm{mmol}, 1.10$ equiv.) and $\mathbf{2 3 8 f}$ (136 mg, $0.26 \mathrm{mmol}$, 1.20 equiv. $)$ in dry DCM (3 mL). The reaction was carried out at RT for 12 h. After flash chromatography using (hexane/EtOAc $15 / 1$ to $10: 1$ ) compound 263 was obtained as a yellow oil (78.9 mg, 98\%). ${ }^{1} \mathbf{H}$ NMR $\left(300 \mathrm{MHz}, \mathrm{CDCl}_{3}\right) \delta=7.87$ (ddd, $J=8.2,1.4,0.6 \mathrm{~Hz}, 1 \mathrm{H}), 7.83(\mathrm{ddd}, J=8.2,1.4,0.6 \mathrm{~Hz}, 1 \mathrm{H}), 7.44(\mathrm{ddd}, J=8.2,7.8,1.4,1 \mathrm{H}$ ), 7.34 (ddd, $J=8.2,7.8,1.4 \mathrm{~Hz}, 1 \mathrm{H}), 1.20-1.15$ (m, 21 ) ppm. ${ }^{13} \mathbf{C} \mathbf{~ N M R}\left(126 \mathrm{MHz}, \mathrm{CDCl}_{3}\right) \delta=165.5$, 154.4, 135.8, 126.4, 124.7, 122.1, 121.1, 108.8, 87.6, 18.84, 11.6.ppm. IR (ATR): $\widetilde{v}\left(\mathrm{~cm}^{-1}\right)=2941$, 2889, 2863, 2097, 1464, 1425, 1284, 1365, 1309, 1275, 1258, 1237, 1124, 1073, 1020, 1009, 996, 933, 919, 881, 853, 846, 805, 753, 725, 704, 753, 725, 704, 676, 659. HR-MS calc. for $\mathrm{C}_{18} \mathrm{H}_{25} \mathrm{NS}_{2} \mathrm{Si}$ : 348.1270; found: $348.1270[\mathrm{M}+\mathrm{H}]^{+}$(ESI-HRMS). Analytical data corresponded to those previously reported. ${ }^{161}$ 
Synthesis of $S$-((triisopropylsilyl)ethynyl) benzothioate (264)<smiles>O=C(SC#C[In]S)c1ccccc1</smiles>

Using the general procedure GPD, compound $\mathbf{2 6 4}$ was prepared from the benzothioic $S$-acid (30.4 mg, $0.22 \mathrm{mmol}, 1.00$ equiv.), $\mathrm{Cs}_{2} \mathrm{CO}_{3}$ (78.0 mg, $0.24 \mathrm{mmol}, 1.10$ equiv.) and $238 \mathrm{a}$ ( $136 \mathrm{mg}, 0.26 \mathrm{mmol}, 1.20$ equiv.) in dry DCM (3 mL). The reaction was carried out at RT for $12 \mathrm{~h}$. After flash chromatography using (hexane/EtOAc : 20/1) compound 264 was obtained as a yellow oil (46.0 mg, 66\%). ${ }^{1} \mathbf{H}$ NMR $\left(300 \mathrm{MHz}, \mathrm{CDCl}_{3}\right) \delta=7.87\left(\mathrm{~m}_{\mathrm{C}}, 2 \mathrm{H}\right), 7.63$ (tt, $\left.J=7.5,1.3 \mathrm{HZ}, 1 \mathrm{H}\right),, 7.48(\mathrm{t}, J=$ $7.7 \mathrm{~Hz}, 2 \mathrm{H}), 1.15 \mathrm{ppm}\left(\mathrm{m}_{\mathrm{C}}, 21 \mathrm{H}\right) .{ }^{13} \mathbf{C}$ NMR $\left(126 \mathrm{MHz}, \mathrm{CDCl}_{3}\right) \delta=187.5,135.5,134.3,129.2$, 127.5, 109.6, 86.0, 18.8, 11.6 ppm. IR (ATR): $\widetilde{v}\left(\mathrm{~cm}^{-1}\right)=2942,2864,2104,1703,1462,1448,1201$, 1176, 1072, 1017, 997, 919, 880, 856, 804, 767, 742, 673, 637. HR-MS calc. for $\mathrm{C}_{18} \mathrm{H}_{26} \mathrm{OSSiNa}$ 341.1360; found: 341.1366 [M+Na] $]^{+}$(ESI-HRMS). Analytical data corresponded to those previously reported..$^{104}$

Synthesis of methyl $N$-(tert-butoxycarbonyl)-S-((triisopropylsilyl)ethynyl)-L-cysteinate (266)<smiles>COC(=O)C(CSC#CS)NC(=O)OCc1ccccc1</smiles>

Using the general procedure GPD, compound 266 was prepared from methyl-(tert-butoxycarbonyl)- $L$-cysteinate $\quad(51.8 \mathrm{mg}$, $0.22 \mathrm{mmol}, 1.00$ equiv.), $\mathrm{Cs}_{2} \mathrm{CO}_{3}$ (78.0 mg, $0.24 \mathrm{mmol}, 1.10$ equiv.) and $238 f$ (136 mg, $0.26 \mathrm{mmol}, 1.20$ equiv.) in dry DCM ( $3 \mathrm{~mL})$.

The reaction was carried out at RT for $12 \mathrm{~h}$. After flash chromatography using (hexane/EtOAc : 10/1) compound 266 was obtained as a yellow oil $(731 \mathrm{mg}, 80 \%) .{ }^{1} \mathbf{H}$ NMR $\left(300 \mathrm{MHz}, \mathrm{CDCl}_{3}\right) \delta=5.49(\mathrm{~d}$, $J=7.9 \mathrm{~Hz}, 1 \mathrm{H}), 4.70(\mathrm{~s}, 1 \mathrm{H}), 3.26(\mathrm{dd}, J=13.1,4.4 \mathrm{~Hz}, 1 \mathrm{H}), 3.13(\mathrm{dd}, J=14.3,5.1 \mathrm{~Hz}, 1 \mathrm{H})$, 1.46 (s, $9 \mathrm{H}), 1.08$ (s, $21 \mathrm{H}) .{ }^{13} \mathbf{C}$ NMR $\left(126 \mathrm{MHz}, \mathrm{CDCl}_{3}\right) \delta=170.7,155.2,98.2,94.5,80.3,53.9$, 52.7, 38.4, 28.2, 18.6, 11.3 ppm. IR (ATR): $\widetilde{v}\left(\mathrm{~cm}^{-1}\right)=3370,2943,2981,2865,2091,1749,1717$, 1499, 1461, 1437, 1415, 1391, 1365, 1349, 1309, 1249, 1214, 1161, 1056, 1016, 995, 918, 881, 854, 800, 777, 759, 734, 676, 659. HR-MS calc. for $\mathrm{C}_{20} \mathrm{H}_{37} \mathrm{NOSSi}$ : 433.2551 ; found: $433.2549\left[\mathrm{M}+\mathrm{NH}_{4}\right]^{+}$ (ESI-HRMS). Analytical data corresponded to those previously reported. ${ }^{161}$ 
Synthesis of methyl 1-oxo-2-(phenylethynyl)-2,3-dihydro- $1 H$-indene-2-carboxylate (232)

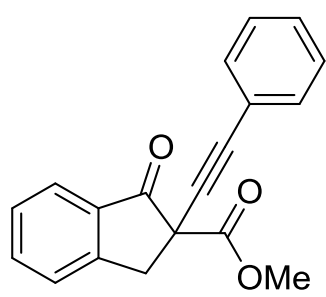

232

Using the general procedure GPD, compound 232 was prepared from 2,3dihydro-1-oxo-1H-Indene-2-carboxylic acid methyl ester $(81 \mathrm{mg}, 0.43 \mathrm{mmol}$, 1.00 equiv.), $\mathrm{Cs}_{2} \mathrm{CO}_{3}$ (151 mg, $0.47 \mathrm{mmol}, 1.10$ equiv.) and 238a (284 mg, $0.65 \mathrm{mmol}, 1.50$ equiv.) in dry DCE $(6 \mathrm{~mL})$. The reaction was carried out at $60{ }^{\circ} \mathrm{C}$ for $12 \mathrm{~h}$. After flash chromatography using (hexane/EtOAc : 15/1) compound 232 was obtained as a yellow oil $(98.5 \mathrm{mg}, 79 \%) .{ }^{1} \mathbf{H}$ NMR (300 $\left.\mathrm{MHz}, \mathrm{CDCl}_{3}\right) \delta=7.82(\mathrm{dd}, J=7.7,0.5 \mathrm{~Hz}, 1 \mathrm{H}), 7.64(\mathrm{ddd}, J=7.7,7.2,1.2 \mathrm{~Hz}, 1 \mathrm{H}), 7.49(\mathrm{dt}, J=7.7$, $0.9 \mathrm{~Hz}, 1 \mathrm{H}), 7.47-7.35$ (m, $3 \mathrm{H}), 7.31-7.19$ (m, 4H), 4.00 (d, $J=17.1 \mathrm{~Hz}, 1 \mathrm{H}), 3.80$ (s, $3 \mathrm{H})$, $3.59 \mathrm{ppm}(\mathrm{d}, J=17.2 \mathrm{~Hz}, 1 \mathrm{H}) .{ }^{13} \mathbf{C}$ NMR $\left(126 \mathrm{MHz}, \mathrm{CDCl}_{3}\right) \delta=196.0,168.5,152.0,135.8,133.2$, $131.8,128.3,128.0,128.0,126.3,125.6,122.2,85.2,83.7,55.9,53.7,41.0 \mathrm{ppm}$. IR (ATR): $\widetilde{v}\left(\mathrm{~cm}^{-1}\right)$ $=3054,3034,2953,2842,2150,2059,1997,1956,1718,1605,1589,1573,1490,1476,1463,1432$, 1326,1300, 1229, 1211, 1173, 1155, 1094, 1063, 990, 954, 917, 884, 807, 791, 753, 732, 689, 650.

HR-MS calc. for $\mathrm{C}_{19} \mathrm{H}_{14} \mathrm{O}_{3}: 291.1016$; found: 291.1018 [M] $]^{+}$(ESI-HRMS).

Synthesis of methyl 2-((2-bromophenyl)ethynyl)-1-oxo-2,3-dihydro-1H-indene-2-carboxylate (269)

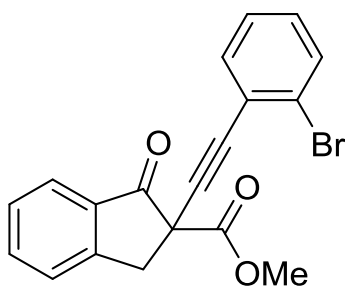

269

Using the general procedure GPD, compound 269 was prepared from 2,3dihydro-1-oxo-1 $H$-Indene-2-carboxylic acid methyl ester $(81 \mathrm{mg}$, $0.43 \mathrm{mmol}, 1.00$ equiv.), $\mathrm{Cs}_{2} \mathrm{CO}_{3}$ (151 mg, $0.47 \mathrm{mmol}, 1.10$ equiv.) and 238e (330 mg, $0.65 \mathrm{mmol}, 1.50$ equiv.) in dry DCE $(6 \mathrm{~mL})$. The reaction was carried out at $60{ }^{\circ} \mathrm{C}$ for $12 \mathrm{~h}$. After flash chromatography using (hexane/EtOAc : 15/1) compound $\mathbf{2 6 9}$ was obtained as a yellow oil $(125.0 \mathrm{mg}, 79 \%) .{ }^{1} \mathbf{H}$ NMR $\left(300 \mathrm{MHz}, \mathrm{CDCl}_{3}\right) \delta=7.87-7.79(\mathrm{~m}, 1 \mathrm{H}), 7.66(\mathrm{td}, J=7.5,1.2 \mathrm{~Hz}$, $1 \mathrm{H}), 7.56-7.36(\mathrm{~m}, 4 \mathrm{H}), 7.27-7.06(\mathrm{~m}, 2 \mathrm{H}), 4.03(\mathrm{~d}, J=17.1 \mathrm{~Hz}, 1 \mathrm{H}), 3.82(\mathrm{~s}, 3 \mathrm{H}), 3.67 \mathrm{ppm}(\mathrm{d}$, $J=17.1 \mathrm{~Hz}, 1 \mathrm{H}) .{ }^{13} \mathbf{C}$ NMR $\left(126 \mathrm{MHz}, \mathrm{CDCl}_{3}\right) \delta=195.7,168.3,152.2,136.0,133.6,133.2,132.3$, $129.7,128.2,126.9,126.5,125.9,125.8,124.5,90.0,82.5,56.3,53.9,40.9$ ppm. IR (ATR): $\widetilde{v}\left(\mathrm{~cm}^{-1}\right)=$ 3648, 3439, 3061, 2952, 2930, 2841, 1719, 1605, 1588, 1557, 1467, 1429, 1326, 1300, 1254, 1230, $1211,1174,1154,1121,1108,1095,1062,1042,1026,987,953,920,883,863,831,811,792,752$, 706, 689, 664, 652, 605. HR-MS calc. for $\mathrm{C}_{19} \mathrm{H}_{13} \mathrm{BrO}_{3}$ : 369.0121; found: $369.0118[\mathrm{M}+\mathrm{H}]^{+}$(ESIHRMS). 
Synthesis of methyl 1-oxo-2-((4-(trifluoromethyl)phenyl)ethynyl)-2,3-dihydro-1 $H$-indene-2carboxylate (270)

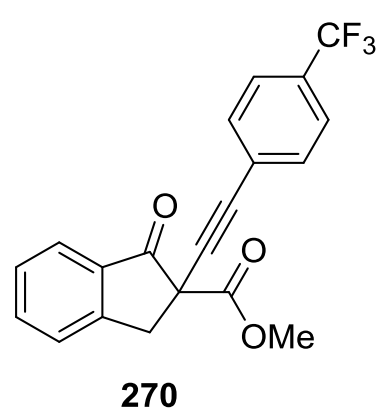

Using the general procedure GPD, compound 270 was prepared from 2,3dihydro-1-oxo-1H-Indene-2-carboxylic acid methyl ester $(81 \mathrm{mg}$, $0.43 \mathrm{mmol}, 1.00$ equiv.), $\mathrm{Cs}_{2} \mathrm{CO}_{3}(151 \mathrm{mg}, 0.47 \mathrm{mmol}, 1.10$ equiv.) and 238c (323 mg, $0.65 \mathrm{mmol}, 1.50$ equiv.) in dry DCE (6 mL). The reaction was carried out at $60{ }^{\circ} \mathrm{C}$ for $12 \mathrm{~h}$. After flash chromatography using (hexane/EtOAc : 15/1) compound 270 was obtained as a yellow oil $(109 \mathrm{mg}, 74 \%) .{ }^{1} \mathbf{H}$ NMR $\left(300 \mathrm{MHz}, \mathrm{CDCl}_{3}\right) \delta=7.88-7.82(\mathrm{~m}, 1 \mathrm{H})$, 7.68 (ddd, $J=7.7,7.2,1.2 \mathrm{~Hz}, 1 \mathrm{H}), 7.54$ (s, $4 \mathrm{H}), 7.52-7.50$ (m, $1 \mathrm{H}$ ), 7.45 (ddd, $J=7.9,7.2,0.9$ $\mathrm{Hz}, 1 \mathrm{H}), 4.03(\mathrm{~d}, J=17.1 \mathrm{~Hz}, 1 \mathrm{H}), 3.82(\mathrm{~s}, 3 \mathrm{H}), 3.62 \mathrm{ppm}(\mathrm{d}, J=17.2 \mathrm{~Hz}, 1 \mathrm{H}) .{ }^{13} \mathbf{C} \mathbf{~ N M R}(126$ $\left.\mathrm{MHz}, \mathrm{CDCl}_{3}\right) \delta=195.8,168.3,152.2,136.1,133.2,132.3,130.3(\mathrm{q}, J=32.5 \mathrm{~Hz}), 128.4,126.5,126.3$, $125.9,125.1(\mathrm{q}, J=3.8 \mathrm{~Hz}), 122.8,88.0,82.6,56.1,54.0,41.0 \mathrm{ppm} .{ }^{19} \mathbf{F}$ NMR $\left(282 \mathrm{MHz}, \mathrm{CDCl}_{3}\right) \delta=$ -62.87 ppm. IR (ATR): $\widetilde{v}\left(\mathrm{~cm}^{-1}\right)=2953,2143,1721,1607,1437,1320,1263,1235,1212,1165$, 1121, 1104, 1063, 1014, 919, 842, 751, 702, 689. HR-MS calc. for $\mathrm{C}_{20} \mathrm{H}_{13} \mathrm{O}_{238 \times 3}$ : 358.0817; found: $358.0822[\mathrm{M}]^{+}($EI-HRMS).

Synthesis of methyl 2-((4-fluorophenyl)ethynyl)-1-oxo-2,3-dihydro- $1 H$-indene-2-carboxylate (271)

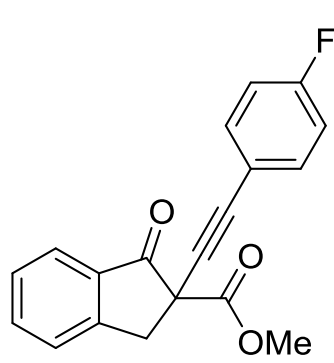

271

Using the general procedure GPD, compound 271 was prepared from 2,3dihydro-1-oxo-1 $H$-Indene-2-carboxylic acid methyl ester $(81 \mathrm{mg}$, $0.43 \mathrm{mmol}, 1.00$ equiv.), $\mathrm{Cs}_{2} \mathrm{CO}_{3}(151 \mathrm{mg}, 0.47 \mathrm{mmol}, 1.10$ equiv.) and 238d (291 mg, $0.65 \mathrm{mmol}, 1.50$ equiv.) in dry DCE ( $6 \mathrm{~mL})$. The reaction was carried out at $60{ }^{\circ} \mathrm{C}$ for $12 \mathrm{~h}$. After flash chromatography using (hexane/EtOAc : 15/1) compound 271 was obtained as a yellow oil $(87.0 \mathrm{mg}, 65 \%) .{ }^{1} \mathbf{H}$ NMR $\left(300 \mathrm{MHz}, \mathrm{CDCl}_{3}\right) \delta=7.81(\mathrm{qd}, J=7.7,0.7 \mathrm{~Hz}$, $1 \mathrm{H}), 7.66(\mathrm{dt}, J=7.6,1.2 \mathrm{~Hz}, 1 \mathrm{H}), 7.50(\mathrm{dt}, J=7.6,0.9 \mathrm{~Hz}, 1 \mathrm{H}), 7.46-7.39(\mathrm{~m}, 3 \mathrm{H}), 6.95(\mathrm{tt}, J=$ 8.7, 2.3, $2 \mathrm{H}), 4.00(\mathrm{~d}, J=17.1 \mathrm{~Hz}, 1 \mathrm{H}), 3.81(\mathrm{~s}, 3 \mathrm{H}), 3.60 \mathrm{ppm}(\mathrm{d}, J=17.1 \mathrm{~Hz}, 1 \mathrm{H}) .{ }^{13} \mathbf{C}$ NMR $(75$ $\left.\mathrm{MHz}, \mathrm{CDCl}_{3}\right) \delta=196.2,168.7,164.3,161.0,152.3,136.1,134.0$ (d, $\left.J=8.3 \mathrm{~Hz}\right), 133.4,128.3,126.5$, 125.9, $118.5(\mathrm{~d}, J=3.6 \mathrm{~Hz}), 115.5(\mathrm{~d}, J=22.5 \mathrm{~Hz}, 85.1(\mathrm{~d}, J=2.0 \mathrm{~Hz}), 82.9,60.4,56.0,53.8,41.1$, 21.1, 14.3. ppm. IR (ATR): $\widetilde{v}\left(\mathrm{~cm}^{-1}\right)=3073,2953,1718,1655,1600,1589,1505,1476,1464,1433$, 1405, 1327, 1299, 1212, 1174, 1154, 1093, 1060, 1013, 990, 954, 919, 884, 863, 836, 818, 800, 790, 818, 800, 790, 750, 688, 636, 750, 688, 636. HR-MS calc. for $\mathrm{C}_{19} \mathrm{H}_{1238 \mathrm{f}} \mathrm{O}_{3}: 326.1187$; found: 326.1183 $\left[\mathrm{M}+\mathrm{NH}_{4}\right]^{+}(\mathrm{ESI}-\mathrm{HRMS})$. 


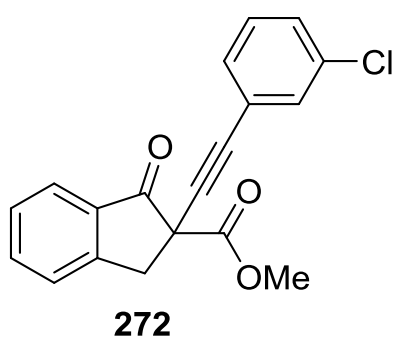

272

Using the general procedure GPD, compound $\mathbf{2 3}$ was prepared from 2,3dihydro-1-oxo-1H-Indene-2-carboxylic acid methyl ester $(81 \mathrm{mg}$, $0.43 \mathrm{mmol}, 1.00$ equiv.), $\mathrm{Cs}_{2} \mathrm{CO}_{3}$ (151 mg, $0.47 \mathrm{mmol}, 1.10$ equiv.) and 238b (302 mg, $0.65 \mathrm{mmol}, 1.50$ equiv.) in dry DCE. The reaction was carried out at $60{ }^{\circ} \mathrm{C}$ for $12 \mathrm{~h}$. After flash chromatography using (hexane/EtOAc : 15/1) compound 272 was obtained as a yellow oil $(113 \mathrm{mg}, 81 \%) .{ }^{1} \mathbf{H}$ NMR $\left(300 \mathrm{MHz}, \mathrm{CDCl}_{3}\right) \delta=7.88-7.83(\mathrm{~m}, 1 \mathrm{H}), 7.75-7.63$ (m, $\left.1 \mathrm{H}\right), 7.53$ (dt, $J=7.8,0.9 \mathrm{~Hz}, 1 \mathrm{H}), 7.48-7.42(\mathrm{~m}, 2 \mathrm{H}), 7.33$ (dt, $J=7.4,1.5 \mathrm{~Hz}, 1 \mathrm{H}), 7.21$ (ddd, $J=8.0,7.4,0.5$ $\mathrm{Hz}, 1 \mathrm{H}), 4.03(\mathrm{~d}, J=17.2 \mathrm{~Hz}, 1 \mathrm{H}), 3.83(\mathrm{~s}, 3 \mathrm{H}), 3.61 \mathrm{ppm}(\mathrm{d}, J=17.6 \mathrm{~Hz}, 1 \mathrm{H}) .{ }^{13} \mathbf{C} \mathbf{~ N M R}(75$ $\left.\mathrm{MHz}, \mathrm{CDCl}_{3}\right) \delta=195.9,168.4,152.1,136.1,134.0,133.2,131.9,130.1,129.4,128.8,128.3,126.5$, 125.8, 124.1, 86.7, 82.5, 56.0, 53.9, 41.0 ppm. IR (ATR): $\widetilde{v}\left(\mathrm{~cm}^{-1}\right)=3646,3562,3439,3066,3035$, 2953, 2927, 2847, 1719, 1605, 1590, 1560, 1474, 1463, 1431, 1409, 1328, 1294, 1262, 1231, 1211, $1174,1155,1095,1074,1062,1018,996,954,926,883,852,820,786,767,751,717,680,602$. HRMS calc. for $\mathrm{C}_{19} \mathrm{H}_{13} \mathrm{ClO}_{3}: 325.0630$; found: $325.0626[\mathrm{M}]^{+}$(ESI-HRMS).

Synthesis of methyl 1-oxo-2-((triisopropylsilyl)ethynyl)-2,3-dihydro-1 $H$-indene-2-carboxylate (273)

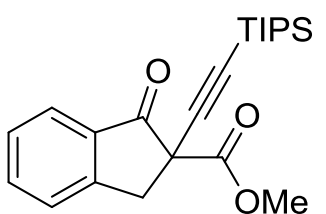

273

Using the general procedure GPD, compound 273 was prepared from 2,3dihydro-1-oxo-1H-Indene-2-carboxylic acid methyl ester $(81.8 \mathrm{mg}$, 0.43 mmol, 1.00 equiv.), $\mathrm{Cs}_{2} \mathrm{CO}_{3}$ (151 $\mathrm{mg}, 0.47 \mathrm{mmol}, 1.10$ equiv.) and $\mathbf{2 3 8 f}$ (267 mg, $0.52 \mathrm{mmol}, 1.20$ equiv.) in dry DCM $(6 \mathrm{~mL})$. The reaction was carried out at RT for $12 \mathrm{~h}$. After flash chromatography using (hexane/EtOAc : 15/1) compound 273 was obtained as a yellow oil $(86.0 \mathrm{mg}, 93 \%) .{ }^{\mathbf{1}} \mathbf{H} \mathbf{N M R}\left(300 \mathrm{MHz}, \mathrm{CDCl}_{3}\right) \delta=\delta$ $7.80(\mathrm{qd}, J=7.6,0.7 \mathrm{~Hz}, 1 \mathrm{H}), 7.64(\mathrm{dt}, J=7.6,1.3 \mathrm{~Hz}, 1 \mathrm{H}),, 7.47(\mathrm{qd}, J=7.8,0.9 \mathrm{~Hz}, 1 \mathrm{H}), 7.40$ (qt, $J=7.5,9.0 \mathrm{~Hz}, 1 \mathrm{H}), 3.91(\mathrm{~d}, J=17.4 \mathrm{~Hz}, 1 \mathrm{H}), 3.75(\mathrm{~s}, 3 \mathrm{H}), 3.47(\mathrm{~d}, J=17.4 \mathrm{~Hz}, 1 \mathrm{H}), 1.03$ ppm (s, $21 \mathrm{H}) .{ }^{13} \mathbf{C}$ NMR $\left(126 \mathrm{MHz}, \mathrm{CDCl}_{3}\right) \delta=195.8,168.7,152.1,135.8,133.5,128.2,126.4,125.8$, 103.2, 85.7, 56.5, 53.7, 18.8, 11.4. ppm. IR (ATR): $\widetilde{v}\left(\mathrm{~cm}^{-1}\right)=2942,2809,2168,1754,1725,1607$, 1590, 1463, 1433, 1249, 1210, 1176, 1134, 1093, 1070, 1017, 995, 966, 955, 921, 881, 827, 811, 774, 751, 713, 675, 661, 635. HR-MS calc. for $\mathrm{C}_{22} \mathrm{H}_{30} \mathrm{O}_{3} \mathrm{Si}: 371.2037$; found: $371.2034[\mathrm{M}+\mathrm{H}]^{+}$(ESIHRMS). 
<smiles>O=C1c2ccccc2C(=O)C1(C#C[In])c1ccccc1</smiles>

Using the general procedure GPD, compound 274 was prepared from 2phenyl-1H-indene-1,3(2H)-dione $\quad(48.9 \mathrm{mg}, \quad 0.22 \mathrm{mmol}, \quad 1.00$ equiv.), $\mathrm{Cs}_{2} \mathrm{CO}_{3}$ (78.0 mg, $0.24 \mathrm{mmol}, 1.10$ equiv.) and $238 f$ (136 mg, $0.26 \mathrm{mmol}$, 1.20 equiv.) in dry DCM (3 mL). The reaction was carried out at $60^{\circ} \mathrm{C}$ for $12 \mathrm{~h}$. After flash chromatography using (hexane/EtOAc : 15/1) compound 274 was obtained as a yellow oil $(84.0 \mathrm{mg}, 95 \%) .{ }^{1} \mathbf{H}$ NMR $\left(300 \mathrm{MHz}, \mathrm{CDCl}_{3}\right) \delta=78.13(\mathrm{dd}, J=5.9$, $3.1 \mathrm{~Hz}, 2 \mathrm{H}), 7.94(\mathrm{dd}, J=5.9,3.1 \mathrm{~Hz}, 2 \mathrm{H}), 7.39-7.3$ (m, $5 \mathrm{H}), 1.06 \mathrm{ppm}(\mathrm{m}, 21 \mathrm{H}) .{ }^{13} \mathbf{C}$ NMR $(126$ $\left.\mathrm{MHz}, \mathrm{CDCl}_{3}\right) \delta=194.9,141.5,136.4,135.3,128.9,128.3,127.4,124.9,101.0,89.5,59.9,18.8$, 11.5 ppm. IR (ATR): $\widetilde{v}\left(\mathrm{~cm}^{-1}\right)=2931,2881,2360,2348,2170,1755,1735,1709,1585,1498,1460$, 1337, 1249, 1160, 1037, 1019, 997, 919, 880, 855, 759, 727, 695, 678, 581. HR-MS calc. for $\mathrm{C}_{26} \mathrm{H}_{30} \mathrm{O}_{2} \mathrm{SiNa}$ : 425.1902; found: $425.1632[\mathrm{M}+\mathrm{Na}]^{+}$(EI-HRMS).

Synthesis of ethyl 2-benzyl-2-cyano-4-(triisopropylsilyl)but-3-ynoate (275)

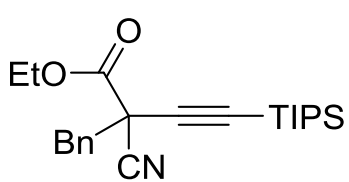

275

Using the general procedure GPD, compound 275 was prepared from $\alpha$ cyano-benzenepropanoic acid ethyl ester (29.0 mg, $0.22 \mathrm{mmol}, 1.00$ equiv.), $\mathrm{Cs}_{2} \mathrm{CO}_{3}$ (78.0 mg, $0.24 \mathrm{mmol}, 1.10$ equiv.) and $238 f(136 \mathrm{mg}, 0.26 \mathrm{mmol}$, 1.20 equiv.) in dry DCM (3 mL). The reaction was carried out at RT for $12 \mathrm{~h}$. After flash chromatography using ( $n$-Hexane/EtOAc 20/1) compound 275 was obtained as a yellow oil (38.0 mg, 70\%). ${ }^{1} \mathbf{H}$ NMR (300 MHz, $\left.\mathrm{CDCl}_{3}\right) \delta=7.38-7.30(\mathrm{~m}, 5 \mathrm{H}), 4.27(\mathrm{dd}, J=14.3$, $7.5 \mathrm{~Hz}, 2 \mathrm{H}), 4.27(\mathrm{dd}, J=17.8,13.7 \mathrm{~Hz}, 2 \mathrm{H}), 3.40 \mathrm{ppm}(\mathrm{m}, 21 \mathrm{H}) .{ }^{13} \mathbf{C} \mathbf{N M R}\left(126 \mathrm{MHz}, \mathrm{CDCl}_{3}\right) \delta=$ 164.7, 133.2, 128.4, 115.8, 97.3, 90.3, 64.0, 44.3, 18.6, 13.96, 11.2 ppm. IR (ATR): $\widetilde{v}\left(\mathrm{~cm}^{-1}\right)=2945$, 2890, 2863, 1742, 1703, 1495, 1463, 1453, 1389, 1381, 1366, 1276, 1236, 1162, 1098, 1070, 1059, 1030, 1009, 997, 919, 906, 883, 853, 806, 772, 742, 706, 699, 678, 660, 627, 607. HR-MS calc. for $\mathrm{C}_{23} \mathrm{H}_{33} \mathrm{NOSiNa}$ : 406.2173; found: 406.2165 [M+Na] ${ }^{+}$(ESI-HRMS). 
Synthesis of $N, 4$-dimethyl- $N$-((triisopropylsilyl)ethynyl)benzenesulfonamide (281)<smiles></smiles>

281

Using the general procedure GPD, compound 281 was prepared from $\mathrm{N}$ methyl-4-(methylbenzene)sulfonamide ( $40.8 \mathrm{mg}, 0.22 \mathrm{mmol}, 1.00$ equiv.), $\mathrm{Cs}_{2} \mathrm{CO}_{3}$ (78.0 mg, $0.24 \mathrm{mmol}, 1.10$ equiv.) and $238 f$ (136 mg, $0.26 \mathrm{mmol}$, 1.20 equiv.) in dry DCM. The reaction was carried out at RT for $12 \mathrm{~h}$. After flash chromatography using (hexane/EtOAc : 8/1) compound 281 was obtained as a yellow oil $(53.8 \mathrm{mg}, 67 \%)$. ${ }^{1} \mathbf{H}$ NMR $\left(300 \mathrm{MHz}, \mathrm{CDCl}_{3}\right) \delta=$ $7.80(\mathrm{td}, J=8.3,1.7 \mathrm{~Hz}, 2 \mathrm{H}), 7.33$ (d, $J=7.3 \mathrm{~Hz}, 2 \mathrm{H}), 3.07$ (s, $3 \mathrm{H}), 2.45$ (s, $3 \mathrm{H}), 1.04 \mathrm{ppm}(\mathrm{s}, 21$ H). ${ }^{13} \mathrm{C}$ NMR $\left(75 \mathrm{MHz}, \mathrm{CDCl}_{3}\right) \delta=144.8,133.5,129.8,128.0,98.2,67.6,39.5,21.8,18.7,11.0 \mathrm{ppm}$. HR-MS calc. for $\mathrm{C}_{24} \mathrm{H}_{33} \mathrm{NO}_{2} \mathrm{SSiNa}$ : 450.1893; found: 450.1444 [M+Na] ${ }^{+}$(ESI-HRMS). Analytical data corresponded to those previously reported. ${ }^{163}$

Synthesis of $N, 4$-dimethyl- $N$-(phenylethynyl)benzenesulfonamide (282)<smiles>Cc1ccc(S(=O)(=O)N(C)C#Cc2ccccc2)cc1</smiles>

282

Using the general procedure GPD, compound 282 was prepared from $\mathrm{N}$ methyl-4-(methylbenzene)sulfonamide (79.7 mg, $0.43 \mathrm{mmol}, 1.00$ equiv.), $\mathrm{Cs}_{2} \mathrm{CO}_{3}$ (151 mg, $0.47 \mathrm{mmol}, 1.10$ equiv.) and 238a (283 mg, $0.65 \mathrm{mmol}$, 1.50 equiv.) in dry DCM. The reaction was carried out at RT for $12 \mathrm{~h}$. After flash chromatography using (hexane/EtOAc : 8/1) compound 282 was obtained as a yellow oil $(67.7 \mathrm{mg}, 55 \%) .{ }^{1} \mathbf{H}$ NMR $\left(300 \mathrm{MHz}, \mathrm{CDCl}_{3}\right) \delta=$ $7.76(\mathrm{td}, J=8.3,1.5 \mathrm{~Hz}, 2 \mathrm{H}), 7.30-7.17(\mathrm{~m}, 7 \mathrm{H}), 3.06(\mathrm{~s}, 3 \mathrm{H}), 2.37 \mathrm{ppm}(\mathrm{s}, 3 \mathrm{H}) .{ }^{13} \mathbf{C}$ NMR $\left(75 \mathrm{MHz}, \mathrm{CDCl}_{3}\right) \delta=144.9,133.4,131.5,129.9,128.4,127.9,122.8,84.1,77.2,69.2,39.4,21.7$ ppm. IR (ATR): $\widetilde{v}\left(\mathrm{~cm}^{-1}\right)=2940,2890,2964,2172,1747,1710,1695,1589,1456,1383,1362,1348,1332$, $1310,1277,1255,1245,1232,1224,1200,1189,1142,1126,1105,1061,1051,1020,995,937,882$, 840, 805, 784, 768, 747, 692, 676, 662, 640. HR-MS calc. for $\mathrm{C}_{16} \mathrm{H}_{15} \mathrm{NO}_{2} \mathrm{~S}$ : 286.0898; found: $286.0896[\mathrm{M}+\mathrm{H}]^{+}$(ESI-HRMS). Analytical data corresponded to those previously reported. ${ }^{164}$ 
Synthesis of Ethyl 4-((4-methyl- $N$-((triisopropylsilyl)ethynyl)phenyl)sulfonamido)benzoate (283)<smiles></smiles>

283

Using the general procedure GPD, compound 283 was prepared from ethyl 4-((4-methylphenyl)sulfonamido)benzoate (67.7 mg, $0.22 \mathrm{mmol}, 1.00$ eq.), $\mathrm{Cs}_{2} \mathrm{CO}_{3}$ (78.0 mg, $0.24 \mathrm{mmol}$, 1.10 eq.) and the dibenzothiophenium salt $\mathbf{2 3 8 f}$ (136 $\mathrm{mg}, 0.26$ mmol, 1.20 eq.) in dry DCM (3 mL). The reaction was carried out at RT for $12 \mathrm{~h}$. After flash chromatography using (hexane/EtOAc 15/1) compound $\mathbf{2 8 3}$ was obtained as a colorless oil (63.7 mg, 55\%). ${ }^{1} \mathbf{H}$ NMR $\left(300 \mathrm{MHz}, \mathrm{CDCl}_{3}\right) \delta=8.00(\mathrm{td}, J=8.7,2.2 \mathrm{H}, 2 \mathrm{H}), 7.56(\mathrm{td}, J$ = 8.4, $2.1 \mathrm{~Hz}, 2 \mathrm{H}), 7.41(\mathrm{td}, J=8.7,2.6 \mathrm{~Hz}, 2 \mathrm{H}), 7.24(\mathrm{~d}, \mathrm{~J}=8.4 \mathrm{~Hz}, 2 \mathrm{H}), 4.37(\mathrm{q}, J=7.0 \mathrm{~Hz}, 2 \mathrm{H})$, $2.42(\mathrm{~s}, 3 \mathrm{H}), 1.38$ (t, $J=7.1 \mathrm{~Hz} 3 \mathrm{H}), 1.06 \mathrm{ppm}(\mathrm{s}, 21 \mathrm{H}) .{ }^{13} \mathbf{C ~ N M R}\left(126 \mathrm{MHz}, \mathrm{CDCl}_{3}\right) \delta=165.7$, 145.3, 142.8, 139.9 130.4, 129.6, 128.2, 125.0, 95.6, 71.4, 61.4, 21.9, 18.8, 17.9, 14.5, 12.5, 11.6 ppm. IR (ATR): $\widetilde{v}\left(\mathrm{~cm}^{-1}\right)=2941,2923,2863,2160,2154,1504,1464,1370,1253,1186,1169,1088$, $1029,1017,995,905,881,836,807,791,733,703,791,733,703,676,664,649,574,550,524$. HRMS for $\mathrm{C}_{27} \mathrm{H}_{37} \mathrm{NO}_{4} \mathrm{SSi}$ : calc.: 500.2285; found: $500.2281[\mathrm{M}+\mathrm{H}]^{+}$(ESI-HRMS).

Synthesis of $N$-(4-methoxyphenyl)-4-methyl- $N$-((triisopropylsilyl)ethynyl)benzenesulfonamide (284)<smiles>COc1ccc(N(C#C[14C](C)(C)C)S(=O)(=O)c2ccc(OC)cc2)cc1</smiles>

${ }^{1} \mathbf{H}$ NMR $\left(300 \mathrm{MHz}, \mathrm{CDCl}_{3}\right) \delta=7.56(\mathrm{td}, J=8.2,2.1 \mathrm{~Hz}, 2 \mathrm{H}), 7.25(\mathrm{qd}, J=8.0,0.7 \mathrm{~Hz}, 2 \mathrm{H}), 7.14$ $(\mathrm{td}, J=9.2,2.3 \mathrm{~Hz}, 2 \mathrm{H}), 6.823 .80$ (s, $3 \mathrm{H}), 2.44$ (s, $3 \mathrm{H}), 1.05 \mathrm{ppm}(\mathrm{s}, 21 \mathrm{H}) .{ }^{13} \mathbf{C}$ NMR $(75 \mathrm{MHz}$, $\left.\mathrm{CDCl}_{3}\right) \delta=145.2,138.8,138.1,132.6,129.5,128.3,127.6,95.9,93.3,70.4,21.7,18.6,11.4$ ppm. IR (ATR): $\widetilde{v}\left(\mathrm{~cm}^{-1}\right)=2958,2941,2922,2890,2863,2157,1597,1585,1505,1464,1444,1420,1399$, 1370, 1356, 1302, 1254, 1209, 1186, 1169, 1138, 1118, 1106, 1087, 1072, 1029, 1018, 995, 970, 944, 905, 881, 836, 808, 790, 733, 703, 675, 665, 648, 603. HR-MS calc. for $\mathrm{C}_{25} \mathrm{H}_{35} \mathrm{NO}_{3} \mathrm{SSiNa}$ : 458.2180; found: $458.2174[\mathrm{M}+\mathrm{Na}]^{+}(\mathrm{ESI}-\mathrm{HRMS})$. 
Synthesis of $N$-(4-iodophenyl)-4-methyl- $N$-((triisopropylsilyl)ethynyl)benzenesulfonamide (285)<smiles>Cc1ccc(S(=O)(=O)N(C#C[P+](C)(C)[SH3+])c2ccc(I)cc2)cc1</smiles>

285

Using the general procedure GPD, compound 285 was prepared from the $\quad N$-(4-iodophenyl)-4-methylbenzenesulfonamide $\quad(122.0 \mathrm{mg}$, 0.22 mmol, 1.00 equiv.), $\mathrm{Cs}_{2} \mathrm{CO}_{3}$ (78.0 mg, $0.24 \mathrm{mmol}, 1.10$ equiv.) and $238 f$ (136 mg, $0.26 \mathrm{mmol}, 1.20$ equiv.) in dry DCM ( $3 \mathrm{~mL})$. The reaction was carried out at $60{ }^{\circ} \mathrm{C}$ for $12 \mathrm{~h}$. After flash chromatography using (hexane/EtOAc : 15/1) compound 285 was obtained as a white solid $(73.0 \mathrm{mg}, 62 \%) .{ }^{1} \mathbf{H}$ NMR $\left(300 \mathrm{MHz}, \mathrm{CDCl}_{3}\right) \delta=7.64(\mathrm{td}, J=8.5,2.6 \mathrm{~Hz}, 2 \mathrm{H}), 7.56(\mathrm{td}, J=$ 8.3, 2.3 Hz, $2 \mathrm{H}), 7.26$ (d, $J=8.0 \mathrm{~Hz}, 2 \mathrm{H}), 7.03$ (td, $J=8.5,2.6 \mathrm{~Hz}, 2 \mathrm{H}), 2.43$ (s, $3 \mathrm{H}), 1.05$ ppm (m, $21 \mathrm{H}) .{ }^{13} \mathbf{C}$ NMR $\left(75 \mathrm{MHz}, \mathrm{CDCl}_{3}\right) \delta=145.3,138.9,138.3,132.7,129.6,128.4,127.7,96.0,93.4$, 70.5, 21.8, 18.7, 11.5 ppm. IR (ATR): $\widetilde{v}\left(\mathrm{~cm}^{-1}\right)=2958,2941,2921,2889,2863,2157,1597,1585$, 1505, 1464, 1444, 1370, 1356, 1302, 1254, 118, 1106, 1088, 1072, 1029, 1018, 995, 905, 881, 836, 808, 7890, 733, 703, 675, 665, 648, 603. HR-MS calc. for $\mathrm{C}_{24} \mathrm{H}_{32} \mathrm{NO}_{2} \mathrm{SSiINa}$ : 576.0860; found: $576.0848[\mathrm{M}+\mathrm{Na}]^{+}(\mathrm{ESI}-\mathrm{HRMS})$.

Synthesis of 4-methyl- $N$-phenyl- $N$-((triisopropylsilyl)ethynyl)benzenesulfonamide (286)

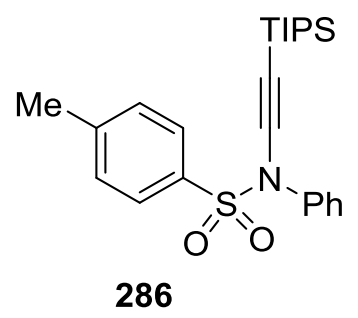

Using the general procedure GPD, compound 286 was prepared from $\mathrm{N}$ phenyl- tolylsulfonamide $(54.4 \mathrm{mg}, 0.22 \mathrm{mmol}, 1.00$ equiv. $), \mathrm{Cs}_{2} \mathrm{CO}_{3}$ (78.0 mg, $0.24 \mathrm{mmol}, 1.10$ equiv.) and $\mathbf{2 3 8 f}$ (136 mg, $0.26 \mathrm{mmol}$, 1.20 equiv.) in dry DCM (3 mL). The reaction was carried out at RT for 12 h. After flash chromatography using (hexane/EtOAc : 15/1) compound 286 was obtained as a yellow oil $(63.3 \mathrm{mg}, 67 \%) .{ }^{1} \mathbf{H}$ NMR $\left(300 \mathrm{MHz}, \mathrm{CDCl}_{3}\right)$ $\delta=7.56(\mathrm{td}, J=8.3,2.0 \mathrm{~Hz}), 7.35-7.27(\mathrm{~m}, 5 \mathrm{H}), 7.26-7.22(\mathrm{~m}, 2 \mathrm{H}), 2.43(\mathrm{~s}, 3 \mathrm{H}), 1.05 \mathrm{ppm}(\mathrm{s}, 21 \mathrm{H})$. ${ }^{13}$ C NMR $\left(126 \mathrm{MHz}, \mathrm{CDCl}_{3}\right) \delta=144.9,138.9,133.1,129.4,129.0,128.4,128.0,126.0,96.7,69.8$, 21.9, 18.9, 11.7 ppm. IR (ATR): $\widetilde{v}\left(\mathrm{~cm}^{-1}\right)=2942,2867,2361,2163,1709,1591,1486,1461,1368$, 1291, 1250, 1171, 1133, 1090, 1073, 1039, 1017, 996, 923, 896, 881, 812, 773, 713, 661, 643. HRMS calc. for $\mathrm{C}_{24} \mathrm{H}_{33} \mathrm{O}_{2} \mathrm{SSiNa}$ : 450.1893; found: 450.1883 [M+Na $]^{+}$(ESI-HRMS). Analytical data corresponded to those previously reported. ${ }^{165}$ 
Synthesis of $N$-phenyl- $N$-((triisopropylsilyl)ethynyl)-2,3-dihydrobenzo[b][1,4]dioxine-6-sulfonamide (287)

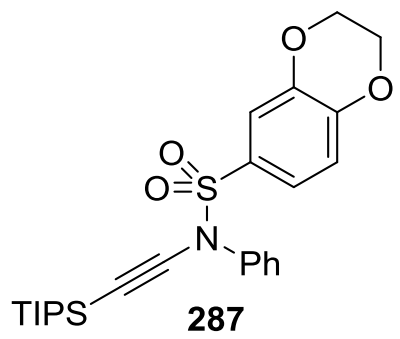

Using the general procedure GPD, compound 287 was prepared from $N$-phenyl-2,3-dihydrobenzo[b][1,4]dioxine-6-sulfonamide $\quad(64.0 \mathrm{mg}$, $0.22 \mathrm{mmol}, 1.00$ equiv.), $\mathrm{Cs}_{2} \mathrm{CO}_{3}$ (78.0 mg, $0.24 \mathrm{mmol}, 1.10$ equiv.) and $238 f$ (136 $\mathrm{mg}, 0.26 \mathrm{mmol}, 1.20$ equiv.) in dry DCM (3 mL). The reaction was carried out at RT for $12 \mathrm{~h}$. After flash chromatography using (hexane/EtOAc 15/1 to 10:1) compound 287 was obtained as a white solid (64.0 mg, 62\%). ${ }^{1} \mathbf{H}$ NMR $\left(300 \mathrm{MHz}, \mathrm{CDCl}_{3}\right) \delta=7.36-7.26(\mathrm{~m}, 6 \mathrm{H}), 7.11(\mathrm{dd}, J=8.9$, $2.1 \mathrm{HZ}), 6.87$ (d, $J=8.9 \mathrm{~Hz}, 1 \mathrm{H}), 4.33-4.30$ (m, $2 \mathrm{H}), 4.27-4.25$ (m, $2 \mathrm{H}), 1.06$ (s, $21 \mathrm{H}) .{ }^{13} \mathbf{C}$ NMR $\left(126 \mathrm{MHz}, \mathrm{CDCl}_{3}\right)=148.5,143.3,139.0,129.0,128.2,128.0,126.0,122.1,118.3,117.5,96.8,69.9$, 64.8, 64.2, 18.9, 11.6 ppm. IR (ATR): $\widetilde{v}\left(\mathrm{~cm}^{-1}\right)=2941,2889,2863,2161,1591,1581,1489,1460$, 1420, 1373, 1319, 1285, 1253, 1204, 1168, 1126, 1105, 1075, 1063, 1047, 1027, 1017, 995, 920, 900, 878, 814, 768, 711, 697, 687, 677, 662, 645, 627, 611. HR-MS calc. for $\mathrm{C}_{25} \mathrm{H}_{33} \mathrm{NO}_{4} \mathrm{SSiNa}$ : 494.1780; found: $494.1792[\mathrm{M}+\mathrm{Na}]^{+}(\mathrm{ESI}-\mathrm{HRMS})$.

Synthesis of $1-((1 R, 4 R)-7,7-$ dimethyl-2-oxobicyclo[2.2.1]heptan-1-yl)- $N$-phenyl- $N$-((triisopropylsilyl)ethynyl)methanesulfonamide (288)

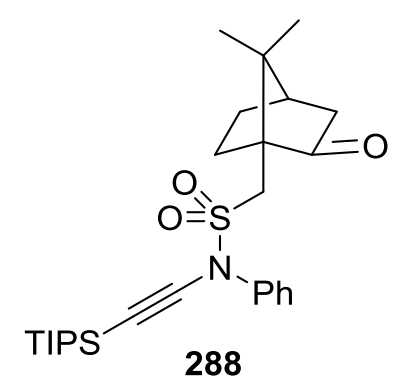

7.58-7.55 (m, $2 \mathrm{H}), 7.45-7.39$ (m, 2 H), 7.32 (tt, $J=7.7,1.3 \mathrm{~Hz}, 1 \mathrm{H}), 3.79$ (d, $J=13.6 \mathrm{~Hz}, 1 \mathrm{H}), 3.27$ $(\mathrm{d}, J=13.6 \mathrm{~Hz}, 1 \mathrm{H}), 2.52(\mathrm{dt}, J=13.6,3.3 \mathrm{~Hz}, 1 \mathrm{H}), 2.38$ (td, $J=19.5,4.4 \mathrm{~Hz}, 1 \mathrm{H}), 2.11-1.95(\mathrm{~m}$, 2 H), $1.92(\mathrm{~d}, J=19.5 \mathrm{H}, 1 \mathrm{H}), 1.64-1.55(\mathrm{~m}, 1 \mathrm{H}), 1.44-1.36(\mathrm{dt}, J=8.7,3.9 \mathrm{~Hz}, 1 \mathrm{H}), 1.18-1.05(\mathrm{~m}$, $24 \mathrm{H}, 21 \mathrm{H}), 0.87$ (s,.3 H) ppm. ${ }^{13} \mathbf{C}$ NMR $\left(75 \mathrm{MHz}, \mathrm{CDCl}_{3}\right) \delta=214.3,138.8,129.4,128.0,125.2$, $96.2,71.0,58.5,47.9,46.6,43.1,42.5,27.0,25.5,20.2,20.0,18.8,11.5$ ppm. IR $(A T R): \widetilde{v}\left(\mathrm{~cm}^{-1}\right)=$ 2954, 2941, 2888, 2823, 2162, 1739, 1591, 1489, 1456, 1414, 1397, 1369, 1296, 1281, 1260, 1245, 1208, 1167, 1130, 1106, 1070, 1051, 1028, 1011, 997, 972, 920, 893, 881, 855, 819, 772, 743, 704, 687, 678, 662, 688, 678, 662, 640, 625, 614. HR-MS calc. for $\mathrm{C}_{27} \mathrm{H}_{41} \mathrm{NO}_{3} \mathrm{SSiNa}$ : 486.2504; found: $486.2486[\mathrm{M}+\mathrm{Na}]^{+}(\mathrm{ESI}-\mathrm{HRMS})$. 
Synthesis of 1 -((1R,4R)-7,7-dimethyl-2-oxobicyclo[2.2.1] heptan-1-yl)- $N$-phenyl- $N$-(phenylethynyl)methanesulfonamide (289)

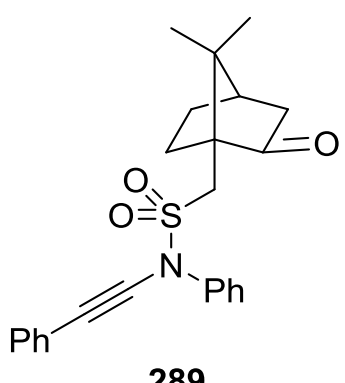

289

Using the general procedure, compound 289 was prepared from $1-((1 R, 4 R)$ 7,7-dimethyl-2-oxobicyclo[2.2.1]heptan-1-yl)- $N$-phenylmethanesulfonamide (79.7 mg, $0.22 \mathrm{mmol}, 1.00$ eq.), $\mathrm{Cs}_{2} \mathrm{CO}_{3}$ (151 mg, $0.24 \mathrm{mmol}, 1.10$ eq.) and the dibenzothiophenium salt $\mathbf{3 a}(115 \mathrm{mg}, 0.26 \mathrm{mmol}, 1.20 \mathrm{eq}$.) in dry DCM (3 mL). The reaction was carried out at RT for $12 \mathrm{~h}$. After flash chromatography using (hexane/EtOAc 12/1 to 10/1) compound 289 was obtained as a yellow oil $(50.1 \mathrm{mg}, 56 \%) .{ }^{1} \mathbf{H}$ NMR $\left(500 \mathrm{MHz}, \mathrm{CDCl}_{3}\right) \delta=$ 7.64-7.62 (m, 2 H), 7.47-7.43 (m, 4 H), 7.36 (tt, $J=7.34,1.8 \mathrm{~Hz}, 1 \mathrm{H}), 7.34-7.30$ (m, $3 \mathrm{H}), 3.85$ (d, $J=$ $15.3 \mathrm{~Hz}, 1 \mathrm{H}), 3.38(\mathrm{~d}, J=15.3 \mathrm{~Hz}, 1 \mathrm{H}), 2.52(\mathrm{dt}, J=12.7,4.2 \mathrm{~Hz}, 1 \mathrm{H}), 2.40(\mathrm{td}, J=18.4,4.2 \mathrm{~Hz}$, $1 \mathrm{H}), 2.12-2.03(\mathrm{~m}, 2 \mathrm{H}), 1.94$ (d, $J=17.4 \mathrm{~Hz}, 1 \mathrm{H}), 1.66$ (q, $J=4.4 \mathrm{~Hz}, 1 \mathrm{H}), 1.42$ (ddd, $J=9.8,3.3$, $3.3 \mathrm{~Hz}, 1 \mathrm{H}), 1.16$ (s, $3 \mathrm{H}), 0.89$ ppm (s, $3 \mathrm{H}) .{ }^{13} \mathbf{C}$ NMR $\left(126 \mathrm{MHz}, \mathrm{CDCl}_{3}\right) \delta=214.4,138.9,131.6$, $129.6,128.4,128.2,125.5,122.6,82.4,71.5,58.6,47.3,43.2,42.6,27.0,25.5,20.3,19.9$ ppm. IR $(A T R): \widetilde{v}\left(\mathrm{~cm}^{-1}\right)=2957,2888,2864,2238,2161,1742,1684,1591,1489,1471,1455,1443,1415$, 1392, 1369, 1338, 1300, 1281, 1262, 1201, 1165, 1130, 1106, 1081, 1066, 1052, 1025, 998, 966, 920, 894, 854, 817, 784, 774, 754, 689, 641, 598, 571, 554, 533, 524, 518. HR-MS for $\mathrm{C}_{24} \mathrm{H}_{25} \mathrm{NO}_{3} \mathrm{~S}$ : calc.: 406.1482; found: 406.1482 [M-H] $]^{-}$(ESI-HRMS).

Synthesis of 4-amino- $N$-(4,6-dimethylpyrimidin-2-yl)- $N$-((triisopropylsilyl)ethynyl)benzenesulfonamide (290)

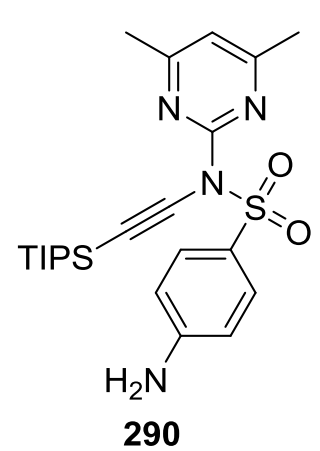

Using the general procedure, compound $\mathbf{2 9 0}$ was prepared from Sulfadimidine (55.1 mg, $0.22 \mathrm{mmol}, 1.00$ equiv.), $\mathrm{Cs}_{2} \mathrm{CO}_{3}$ (78.0 mg, $0.24 \mathrm{mmol}, 1.10$ equiv.) and the dibenzothiophenium salt $\mathbf{2 3 8 f}$ ( $136 \mathrm{mg}, 0.26 \mathrm{mmol}, 1.20$ equiv.) in dry DCM (3 mL). The reaction was carried out at $\mathrm{rt}$ for $12 \mathrm{~h}$. A saturated aqueous solution of $\mathrm{NH}_{4} \mathrm{Cl}$ was added. After flash chromatography using (DCM/methanol 25:1) compound 290 was obtained as a white solid (59.0 mg, 58\%). ${ }^{1} \mathbf{H}$ NMR $\left(300 \mathrm{MHz}, \mathrm{CDCl}_{3}\right) \delta=7.96(\mathrm{td}, J=8.7,2.7 \mathrm{~Hz}, 2 \mathrm{H}), 6.67$ (s, $1 \mathrm{H}), 6.63(\mathrm{td}, J=8.7,2.7 \mathrm{~Hz}, 2 \mathrm{H}), 4.20(\mathrm{~s}, 2 \mathrm{H}), 2.36(\mathrm{~s}, 6 \mathrm{H}), 1.12(\mathrm{~s}, 21 \mathrm{H})$ ppm. ${ }^{13} \mathbf{C}$ NMR $\left(126 \mathrm{MHz}, \mathrm{CDCl}_{3}\right) \delta=168.1,158.0,151.7,132.0,126.7,116.1,113.2,92.7,74.7$, 23.8, 18.9, 11.7 ppm. IR (ATR): $\widetilde{v}\left(\mathrm{~cm}^{-1}\right)=2954,2941,2888,2823,2162,1739,1591,1489,1456$, 1414, 1397, 1369, 1296, 1281, 1260, 1245, 1208, 1167, 1130, 1106, 1070, 1051, 1028, 1011, 997, $972,920,893,881,855,819,772,743,704,687,678,662,688,678,662,640,625,614,597,625$, 614, 597, 530, 521. HR-MS for $\mathrm{C}_{23} \mathrm{H}_{34} \mathrm{~N}_{4} \mathrm{Si}_{1}$ : calc.: 395.2626; found: 395.2626 [M+H] ${ }^{+}$(ESI-HRMS). 
Synthesis of 2-((triisopropylsilyl)ethynyl)-1H-benzo[de]isoquinoline-1,3(2H)-dione (291)

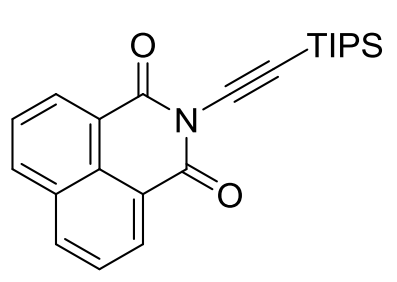

291

Using the general procedure GPD, compound 291 was prepared from $1 \mathrm{H}$ benzoisoquinoline-1,3(2H)-dione (43.4 $\mathrm{mg}, \quad 0.22 \mathrm{mmol}, \quad 1.00$ equiv.), $\mathrm{Cs}_{2} \mathrm{CO}_{3}$ (78.0 mg, $0.24 \mathrm{mmol}, 1.10$ equiv.) and $238 f(136 \mathrm{mg}, 0.26 \mathrm{mmol}$, 1.20 equiv.) in dry DCM $(3 \mathrm{~mL})$. The reaction was carried out at $60{ }^{\circ} \mathrm{C}$ for $12 \mathrm{~h}$. After flash chromatography using ( $n$-Hexane/EtOAc : 10/1) compound 291 was obtained as a white solid $(50.0 \mathrm{mg}, 60 \%) .{ }^{1} \mathbf{H}$ NMR $\left(300 \mathrm{MHz}, \mathrm{CDCl}_{3}\right) \delta=8.66(\mathrm{dd}, J=7.4,1.1 \mathrm{~Hz}, 2 \mathrm{H}), 8.26(\mathrm{dd}, J=8.3,1.1 \mathrm{~Hz}, 2 \mathrm{H}), 7.79(\mathrm{dd}, J=$ 8.3, 7.4 HZ, $2 \mathrm{H}), 1.20 \mathrm{ppm}$ (m, $21 \mathrm{H}) .{ }^{13} \mathbf{C}$ NMR $\left(126 \mathrm{MHz}, \mathrm{CDCl}_{3}\right) \delta=162.8,134.9,132.0,131.8$, 127.1, 127.2, 121.6, 89.0, 80.5, 77.2, 18.9, 11.6 ppm. IR (ATR): $\widetilde{v}\left(\mathrm{~cm}^{-1}\right)=2955,2940,2924,28889$, 2862, 2722, 2364, 2353, 2333, 2209, 2192, 2170, 2162, 2148, 1726, 1692, 1635, 1625, 1583, 1559, 1540, 1512, 1489, 1459, 1512, 1489, 1459, 1434, 1409, 1370, 1351, 1335, 1254, 1231, 1223, 1173, 1142, 1104, 1081, 1047, 1015, 993, 940, 908, 892, 880, 839, 798, 767, 729, 697, 677, 646, 623, 614. HR-MS calc. for $\mathrm{C}_{23} \mathrm{H}_{27} \mathrm{NO}_{2} \mathrm{Si}$ : 378.1884; found: $378.1893[\mathrm{M}+\mathrm{H}]^{+}$(ESI-HRMS).

Synthesis of 2-((triisopropylsilyl)ethynyl)isoindoline-1,3-dione (292)

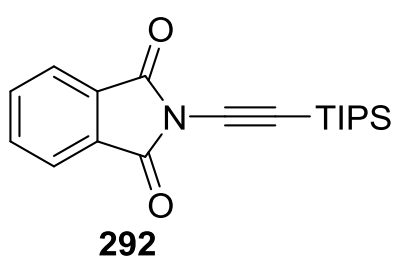

Using the general procedure GPD, compound 292 was prepared from the compound $238 f$ (33.0 mg, $0.22 \mathrm{mmol}, 1.00$ equiv.), $\mathrm{Cs}_{2} \mathrm{CO}_{3}$ (78.0 mg, $0.24 \mathrm{mmol}, 1.10$ equiv.) and the dibenzothiophenium salt $292(136 \mathrm{mg}$, $0.26 \mathrm{mmol}, 1.20$ equiv.) in dry DCM (3 mL). The reaction was carried out at RT for $12 \mathrm{~h}$. After flash chromatography using (hexane/EtOAc 15/1) compound 292 was obtained as a white solid (24.0 mg, 33\%). ${ }^{1} \mathbf{H}$ NMR (300 MHz, Chloroformd) $\delta=7.93(\mathrm{dd}, J=6.9,2.9 \mathrm{~Hz}, 2 \mathrm{H}), 7.82(\mathrm{dd}, J=6.9,2.9 \mathrm{~Hz}, 2 \mathrm{H}), 1.16\left(\mathrm{~s}_{\mathrm{br}}, 21 \mathrm{H}\right) \mathrm{ppm} .{ }^{13} \mathrm{C} \mathrm{NMR}$ (126 MHz, Chloroform- $d$ ) $\delta=165.1,135.1,131.2,124.2,86.2,76.6,18.6,11.2$ ppm. IR (ATR): $\widetilde{v}\left(\mathrm{~cm}^{-1}\right)=2940,2890,2864,2172,1747,1710,1695,1589,1456,1332,1309,1277,1255$, $1245,1232,1224,1200,1189,1132,1126,1105,1061,1051,1020,995,937,882,840,805,784$, $768,747,693,676,662,640,676,662,640,597,573,528$. 
Synthesis of triphenyl((triisopropylsilyl)ethynyl)phosphonium trifluoromethanesulfonate (303)

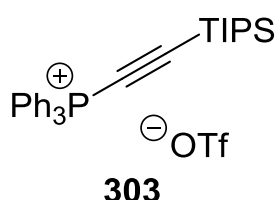

To a solution of triphenylphospine (116 mg, $0.44 \mathrm{mmol}, 1.00$ equiv.) in DCM ( $6 \mathrm{ml})$ was added compound $238 \mathrm{f}$ ( $237 \mathrm{mg}, 0.46 \mathrm{mmol}, 1.00$ equiv.) and the resulting reaction mixture was stirred for $12 \mathrm{~h}$ at RT. Then the solvent was removed in vacuo and the residue washed with ether $(3 \times 10 \mathrm{~mL})$ and pentane $(2$ $\mathrm{x} 10 \mathrm{ml}$ ). The remaining solid was dried in vacuo to afford the compound $\mathbf{3 0 3}$ as white solid $(231 \mathrm{mg}$, 88\%). ${ }^{1} \mathbf{H}$ NMR $\left(300 \mathrm{MHz}, \mathrm{CD}_{2} \mathrm{Cl}_{2}\right) \delta=7.96-7.89\left(\mathrm{~m}_{\mathrm{C}} 3 \mathrm{H}\right), 7.80-7.74(\mathrm{~m}, 9 \mathrm{H}), 7.71-7.68(\mathrm{~m}, 3 \mathrm{H})$ ppm. ${ }^{13} \mathbf{C}$ NMR $\left(101 \mathrm{MHz}, \mathrm{CD}_{2} \mathrm{Cl}_{2}\right) \delta=136.3(\mathrm{~d}, J=3.1 \mathrm{~Hz}), 133.2(\mathrm{~d}, J=12.6 \mathrm{~Hz}), 130.9(\mathrm{~d}, J=$ $14.2 \mathrm{~Hz}), 118.0(J=100.2 \mathrm{~Hz}), 86.0(J=159.9 \mathrm{~Hz}), 18.5,11.3 \mathrm{ppm} .{ }^{19} \mathbf{F}$ NMR $\left(282 \mathrm{MHz}, \mathrm{CD}_{2} \mathrm{Cl}_{2}\right) \delta$ $=-76.97 \mathrm{ppm}$. IR (ATR): $\widetilde{v}\left(\mathrm{~cm}^{-1}\right)=2953,2868,2125,1460,1439,1264,1223,1179,1146,1109$, 1067, 1030, 995, 882, 824, 764, 750, 726, 705, 689, 665, 635. HR-MS calc. for $\mathrm{C}_{29} \mathrm{H}_{36} \mathrm{PSi}: 443.2318$; found: $443.2315[\mathrm{M}+\mathrm{H}]^{+}(\mathrm{ESI}-\mathrm{HRMS})$.

Synthesis of triisopropyl((4-methoxyphenyl)buta-1,3-diyn-1-yl)silane (304)

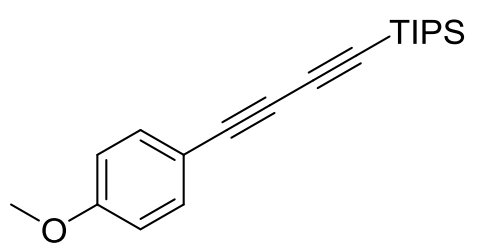

304

To a solution of the alkyne (29.0 $\mathrm{mg}, 0.22 \mathrm{mmol}, 1.00$ equiv.) in THF (3 mL) was added $n \operatorname{BuLi}(2.5 \mathrm{M}, 0.1 \mathrm{~mL}, 0.23 \mathrm{mmol}, 1.05$ equiv.) at $78{ }^{\circ} \mathrm{C}$. The solution was warmed up to $0{ }^{\circ} \mathrm{C}$ and stirred at this temperature for $5 \mathrm{~min}$. Then the solution was cooled back to $-78{ }^{\circ} \mathrm{C}$ and dibenzothiophenium salt $\mathbf{2 3 8 f}$ ( $136 \mathrm{mg}, 0.26 \mathrm{mmol}, 1.20$ equiv.) was added to the reaction mixture. The reaction mixture was warmed up slowly to rt and stirred for another $12 \mathrm{~h}$ at this temperature. The reaction mixture was extracted with ethyl acetate $(3 \times 20 \mathrm{~mL})$ and the combined organic phases were dried over $\mathrm{MgSO}_{4}$. Column chromatography (pure hexane) afford the desired product 304 as yellow oil. (13.0 mg, $4.25 \mu \mathrm{mol}, 19 \%) .{ }^{1} \mathbf{H}$ NMR $(300 \mathrm{MHz}$, Chloroform- $d$ ) $\delta=7.46(\mathrm{td}, J=8.9,2.1 \mathrm{~Hz}, 2 \mathrm{H}), 6.84(\mathrm{td}, J=8.9 \mathrm{~Hz}, 2 \mathrm{H}), 3.81(\mathrm{~s}, 3 \mathrm{H}), 1.11$ (s, $21 \mathrm{H}) \mathrm{ppm} .{ }^{13} \mathrm{C}$ NMR $(126 \mathrm{MHz}$, Chloroform- $d$ ) $\delta=160.4,134.4,114.2,113.5,89.9,87.2,75.9,73.7$, 55.5, 18.8, 11.6 ppm. IR (ATR): $\widetilde{v}\left(\mathrm{~cm}^{-1}\right)=3003,2942,2891,2865,2363,2200,2097,1716,1603$, 1567, 1508, 1462, 1442, 1416, 1384, 1365, 1295, 1250, 1172, 1105, 1097, 1071, 1028, 1017, 997, 919, 881, 829, 802, 673, 641, 590, 578, 533. HR-MS for $\mathrm{C}_{20} \mathrm{H}_{28}$ OSi: calc.: 312.1909; found: 312.1908 $[\mathrm{M}]^{+}$(ESI-HRMS). Analytical data corresponded to those previously reported. ${ }^{166}$ 


\section{Synthesis of Labeled Compounds}

Synthesis of labeled (4-methoxybenzyl)(phenylethynyl)sulfane (256*)

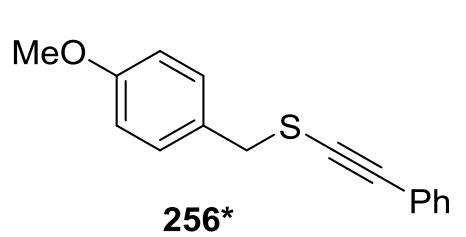

Using the general procedure GPD, compound $\mathbf{2 5 6}^{*}$ was prepared from (4-methoxyphenyl)methanethiol $\quad(34.0 \mathrm{mg}, \quad 0.22 \mathrm{mmol}$, 1.00 equiv.), $\mathrm{Cs}_{2} \mathrm{CO}_{3}$ (78 $\mathrm{mg}, 0.24 \mathrm{mmol}, 1.10$ equiv.) and $\mathbf{2 3 8}$ * $(115 \mathrm{mg}, 0.65 \mathrm{mmol}, 1.20$ equiv.) in dry DCM $(3 \mathrm{~mL})$. The reaction was carried out at RT for $12 \mathrm{~h}$. After flash chromatography using (hexane/EtOAc 5/1) compound 256* was obtained as a yellow oil $(31.2 \mathrm{mg}, 56 \%) .{ }^{1} \mathbf{H}$ NMR $\left(500 \mathrm{MHz}, \mathrm{CDCl}_{3}\right) \delta=7.367 .28(\mathrm{~m}, 7 \mathrm{H})$, $6.89(\mathrm{td}, J=8.6,3.3 \mathrm{~Hz}, 2 \mathrm{H}), 4.00(\mathrm{~s}, 2 \mathrm{H}), 3.81 \mathrm{ppm}(\mathrm{s}, 3 \mathrm{H}) .{ }^{13} \mathrm{C} \mathrm{NMR}\left(126 \mathrm{MHz}, \mathrm{CDCl}_{3}\right) \delta=$ 159.4, 131.5, 130.4, 128.7, 128.4, 128.1, 123.6, 114.1 (enriched, 100\%), 94.6, 79.6, 55.4, 40.2 ppm. IR (ATR): $\widetilde{v}\left(\mathrm{~cm}^{-1}\right)=3059,3030,2997,2954,2930,2906,2833,2164,1608,1595,1583,1572,1509$, 1486, 1462, 1440, 1421, 1317, 1201, 1248, 1236, 1205, 1174, 1126, 1105, 1068, 1030, 1000, 912, 882, 863, 828, 752, 727, 689, 653, 635. HR-MS calc. for $\mathrm{C}_{16} \mathrm{H}_{14} \mathrm{OS}: 255.0838$; found: 255.0838 $[\mathrm{M}+\mathrm{H}]^{+}(\mathrm{ESI}-\mathrm{HRMS})$.

Synthesis of labeled methyl 1-oxo-2-(phenylethynyl)-2,3-dihydro-1H-indene-2-carboxylate (232*)

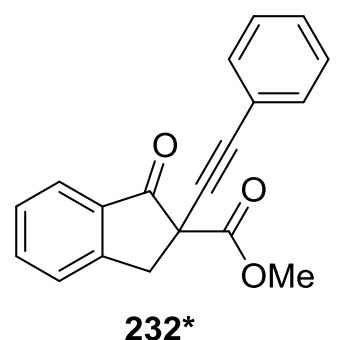

a yellow oil (36.0 mg, $62 \%) .{ }^{1} \mathbf{H}$ NMR $\left(300 \mathrm{MHz}, \mathrm{CDCl}_{3}\right) \delta=7.84(\mathrm{~d}, J=7.9 \mathrm{~Hz}, 1 \mathrm{H}), 7.67(\mathrm{dd}, J=$ 8.0, 7.5 Hz, $1 \mathrm{H}), 7.51(\mathrm{~d}, J=7.5 \mathrm{~Hz}, 1 \mathrm{H}), 7.46-7.41(\mathrm{~m}, 3 \mathrm{H}), 7.29-7.22(\mathrm{~m}, 3 \mathrm{H}) .{ }^{13} \mathbf{C}$ NMR $(75$ $\left.\mathrm{MHz}, \mathrm{CDCl}_{3}\right)=196.5,168.8,152.4,136.1,133.4,132.1,128.6,128.35,126.6,126.0,122.5,85.4$ (enriched, 57\%), 84.0 (enriched, 43\%), 56.1, 54.0, 41.2. ppm. IR (ATR): $\widetilde{v}\left(\mathrm{~cm}^{-1}\right)=3439,3054,3034$, 3021, 2952, 2846, 1718, 1605, 1589, 1574, 1536, 1514, 1490. 1476, 1463, 1432, 1340, 1326, 1300, 1230, 1211, 1172, 1154, 1094, 1066, 1027, 1019, 990, 954, 918, 883, 863, 829, 809, 793, 752, 689, 623, 601; HR-MS calc. for $\mathrm{C}_{19} \mathrm{H}_{14} \mathrm{O}_{3}: 291.1016$; found: 291.1012 [M] $]^{+}$(ESI-HRMS). 
Synthesis of labeled 4-methyl- $N$-phenyl- $N$-(phenylethynyl)benzenesulfonamide (286*)<smiles>Cc1ccc(S(=O)(=O)N(C#Cc2ccccc2)c2ccccc2)cc1</smiles>

238*

Using the general procedure GPD, compound 286* was prepared from 4methyl- $N$-phenylbenzenesulfonamide (54.4 $\mathrm{mg}, 0.22 \mathrm{mmol}, 1.00$ equiv.), $\mathrm{Cs}_{2} \mathrm{CO}_{3}$ (78.0 mg, $0.24 \mathrm{mmol}, 1.10$ equiv.) and 238a* (114 mg, $0.26 \mathrm{mmol}$, 1.20 equiv.) in dry DCM (3 mL). The reaction was carried out at RT for 12 h. After flash chromatography using (hexane/EtOAc 15/1) compound 286* was obtained as a yellow solid $(45.0 \mathrm{mg}, 58 \%)$. ${ }^{1} \mathbf{H}$ NMR $(300 \mathrm{MHz}$, $\left.\mathrm{CDCl}_{3}\right) \delta=7.55(\mathrm{td}, J=8.3,2.1 \mathrm{~Hz}, 2 \mathrm{H}), 7.33-7.18(\mathrm{~m}, 12 \mathrm{H}), 2.37 \mathrm{ppm}(\mathrm{s}, 3 \mathrm{H}) .{ }^{13} \mathbf{C}$ NMR $(75$ $\left.\mathrm{MHz}, \mathrm{CDCl}_{3}\right) \delta=145.1,142.2,139.1,133.1,131.6,129.6,129.2,128.4,128.4,128.1,126.4,122.8$, 83.1 (enriched, 100\%), 77.2, 70.6, 21.9 ppm. IR (ATR): $\widetilde{v}\left(\mathrm{~cm}^{-1}\right)=3062,3033,2953,2922,2868$, 2238, 2197, 1705, 1665, 1593, 1489, 1454, 1593, 1489, 1454, 1443, 1402, 1369, 1307, 1293, 1257, $1168,1120,1087,1068,1024,1004,972,917,886,836,812,781,754,702,689,681,652,611$. HRMS calc. for $\mathrm{C}_{21} \mathrm{H}_{17} \mathrm{NOS}$ : 348.1053; found: 348.1056 [M+H] $]^{+}$(ESI-HRMS).

Synthesis of labeled triisopropyl(((4-methoxybenzyl)thio)ethynyl)silane $\left(\mathbf{2 5 5}^{*}\right)$

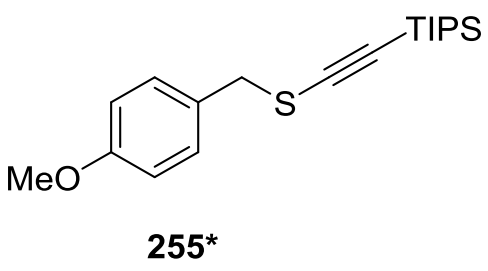

Using the general procedure, compound $255^{*}$ was prepared from (4-methoxyphenyl)methanethiol $\quad(30.9 \mathrm{mg}, \quad 0.22 \mathrm{mmol}$, 1.00 equiv.), $\mathrm{Cs}_{2} \mathrm{CO}_{3}$ (78.0 mg, $0.24 \mathrm{mmol}, 1.10$ equiv.) and the 238f* (136 mg, $0.26 \mathrm{mmol}, 1.20$ equiv.) in dry DCM (3 mL). The reaction was carried out at RT for $12 \mathrm{~h}$. After flash chromatography using (hexane/EtOAc : 20/1) compound $255^{*}$ was obtained as a yellow oil $(51.0 \mathrm{mg}$, 70\%). ${ }^{1} \mathbf{H}$ NMR $\left(300 \mathrm{MHz}, \mathrm{CDCl}_{3}\right) \delta=7.29(\mathrm{td}, J=8.6,2.9 \mathrm{~Hz}, 2 \mathrm{H}), 6.87(\mathrm{td}, J=8.6,2.9 \mathrm{~Hz}, 2 \mathrm{H})$, 3.94 (s, $2 \mathrm{H}), 3.82$ (s, $3 \mathrm{H}), 1.07$ (s, $21 \mathrm{H})$ ppm. ${ }^{13} \mathbf{C ~ N M R}\left(126 \mathrm{MHz}, \mathrm{CDCl}_{3}\right) \delta=159.0,130.1,128.6$, 113.9, 98.5 (enriched, 76\%), 95.5 (enriched, 24\%), 55.3, 40.2, 18.6, 11.6 ppm. IR (ATR): $\widetilde{v}\left(\mathrm{~cm}^{-1}\right)=$ 2942, 2891, 2864, 2087, 1610, 1512, 1463, 1441, 1302, 1251, 1237, 1175, 1037, 1017, 996, 882, 856, 830, 675, 657. HR-MS calc. for $\mathrm{C}_{19} \mathrm{H}_{30} \mathrm{OSSi}$ : 335.1852; found: 335.1859 [M+H] ${ }^{+}$(EI-HRMS). 
Synthesis of labeled methyl 1-oxo-2-((triisopropylsilyl)ethynyl)-2,3-dihydro- $1 H$-indene-2-carboxylate $(273 *)$

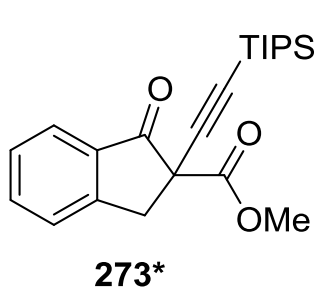

Using the general procedure GPD, compound $273^{*}$ was prepared from methyl 1-oxo-2,3-dihydro-1H-indene-2-carboxylate $\quad(41.8 \mathrm{mg}, \quad 0.22 \mathrm{mmol}$, 1.00 equiv.), $\mathrm{Cs}_{2} \mathrm{CO}_{3}$ (78 mg, $0.24 \mathrm{mmol}, 1.10$ equiv.) and 238f* (136 mg, $0.24 \mathrm{mmol}, 1.20$ equiv. $)$ in dry DCM $(6 \mathrm{~mL})$. The reaction was carried out at RT for $12 \mathrm{~h}$. After flash chromatography using (hexane/EtOAc : 15/1) compound 273* was obtained as a yellow oil $(53.0 \mathrm{mg}, 78 \%) .{ }^{1} \mathbf{H} \mathbf{~ N M R}\left(300 \mathrm{MHz}, \mathrm{CDCl}_{3}\right) \delta=7.81$ $(\mathrm{d}, J=7.5 \mathrm{~Hz}, 1 \mathrm{H}), 7.65(\mathrm{dt}, J=8.3,1.2 \mathrm{~Hz}, 1 \mathrm{H}), 7.48(\mathrm{~d}, J=7.3 \mathrm{~Hz}, 1 \mathrm{H}), 7.42(\mathrm{t}, J=7.5 \mathrm{~Hz}, 1 \mathrm{H})$, $3.94(\mathrm{~d}, J=17.3 \mathrm{~Hz}, 1 \mathrm{H}), 3.77(\mathrm{~s}, 3 \mathrm{H}), 3.50$ (d, $J=17.3 \mathrm{~Hz}, 1 \mathrm{H}), 1.04(\mathrm{~s}, 21 \mathrm{H}) .{ }^{13} \mathbf{C}$ NMR $(126$ $\left.\mathrm{MHz}, \mathrm{CDCl}_{3}\right) \delta=195.9,168.7,152.1,135.8,133.4,128.1,126.4,125.7,103.2$ (enriched, minor), 85.7 (enriched, major), 56.5, 53.7, 41.4, 18.8, 11.4 ppm. IR (ATR): $\widetilde{v}\left(\mathrm{~cm}^{-1}\right)=2942,2891,2864,2169$, 1754, 1724, 1607, 1590, 1463, 1433, 1384, 1366, 1325, 1201, 1250, 1210, 1196, 1176, 1154, 1096, 1064, 1016, 995, 955, 920, 881, 826, 807, 792, 750, 676, 661, 637. HR-MS calc. for $\mathrm{C}_{22} \mathrm{H}_{30} \mathrm{O}_{3} \mathrm{Si}$ : 335.1852; found: 335.1859 [M+H] $]^{+}$(ESI-HRMS).

Synthesis of labeled 4-methyl- $N$-phenyl- $N$-((triisopropylsilyl)ethynyl)benzenesulfonamide $(\mathbf{2 8 1 *})$<smiles></smiles>

$281^{*}$

Using the general procedure, compound 281* was prepared from 4-methyl$\mathrm{N}$-phenylbenzenesulfonamide $\left(54.4 \mathrm{mg}, 0.22 \mathrm{mmol}, 1.00\right.$ equiv.), $\mathrm{Cs}_{2} \mathrm{CO}_{3}$ (78.0 mg, $0.24 \mathrm{mmol}, 1.10$ equiv.) and 238f* (136 mg, $0.26 \mathrm{mmol}$, 1.20 equiv.) in dry DCM ( $3 \mathrm{~mL})$. The reaction was carried out at RT for 12 h. After flash chromatography using (hexane/EtOAc 15/1) compound 281*was obtained as a yellow oil (30.0 mg, $32 \%)$. ${ }^{1} \mathbf{H}$ NMR (300 MHz, $\left.\mathrm{CDCl}_{3}\right) \delta=7.55(\mathrm{td}, J=8.1,1.5 \mathrm{~Hz}, 2 \mathrm{H}), 7.34-7.24(\mathrm{~m}, 5 \mathrm{H}), 7.23(\mathrm{~d}, J=9.4 \mathrm{~Hz}, 2 \mathrm{H}), 2.41(\mathrm{~s}, 3 \mathrm{H})$, $1.04(\mathrm{~s}, 21 \mathrm{H}) .{ }^{13} \mathbf{C}$ NMR $\left(126 \mathrm{MHz}, \mathrm{CDCl}_{3}\right) \delta=144.9,138.9,133.0,129.4,129.0,128.4,128.0$, 126.0, 96.7 (enriched, minor), 69.8 (enriched, major), 21.9, 18.8, 11.7. IR (ATR): $\widetilde{v}\left(\mathrm{~cm}^{-1}\right)=2958$, 2939, 2923, 2888, 2862, 2165, 2129, 1591, 1488, 1455, 1367, 1304, 1291, 1261, 1176, 1167, 1132, 1120, 1088, 1073, 1018, 996, 926, 891, 882, 812, 801. 771, 712, 702, 688, 680, 670, 654, 628, 583,. HR-MS calc. for $\mathrm{C}_{24} \mathrm{H}_{33} \mathrm{O}_{2} \mathrm{SSi}$ : 428.2074; found: 428.2077 [M+H] $]^{+}$(ESI-HRMS). 


\subsubsection{Attempts towards metal catalyzed reactions}

\section{Lewis acid catalysis}

General procedure E (GPE):

To a solution of the indole $(0.22 \mathrm{mmol}, 1.00$ equiv. $)$ in the desired solvent $(0.07 \mathrm{M})$ was added the catalyst system, the base ( $0.24 \mathrm{mmol}, 1.10$ equiv.) and the reagent (136 mg, $0.26 \mathrm{mmol}, 1.20$ equiv.). The reaction mixture was stirred at specified temperature for $12 \mathrm{~h}$. Then the reaction mixture was filtered through a short pad of silica with ethyl acetate (around $100 \mathrm{~mL}$ ) as eluent and subsequently the solvent was removed under reduced pressure. The residue was purified by flash chromatography and the resulting products were examined by NMR and mass spectroscopy.

Synthesis of 1-((triisopropylsilyl)ethynyl)-1H-indole (337)

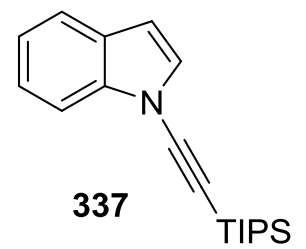

Following the general procedure GPE: Indole ( $25.0 \mathrm{mg}, 0.22 \mathrm{mmol}, 1.00$ equiv.), the catalyst system chloro(triphenylphosphine)gold(I) $(10.0 \mathrm{mg}, 0.02 \mathrm{mmol}, 0.10$ equiv.) and silver hexafluoroantimonate(V) (7.0 mg, $0.02 \mathrm{mmol}, 1.00$ equiv.), the reagent, $\mathrm{Cs}_{2} \mathrm{CO}_{3}(78.0 \mathrm{mg}, 0.24 \mathrm{mmol}, 1.10$ equiv.) and $\mathrm{DCM}(3 \mathrm{~mL})$ were used. The reaction was stirred at $\mathrm{rt}$ and after flash chromatography the product $\mathbf{3 3 7}$ could be isolated as yellow oil (25.0 mg, $0.08 \mathrm{mmol}, 38 \%) .{ }^{1} \mathbf{H}$ NMR $\left(300 \mathrm{MHz}, \mathrm{CDCl}_{3}\right) \delta=7.65(\mathrm{~d}, J$ $=7.9 \mathrm{~Hz}, 1 \mathrm{H}), 7.60(\mathrm{~d}, J=7.9 \mathrm{~Hz}, 1 \mathrm{H}), 7.38(\mathrm{dt}, J=7.4,0.9 \mathrm{~Hz}, 1 \mathrm{H}), 7.30-7.23(\mathrm{~m}, 2 \mathrm{H}), 6.59$ (dd, $J$ $=3.5,0.9 \mathrm{~Hz}, 1 \mathrm{H}), 1.22$ (s, $21 \mathrm{H}) \mathrm{ppm} .{ }^{13} \mathbf{C} \mathbf{~ N M R}\left(126 \mathrm{MHz}, \mathrm{CDCl}_{3}\right) \delta=138.4,129.1,127.8,123.7$, 122.1, 121.3, 111.5, 105.3, 94.7, 68.9, 18.9, 11.5 ppm. IR (ATR): $\widetilde{v}\left(\mathrm{~cm}^{-1}\right)=2941,2890,2863,2179$, 1612, 1524, 1457, 1383, 1352, 1340, 1324, 1295, 1221, 1201, 1122, 1088, 1072, 1041, 1011, 995, $919,881,777,760,740,713,674,658,623,589,562,517,503$. HR-MS calc. for $\mathrm{C}_{19} \mathrm{H}_{27} \mathrm{NSi}$ : 298.1986; found: $298.1982[\mathrm{M}+\mathrm{H}]^{+}$(EI-HRMS). Analytical data corresponded to those previously reported. ${ }^{167}$ 


\begin{tabular}{|c|c|c|c|c|c|c|}
\hline Entry & Catalyst & Additive & Base & Solvent & $\begin{array}{l}\text { Yield } \\
(\%)\end{array}$ & Comments \\
\hline 1 & $\mathrm{AuClPPh}_{3}$ & $\mathrm{AgSbF}_{6}$ & $\mathrm{Cs}_{2} \mathrm{CO}_{3}$ & DCM & 38 & $\begin{array}{l}N \text {-alkynylated } \\
\text { product } \mathbf{3 3 7}\end{array}$ \\
\hline 2 & $\mathrm{AuClPPh}_{3}$ & $\mathrm{AgSbF}_{6}$ & $\mathrm{~K}_{3} \mathrm{PO}_{4}$ & DCM & 0 & $\begin{array}{l}\text { Isolated starting } \\
\text { material } \mathbf{3 3 3}\end{array}$ \\
\hline 3 & $\mathrm{AuClPPh}_{3}$ & $\mathrm{AgSbF}_{6}$ & TBAOAC & $\overline{\mathrm{DCM}}$ & 0 & $\begin{array}{l}\text { Isolated starting } \\
\text { material } \mathbf{3 3 3}\end{array}$ \\
\hline 4 & $\mathrm{AuClPPh}_{3}$ & $\mathrm{AgSbF}_{6}$ & KOAC & DCM & 0 & $\begin{array}{l}\text { Isolated starting } \\
\text { material } \mathbf{3 3 3}\end{array}$ \\
\hline 5 & $\mathrm{AuClPPh}_{3}$ & $\mathrm{AgSbF}_{6}$ & $\mathrm{Cs}_{2} \mathrm{CO}_{3}$ & DCE & 23 & Reaction at $60^{\circ} \mathrm{C}$ \\
\hline 6 & $\mathrm{AuClPPh}_{3}$ & $\mathrm{AgSbF}_{6}$ & $\mathrm{Cs}_{2} \mathrm{CO}_{3}$ & $\overline{\mathrm{DCM}}$ & 0 & $\begin{array}{l}N \text {-Methylindole } \\
\text { 334 as a substrate; } \\
\text { re-isolated }\end{array}$ \\
\hline 7 & $\mathrm{AgCl}$ & - & $\mathrm{Cs}_{2} \mathrm{CO}_{3}$ & DCM & 23 & $\begin{array}{l}N \text {-alkynylated } \\
\text { product } \mathbf{3 3 7}\end{array}$ \\
\hline 8 & $\mathrm{AgCl}$ & - & $\mathrm{Cs}_{2} \mathrm{CO}_{3}$ & $\mathrm{Et}_{2} \mathrm{O}$ & 25 & $\begin{array}{l}N \text {-alkynylated } \\
\text { product } \mathbf{3 3 7}\end{array}$ \\
\hline 9 & $\mathrm{AgCl}$ & - & $\mathrm{K}_{2} \mathrm{CO}_{3}$ & THF & 23 & $\begin{array}{l}N \text {-alkynylated } \\
\text { product } \mathbf{3 3 7}\end{array}$ \\
\hline 10 & $\mathrm{AgCl}$ & - & - & DCM & 0 & $\begin{array}{l}\text { Isolated starting } \\
\text { material } \mathbf{3 3 3}\end{array}$ \\
\hline 11 & $\mathrm{PtCl}_{2}$ & - & $\mathrm{Cs}_{2} \mathrm{CO}_{3}$ & DCM & 0 & No reaction \\
\hline 12 & $\mathrm{PtCl}_{2}$ & - & DIPEA & DCM & 0 & $\begin{array}{l}\text { Reaction at } 60^{\circ} \mathrm{C} \text {, } \\
\text { Isolated starting } \\
\text { material } \mathbf{3 3 3}\end{array}$ \\
\hline 13 & $\mathrm{PtCl}_{2}$ & - & - & DCE & 0 & $\begin{array}{l}\text { Reaction at } 80^{\circ} \mathrm{C} \text {, } \\
\text { Isolated starting } \\
\text { material } \mathbf{3 3 3}\end{array}$ \\
\hline 14 & $\mathrm{AuCl}_{3}$ & - & $\mathrm{Cs}_{2} \mathrm{CO}_{3}$ & DCM & 0 & No reaction \\
\hline 15 & $\mathrm{AuCl}_{3}$ & - & - & $\overline{\mathrm{DCM}}$ & 0 & $\begin{array}{l}N \text {-Methylindole as } \\
\text { a substrate }\end{array}$ \\
\hline
\end{tabular}




\section{C-H alkynylation experiments}

Synthesis of 2-(2-((triisopropylsilyl)ethynyl)phenyl)pyridine (339)<smiles>CC(C)CSCC#Cc1ccccc1-c1ccccn1</smiles>

General procedure: To a solution of the 2-phenylpyridine $(34.1 \mathrm{mg}, 0.22 \mathrm{mmol}$, 1.00 equiv.) in DCE/DCM $(0.1 \mathrm{M})$ was added the catalyst and the corresponding base. The reagent (136 mg, $0.26 \mathrm{mmol}, 1.20$ equiv.) was added and the reaction mixture was stirred for $12 \mathrm{~h}$ at the elaborated temperature. The reaction mixture was filtrated over a short pad of silica and the solvent was removed by evaporation. The residue was purified by column chromatography (hexane: EtOAc $=95: 5$ ) to afford the product 339 as colorless oil. Analytical data corresponded to those described in the literature.

\begin{tabular}{|c|c|c|c|c|c|c|}
\hline Entry & Catalyst & Additive & Base & Solvent & $\mathrm{T}\left({ }^{\circ} \mathrm{C}\right)$ & Yield (\%) \\
\hline 1 & $\begin{array}{l}{\left[\mathrm{RhCp} * \mathrm{Cl}_{2}\right]_{2}} \\
(2 \%)\end{array}$ & $\begin{array}{l}\mathrm{AgSbF}_{6} \\
(10 \%)\end{array}$ & - & DCM & $\mathrm{rt}$ & $\begin{array}{l}\text { Traces of the } \\
\text { product } \mathbf{3 3 9}\end{array}$ \\
\hline 2 & $\begin{array}{l}{\left[\mathrm{RhCp} * \mathrm{Cl}_{2}\right]_{2}} \\
(2 \%)\end{array}$ & $\begin{array}{l}\mathrm{Zn}(\mathrm{OTf})_{2} \\
(10 \%)\end{array}$ & - & DCE & $\mathrm{rt}$ & $\begin{array}{l}\mathrm{SM}^{*}+\text { traces } \\
\text { of the product } \\
\text { 339 }\end{array}$ \\
\hline 3 & $\begin{array}{l}{\left[\mathrm{RhCp}^{*} \mathrm{Cl}_{2}\right]_{2}} \\
(2 \%)\end{array}$ & $\begin{array}{l}\mathrm{AgSbF}_{6} \\
(10 \%)\end{array}$ & - & DCE & 80 & 34 \\
\hline 4 & $\begin{array}{l}{\left[\mathrm{RhCp} * \mathrm{Cl}_{2}\right]_{2}} \\
(2 \%)\end{array}$ & $\begin{array}{l}\mathrm{Zn}(\mathrm{OTf})_{2} \\
(10 \%)\end{array}$ & - & $\overline{\mathrm{DCE}}$ & 80 & 32 \\
\hline 5 & $\begin{array}{l}{\left[\mathrm{IrCp} * \mathrm{Cl}_{2}\right]_{2}} \\
(4 \%)\end{array}$ & $\begin{array}{l}\mathrm{AgSbF}_{6} \\
(10 \%)\end{array}$ & - & DCM & $\mathrm{rt}$ & $0(\mathrm{SM})$ \\
\hline 6 & $\begin{array}{l}{\left[\mathrm{RhCp} * \mathrm{Cl}_{2}\right]_{2}} \\
(2 \%)\end{array}$ & $\begin{array}{l}\mathrm{AgSbF}_{6} \\
(10 \%)\end{array}$ & - & $\mathrm{MeCN}$ & 80 & 4 \\
\hline 7 & $\mathrm{MnBr}(\mathrm{CO})_{5}$ & $\mathrm{HNCy}_{2}(20 \%)$ & - & DCE & 80 & $\begin{array}{l}\text { Traces of the } \\
\text { product } \mathbf{3 3 9}\end{array}$ \\
\hline 8 & $\begin{array}{l}{\left[\mathrm{RhCp}^{*} \mathrm{Cl}_{2}\right]_{2}} \\
(4 \%)\end{array}$ & $\begin{array}{l}\mathrm{AgSbF}_{6} \\
(10 \%)\end{array}$ & - & DCE & 80 & $\begin{array}{l}\text { Mixture of SM } \\
\text { and product }\end{array}$ \\
\hline 9 & $\begin{array}{l}{\left[\mathrm{RhCp} * \mathrm{Cl}_{2}\right]_{2}} \\
(2 \%)\end{array}$ & $\begin{array}{l}\mathrm{AgSbF}_{6} \\
(10 \%)\end{array}$ & - & $\begin{array}{l}\text { DCE (twice } \\
\text { diluted) }\end{array}$ & 80 & 24 \\
\hline 10 & $\begin{array}{l}{\left[\mathrm{RhCp} * \mathrm{Cl}_{2}\right]_{2}} \\
(2 \%)\end{array}$ & $\begin{array}{l}\mathrm{AgSbF}_{6} \\
(20 \%)\end{array}$ & - & DCE & 80 & $\begin{array}{l}\text { Mixture of SM } \\
\text { and product }\end{array}$ \\
\hline 11 & $\begin{array}{l}{\left[\mathrm{RhCp} * \mathrm{Cl}_{2}\right]_{2}} \\
(8 \%)\end{array}$ & $\begin{array}{l}\mathrm{AgSbF}_{6} \\
(10 \%)\end{array}$ & - & DCE & 80 & $\begin{array}{l}\text { Mixture of SM } \\
\text { and product }\end{array}$ \\
\hline 12 & $\begin{array}{l}{\left[\mathrm{RhCp}^{*} \mathrm{Cl}_{2}\right]_{2}} \\
(4 \%)\end{array}$ & $\mathrm{AgSbF}_{6}(5 \%)$ & - & DCE & 80 & $\begin{array}{l}\text { Mixture of SM } \\
\text { and product }\end{array}$ \\
\hline 13 & $\begin{array}{l}{\left[\mathrm{RhCp} * \mathrm{Cl}_{2}\right]_{2}} \\
(2 \%)\end{array}$ & $\begin{array}{l}\mathrm{AgSbF}_{6} \\
(10 \%)\end{array}$ & $\mathrm{Cs}_{2} \mathrm{CO}_{3}$ & DCM & $\mathrm{rt}$ & $0\left(\mathrm{SM}^{*}\right)$ \\
\hline 14 & $\begin{array}{l}{\left[\mathrm{IrCp} * \mathrm{Cl}_{2}\right]_{2}} \\
(4 \%)\end{array}$ & $\begin{array}{l}\mathrm{AgSbF}_{6} \\
(10 \%)\end{array}$ & $\mathrm{Cs}_{2} \mathrm{CO}_{3}$ & DCM & $\mathrm{rt}$ & $0(\mathrm{SM})$ \\
\hline 15 & $\begin{array}{l}{\left[\mathrm{RhCp} * \mathrm{Cl}_{2}\right]_{2}} \\
(4 \%)\end{array}$ & $\mathrm{AgSbF}_{6}(5 \%)$ & $\begin{array}{l}\mathrm{Cs}_{2} \mathrm{CO}_{3} \\
\text { (2.00 equiv.) }\end{array}$ & DCE & 80 & $\begin{array}{l}\text { Traces of the } \\
\text { product } \mathbf{3 3 9}\end{array}$ \\
\hline 16 & $\begin{array}{l}{\left[\mathrm{RhCp} * \mathrm{Cl}_{2}\right]_{2}} \\
(2 \%)\end{array}$ & $\begin{array}{l}\mathrm{AgSbF}_{6} \\
(10 \%)\end{array}$ & TBAOAc & $\mathrm{DCM}$ & $\mathrm{rt}$ & $0(\mathrm{SM})$ \\
\hline 17 & $\begin{array}{l}{\left[\mathrm{RhCp} * \mathrm{Cl}_{2}\right]_{2}} \\
(2 \%)\end{array}$ & $\begin{array}{l}\mathrm{AgSbF}_{6} \\
(10 \%)\end{array}$ & $\begin{array}{l}\text { Cesium } \\
\text { pivalate }\end{array}$ & DCE & 80 & $\begin{array}{l}\text { Decomposition } \\
\text { of } \mathbf{2 3 8 f}\end{array}$ \\
\hline
\end{tabular}




\begin{tabular}{|c|c|c|c|c|c|c|}
\hline 18 & $\begin{array}{l}{\left[\mathrm{RhCp}^{*} \mathrm{Cl}_{2}\right]_{2}} \\
(2 \%)\end{array}$ & $\begin{array}{l}\mathrm{AgSbF}_{6} \\
(10 \%)\end{array}$ & $\mathrm{K}_{3} \mathrm{PO}_{4}$ & $\mathrm{DCE}$ & $\mathrm{rt}$ & $\begin{array}{l}\text { Traces of the } \\
\text { product } 339\end{array}$ \\
\hline 19 & $\begin{array}{l}{\left[\mathrm{RhCp}^{*} \mathrm{Cl}_{2}\right]_{2}} \\
(2 \%)\end{array}$ & $\begin{array}{l}\mathrm{AgSbF}_{6} \\
(10 \%)\end{array}$ & $\mathrm{H}_{2} \mathrm{O}$ & DCE & 80 & $\begin{array}{l}\text { Traces of the } \\
\text { product } \mathbf{3 3 9}\end{array}$ \\
\hline 20 & $\begin{array}{l}{\left[\mathrm{RhCp} * \mathrm{Cl}_{2}\right]_{2}} \\
(2 \%)\end{array}$ & $\begin{array}{l}\mathrm{AgSbF}_{6} \\
(10 \%)\end{array}$ & $\mathrm{K}_{4} \mathrm{P}_{2} \mathrm{O}_{7}$ & DCE & $\mathrm{rt}$ & SM \\
\hline 21 & $\begin{array}{l}{\left[\mathrm{RhCp} * \mathrm{Cl}_{2}\right]_{2}} \\
(2 \%)\end{array}$ & $\begin{array}{l}\mathrm{AgSbF}_{6} \\
(10 \%)\end{array}$ & Pyridine & DCE & 80 & SM \\
\hline 22 & $\begin{array}{l}{\left[\mathrm{RhCp}^{*} \mathrm{Cl}_{2}\right]_{2}} \\
(2 \%)\end{array}$ & $\begin{array}{l}\mathrm{AgSbF}_{6} \\
(10 \%)\end{array}$ & Lutidine & $\mathrm{DCE}$ & 80 & SM \\
\hline 23 & $\begin{array}{l}{\left[\mathrm{RhCp}^{*} \mathrm{Cl}_{2}\right]_{2}} \\
(2 \%)\end{array}$ & $\begin{array}{l}\mathrm{AgSbF}_{6} \\
(10 \%)\end{array}$ & $\begin{array}{l}\text { 2,6-Di-tert- } \\
\text { butylpyridine }\end{array}$ & $\mathrm{DCE}$ & 80 & $\begin{array}{l}\text { Product } 339 \\
(4 \%)\end{array}$ \\
\hline 24 & $\begin{array}{l}{\left[\mathrm{RhCp}^{*} \mathrm{Cl}_{2}\right]_{2}} \\
(2 \%)\end{array}$ & $\begin{array}{l}\mathrm{AgSbF}_{6} \\
(10 \%)\end{array}$ & $\begin{array}{l}\text { 2,6-Di-tert- } \\
\text { butylpyridine }\end{array}$ & $\mathrm{DCE}$ & $\mathrm{rt}$ & $\begin{array}{l}\text { Traces of the } \\
\text { product } 339\end{array}$ \\
\hline 25 & $\begin{array}{l}{\left[\mathrm{RhCp} * \mathrm{Cl}_{2}\right]_{2}} \\
(2 \%)\end{array}$ & $\begin{array}{l}\mathrm{AgSbF}_{6} \\
(10 \%)\end{array}$ & $\begin{array}{l}\text { 2,6-Di-tert- } \\
\text { butylpyridine } \\
(0.50 \mathrm{eq})\end{array}$ & DCE & $\mathrm{rt}$ & $\begin{array}{l}\text { Traces of the } \\
\text { product } \mathbf{3 3 9}\end{array}$ \\
\hline 26 & $\mathrm{MnBr}(\mathrm{CO})_{5}$ & - & $\mathrm{HNCy}_{2}$ & DCE & 80 & $\begin{array}{l}\text { Traces of the } \\
\text { product } \mathbf{3 3 9}\end{array}$ \\
\hline 27 & $\begin{array}{l}{\left[\mathrm{RhCp} * \mathrm{Cl}_{2}\right]_{2}} \\
(2 \%)\end{array}$ & $\begin{array}{l}\mathrm{AgSbF}_{6} \\
(10 \%)\end{array}$ & DMAP & DCE & 80 & $\begin{array}{l}\text { Traces of the } \\
\text { product } \mathbf{3 3 9}\end{array}$ \\
\hline 28 & $\begin{array}{l}{\left[\mathrm{RhCp}^{*} \mathrm{Cl}_{2}\right]_{2}} \\
(2 \%)\end{array}$ & $\begin{array}{l}\mathrm{AgSbF}_{6} \\
(10 \%)\end{array}$ & DIPEA & DCE & 80 & $\begin{array}{l}\text { Traces of the } \\
\text { product } \mathbf{3 3 9}\end{array}$ \\
\hline 29 & $\begin{array}{l}{\left[\mathrm{RhCp}^{*} \mathrm{Cl}_{2}\right]_{2}} \\
(2 \%)\end{array}$ & $\begin{array}{l}\mathrm{AgSbF}_{6} \\
(10 \%)\end{array}$ & $\begin{array}{l}\text { Proton } \\
\text { sponge }\end{array}$ & DCE & $\mathrm{rt}$ & $0(\mathrm{SM})$ \\
\hline 30 & $\begin{array}{l}{\left[\mathrm{RhCp}^{*} \mathrm{Cl}_{2}\right]_{2}} \\
(2 \%)\end{array}$ & $\begin{array}{l}\mathrm{AgSbF}_{6} \\
(10 \%)\end{array}$ & $\overline{\mathrm{DBU}}$ & DCE & 80 & $\begin{array}{l}\text { Decomposition } \\
\text { of } \mathbf{2 3 8 f}\end{array}$ \\
\hline
\end{tabular}

$* \mathrm{SM}=$ Starting material 338. 


\subsection{Synthesis attemps towards a system with internal base}

Synthesis of methyl 2-mercaptobenzoate (341)

To a solution of thiosalicylic acid $(\mathbf{3 4 0}, 2.50 \mathrm{~g}, 16.2 \mathrm{mmol}, 1.00$ equiv.) in methanol (13 $\mathrm{mL})$ was added sulfuric acid $\left(0.43 \mathrm{~mL}, 8.10 \mathrm{mmol}, 0.50\right.$ equiv.) at $0{ }^{\circ} \mathrm{C}$ and the reaction mixture was stirred under reflux for $18 \mathrm{~h}$. The solvent was removed under reduced pressure and sat $\mathrm{NaHCO}_{3}$-solution was added to the residue. The aqueous phase was extracted with DCM $(3 \times 15 \mathrm{~mL})$. The combined organic phases were washed by brine. After removal of the solvent under reduced pressure the product 341 could be isolated as yellow oil (2.55 g, $15.2 \mathrm{mmol}, 94 \%) . ~{ }^{1} \mathbf{H}-\mathbf{N M R}\left(300 \mathrm{MHz}, \mathrm{CDCl}_{3}\right): \delta[\mathrm{ppm}]=$ 7.95-8.00 (m, 1H), 7.26-7.29 (m, 2 H), 7.08-7.15 (m, 1 H), 4.67 (s, 1 H), 3.89 (s, 3 H). ${ }^{13}$ C NMR (126 $\left.\mathrm{MHz}, \mathrm{CDCl}_{3}\right) \delta=166.9,138.0,132.2,131.5,130.7,125.6,124.3,52.0 \mathrm{ppm}$. HR-MS calc. for $\mathrm{C}_{8} \mathrm{H}_{8} \mathrm{O}_{2} \mathrm{~S}$ : 167.0172; found: $167.0172[\mathrm{M}+\mathrm{H}]^{+}$(ESI-HRMS). Analytical data corresponded to those previously reported. ${ }^{168}$

Synthesis of 2-((2-(methoxycarbonyl)phenyl)thio)benzoic acid (343)<smiles>COC(=O)c1ccccc1Sc1ccccc1C(=O)O</smiles>

solution was extracted by ethyl acetate $(3 \times 50 \mathrm{~mL})$. The combined organic phases were washed by diluted hydrochloric acid $(1 \mathrm{M}, 3 \mathrm{x} 100 \mathrm{~mL})$, dried over $\mathrm{Na}_{2} \mathrm{SO}_{4}$ and the solvent removed under reduced pressure. The residue was washed with hexane and chloroform to afford the desired compound 343 (1.16 g, $4.02 \mathrm{mmol}, 68 \%)$ as yellow solid. ${ }^{1} \mathbf{H}-\mathbf{N M R}\left(300 \mathrm{MHz}, \mathrm{CD}_{3} \mathrm{CN}\right): \delta[\mathrm{ppm}]=$ 7.94-7.90 (m, $1 \mathrm{H})$, 7.86-7.84 (m, $1 \mathrm{H})$, 7.49-7.31 (m, $5 \mathrm{H})$, 7.26-7.26 (m, 1H), 7.14-7.10 (m, $1 \mathrm{H})$, 3.78 (s, $3 \mathrm{H})$ ppm. ${ }^{13} \mathrm{C}-\mathrm{NMR}\left(126 \mathrm{MHz}, \mathrm{CD}_{3} \mathrm{CN}\right): \delta$ [ppm] = 168.0, 167.9, 134.2, 133.7, 133.6, 133.3, 133.2, 133.0, 132.3, 131.6, 131.3, 128.4, 128.0, 127.7, 52.9 ppm. IR (ATR): $\tilde{v}\left[\mathrm{~cm}^{-1}\right]=557,694,720$, 743, 932, 1039, 1057, 1111, 1253, 1270, 1666, 1728, 2643, 2817, 2951. HR-MS calc. for $\mathrm{C}_{15} \mathrm{H}_{12} \mathrm{O}_{4} \mathrm{~S}$ : 287.0384; found: 287.0385 [M+H] $]^{+}$(ESI-HRMS). ). Analytical data corresponded to those previously reported. $^{136 \mathrm{~b}}$ 
Synthesis of methyl 2-((2-(methylcarbamoyl)phenyl)thio)benzoate (344)<smiles>CNC(=O)c1ccccc1Sc1ccccc1C(=O)OC</smiles>

For the synthesis of $\mathbf{3 4 4}$ a slightly modified literature procedure was used. ${ }^{136 \mathrm{~b}}$ To a solution of the acid $\mathbf{3 4 3}$ (798 $\mathrm{mg}, 2.77 \mathrm{mmol}, 1.00$ equiv.) was added thionyl chloride $(6.30 \mathrm{~mL}, 87.0 \mathrm{mmol}, 31.4$ equiv.) and the resulting solution was stirred for $3 \mathrm{~h}$ at $70{ }^{\circ} \mathrm{C}$. The excess of thionyl chloride was removed under reduced pressure and residue was dissolved in THF $(40 \mathrm{~mL})$. The solution was cooled to $0{ }^{\circ} \mathrm{C}$, methylamine was added dropwise to the reaction mixture and the solution was stirred for $12 \mathrm{~h}$ at $\mathrm{rt}$. The reaction mixture was poured to water and extracted by DCM $(3 \mathrm{x}$ $100 \mathrm{~mL}$ ). The combined organic phases were dried over $\mathrm{Na}_{2} \mathrm{SO}_{4}$ and the solvent was removed under reduced pressure. The residue was purified by column chromatography (hexane/EtOAc $+1 \% \mathrm{Net}_{3}$, 1:5) to afford the desired compound $\mathbf{3 4 4}$ as white solid (586 mg, $1.94 \mathrm{mmol}, 70 \%$ ). ${ }^{1} \mathbf{H}$-NMR $\left(500 \mathrm{MHz}, \mathrm{CDCl}_{3}\right): \delta[\mathrm{ppm}]=$ 7.98-7.95 (m, 1H), 7.89-7.86 (m, $\left.1 \mathrm{H}\right), 7.39-7.55(\mathrm{~m}, 3 \mathrm{H}), 7.30$ (ddd, $J=8.1 \mathrm{~Hz}, 7.3 \mathrm{~Hz}, 1.7 \mathrm{~Hz}, 1 \mathrm{H}), 7.19(\mathrm{dd}, J=7.4 \mathrm{~Hz}, 1.3 \mathrm{~Hz}, 1 \mathrm{H}), 6.89(\mathrm{dd}, J=7.9 \mathrm{~Hz}, 1.7 \mathrm{~Hz}, 1 \mathrm{H})$, ), 3.92 (s, $3 \mathrm{H}), 2.83$ (d, $J=4.9 \mathrm{~Hz}, 3 \mathrm{H}) \mathrm{ppm} .{ }^{13} \mathbf{C}-\mathbf{N M R}\left(126 \mathrm{MHz}, \mathrm{CDCl}_{3}\right): \delta[\mathrm{ppm}]=168.2,167.9$, 140.7, 139.9, 136.5, 132.8, 131.2, 130.7, 130.2, 130.1, 129.6, 128.9, 125.5, 52.5, 26.9 ppm. IR (ATR): $\tilde{v}\left[\mathrm{~cm}^{-1}\right]=526,688,705,740,1252,1434,1561,1634,1709,2955,3099,3261$. HR-MS calc. for $\mathrm{C}_{16} \mathrm{H}_{15} \mathrm{NO}_{3} \mathrm{~S}$ : 300.0700; found: $300.0695[\mathrm{M}+\mathrm{H}]^{+}$(ESI-HRMS). ). Analytical data corresponded to those previously reported. ${ }^{136 \mathrm{~b}}$

Synthesis of (2-((2-((methylamino)methyl)phenyl)thio)phenyl)methanol (345)<smiles>CNCc1ccccc1Sc1ccccc1CO</smiles>

For the synthesis of $\mathbf{3 4 5}$ a slightly modified literature procedure was used. ${ }^{136 \mathrm{~b}}$ To a solution of the amide 344 (1.20 g, $3.99 \mathrm{mmol}, 1.00$ equiv.) in benzene was added phosphorus pentachloride $(0.83 \mathrm{~g}, 3.99 \mathrm{mmol}$, 1.00 equiv.) and the reaction mixture was heated under reflux for 2 and subsequently the solvent was removed by reduced pressure. The residue was taken up by THF $(15 \mathrm{~mL})$ and a suspension of lithium aluminium hydride was added to the reaction mixture at $0{ }^{\circ} \mathrm{C}$. The reaction mixture was stirred for $1 \mathrm{~h}$ at $0{ }^{\circ} \mathrm{C}$ and afterwards for another $30 \mathrm{~h}$ at $\mathrm{rt}$. Iso-propanol was added at $-78{ }^{\circ} \mathrm{C}$ to the reaction mixture. The suspension was filtrated over celite and the solvent removed under reduced pressure. The water $(50 \mathrm{~mL})$ was added to the reaction mixture and aqueous phase was extracted by DCM $(3 \times 15 \mathrm{~mL})$. The combined organic phases were dried over $\mathrm{Na}_{2} \mathrm{SO}_{4}$ and the solvent removed under reduced pressure to afford the desired product $\mathbf{3 4 5}$ as colorless oil (698 mg, $2.70 \mathrm{mmol}, 68 \%) .{ }^{1} \mathbf{H}-\mathrm{NMR}\left(500 \mathrm{MHz}, \mathrm{CDCl}_{3}\right): \delta[\mathrm{ppm}]=7.44$ (ddt, $J=7.5 \mathrm{~Hz}, 1.3 \mathrm{~Hz}$, $0.7 \mathrm{~Hz}, 1 \mathrm{H}), 7.35-7.18(\mathrm{~m}, 5 \mathrm{H}), 7.12\left(\mathrm{~m}_{\mathrm{C}}, 2 \mathrm{H}\right) 7.07$ (td, $\left.J=8.0 \mathrm{~Hz}, 7.5 \mathrm{~Hz}, 1.7 \mathrm{~Hz}, 1 \mathrm{H}\right), 4.64$ (s, $2 \mathrm{H}), 3.84$ (s, $2 \mathrm{H}), 2.43$ (s, $5 \mathrm{H})$ ppm. ${ }^{13} \mathbf{C}-\mathbf{N M R}\left(126 \mathrm{MHz}, \mathrm{CDCl}_{3}\right): \delta$ [ppm] = 142.1, 139.4, 135.0, 133.4, 133.3, 131.6, 130.0, 129.2, 128.5, 128.3, 128.2, 127.1, 63.3, 54.0, 35.9 ppm. HR-MS calc. for $\mathrm{C}_{8} \mathrm{H}_{8} \mathrm{O}_{2} \mathrm{~S}: 282.0923$; found: 282.0922 [M+Na] $^{+}$(ESI-HRMS). Analytical data corresponded to those previously reported. ${ }^{136 \mathrm{~b}}$ 
<smiles>CN1Cc2ccccc2Sc2ccccc2C1</smiles>

For the synthesis of $\mathbf{3 4 5}$ a slightly modified literature procedure was used. ${ }^{136 \mathrm{~b}}$ To a solution of the alcohol 345 (673 mg, $2.59 \mathrm{mmol}, 1.00$ equiv.) in benzene $(11 \mathrm{~mL})$ was added thionyl chloride $(6.70 \mathrm{~mL}, 92.2 \mathrm{mmol}, 35.5$ equiv.) and the solution was stirred for $3 \mathrm{~h}$ at $70{ }^{\circ} \mathrm{C}$. Afterwards the solvent was removed under reduced pressure and the residue was taken up by ethanol $(5.6 \mathrm{~mL})$. A solution of sodium hydroxide ( $1.45 \mathrm{~g}, 25.8 \mathrm{mmol}, 9.95$ equiv.) in ethanol $(5.6 \mathrm{~mL})$ was added to the residue and the reaction mixture was stirred at $70{ }^{\circ} \mathrm{C}$ overnight. Afterwards the solvent was removed under reduced pressure and water $(50 \mathrm{~mL})$ was added. The aqueous phase was extracted by ethyl acetate $(50 \mathrm{~mL})$ and the solvent was removed under reduced pressure. After purification by column chromatography (hexane/EtOAc $+1 \% \mathrm{NEt}_{3}, 2: 1$ ) the desired compound 346 could be isolated as white solid (452 mg, $1.87 \mathrm{mmol}, 72 \%)$. ${ }^{1} \mathbf{H}-\mathbf{N M R}\left(300 \mathrm{MHz}, \mathrm{CD}_{3} \mathrm{CN}\right): \delta[\mathrm{ppm}]=2.09$ (s, $3 \mathrm{H}$ ), 3.79 (d, $J=1.4 \mathrm{~Hz}, 2 \mathrm{H})$, 7.01-7.07 (m, $3 \mathrm{H}), 7.12-7.18$ (m, $2 \mathrm{H}), 7.19-7.24(\mathrm{~m}, 1 \mathrm{H}), 7.30-7.35$ (m, $1 \mathrm{H})$, 7.42-7.46 (m, $1 \mathrm{H})$. IR (ATR): $\tilde{v}\left[\mathrm{~cm}^{-1}\right]=2876,2360,1467,1435,1427,1416,1357,1326,1276$, 1261, 1185, 1174, 1152, 1117, 1056, 1032, 985, 954, 926, 824, 767, 756, 726, 678, 607, 547, 517. HR-MS calc. for $\mathbf{C}_{15} \mathbf{H}_{15} \mathbf{N S}$ : 242.0996; found: $242.0998[\mathrm{M}+\mathrm{H}]^{+}$(ESI-HRMS). Analytical data corresponded to those previously reported. ${ }^{136 \mathrm{~b}}$ 


\subsection{Synthesis of potential fluorine containing transfer-reagents}

\subsubsection{Synthesis of a trifluoromethyl-reagent}

Synthesis of silver(I) trifluoromethanethiolate (350)

$\mathrm{AgSCF}_{3}$ Following a slightly modified literature procedure, ${ }^{137}$ to a solution of silver fluoride

$350(2.15 \mathrm{~g}, 17.0 \mathrm{mmol}, 1.00$ equiv. $)$ in $\mathrm{MeCN}(15 \mathrm{~mL})$ was added carbon disulfide $(2.04 \mathrm{~mL}$, 33.9 mmol. 2.00 equiv.). The reaction mixture was stirred for $18{ }^{\circ} \mathrm{C}$ under reflux. Then the solvent was removed in vacuo and the residue was dissolved in $\mathrm{Et}_{2} \mathrm{O}(300 \mathrm{~mL})$. The mixture led rest at $0{ }^{\circ} \mathrm{C}$. After approximately $7 \mathrm{~d}$ the product could be isolated as white crystals $(1.90 \mathrm{~g}, 9.08 \mathrm{mmol}, 54 \%)$. Analytical data corresponded to those described in the literature. ${ }^{137}$

Synthesis of 2-iodo-1-methyl-1H-imidazole (352)

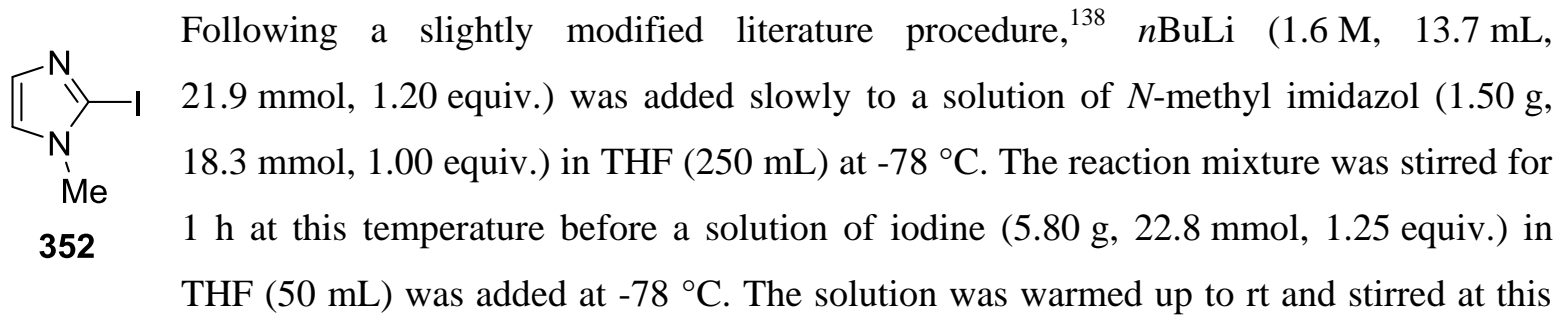
temperature for $3 \mathrm{~d}$. Then the solvent was removed by evaporation. The residue was taken up by DCM, washed with water, sat. $\mathrm{Na}_{2} \mathrm{~S}_{2} \mathrm{O}_{4}$ solution, brine and dried over $\mathrm{Na}_{2} \mathrm{SO}_{4}$. After removal of the solvent the product 352 could be isolated as white solid (3.20 g, $15.4 \mathrm{mmol}, 84 \%)$. Analytical data corresponded to those described in the literature. ${ }^{138}$ 
Synthesis of 2-iodo-1,3-dimethyl-1 $H$-imidazol-3-ium trifluoromethanesulfonate (354)

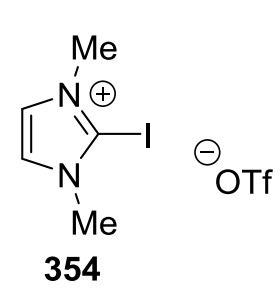

Following a slightly modified literature procedure, ${ }^{138}$ to a solution of compound 352 (4.08 g, $19.6 \mathrm{mmol}, 1.00$ equiv.) in DCM (100 mL) was added MeOTf ( $6.44 \mathrm{~g}, 39.2 \mathrm{mmol}, 2.00$ equiv.) at rt. The Solution was stirred for $16 \mathrm{~h}$ at rt. After removal of the solvent by filtration the product $\mathbf{3 5 4}$ could be obtained as white solid (5.35 g, $14.4 \mathrm{mmol}, 73 \%)$. Analytical data corresponded to those described in the literature. ${ }^{138}$

Synthesis of 1,3-dimethyl-2-((trifluoromethyl)thio)-1H-imidazol-3-ium trifluoromethanesulfonate (355)<smiles></smiles>

355

A solution of the imidazolium salt 354 (1.00 g, $2.69 \mathrm{mmol}, 1.00$ equiv.) and the silver thiolate 350 (561 mg, $2.69 \mathrm{mmol}, 1.00$ equiv.) in dry $\mathrm{MeCN}(10 \mathrm{~mL})$ was stirred at $100{ }^{\circ} \mathrm{C}$ for $12 \mathrm{~h}$ in the microwave. The solution was separated from the AgI via filtration and the solvent was evaporated in vacuo. The remaining solid was washed with DCM $(2 \times 4 \mathrm{ml})$ to afford the product 355 as white solid $(651 \mathrm{mg}, 1.88 \mathrm{mmol}$, 76\%). ${ }^{1} \mathbf{H}-\mathbf{N M R}\left(300 \mathrm{MHz}, \mathrm{CD}_{3} \mathrm{CN}\right): \delta$ [ppm] = 7.76 (s, $\left.2 \mathrm{H}\right), 3.98(\mathrm{~s}, 6 \mathrm{H}) .{ }^{13} \mathbf{C}$ NMR $(126 \mathrm{MHz}$, $\left.\mathrm{CD}_{2} \mathrm{Cl}_{2}\right) \delta=130.8,128.5127 .9(\mathrm{q}, J=315.3 \mathrm{~Hz}), 122.0(\mathrm{q}, J=317.9 \mathrm{~Hz}), 38.0$ ppm. ${ }^{19} \mathbf{F}$ NMR $(282$ $\left.\mathrm{MHz}, \mathrm{CD}_{3} \mathrm{CN}\right)=-39.97,-79.32 \mathrm{ppm}$. IR $(\mathrm{ATR}): \widetilde{v}\left(\mathrm{~cm}^{-1}\right)=3121,2360,2342,1509,1280,1242$, 1226, 1182, 1147, 1109, 1095, 1026, 800, 759, 739, 637, 630, 571, 541, 516. HR-MS calc. for $\mathrm{C}_{6} \mathrm{H}_{8} \mathrm{~F}_{3} \mathrm{~N}_{2} \mathrm{~S}$ : 197.0355; found: $197.0358[\mathrm{M}]^{+}$(ESI-HRMS).

Synthesis of 1,3-dimethyl-2-((4-nitrophenyl)thio)-1H-imidazol-3-ium trifluoromethanesulfonate (368)<smiles></smiles>

368 To a solution of the imidazolium salt $355(50.0 \mathrm{mg}$, and the thiol in $\mathrm{MeCN}$ (1.5 mL) was added DIPEA (55.9 mg, $0.43 \mathrm{mmol}, 3.00$ equiv.). The solution was stirred for $12 \mathrm{~h}$ at rt. Afterwards the solvent was removed under reduced pressure and the residue was washed with mixture of THF/ether $(3: 7,8 \times 15 \mathrm{~mL})$ to afford the product 368 as yellow solid ${ }^{1} \mathbf{H}-\mathbf{N M R}\left(300 \mathrm{MHz}, \mathrm{CD}_{2} \mathrm{Cl}_{2}\right): \delta[\mathrm{ppm}]=8.24$ $(\mathrm{td}, J=9.0,2.6 \mathrm{~Hz}, 2 \mathrm{H}), 7.81(\mathrm{~s}, 2 \mathrm{H}), 7.33(\mathrm{td}, J=9.0,2.6 \mathrm{~Hz}, 2 \mathrm{H}), 3.98(\mathrm{~s}, 6$ H). ${ }^{19}$ F NMR $\left(282 \mathrm{MHz}, \mathrm{CD}_{2} \mathrm{Cl}_{2}\right)=-79.32 \mathrm{ppm}$. IR (ATR): $\widetilde{v}\left(\mathrm{~cm}^{-1}\right)=3158,3130,3114,3090,3068$, $1598,1571,1513,1478,1340,1258,1227,1185,1169,1151,1010,853,825,785,757,739,724$, 687, 678, 636, 574, 528, 517. HR-MS calc. for $\mathrm{C}_{11} \mathrm{H}_{12} \mathrm{~N}_{3} \mathrm{O}_{2} \mathrm{~S}: 250.064474$; found: $250.064390[\mathrm{M}]^{+}$ (ESI-HRMS). 


\section{General procedure for the "transfer"-reaction of compound 355}

To a solution of the nucleophile (1.00 equiv.) was added the compound 355 (1.20 equiv.) and the base (1.10 equiv.) and the reaction was stirred for $12 \mathrm{~h}$ at the elaborated temperature in the chosen solvent $(0.14 \mathrm{M})$. Afterwards a saturated, aqueous solution of $\mathrm{NH}_{4} \mathrm{Cl}$ was added to the reaction mixture and the aqueous solution was extracted with DCM $(3 \times 15 \mathrm{~mL})$. The combined organic phases were dried over $\mathrm{Na}_{2} \mathrm{SO}_{4}$ and the solvent was removed by evaporation. The residues were analyzed by NMR, GCMS and TLC.

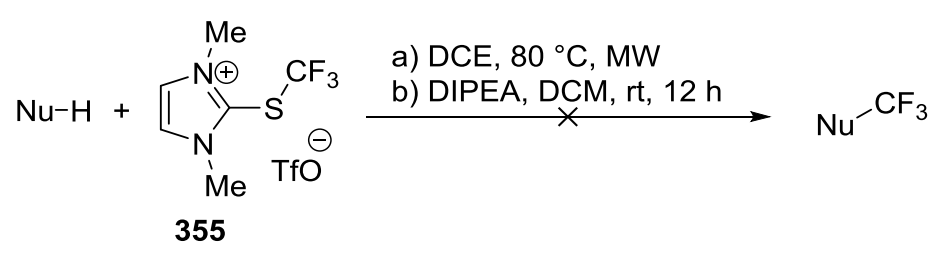<smiles>COC(=O)C1Cc2ccccc2C1=O</smiles>

202<smiles>Cc1cc([N+](=O)[O-])cc([N+](=O)[O-])c1O</smiles>

356<smiles>Cn1ccc2ccccc21</smiles>

357<smiles>Cn1c(-c2ccccc2)cc2ccccc21</smiles>

358<smiles>COc1cccc(OC)c1</smiles>

359<smiles>COc1cc2c(cc1OC)CNCC2</smiles>

360<smiles>Sc1cccc2ccccc12</smiles>

361<smiles>O=[N+]([O-])c1ccc(S)cc1</smiles>

362<smiles>Cc1ccc(S[18O])cc1</smiles>

363<smiles>COC(OC)=C(C)C</smiles>

364<smiles>Cc1cc(C)c([N+](=O)[O-])c(C)c1</smiles>

365<smiles>CCCCCCCC[Ge]Cl</smiles> 


\begin{tabular}{|c|c|c|c|c|c|}
\hline Entry & Nucleophile & Base & Solvent & temperature & comment \\
\hline 1 & naphthalene-1-thiol & DIPEA & $\mathrm{MeCN}$ & $\mathrm{rt}$ & dimer formation \\
\hline 2 & beta-keto ester & $\mathrm{K}_{2} \mathrm{CO}_{3}$ & $\mathrm{MeCN}$ & $\mathrm{rt}$ & Starting material \\
\hline 3 & thiolate & - & $\mathrm{MeCN}$ & $\mathrm{rt}$ & Protonated starting material \\
\hline 4 & beta-keto ester & DIPEA & $\mathrm{MeCN}$ & $\mathrm{rt}$ & Starting material \\
\hline 5 & $\begin{array}{l}\text { 1,3- } \\
\text { dimethoxybenzene }\end{array}$ & - & DCE & $80^{\circ} \mathrm{C}$ & mw, starting material \\
\hline 6 & $\begin{array}{l}\text { 1,3- } \\
\text { dimethoxybenzene }\end{array}$ & - & $\mathrm{MeCN}$ & $80^{\circ} \mathrm{C}$ & mw, starting material \\
\hline 7 & Nitro-thiol & DIPEA & $\mathrm{MeCN}$ & $\mathrm{rt}$ & Dimer + trithiocarbonate \\
\hline 8 & Nitro-thiol & DIPEA & DMF & $-78^{\circ} \mathrm{C}$ to $\mathrm{rt}$ & Dimer + trithiocarbonate \\
\hline 9 & Nitro-thiol & DIPEA & DMF & $-50^{\circ} \mathrm{C}$ to $\mathrm{rt}$ & Dimer + trithiocarbonate \\
\hline 10 & $\begin{array}{l}2,4,6- \\
\text { trimethylphenol }\end{array}$ & DIPEA & $\mathrm{MeCN}$ & $\mathrm{rt}$ & decomposition \\
\hline 11 & $\begin{array}{l}\text { mesitylmagnesium } \\
\text { bromide }\end{array}$ & - & THF & $0^{\circ} \mathrm{C}$ to $\mathrm{rt}$ & decomposition \\
\hline 12 & $\begin{array}{l}\text { 1-methyl-2-phenyl- } \\
\text { 1H-indole }\end{array}$ & l & DCE & $80{ }^{\circ} \mathrm{C}$ & mw, starting material \\
\hline 13 & $\begin{array}{l}\text { 1-methyl-2-phenyl- } \\
\text { 1H-indole }\end{array}$ & l & DCE & $80{ }^{\circ} \mathrm{C}$ & $\mathrm{AgSbF}_{6}, \mathrm{mw}$, starting material \\
\hline 14 & $\begin{array}{l}\text { 6,7-dimethoxy- } \\
1,2,3,4- \\
\text { tetrahydroisoquinoli } \\
\text { ne }\end{array}$ & DIPEA & toluene & $\mathrm{rt}$ & starting material \\
\hline 15 & Nitro-thiol & - & $\mathrm{MeCN}$ & $\mathrm{rt}$ & $\begin{array}{l}\text { + Bortrifluorid-etherat, starting } \\
\text { material }\end{array}$ \\
\hline 16 & $\begin{array}{l}\text { 1-Methoxy-2- } \\
\text { methyl-1- } \\
\text { trimethylsiloxy- } \\
\text { propen }\end{array}$ & - & $\mathrm{MeCN}$ & $\mathrm{rt}$ & Starting material \\
\hline 17 & theophylline & - & $\begin{array}{l}\text { DCM/ } \\
\text { water }\end{array}$ & $\mathrm{rt}$ & $\begin{array}{l}+1.00 \text { equiv. of } \mathrm{H}_{2} \mathrm{O}_{2} \text {, starting } \\
\text { material }\end{array}$ \\
\hline 18 & $\mathrm{ZnCuIC}_{8} \mathrm{H}_{17}$ & - & THF & $\mathrm{rt}$ & decomposition \\
\hline
\end{tabular}




\subsubsection{Preparation of the trifluoroethylene-compound}

Synthesis of 1,3-diisopropyl-4,5-dimethyl-2-((1,2,2-trifluorovinyl)thio)-1H-imidazol-3-ium hexafluorostibate(V) (385)<smiles></smiles>

385

Step 1: The zinc solution was prepared by a slightly modified literature procedure. ${ }^{146}$ A solution of $\mathrm{ZnCl}_{2}(1.72 \mathrm{~g}, 12.5 \mathrm{mmol}, 1.00$ equiv.) in THF $(7.5 \mathrm{~mL})$ in a flame dried three-neck flask equipped with a dry ice reflux condenser was cooled to $15^{\circ} \mathrm{C}$. Condensed 1,1,1,2-tetrafluoroethane $(1.50 \mathrm{~mL}$, $18.0 \mathrm{mmol}, 1.50 \mathrm{mmol}$ ) was added to the reaction mixture. Then freshly prepared LDA (in hexane, $13.5 \mathrm{~mL}, 25 \mathrm{mmol}, 2.00$ equiv.), was added to the reaction mixture. The reaction mixture was stirred for $1 \mathrm{~h}$ at $15{ }^{\circ} \mathrm{C}$ and subsequently warmed up to $\mathrm{rt}$. The concentration of the zinc solution $(22.5 \mathrm{~mL}, 0.3 \mathrm{M} / \mathrm{L})$ was determined by the Knochel-titration method. ${ }^{147}$

Step 2: To a solution of the dibromide 185 (2.42 g, $6.5 \mathrm{mmol}, 1.00$ equiv.) in THF (15 mL) was added at $-78{ }^{\circ} \mathrm{C}$ the formerly prepared zincate solution. The solution was stirred for $1 \mathrm{~h}$ at $-78^{\circ} \mathrm{C}$ and then slowly warmed up to rt. The solvent was removed and the residue was washed twice with diethylether ( $2 \times 50 \mathrm{~mL}$ ). The resulting grey solid was solved in DCM and filtrate over a short pad of celite. Then the solution was washed three times with a saturated solution of $\mathrm{NaSbF}_{6}$ and the combined organic phases were dried over $\mathrm{Na}_{2} \mathrm{SO}_{4}$. After removing the solvent under reduced pressure the product could be obtained as yellow solid. ${ }^{1} \mathbf{H}$ NMR $\left(300 \mathrm{MHz}, \mathrm{CD}_{2} \mathrm{Cl}_{2}\right.$ ) $\delta=5.43$ (hept, J = 7.3 Hz, $2 \mathrm{H}$ ), 2.45 (s, $6 \mathrm{H}), 1.63(\mathrm{~d}, 7.3 \mathrm{~Hz}, 12 \mathrm{H}) \mathrm{ppm} .{ }^{13} \mathbf{C} \mathbf{N M R}\left(101 \mathrm{MHz}, \mathrm{CD}_{2} \mathrm{Cl}_{2}\right) \delta=157.3$ (ddd, $J=302.3$, 283.2, $47.1 \mathrm{~Hz}), 132.6,130.0,121.4(\mathrm{ddd}, J=302.1,26.0,26.0 \mathrm{~Hz}), 54.8,21.2,11.0 \mathrm{ppm} .{ }^{19} \mathbf{F}$ NMR (282 $\left.\mathrm{MHz}, \mathrm{CD}_{2} \mathrm{Cl}_{2}\right) \delta=-82.22(\mathrm{dd}, 41.7,35.2 \mathrm{~Hz}),-102.24(\mathrm{dd}, J=121.3,35.2 \mathrm{~Hz}),-116.55(\mathrm{~s}),-153.36$ (dd, $J=121.3,41.3 \mathrm{~Hz}) \mathrm{ppm}$. IR (ATR): $\widetilde{v}\left(\mathrm{~cm}^{-1}\right)=3647,2999,1747,1614,1459,1334,1220,1131$, 1051, 937, 663, 628, 592. HR-MS calc. for $\mathrm{C}_{13} \mathrm{H}_{20} \mathrm{~F}_{3} \mathrm{~N}_{2} \mathrm{~S}$ : 293.1294; found: 293.1293 [M] ${ }^{+}$(ESIHRMS). 


\section{General procedure for the "transfer"-reaction of compound 385}

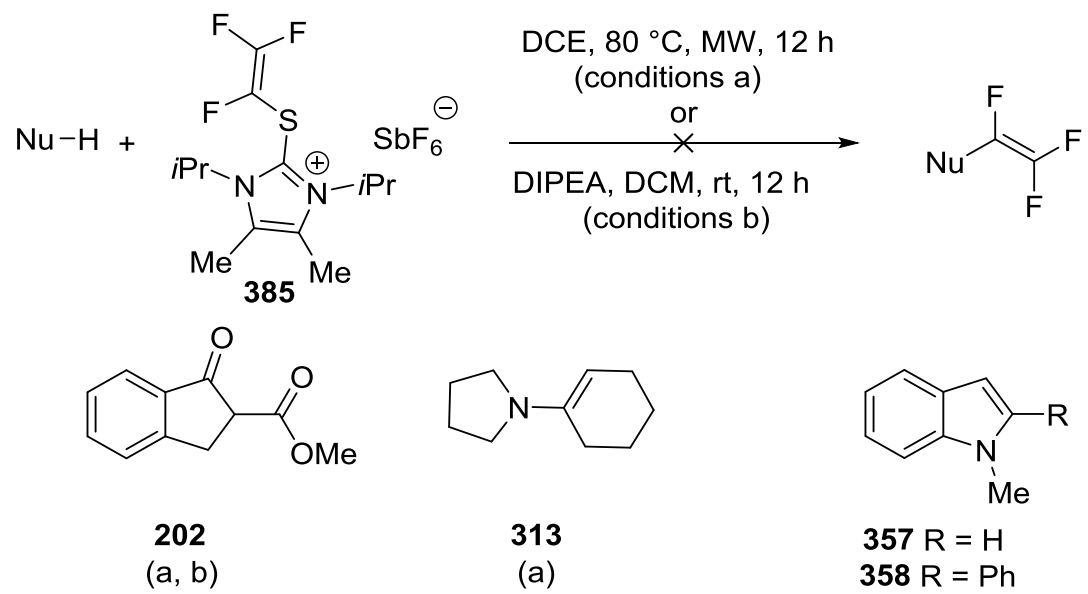

(a)<smiles>COc1cccc(OC)c1</smiles>

359

(a)

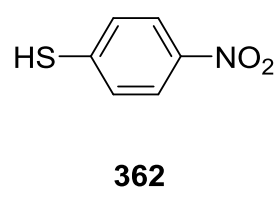

$(a, b)$<smiles>COc1cccc(OC)c1O</smiles>

386

(a)

Method A: To a solution of the nucleophile $(0.13 \mathrm{mmol}, 1.00$ equiv. $)$ was added the transfer reagent ( $0.15 \mathrm{mmol}, 1.20$ equiv.) and the reaction was stirred for the elaborated time in the DCE $(0.14 \mathrm{M})$ at $80{ }^{\circ} \mathrm{C}$. Afterwards a saturated, aqueous solution of $\mathrm{NH}_{4} \mathrm{Cl}$ was added to the reaction mixture and the aqueous solution was extracted with DCM $(3 \times 15 \mathrm{~mL})$. The combined organic phases were dried over $\mathrm{Na}_{2} \mathrm{SO}_{4}$ and the solvent was removed by evaporation. The residues were analyzed by NMR, GC-MS and TLC.

Method B: To a solution of the nucleophile $(0.13 \mathrm{mmol}, 1.00$ equiv. $)$ was added the transfer reagent ( $0.15 \mathrm{mmol}, 1.20$ equiv.) and the reaction was stirred for the elaborated time in DCM (0.14 M). Afterwards a saturated, aqueous solution of $\mathrm{NH}_{4} \mathrm{Cl}$ was added to the reaction mixture and the aqueous solution was extracted with DCM $(3 \times 15 \mathrm{~mL})$. The combined organic phases were dried over $\mathrm{Na}_{2} \mathrm{SO}_{4}$ and the solvent was removed by evaporation. The residues were analyzed by NMR, GC-MS and TLC.

Method A

\begin{tabular}{|l|l|l|}
\hline Entry & Nucleophile & comment \\
\hline 1 & Nitro-thiol & starting material (nucleophile) \\
\hline 2 & $\beta$-keto ester & decomposition \\
\hline 3 & 2,6-dimethoxyphenol & starting material (nucleophile) \\
\hline 4 & 1,3-dimethoxybenzene & starting material (nucleophile) \\
\hline 5 & 1-(cyclohex-1-en-1-yl)pyrrolidine & starting material (nucleophile) \\
\hline 6 & 1-methyl-2-phenyl-1H-indole & starting material (nucleophile) \\
\hline 7 & 1-methyl-2-phenyl-1H-indole & starting material (nucleophile) \\
\hline
\end{tabular}


Method B

\begin{tabular}{|l|l|l|}
\hline Entry & Nucleophile & comment \\
\hline 1 & Nitro-thiol & starting material(nucleophile) \\
\hline 2 & $\beta$-keto ester & decomposition \\
\hline
\end{tabular}




\subsection{Investigations towards the Isomerisation of compound 238f*}

A NMR solution of the reagent 238\%* in Methylene chloride- $\mathrm{d}^{2}$ was measured directly after synthesis (20 min in solution), after $2 \mathrm{~d}$ in solution and after $7 \mathrm{~d}$, showing no further Isomerisation of the compound 238**.
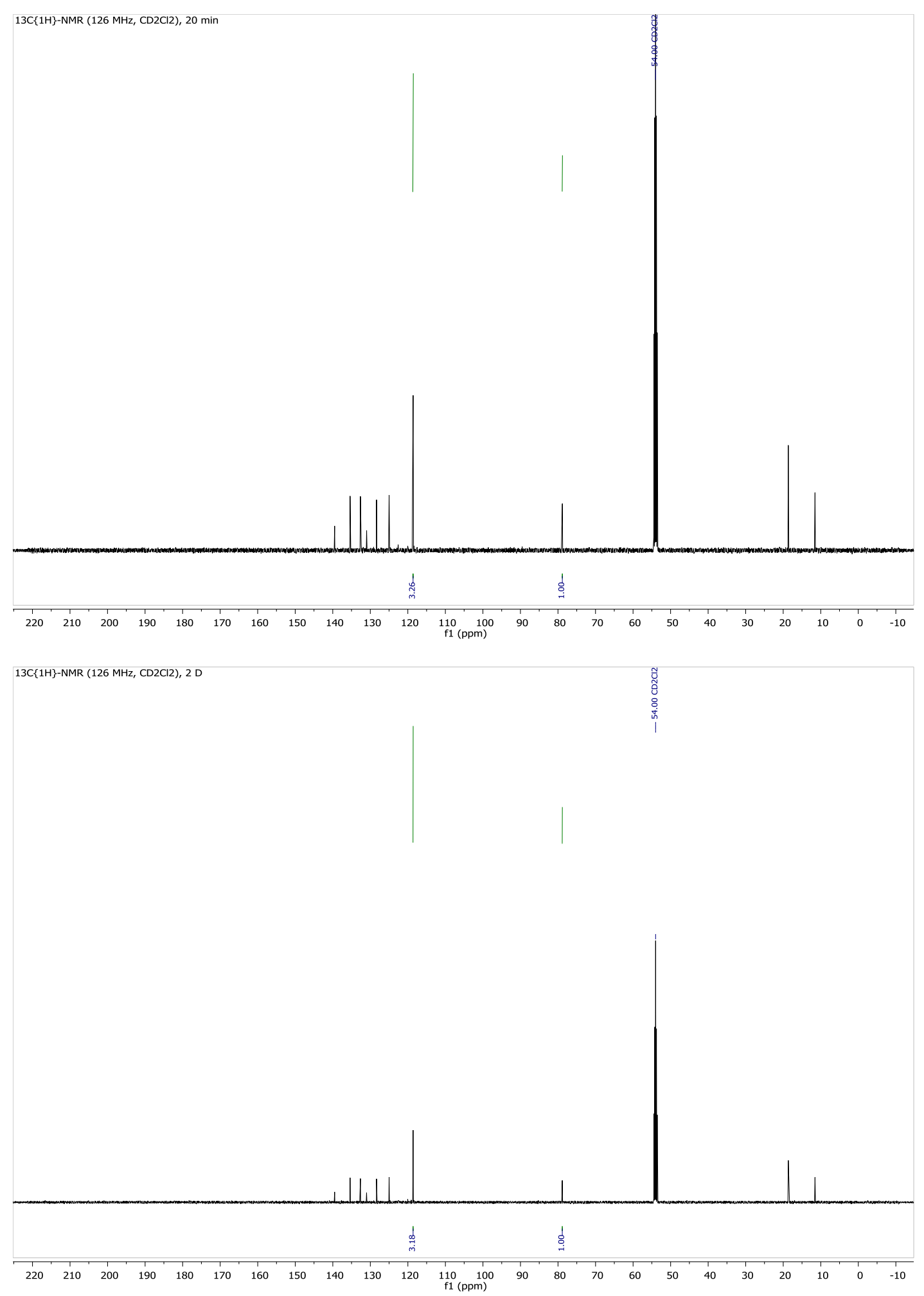


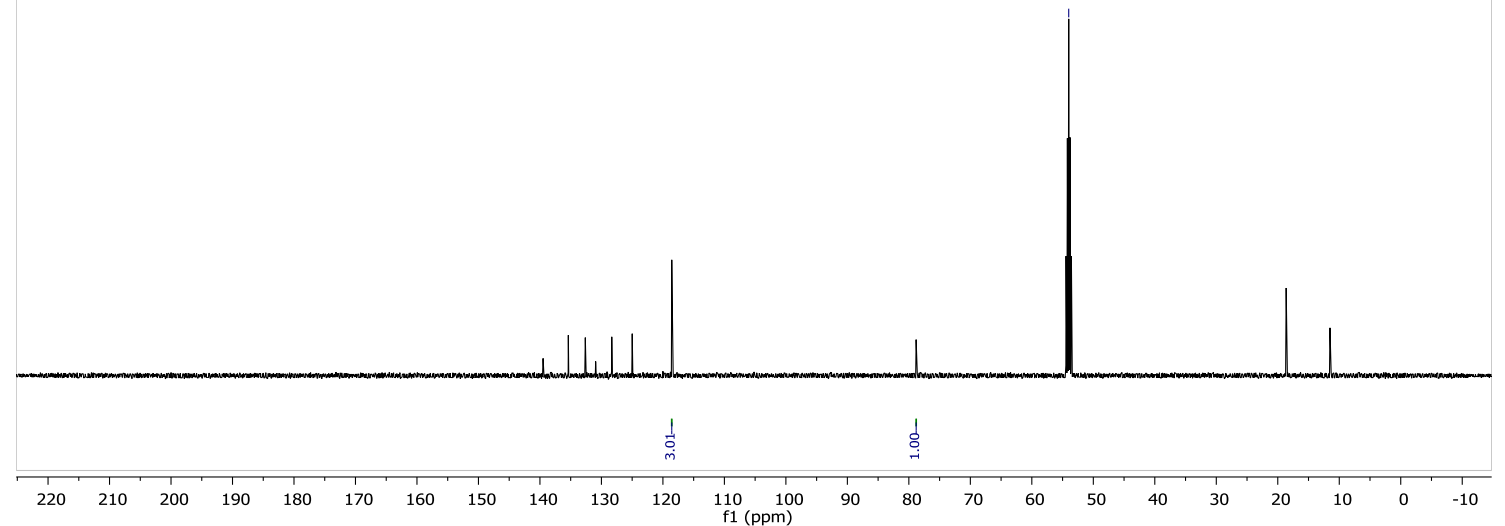




\subsection{Differential scanning calorimetry (DSC)}
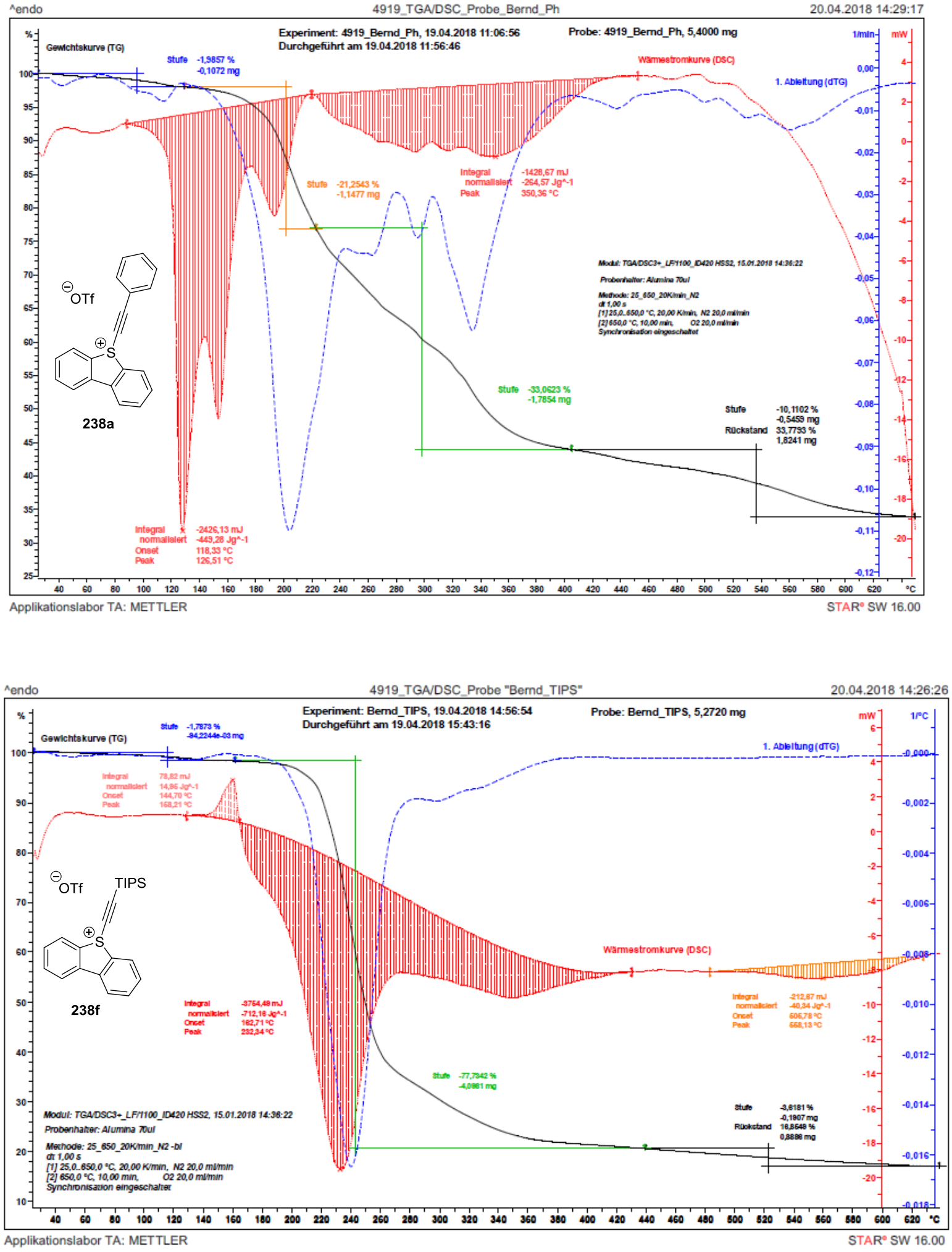
${ }^{1}$ P. M Dewick, Medicinal Natural Products: A Biosynthetic Approach, $2^{\text {nd }}$ Edition, Chapter 2, John Wiley \& Sons Ltd., Lane, Chichester, West Sussex, England, 2002.

2 (a) J. Boström, D. G. Brown, R. J. Young, G. M. Keserü, Nat. Rev. Drug Discovery 2018, 17, 709-727; (b) B. M. Trost, J. S. Tracy, Isr. J. Chem. 2018, 58, 18-27.

${ }^{3}$ B. M. Trost, C.-J. Li, Modern Alkyne Chemistry: Catalytic and Atom-Economic Transformations, $1^{\text {st }}$ Edition, Chapter 1, Wiley-VCH, Weinheim, 2015.

${ }^{4}$ (a) Synthesis of Acetylenes, Allenes and Cumulenes: Methods and Techniques, $1^{\text {st }}$ Edition (Ed.: L. Brandsma), Elsevier Academic Press, Amsterdam, 2004, 469 pp.; (b) I.-T. Trotuş, T. Zimmermann, F. Schüth, Chem. Rev. 2014, 114, 1761-1782; (c) H. Schobert, Chem. Rev. 2014, 114, 1743-1760.

${ }^{5}$ (a) A. L. K. Shi Shun, R. R. Tykwinski, Angew. Chem. Int. Ed. 2006, 45, 1034-1057; (b) Acetylene Chemistry: Chemistry, Biology and Material Science (Eds.: F. Diederich, P. J. Stang, R. R. Tykwinski), Wiley-VCH, Weinheim, 2005.

${ }^{6}$ Y. Zhang, Y. Wu, Org. Biomol. Chem. 2010, 8, 4744-4752.

${ }^{7}$ Y. Gao, W.-L. Wu, Y.- L. Wu, B. Ye, R. Zhou, Tetrahedron 1998, 54, 12523-12538.

${ }^{8}$ A. Marrocchi A. Facchetti, D. Lanari, S. Santoroa, L. Vaccaro, Chem. Sci. 2016, 7, 6298-6308.

${ }^{9}$ G. C. Tron, T. Pirali, R. A. Billington, P. L. Canonico, G. Sorba, A. A. Genazzani, Med. Res. Rev. 2008, 28, 2 , $278-308$.

${ }^{10}$ C. V. McGuire, R. S. Forgan, Chem. Commun. 2015, 51, 5199-5217.

${ }^{11}$ (a) C. S. McKay, M. G. Finn, Chem Biol. 2014, 21,-1075-1101; (b) V. Hong, N. F. Steinmetz, M. Manchester, M. G. Finn, Bioconjugate Chem. 2010, 21, 1912-1916.

12 (a) A. Orita, J. Otera, Chem. Rev. 2006, 106, 5387-5412; (b) T. L. Jakobs, Org. React. 1948, 5, 1-78.

13 (a) H. Gilman, W. Langham, F. W. Moore, J. Am. Chem. Soc. 1940, 62, 2327-2335. (b) D. Y. Curtin, E. E. Harris, J. Am. Chem. Soc. 1951, 73, 4519-4521.

${ }^{14}$ H. N. C. Wong, P. J. Garratt, F. Sondheimer, J. Am. Chem. Soc. 1974, 96, 5604-5605.

${ }^{15}$ T. Tsuji, Y. Watanabe, T. Mukaiyama, Chem. Lett. 1979, 8, 481-482.

${ }^{16}$ E. J. Corey, P. L. Fuchs, Tetrahedron Lett. 1972, 13, 3769-3772.

${ }^{17}$ N. B. Desai, N. McKelvie, F. Ramirez, J. Am. Chem. Soc. 1962, 84, 1745-1747.

${ }^{18}$ (a) W. P. Buttenberg, Justus Liebigs Ann. Chem. 1894, 279, 324-337; (b) H. Wiechell, Justus Liebigs Ann. Chem. 1894, 279, 337-344; (c) P. Fritsch, Liebigs Ann. Chem. 1894, 279, 319-324. (d) Essentially, the CoreyFuchs reaction is a particular case of the FBW, see: E. Jahnke, R. R. Tykwinski, Chem. Commun. 2010, 46, 3235-3249.

19 (a) L. Kürti, B. Czakó, Strategic Applications of Named Reactions in Organic Synthesis, Elsevier Academic Press, London, 2005; (b) M. Heravi, S, Asadi, N. Nazari, B. M. Lashkariani, Curr. Org. Chem. 2015, 19, 22 , 2196-2219; (c) This mechanism differs from those by employing zinc powder, where such an excess of $\mathrm{Ph}_{3} \mathrm{P}$ is not necessary, see ref. [16]. (d) For the reviews on further improvements of the reaction and its application towards ketones see ref. [18d] and ref. [23b].

${ }^{20}$ (a) G. Köbrich, G. Reitz, U. Schumacher, Chem. Ber. 1972, 105, 1674-1682; (b) R. Knorr, Chem. Rev. 2004, $104,3795-3849$. 
${ }^{21}$ S. Clément, L. Guyard, M. Knorr, S. Dilsky, C. Strohmann, M. Arroyo, J. Organomet. Chem. 2007, 692, 839850 .

${ }^{22}$ M. Austeri, M. Enders, M. Nieger, S. Bräse, Eur. J. Chem. 2013, 9, 1667-1670.

23 (a) P. Va., W. R. Roush. J. Am. Chem. Soc. 2006, 128, 15960-15961.; (b) D. Habrant, V. Rauhala. A. M. P. Koskinen, Chem. Soc. Rev. 2010, 39, 2007-2017.

${ }^{24}$ J. Kobayashi, M. Tsuda, Nat. Prod. Rep. 2004, 21, 77-93.

${ }^{25}$ L. S.-M. Wong, L. A. Sharp, N. M. C. Xavier, P. Turner, M. S. Sherburn, Org. Lett. 2002, 4, $1955-1957$.

${ }^{26}$ A. P. Kozikowski, A. H. Fauq; J. H. Miller, M. McKinney, Bioorg. Med. Chem. Lett. 1992, 2, $797-802$.

27 (a) D. Seyferth, P. Hilbert, R. S. Marmor, J. Am. Chem. Soc. 1967, 89, 4811-4812; (b) J. C. Gilbert, U. Weerasooriya, J. Org. Chem. 1979, 44, 26, 4997-4998.

${ }^{28}$ (a) S. Ohira, Synth. Commun. 1989, 19, 561-564; (b) S. Müller, B. Liepold, G. J. Roth, H. J. Bestmann, Synlett 1996, 6, 521-522.

${ }^{29}$ J. C. Gilbert, U. Weerasooriya, J. Org. Chem. 1982, 47,-1837-1845.

${ }^{30}$ P. Krapf, R. Richarz, E. A. Urusova, B. Neumaier, B. D. Zlatopolskiy, Eur. J. Org. Chem. 2016, 430-434.

${ }^{31}$ H. Yoneyama, M. Numata, K. Uemura, Y. Usami, S. Harusawa, J. Org. Chem. 2017, 82, 5538-5556.

32 (a) D. Wang, D. Astruc, Chem. Rev. 2015, 115, 6621-6686; (b) J. A. Delgado, O. Benkirane, C. Claver, D. Curulla-Ferréc, C. Godard, Dalton Trans. 2017, 46, 12367-12734.

${ }^{33}$ C. M. Crudden, D. Edwards, Eur. J. Org. Chem. 2003, 4695-4712.

${ }^{34}$ S. W. Lim, Edward A. Anderson, Synthesis 2012, 44, 983-1010.

35 (a) N. D. Smith, J. Mancuso, M. Lautens, Chem. Rev. 2000, 100, 3257-3282; (b) V. V. Voronin, M. S. Ledovskaya, A. S. Bogachenkov, K. S. Rodygin, V. P. Ananikov, Molecules 2018, 23, Nu. 2442, 84 pp.

${ }^{36}$ H. Lindlar, Helv. Chim. Acta. 1952, 35, 446-450.

${ }^{37}$ L. Hintermann, A. Labonne, Synthesis 2007, 39, 1121-1150.

${ }^{38}$ (a) W. Ren, Y. Xia, S.-J. Ji, Y. Zhang, X. Wan, J. Zhao, Org. Lett. 2009, 11, 1841-1844; (b) X. Liu, T. Cong, P. Liu, P. Sun, J. Org. Chem. 2016, 81, 7256-7261.

${ }^{39}$ D. G. Lee, V. S. Chang, J. Org. Chem. 1979, 44, 2726-2730.

${ }^{40}$ B. R. Galan, T. Rovis, Angew. Chem. Int. Ed. 2009, 48, 2830-2834.

${ }^{41}$ R. A. A. Foster, M. C. Willis, Chem. Soc. Rev. 2013, 42, 63-76.

${ }^{42}$ B: M. Trost, C.-J. Li, Modern Alkyne Chemistry: Catalytic and Atom-Economic Transformations, $1^{\text {st }}$ Edition, Chapter 13, Wiley-VCH, Weinheim, 2015.

43 (a) H. Ehrhorn, M. Tamm, Chem. Eur. J. 2018, 24, 1-20; (b) A. Fürstner, Angew. Chem. Int. Ed. 2013, 52, 2794-2819.

${ }^{44}$ H. C. Kolb, M. G. Finn, K. B. Sharpless, Angew. Chem. Int. Ed. 2001, 40, 2004-2021.

${ }^{45}$ M. S. Singh, S. Chowdhury, S. Koley, Tetrahedron 2016, 72, 5257-5283.

${ }^{46}$ B. T. Worell, J. A. Malik, V. V. Fokin, Science 2013, 340, 457-460.

47 (a) B. C. Boren, S. Narayan, L. K. Rasmussen, L. Zhang, H. Zhao, Z. Lin, G. Jia, V. V. Fokin, J. Am. Chem. Soc. 2008, 130, 8923-8930; (b) J. R. Johansson, T. Beke-Somfai, A. S. Stålsmeden, N. Kann, Chem. Rev. 2016, $116,14726-14768$.

${ }^{48}$ E. Hwang, K. L. Lusker, J. C. Garno, Y. Losovyj, E. E. Nesterov, Chem. Commun. 2011, 47, 11990-11992. 
${ }^{49}$ W. Morris, W. E. Briley, E. Auyeung, M. D. Cabezas, C. A. Mirkin, J. Am. Chem. Soc. 2014, 136, 7261-7264.

${ }^{50}$ W. Reppe, O. Schichting, K. Klager, T. Toepel, Justus Liebigs Ann. Chem. 1948, 560, 1-92.

${ }^{51}$ G. Domínguez, J. Pérez-Castells, Chem. Soc. Rev. 2011, 40, 3430-3444.

52 (a) P. R. Chopadea, J. Louie, Adv. Synth. Catal. 2006, 348, 2307-2327; (b) Y. Shibata, K. Tanaka, Synthesis 2012, 44, 323-350.

${ }^{53}$ J. Míšek, F. Teplý, I. G. Stará, M. Tichý, D. Šaman, I. Císařová, P. Vojtíšek, I. Starý, Angew. Chem. Int. Ed. 2008, 47, 3188-3191.

${ }^{54}$ For the recent reviews see: (a) N. Saleh, C. Shen, J. Crassous, Chem. Sci. 2014, 5, 3680-3694; (b) M. J. Narcis, N. Takenaka, Eur. J. Org. Chem. 2014, 1, 21-34; (c) F. Pammer, W. R. Thiel, Coord. Chem. Rev. 2014, 270, 14-30.

${ }^{55}$ Y. Shen, C.-F. Chen, Chem. Rev. 2012, 112, 1463-1535.

${ }^{56}$ (a) K. Wang, L.-G. Meng, L. Wang, Org. Lett. 2017, 19, 1958-1961; (b) E. C. Ashby, Acc. Chem. Res., 1988, 21, 414-421.

${ }^{57}$ F. Pennella, R.L. Banks, G. C. Bailey, Chem. Commun. (London) 1968, 1548-1549.

58 (a) B. M. Trost, C.-J. Li, Modern Alkyne Chemistry: Catalytic and Atom-Economic Transformations, $1^{\text {st }}$ Edition, Chapter 4, Wiley-VCH, Weinheim, 2015; (b) X. Wu, M. Tamm, Beilst. J. Org. Chem. $2011,7,82-93$.

${ }^{59}$ T. J. Katz, J. McGinnis, J. Am. Chem. Soc. 1975, 97, 1592-1594.

${ }^{60}$ M. Ortiz, C. Yu, Y. Jin, W. Zhang, Top. Curr. Chem. 2017, 375, Nu. 69, 24 pp.

${ }^{61}$ K. Micoine, A. Fürstner, J. Am. Chem. Soc. 2010, 132, 14064-14066.

${ }^{62}$ K. Micoine, P. Persich, J. Llaveria, M.-H. Lam, A. Maderna, F. Loganzo, A. Fürstner, Chem. Eur. J. 2013, 19, $7370-7383$

${ }^{63}$ S. Lee, E. Chénard, D. L. Gray, J. S. Moore, J. Am. Chem. Soc. 2016, 138, 13814-13817.

${ }^{64}$ (a) C. A. Brown, A. Yamashita, J. Am. Chem. Soc. 1975, 97, 891-892. Lithium 2-aminoethylamide (LAETA) can also be applied, see: (b) I. A. Balova, S. N. Morozkina, D. W. Knight, S. F. Vasilevsky, Tetrahedron Lett. 2003, 44, 107-109.

${ }^{65}$ B. M. Trost, M. J. Bartlett, Org. Lett. 2012 , 14, 1322-1325.

${ }^{66}$ U. Halbes-Letinois, J.-M. Weibel, P. Pale, Chem. Soc. Rev. 2007, 36, 759-769.

${ }^{67}$ (a) M. Berend, C. Liebermann, Justus Liebigs Ann. Chem. 1865, 135, 259-290; (b) C. Glaser, Justus Liebigs Ann. Chem. 1870, 154, 157-171.

${ }^{68}$ N. J. Long, C. K. Williams, Angew. Chem. Int. Ed. 2003, 42, 2586-2617

${ }^{69}$ For selected publications on lithium acetylides, see: (a) R. A. Thompson, E. G. Corley, M. F. Huntington, E. J. J. Grabowski, J. F. Remenar, D. B. Collum, J. Am. Chem. Soc. 1998, 120, 2028-2038; (b) R. Schmidt, P. L. Huesmann, W. S. Johnson, J. Am. Chem. Soc. 1980, 102, 5122-5123; (c) H. J. Reich, Chem. Rev. 2013, 113, $7130-7178$.

${ }^{70}$ For selected publications on sodium acetylides, see: J. N. Shepherd, J. R. Stenzel, J. Chem. Educ. 2006, 83, $425-428$.

${ }^{71}$ For selected publications on zinc acetylides, see: (a) T. Murai, Y. Ohta, Y. Mutoh, Tetrahedron Lett. 2005, 46, 3637-3640; (b) E. E. Wilson, A. G. Oliver, R. P. Hughes, B. L. Ashfeld, Organometallics 2011, 30, 5214-5221; (c) C. W. Downey, B. D. Mahoney, V. R. Lipari, J. Org. Chem. 2009, 74, 2904-2906. 
72 (a) A. F. Adeleke, A. P. N. Brown, L.-J. Cheng, K. A. M. Mosleh, C. J. Cordier, Synthesis 2017, 49, A-L; (b) M. Eriksson, T. Iliefski, M. Nilsson, T. Olsson, J. Org. Chem. 1997, 62, 182-187.

${ }^{73}$ A. M. Sladkov, L. Yu. Ukhin, Russ. Chem. Rev. 1968, 37, 748-762.

${ }^{74}$ A. E. Favorskii, L. I. Morev, Zhur. Russ. Fiz.-khim. Obshch. 1920, 50, 571-581.

${ }^{75}$ R. H. Pouwer, C. M. Williams, A. L. Raine, J. B. Harper, Org. Lett. 2005, 7, 1323-1325.

${ }^{76}$ C. S. Musthi, J.-H. Kim, E. J. Corey, J. Am. Chem. Soc. 2006, 128, 14050-14052.

77 (a) D. Green, S. Carmely, Y. Benayahu, Y. Kashman, Tetrahedron Lett. 1988, 29, 1605-1608; (b) A. B. Smith, III; P. J. Carroll, Y. Kashman, D. Green, Tetrahedron Lett. 1989, 30, 3363-3364.

${ }^{78}$ K. Sonogashira, Y. Thoda, N. Hagihara, Tetrahedron Lett. 1975, 16, 4467-4470.

79 (a) R. Chinchilla, C. Nájera, Chem. Rev. 2007, 107, 874-922; (b) R. Chinchilla, C. Nájera, Chem. Soc. Rev. 2011, 40, 5084-5121

${ }^{80}$ I. Paterson, R. D. M. Davies, R. Marquez, Angew. Chem. Int. Ed. 2001, 40, 603-607.

${ }^{81}$ M. J. Corr, S. V. Sharma, C. Pubill-Ulldemolins, R. T. Brown, P. Poirot, D. R. M. Smith, C. Cartmell, A. Abou Fayad, J. M. Goss, Chem. Sci. 2017, 8, 2039-2046.

${ }^{82}$ B.-T. Gröbel , D. Seebach, Synthesis 1977, 9, 357-402.

${ }^{83}$ I. Ruppert, K. Schlich, W. Volbach, Tetrahedron Lett. 1984, 25, 2195-2198.

${ }^{84}$ Y. Ju, D. Kumar, R. S. Varma, J. Org. Chem. 2006, 71, 6697-6700.

${ }^{85}$ S. R. Shenoy, D. M. Smith, K. A. Woerpel, J. Am. Chem. Soc. 2006, 128, 8671-8677.

${ }^{86}$ Y.-Y. Rena, X. Zheng, X. Zhang, Synlett 2018, 29, 1028-1032.

87 (http://www.merckmillipore.com/DE/de/product/Cyanogen-bromide,MDA_CHEM-820194, Date of access 8.1.2019; https://pubchem.ncbi.nlm.nih.gov/compound/10478\#section=Toxicity, Date of access 8.1.2019;

${ }^{88}$ J. Schörgenhumer, M. Waser, Org. Chem. Front. 2016, 3, 1535-1540.

${ }^{89}$ W. Wu, H. Jiang, Acc. Chem. Res. 2014, 47, 2483-2504.

${ }^{90}$ For the recent literature on transition metal-catalyzed alkynylations with alkynyl bromides, see: (a) M. O. Frederick, J. A. Mulder, M. R. Tracey, R. P. Hsung, J. Huang, K. C. M. Kurtz, L. Shen, C. J. Douglas, J. Am. Chem. Soc. 2003, 125, 2368-2369; (b) K. Dooleweerd, H. Birkedal, T. Ruhland, T. Skrydstrup, J. Org. Chem. 2008, 73, 9447-9450; (c) H. Huang, S. Nakanowatari, L. Ackermann, Org. Lett. 2017, 19, 4620-4623; (d) R. Mei, S.-K. Zhang, L. Ackermann, Org. Lett. 2017, 19, 3171-3174; (e) G. Cera, T. Haven, L. Ackermann, Chem. Eur. J. 2017, 23, 3577-3582, (f) S. Zhang, Q.-J. Yao, G. Liao, X. Li, H. Li, H.-M. Chen, X. Hong, B.-F. Shi, ACS Catal. 2019, 9, 1956-1961.

${ }^{91}$ C. Willgerodt, J. Prakt. Chem. 1886, 33, 154-160.

92 (a) G. C. J. Pimentel, Chem. Phys. 1951, 19, 446-448; (b) R. J. Hach, R. E. Rundle, J. Am. Chem. Soc. 1951, 73, 4321-4324.

93 (a) V. V. Zhdankin, ARKIVOC 2009, i, 1-62; (b) V. V. Zhdankin, K. Muñiz, J. Org. Chem. 2017, 82, 1166711668; (c) A. Yoshimura, V. V. Zhdankin, Chem. Rev. 2016, 116, 3328-3435.

94 J. Charpentier, N. Früh, A. Togni, Chem. Rev. 2015, 115, 650-682.

${ }^{95}$ For the reviews on this topic, see: (a) Y. Li, D. Prasad Hari, M. V. Vita, J. Waser, Angew. Chem. Int. Ed. 2016, 55, 4436-4454; (b) J. Waser, Top. Curr. Chem. 2016, 373, 187-222. 
${ }^{96}$ For the recent communications on azidations applying hypervalent iodine reagents, see: (a) V. V. Zhdankin, A. P. Krasutsky, C. J. Kuehl, A. J. Simonsen, J. K. Woodward, B. Mismash, J. T. Bolz, J. Am. Chem. Soc. 1996, 118, 5192-5197; (b) Y. Zong, Y. Rao, Org. Lett. 2014, 16, 5278-5281; (c) Q.-H. Deng, T. Bleith, H. Wadepohl, L. H. Gade, J. Am. Chem. Soc. 2013, 135, 5356-5359; (d) M. V. Vita, J. Waser, Org. Lett. 2013, 15, 3246-3249; (e) B. Zhang, A. Studer, Org. Lett. 2013, 15, 4548-4551; (f) N. Fuentes, W. Kong, L. Fernández-Sánchez, E. Merino, C. Nevado, J. Am. Chem. Soc. 2015, 137, 964-973; (g) W. Kong, N. Fuentes, A. García -Domínguez, E. Merino, C. Nevado, Angew. Chem. Int. Ed. 2015, 54, 2487-2491; (h) S. Alazet, J. Preindl, R. Simonet-Davin, S. Nicolai, A. Nanchen, T. Meyer, J. Waser, J. Org. Chem. 2018, 83, 12334-12356.; (i) W. Song, S. I. Kozhushkov, L. Ackermann, Angew. Chem. Int. Ed. 2013, 52, 6576-6578, and references cited therein.

${ }^{97}$ For the recent communications on cyanations employing hypervalent iodine reagents, see: (a) R. Frei, T. Courant, M. D. Wodrich, J. Waser, Chem. Eur. J. 2015, 21, 2662-2668; (b) Y.-F. Wang, J. Qiu, D. Kong, Y. Gao, F. Lu, P. G. Karmaker, F.-X. Chen, Org. Biomol. Chem. 2015, 13, 365-368; (c) R. Chowdhury, J. Schörgenhumer, J. Novacek, M. Waser, Tetrahedron Lett. 2015, 56, 1911-1914; (d) M. Chen, Z.-T. Huang, Q.Y. Zheng, Org. Biomol. Chem. 2015, 13, 8812-8816; (e) Z. Shu, W. Ji, X. Wang, Y. Zhou, Y. Zhang, J. Wang, Angew. Chem. Int. Ed. 2014, 53, 2186-2189; (f) X. Wang, A. Studer, Angew. Chem. Int. Ed. 2018, 57, 1179211796; (g) F. Xu, Y. Li, X. Huang, X. Fang, Z. Li H. Jiang, J. Qiao, W. Chu, Z. Sun, Adv. Synth. Catal. 2019, $361,520-525$.

${ }^{98}$ M. Ochiai, Y. Masaki, M. Shiro, J. Org. Chem. 1991, 56, 5511-5513.

${ }^{99}$ V. V. Zhdankin, C. J. Kuehl, A. P. Krasutsky, J. T. Bolz, A. J. Simonsen, J. Org. Chem. 1996, 61, 6547-6551.

${ }^{100}$ J. P. Brand, J. Charpentier, J. Waser. Angew. Chem. Int. Ed. 2009, 48, 9346-9349.

${ }^{101}$ J. P. Brand, J. Waser, Synthesis 2012, 44, 1155-1158.

${ }^{102}$ M. J. Bouma, B. Olofsson, Chem. Eur. J. 2012, 18, 14242-14245.

${ }^{103}$ M. D. Wodrich, P. Caramenti, J. Waser, Org. Lett. 2016, 18, 60-63.

${ }^{104}$ R. Frei, M. D. Wodrich, D. Prasad Hari, P.-A. Borin, C. Chauvier, J. Waser, J. Am. Chem. Soc. 2014, 136, $16563-16573$.

105 T. Aubineau, J. Cossy, Chem. Commun. 2013, 49, 3303-3305.

${ }^{106}$ P. Finkbeiner, N. M. Weckenmann, B. J. Nachtsheim, Org. Lett. 2014, 16, 1326-1329.

107 (a) X. Wu, S. Shirakawa, K. Maruoka, Org. Biomol. Chem. 2014, 12, 5388-5392; (b) A. Utaka, L. N. Cavalcanti, L. F. Silva, Jr., Chem. Commun. 2014, 50, 3810-3813; (c) D. Fernández González, J. P. Brand, R. Mondiére, J. Waser, Adv. Synth. Catal. 2013, 355, 1631-1639.

${ }^{108}$ C. C. Chen, J. Waser, Chem. Commun. 2014, 50, 12923-12926.

${ }^{109}$ D. Abegg, R. Frei, L. Cerato, D. P. Hari, C. Wang, J. Waser, A. Adibekian, Angew. Chem. Int. Ed. 2015, 54, $10852-10857$.

110 (a) A. Goel, A. B. Kunnumakkara, B. B. Aggarwal, Biochem. Pharmacol. 2008, 75, 787-809; (b) B. B. Aggarwal, A. Kumar, A. C. Bharti, Anticancer Res. 2003, 23, 363-398.)

${ }^{111}$ H. Shi, C. Tan, W. Zhang, Z. Zhang, R. Long, T. Luo, Z. Yang, Org. Lett. 2015, 17, 2342-2345.

${ }^{112}$ E. D. Morgan, Bioorg. Med. Chem. 2009, 17, 4096-4105.

${ }^{113}$ G. L. Cantoni, Annu. Rev. Biochem. 1975, 44, 435-451. 
${ }^{114}$ D. G. Fujimori, Cur. Opin. Chem. Biol. 2013, 17, 597-604.

${ }^{115}$ T. Umemoto, S. Ishihara, Tetrahedron Lett. 1990, 31, 3579-3582.

${ }^{116}$ T. Umemoto, B. Zhang, T. Zhu, X. Zhou, P. Zhang, S. Hu, Y. Li, J. Org. Chem. 2017, 82, 7708-7719.

${ }^{117}$ H. Li, Synlett 2012, 23, 2289-2290

${ }^{118}$ E. Magnier, J.-C. Blazejewski, M. Tordeux, C. Wakselman, Angew. Chem. Int. Ed. 2006, 45, 1279-1282

119 T. Umemoto, S. Ishihara, J. Am. Chem. Soc. 1993, 115, 2156-2164.

120 (a) Y. Macé, C. Pradet, M. Popkin, J.-C. Blazejewski, E. Magnier, Tetrahedron Lett. 2010, 51, 5388-5391;

(b) Y. Macé, E. Magnier, Eur. J. Org. Chem. 2012, 2479-2494.

${ }^{121}$ J.-A. Ma, D. Cahard, J. Org. Chem. 2003, 68, 8726-8729.

${ }^{122}$ T. Umemoto, K. Adachi, S. Isihara, J. Org. Chem. 2007, 72, 6905-6917.

${ }^{123}$ R. Koller, K. Stanek, D. Stolz, R. Aardoom, K. Niedermann, A. Togni, Angew. Chem. Int. Ed. 2009, 48, 4332-4336.

${ }^{124}$ G. Talavera, J. Peña, and M. Alcarazo, J. Am. Chem. Soc. 2015, 137, 8704-8707.

${ }^{125}$ M. Höfer, R. Liska J. Polym. Sci. A 2009, 47, 3419-3430

126 (a) T. Hiyama, Organofluorine Compounds, Chemistry and Applications (Ed.: H. Yamamoto), Springer, Berlin-Heidelberg, 2000, 263 pp.; (b) P. Jeschke, ChemBioChem. 2004, 5, 570-589; (c) S. Purser, P. R. Moore, S. Swallow, V. Gouverneur, Chem. Soc. Rev. 2008, 37, 320-330; (d) J. P. Bégué, D. Bonnet-Delpon, Bioorganic and Medicinal Chemistry of Fluorine, Wiley-VCH, Weinheim, 2008, 353 pp.; (d) D. O'Hagan, J. Fluorine Chem. 2010, 131, 1071-1081.

${ }^{127}$ M. S. Hossain, A. L. Schwan, Org. Lett. 2011, 13, 5330-5333.

128 (a) R. M. Schaffrin, J. Trotter, J. Chem. Soc. A. 1970, 1561-1565; (b) A. Bondi, J. Phys. Chem. 1964, 68, 441-451; (c) N. Yasuda, H. Uekusa, Y. Ohashi, Acta Cryst. 2001, E57, o1189-o1190.

${ }^{129}$ E. Topp, R. Chapman, M. Devers-Lamrani, A. Hartmann, R. Marti, F. Martin-Laurent, L. Sabourin, A. Scott, M. Sumarah, J. Environ. Qual. 2012, 42, 173-178.

${ }^{130}$ Hypervalent Iodine Chemistry (Ed.: V. V. Zhdankin), Wiley, Hoboken, 2014.

131 The decomposition energy of EBX-Ph is equal to $559 \mathrm{~J} \cdot \mathrm{g}^{-1}$, as determined by differential scanning calorimetric analysis; the decomposition starts at $113{ }^{\circ} \mathrm{C}$. A complete collection of DSC analyses of I(III) reagents can be found at the web page of Prof. J. Wasser, EPFL, Switzerland. The stability of EBX-TIPS is discussed in: "Ethynyl Benziodoxolone Reagents", e-EROS Encyclopedia of Reagents for Organic Synthesis (Eds.: D. Fernandez-Gonzalez, S. Nicolai, J. Waser), Wiley, Hoboken, 2012.

${ }^{132}$ B. Lu, Junliang Wu, N. Yoshikai, J. Am. Chem. Soc. 2014, 136, 11598-11601.

133 (a) J. P. Brand, C. Chevalley, R. Scopelliti, J. Waser, Chem. Eur. J. 2012, 18, 5655-5666. For the recent review (in part), see: (b) V. Pirovano. Eur. J. Org. Chem. 2018, 1925-1945.

134 (a) F. Xie, Z. Qi, S. Yu, X. Li, J. Am. Chem. Soc. 2014, 136, 4780-4787. For the review on directing groupmediated C-H-alkynylations, see: (b) L. D. Caspers, B. J. Nachtsheim, Chem. Asian J. 2018, 13, 1231-1247. For the selected communication, see: (c) Z. Ruan, N. Sauermann, E. Manoni, L. Ackermann, Angew. Chem. Int. Ed. 2017, 56, 3172-3176; (d) R. Mei, S.-K. Zhang, L. Ackermann, Org. Lett. 2017, 19, 3171-3174; (e) H. Fu, P.-X. Shen, J. He, F. Zhang, S. Li, P. Wang, T. Liu, J.-Q. Yu, Angew. Chem. Int. Ed. 2017, 56, 1873-1876; (f) X. Li, 
G. Wu, X. Liu, Z. Zhu, Y. Huo, H. Jiang, J. Org. Chem. 2017, 82, 13003-13011; R. S. Rohokale, R. G. Kalshetti, C. V. Ramana, J. Org. Chem. 2019, 84, 2951-2961.

${ }^{135}$ X. Yu, J. Tang, X. Jin, Y. Yamamoto, M. Bao, Asian J. Org. Chem. 2018, 7, 550-553.

136 (a) L. E. Brieaddy, B. S. Hurlbert, N. B. Mehta, J. Org. Chem. 1981, 46, 1630-1634. (b) K. Ohkata, K. Takee, K.-Y. Akiba, Bull. Chem. Soc. Jpn. 1985, 58, 1946-1952.

${ }^{137}$ G. Teveroskiy, D. S. Surry, S. L. Buchwald, Angew. Chem. Int. Ed. 2011, 50, 7312-7314

${ }^{138}$ W. He, Y.-C. Ge, C.-H. Tan, Org. Lett. 2014, 16, 3244-3247

${ }^{139}$ F. H. Allen, D. G. Watson, L. Brammer, A. G. Orpen, R. Taylor, International Tables for Crystallography 2006, vol. C, 790-811.

140 (a) Q. Zhou, A. Ruffoni, R. Gianatassio, Y. Fujiwara, E. Sella, D. Shabat, P. S. Baran, Angew. Chem. Int. Ed. 2013, 52, 3949-3952; (b) Y. Fujiwara, J. A. Dixon, F. O'Hara1, E. D. Funder, D. D. Dixon, R. A. Rodriguez, R. D. Baxter, B. Herle, N. Sach, M. R. Collins, Y. Ishihara, P. S. Baran, Nature 2012, 492, 95-99.

141 (a) P. G. Janson, I. Ghoneim, N. O. Ilchenko, K. J. Szabó, Org. Lett. 2012, 14, 2882-2885; (b) X. Wang, L. Truesdale, J.-Q. Yu, J. Am. Chem. Soc. 2010, 137, 10547-10553.

142 (a) Y. Chen, G. Ma, H. Gong; Org. Lett. 2018, 20, 4677-4680; (b) R. Beniazza, F. Molton, C. Duboc, A. Tron, N. D. McClenaghan, D. Lastècouéres, J.-M. Vincent, Chem. Commun. 2015, 51, 9571-9574; (c) Z.-M. Chen, W. Bai, S.-H. Wang, B.-M. Yang, Y.-Q. Tu, F.-M. Zhang, Angew. Chem. Int. Ed. 2013, 52, 9781-9785; (d) G.-B. Li, C. Zhang, C. Song, Y.-D. Ma, Beilstein J. Org. Chem. 2018, 14, 155-181.

${ }^{143}$ Y. Huang, X. Fang, X. Ling, H. Li, W. He, K.-W. Huang, Y. Yuan, Z. Weng, Tetrahedron 2012, 68, 99499953.

144 T. Liu, Q. Shen, Org. Lett. 2011, 13, 2342-2345.

${ }^{145}$ S. Mizuta, K. Kitamura, K. Nishi, R. Hashimoto, T. Usui, K. Chiba, RSC Adv. 2016, 6, 43159-43162.

${ }^{146}$ A. Raghavanpillai, D. J. Burton, J. Org. Chem. 2004, 69, 7083-7091.

147 A. Krasovskiy, P. Knochel, Synthesis 2006, 38, 890-891.

${ }^{148}$ A. Kremer, E. Bietlot, A. Zanello, J. M. Malicka, N. Armaroli, D. Bonifazi, Chem. Eur. J. 2015, 21, 11081117.

${ }^{149}$ J. Li, J. Zhang, H. Tan, D. Z. Wang, Org. Lett. 2015, 17, 2522-2525.

${ }^{150}$ S. B. Wagh, Y.-C. Hsu, R.-S. Liu, ACS Catal. 2016, 6, 7160-7165.

${ }^{151}$ K. Sugimoto, R. Hayashi, H. Nemotot, N. Toyooka, Y. Matsuya, Org. Lett. 2012, 14, 13, 3510-3513.

${ }^{152}$ S. Racine, B. Hegedüs, R. Scopelliti, J. Waser, Chem. Eur. J. 2016, 22, 11997-12001.

${ }^{153}$ Y.-C. Chan, Y.-Y. Yeung, Angew. Chem. Int. Ed. 2018, 57, 3483-3487.

${ }^{154}$ H. Tanimoto, T. Shitaoka, K. Yokoyama, T. Morimoto, Y. Nishiyama, K. Kakiuchi, J. Org. Chem. 2016, 81, $8722-8735$.

${ }^{155}$ C. Verrier, P. Melchiorre, Chem. Sci. 2015, 6, 4242-4246.

${ }^{156}$ G.M. Sheldrick, Acta Cryst. 2008, A64, 112-122.

${ }^{157}$ O.V. Dolomanov, L.J. Bourhis, R.J Gildea, J.A.K. Howard, H. Puschmann, J. Appl. Cryst. 2009, 42, 339341.

${ }^{158}$ T. Kottke, D. Stalke, J. Appl. Cryst. 1993, 26, 615-619. 
${ }^{159}$ Z.-T. He, H. Li, A. M. Haydl, G. T. Whiteker, J. F. Hartwig, J. Am. Chem. Soc. 2018, 49, 17197-17202.

${ }^{160}$ D. Prasad Hari, J. Waser, J. Am. Chem. Soc. 2016, 138, 2190-2193.

${ }^{161}$ R. Frei, J. Waser, J. Am. Chem. Soc. 2013, 26, 9620-9623.

${ }^{162}$ Y. Yang, W. Dong, Y. Guod, R. M. Rioux, Green Chemistry 2013, 11, 3170-3175.

${ }^{163}$ X. Y. Mak, A. L. Crombie, R. L. Danheiser, J. Org. Chem. 2011, 76, 1852-1873.

${ }^{164}$ L. Zhu, Y. Yu, Z. Mao, X. Huang, Org. Lett. 2015, 17, 30-33.

165 A. Hentz, P. Retailleau, V. Gandon, K. Cariou, R. H. Dodd, Angew. Chem. Int. Ed. 2014, 53, 8333-8337.

${ }^{166}$ S. Banerjeea, N. T. Patil, Chem. Commun 2017, 53, 7937-7940.

${ }^{167}$ C. P. Seath, G. A. Burley, A. J. B. Watson, Angew. Chem. Int. Ed. 2017, 56, 3314-3318.

${ }^{168}$ X. Du, H. Liu; D.-M. Du, Tetrahedron: Asymmetry 2010, 21, 241-246. 


\section{Danksagungen}

Zunächst möchte ich Prof. Manuel Alcarazo danken für die Möglichkeit meine Dissertation in seiner Arbeitsgruppe anfertigen zu können und für sein stets großes Interesse an Thema und Fortschritt dieser Arbeit. Des Weiteren möchte ich Prof. Lutz Ackermann danken für die Übernahme der Zeitkorrektur dieser Arbeit. Auch danke ich den restlichen Mitgliedern meiner Prüfungskommission: Prof. D. Stalke, Dr. S. Das, Dr. F. Thomas, Dr. M. Hansmann.

Mein Dank gilt dem gesamten Team der Arbeitsgruppe Alcarazo, die täglich ihr Bestes geben um den Doktoranden hervorragende Arbeitsvoraussetzungen zu ermöglichen. Dies betrifft insbesondere Sabine Schacht, Marvin Blaue, Martina Pretor, Martin Simon, Dr. Christopher Golz und Dr. Sergei I. Kozhushkov und natürlich auch Katja Grube.

Ich möchte der NMR- und Massenabteilung der Fakultät für Chemie danken für ihre stets schnellen und zuverlässigen Messungen diverser Spektren, insbesondere auch Christiane Siebert und Martin Weitemeyer für die kurzfristige Messung von instabilen Verbindungen und fehlenden Spektren für Veröffentlichungen. Des Weiteren danke ich Dr. Christopher Golz und Dr. Hendrik Tinnermann für die Aufnahme der Röntgenstrukturanalysen meiner Verbindungen.

Ganz besonderen Dank gilt meinen Kollegen mit denen ich Labor arbeiten, aber auch wundervolle Urlaube (Warschau, Breslau, usw.) und Partys erleben durfte und die diese Zeit ganz besonders gemacht haben. Es war ein wundervoll mit euch zusammen arbeiten zu können. Vielen Dank Leo, Agnes, Adam, Marvin, Kai, Kevin, Alex, Elisa, Hendrik, Thierry, Kristin, Tim, Steeeve, Pablo, Christian, Dr. Peña, Garazi, Liangu, Yin. Auch möchte ich meinen Bachelorstudenten Finn Kraft und Johannes Ulbrich für ihre exzellente Arbeit danken.

Ebenfalls danke ich meiner Familie und meinen besten Freunden Henning Foorden, Jochen Köckert, Sinah Swyter, Sandra Grohs und Thomas Ahrends, die mich stets in allen meinen Entscheidungen unterstützt haben und eine wichtige Stütze in dieser Zeit waren. Besonderen Dank gilt auch die vielen netten Menschen, Freunden und Kommilitonen die diese Zeit in Göttingen einfach unvergesslich gemacht haben, wie meinen Brettspiel-Nerds, meinen Freunden vom Tanzen, meiner Südamerika/Syrien-Gang und natürlich meiner Freitag-Mittag-Essens-Gruppe.

Als letztes möchte ich den Menschen danken, die Teile dieser Arbeit Korrektur gelesen haben und ohne die, diese Arbeit daher nicht möglich gewesen wäre. Mein spezieller Dank gilt daher Marvin Böhm, Katharina Meyer, Adam Zylinski, Dr. Sergei I. Kozhushkov und Leo Nicholls. 
